\title{
Induktion und Spezifikation serotonerger Neurone des ventralen Rhombencephalon der Maus
}

\author{
Dissertation \\ zur Erlangung des mathematisch-naturwissenschaftlichen Doktorgrades \\ "Doctor rerum naturalium" \\ der Georg-August-Universität Göttingen \\ vorgelegt von
}

Nadja Osterberg

aus Kassel (Hessen)

Göttingen 2008 
Referent: Herr Prof. G. Bucher

Korreferent: Herr Prof. R. Heinrich

Tag der mündlichen Prüfung: 12. Januar 2009 
Die vorliegende Dissertation wurde in der Zeit von Oktober 2005 bis Oktober 2008 in der Arbeitsgruppe von Frau Prof. Dr. med. dent. E. Roussa, der Abteilung Neuroanatomie des Zentrums für Anatomie der Georg-August-Universität, Göttingen angefertigt und durch Frau Prof. E. Roussa betreut. Unterstützt wurde die Arbeit durch das DFG Forschungszentrum für Molekulare Physiologie des Gehirns (CMPB), Göttingen. 


\section{Referenzen}

\section{Veröffentlichungen}

Characterization of primary neurospheres generated from mouse ventral rostral hindbrain.

Nadja Osterberg and Eleni Roussa

in press

Sim1 is a novel regulator in the differentiation of a mouse serotonergic neuron subpopulation.

Nadja Osterberg, Michael Wiehle, Oliver Oehlke, Stefanie Heidrich, Cheng Xu, Chen-Ming Fan, Kerstin Krieglstein, and Eleni Roussa

submitted

Posterpräsentationen

Induction and specification of serotonergic neurons of the ventral rhombencephalon. N. Osterberg, B. Rahhal, K. Krieglstein, E. Roussa

23. Arbeitstagung der Anatomischen Gesellschaft in Würzburg, September 2006

\section{Research Field B1: From Neurogenesis to Synaptogenesis}

Induction and specification of hindbrain serotonergic networks.

N. Osterberg, A. Mansouri, A. Stoykova, K. Krieglstein, and E. Roussa

Center of Molecular Physiology of the Brain, CMPB-Retreat, September 2006

Induction and specification of serotonergic neurons of the ventral rhombencephalon.

N. Osterberg, B. Rahhal, K. Krieglstein, E. Roussa

7. Göttinger Tagung der Deutschen Neurowissenschaftlichen Gesellschaft e.V., März 2007

Characterization of primary neurospheres generated from mouse ventral rostral hindbrain.

N. Osterberg, E. Roussa

31. Jahrestagung der Deutschen Gesellschaft für Zellbiologie, März 2008 


\section{Danksagung}

Ich möchte mich an dieser Stelle bei Frau Prof. Krieglstein für die Gelegenheit bedanken, in ihrer Abteilung meine Doktorarbeit anfertigen zu können.

Größter Dank gilt meiner „Doktormutter“ Frau Prof. Roussa. Beginnend mit der Wahl des Themas sowie durch viele Gespräche, durch Hilfestellung bei der Planung von Experimenten bis hin zum Schreiben dieser Arbeit, hat Frau Prof. Roussa unschätzbar zum Gelingen dieser Arbeit und darüber hinaus beigetragen - DANKE!

Meinen Betreuern, seitens der Biologischen Fakultät, Göttingen, Herrn Prof. Bucher und Herrn Prof. Heinrich, möchte ich herzlich für ihr Interesse an meiner Arbeit, ihre Anregungen und für die Zeit, die sie sich genommen haben, danken.

Ich danke Frau Prof. Flügge, Herrn Prof. Mansouri, Herrn Prof. Wimmer und Herrn Prof. Wodarz sehr für ihr Entgegenkommen und ihre Bereitschaft, als Mitglieder der Prüfungskommission zu fungieren.

Es gibt keine Worte, um auszudrücken, wieviel Dank ich Steffi schulde. Dank für ihre kostbare Hilfe, ihre Unterstützung in jeder Hinsicht, am meisten jedoch für ihre unschätzbare Freundschaft - Du fehlst hier!

Felicitas und Markus möchte ich besonderen Dank sagen, ohne sie wäre der Start in Freiburg sehr schwer geworden. Danke, dass ihr mich bei Euch aufgenommen habt und ich mich bei Euch zuhause fühlen durfte. Es gibt nichts, was damit vergleichbar wäre!

Bedanken möchte ich mich auch bei Ellen und Oli für ihre Unterstützung und gute Zusammenarbeit in Freiburg.

Meinen Eltern und meiner Schwester verdanke ich so unendlich viel, so dass ein Danke niemals ausreichen kann. Ihr habt mich immer unterstützt und an mich geglaubt - es gibt keine bessere Familie als Euch. 


\section{Inhaltsverzeichnis}

Referenzen...........................................................................................ii

Danksagung .............................................................................. iv

Inhaltsverzeichnis .............................................................................. V

I. Abstract /Zusammenfassung ...................................................

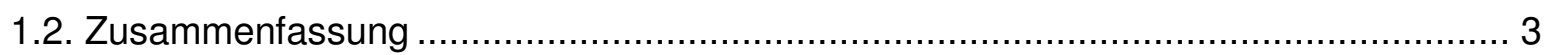

II. Einleitung.................................................................................. 5

2.1. Anatomie und Funktionen des serotonergen Systems .......................................... 5

2.2. Die Entwicklung 5-HT-Neurone des ventralen Rhombencephalon der Maus Zusammenspiel intrinsischer und extrinsischer Faktoren .......................................... 8

2.2.1. Organisationszentren des ZNS der Vertebraten.......................................... 8

2.2.2. Zeitliche und räumliche Entstehung 5 -HT-Neurone........................................ 12

2.2.3. Intrinsische Faktoren bestimmen das Vorläuferstadium 5-HT-Neurone...............13

2.2.4. Vom postmitotischen Neuron bis zum Erlangen des 5-HT-Phänotyps ..................14

2.3. Taf- $\beta$ („,Transforming growth factor- $\left.\beta^{\prime}\right)$ - Ein extrinsisches Signalmolekül und seine Bedeutung für die Entwicklung ventraler Neuronenpopulationen ..................................16

2.4. Der Transkriptionsfaktor „Single-minded“ (sim) - Ein intrinsischer Faktor und seine

Bedeutung für die Bildung der ventralen Mittellinie in D. melanogaster...........................19

III. Zielsetzung der Arbeit................................................................20

IV. Materialien und Methoden............................................................23

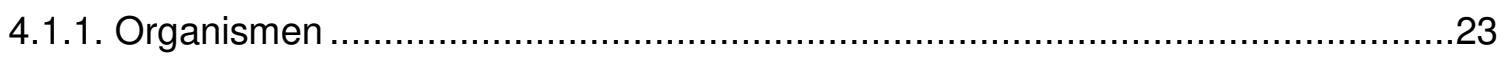

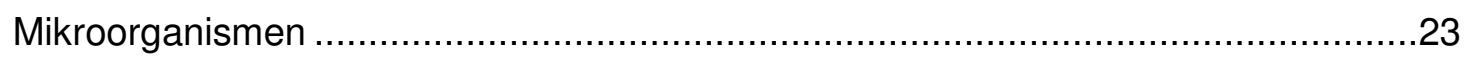

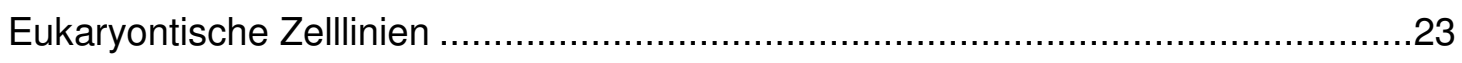

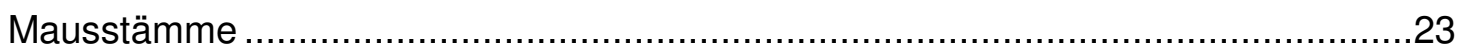

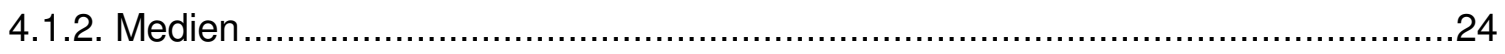

Mikrobiologische Kulturmedien .......................................................................... 24

Eukaryontische Zellkulturmedien ....................................................................24

Antibiotika und Medienzusätze ........................................................................25

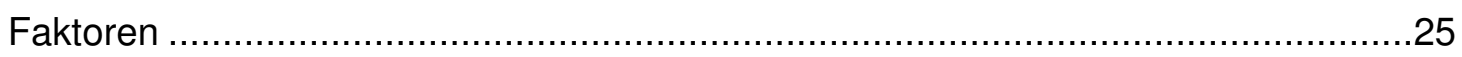

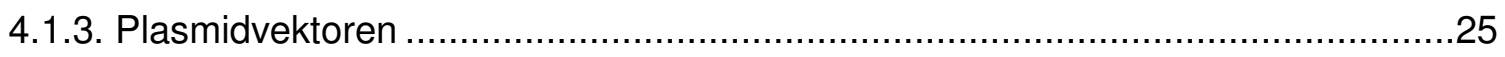

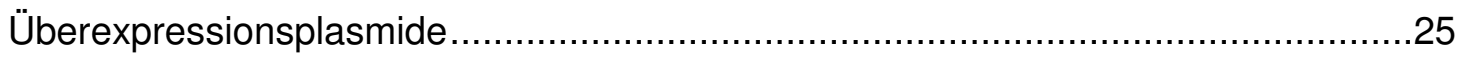

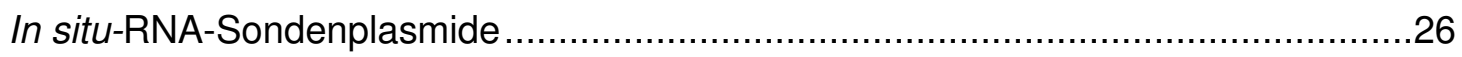

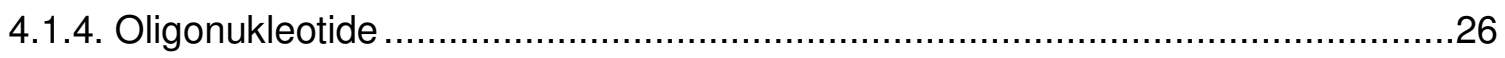

Primer der Polymerase-Ketten-Reaktion .......................................................................26

Primer der Quantitativen-„Real-Time“-Polymerase-Ketten-Reaktion .........................27

Primer der Klonierung von in situ-RNA-Sonden ..................................................27

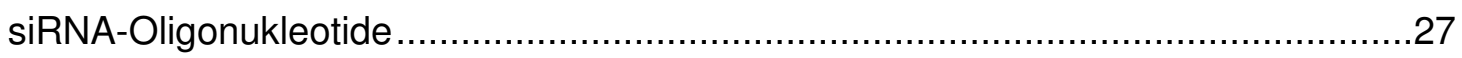

4.1.5. Enzyme, Inhibitoren und Beschichtungskomponenten .................................28

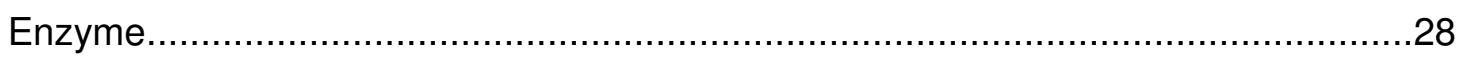

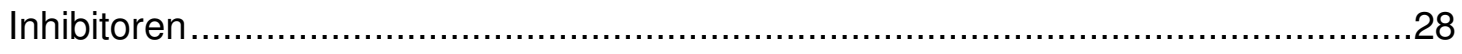

Beschichtungskomponenten und Aminosäurederivate .........................................28

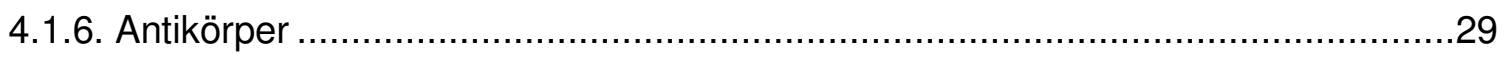


Primäre Antikörper.

Sekundäre Antikörper ......................................................................................29

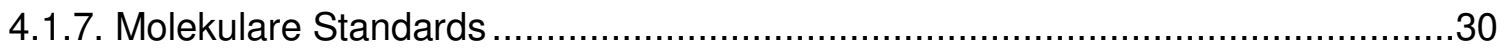

4.1.8. Kommerzielle Reinigungs- und Nachweissysteme .........................................30

4.1.9. Chemikalien und Biochemikalien ............................................................... 30

4.1.10. Lösungen und Puffer................................................................................. 33

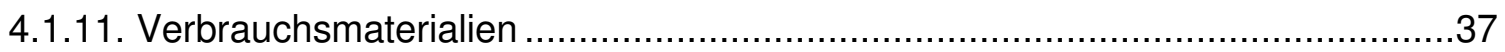

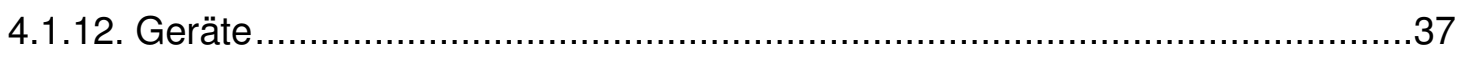

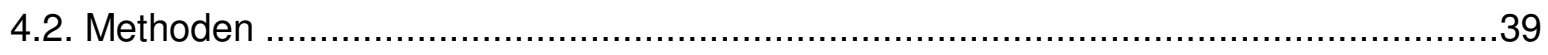

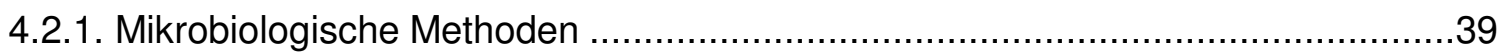

4.2.1.1. Herstellung von Bakterienkulturplatten ...................................................39

4.2.1.2. Herstellung chemisch kompetenter E. coli $D H 5 \alpha$-Zellen.............................39

4.2.1.3. Transformation chemisch kompetenter E. coli $D H 5 \alpha$ Zellen ..........................40

4.2.2. Methoden der eukaryontischen Zellkultur......................................................40

4.2.2.1. Kultivierung und Passage der Zelllinie MN9D........................................40

4.2.2.2. Kryokonservierung und Auftauen von eukaryontischen Zellen .....................41

4.2.2.3. Transiente Transfektion von MN9D-Zellen durch Lipofectamine ..................42

4.2.2.4. Liposomen vermittelte Einbringung von „short interfering“-RNA in Zellen der eukaryontischen Zelllinie MN9D........................................................................43

4.2.3. Techniken der Primärkultur .........................................................................44

4.2.3.1. Präparation des ventralen rostralen Rhombencephalon der Maus (E12) ......44

4.2.3.2. Silikonisierung von Pasteur-Pipetten ...............................................................46

4.2.3.3. Aufarbeitung embryonalen Gewebes (E12) des ventralen rostralen Rhombencephalon der Maus zur Gewinnung einer Einzelzellsuspension .................47

4.2.3.4. Generierung primärer Neurospheres des ventralen rostralen Rhomben-

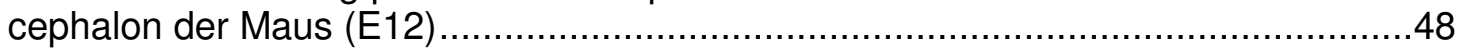

4.2.3.5. Dissoziation generierter primärer Neurospheres .......................................49

4.2.3.6. Erzeugung sekundärer Neurospheres aus dissoziierten primären Neurospheres des ventralen rostralen Rhombencephalon der Maus (E12) .......................50

4.2.3.7. Poly-Ornithine-/Laminin-Beschichtung von Deckgläschen..........................50

4.2.3.8. 5'-Bromodeoxyuridin-(BrdU)-Proliferationsassay ........................................51

4.2.3.9. Behandlung von Primärkulturen und primären Neurospheres des ventralen rostralen Rhombencephalon der Maus (E12) durch Faktorenqabe ..........................52

4.2.4. Immunzytochemische Charakterisierung von Primärzellen und primärer Neurospheres des ventralen rostralen Rhombencephalon der Maus (E12) ..................53

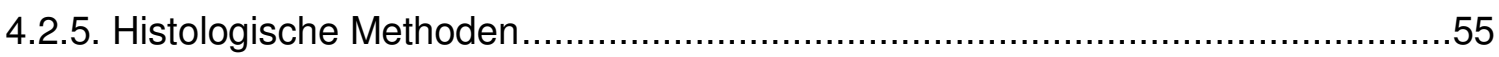

4.2.5.1. Fixierung von Mausembryonen unterschiedlicher Entwicklungsstadien für die

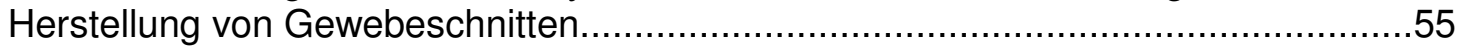

4.2.5.2. Paraffineinbettung von PFA-fixierten Mausembryonen.................................55

4.2.5.3. Herstellung von Gewebeschnitten........................................................56

4.2.5.4. Immunhistochemische Untersuchungen an Schnittpräparaten des zentralen

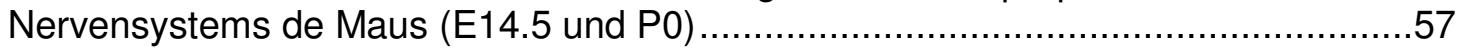

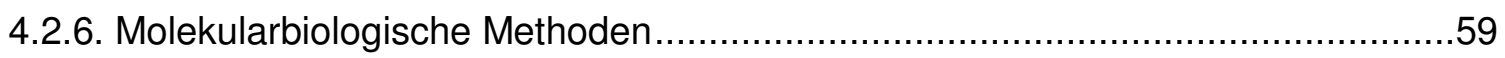

4.2.6.1. Isolierung von Plasmid-DNA ...........................................................59

4.2.6.2. Präparation von Plasmid-DNA in analytischen Mengen ..............................59

4.2.6.3. Restriktionsverdau von Plasmid-DNA.....................................................60 
4.2.6.4. Isolierung von Gesamt-RNA aus eukaryontischen Zellkulturen und embryonalem Gewebe der Maus des Embryonaltages (E) 11 und E12.

4.2.6.5. Gelelektrophoretische Auftrennung von RNA-Proben

4.2.6.7. Photometrische Konzentrationsbestimmung von wässrigen NukleinsäureLösungen....

4.2.6.8. Analyse der Genexpression mittels Polymerase-Ketten-Reaktion (PCR) .....64

4.2.6.9. Quantitative-"Real-Time"-Polymerase-Ketten-Reation (qRT-PCR) ...............65

4.2.6.10. DNA-Aqarosegelelektrophorese .........................................................67

4.2.6.11. Aufreinigung von DNA-Fragmenten aus Agarosegelen ...........................68

4.2.6.12. Genexpressionsstudie mittels cDNA-Mikroarray-Analyse .........................69

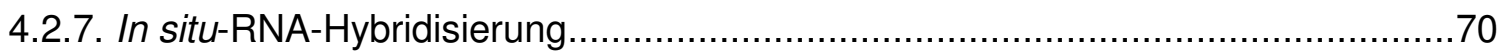

4.2.7.1. Klonierung von in situ-RNA-Sondenplasmiden — Ligation von DNA-

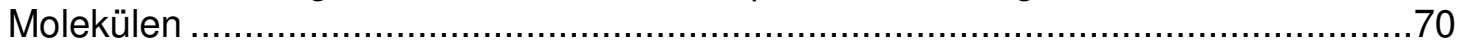

4.2.7.2. Herstellung von in situ-RNA-Sonden durch in vitro-Transkription ..................70

4.2.7.3. Effizienzbestimmung von in situ-RNA-Sonden ......................................71

4.2.7.4. In situ-RNA-Hybridisierung an embryonalen Gewebeschnitten der Maus

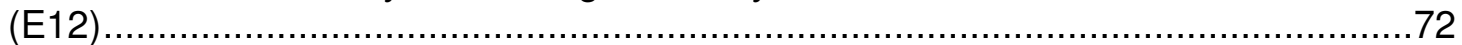

4.2.8. Proteinbiochemische Methoden ................................................................... 75

4.2.8.1. Isolierung des Gesamtproteins aus Gewebe und Zellkulturproben ................75

4.2.8.2. Photometrische Bestimmung der Proteinkonzentration nach Bradford .........75

4.2.8.3. Größenabhängige Auftrennung von Proteinen durch diskontinuierliche SDS-

Polyacrylamidgelelektrophorese (SDS-PAGE) .................................................

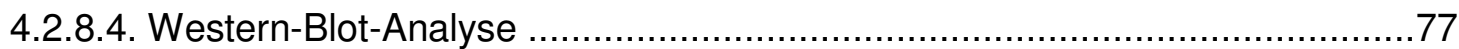

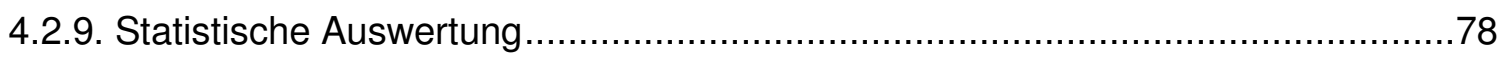

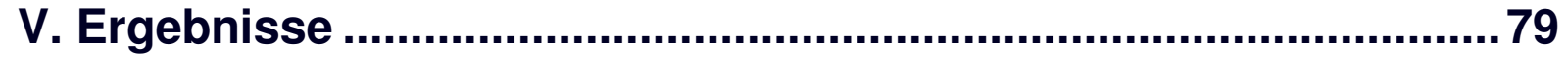

5.1. Etablierung und Charakterisierung eines Kultursystems primärer Neurospheres aus dem ventralen rostralen Rhombencephalon der Maus (E12)

5.1.1. Morphologie primärer Neurospheres aus dem ventralen rostralen Rhomben-

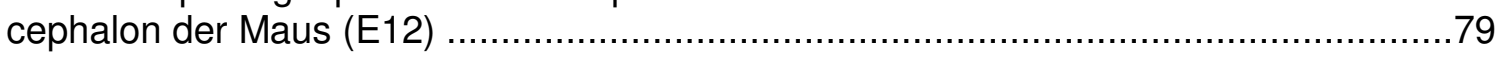

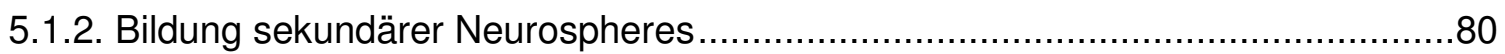

5.1.3. Primäre Neurospheres aus dem ventralen rostralen Rhombencephalon der Maus (E12) besitzen Proliferationspotential

5.1.4. Zelluläre Zusammensetzung primärer Neurospheres aus dem ventralen rostralen Rhombencephalon der Maus (E 12)

5.1.5. Zellen primärer Neurospheres aus dem ventralen rostralen Rhombencephalon der Maus (E12) besitzen die Fähigkeit zur Differenzierung in unterschiedliche zelluläre Abstammungslinien

5.2. Einfluss des extrinsischen Signalmoleküls Tgf- $\beta$ auf die Induktion und Spezifikation rostraler serotonerger Neurone des ventralen Rhombencephalon der Maus (E12)..........89

5.2.1. In vitro-Beeinflussung der Genexpression von primären Neurospheres des ventralen rostralen Rhombencephalon der Maus E12 durch Behandlung mit Faktoren 89 5.2.2. Beeinflussung der Genexpression in vitro von Primärzellen des ventralen rostralen Rhombencephalon der Maus (E12) durch externe Faktoren ....

5.3. Analyse der Bedeutung des Transkriptionsfaktors Sim1 für die Entwicklung von 5-HT-

Neuronen des ventralen Rhombencephalon der Maus

5.3.1. Nachweis der Expression von Sim1 im ventralen Rhombencephalon an verschiedenen Embryonalstadien der Maus 
5.3.2. Sim1-defiziente Mausmutanten (P0) weisen eine signifikante Reduktion der 5-HT-

Neuronenpopulation des Nucleus raphe dorsalis auf

5.3.3. “Gain-of-function" Experimente ................................................................. 100

5.3.4. „Loss-of-function“-Experimente ................................................................. 108

5.4. Identifizierung von Kandidatengenen der Entwicklung von 5-HT-Neuronen durch Vergleich des Genexpressionsmusters von ventralem rostralen Rhombencephalon und ventralem Mesencephalon der Maus (E11)

5.4.1. Uberprüfung der präparierten Gehirnregionen des ventralen Mesencephalon und ventralen Rhombencephalon der Maus, E11 ...................................................113

5.4.2. Validierung der durch cDNA-Mikroarray ermittelten Genexpressionsdaten ........115

5.4.3. Auswahl von Kandidatengenen auf Grundlage der mittels cDNA-Mikroarray

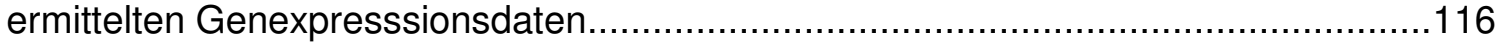

Der Transkriptionsfaktor Brn3.2 -- Ein Zielgen von Sim1 ...................................117

Das Regulatorprotein Rgs4 - Ein Zielgen von Sim1 ...........................................118

Der Transkriptionsfaktor Lhx8 - Ein Zielgen von TGF- $\beta$ und Sim1 .......................118

5.4.4. Sim1-Uberexpression in MN9D-Zellen führt zu einer signifikanten Steigerung der

Expression der Kandidatengene Brn3.2 und Rqs4 ...............................................120

VI. Diskussion ..............................................................................123

VII. Anhang .................................................................................. 147

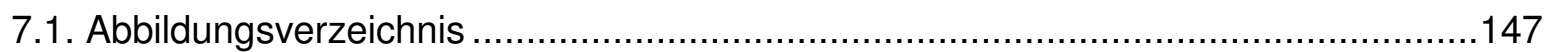

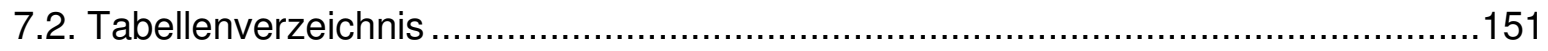

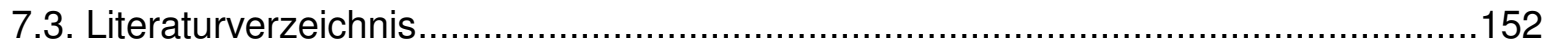

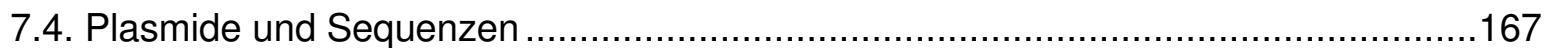

7.5. Verzeichnis der verwendeten Abkürzungen .....................................................170

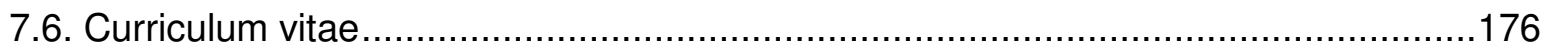

\section{Anmerkung zur Schreibweise:}

In dieser Arbeit verwendete Bezeichnungen von Genen sind in kursiver Schrift angegeben, Proteine in normaler Schrift. Generell ist hierbei der erste Buchstabe gross geschrieben, ausgenommen hiervon sind Bezeichnungen für Gene und Proteine aus D. melanogaster. 


\section{Abstract /Zusammenfassung}

\subsection{Abstract}

The serotonergic (5-HT) system is involved in the modulation of mood and behaviour. Extrinsic factors, such as fibroblast growth factor 4 (Fgf4), Fgf8, and sonic hedghog (Shh), dictate the development of hindbrain 5-HT neurons. In addition, the developmental network is regulated by transcription factors, such as Nkx2.2, Lmx1b, Gata2, and Pet1. However, the regulatory network of extrinsic and intrinsic factors directing the development of $5-\mathrm{HT}$ neurons is not fully elucidated. In order to complete the network, a primary neurospheres culture system from mouse ventral rostral hindbrain embryonic day (E) 12 has been established. This model system exhibits the main characteristics of progenitor cells: a) the ability to proliferate and b) the capacity of multilineage differentiation. Hereby it allows the enrichment of progenitor cells, and also triggers these cells towards a specific cell fate. Tgf- $\beta$ treatment of primary neurospheres from mouse ventral rostral hindbrain (E12) does not influence the expression of Gata2. However, the functional blocking of Tgf- $\beta$ signalling results in a significant down regulation of Gata2, indicating that the maintenance of Gata2 expression is Tgf- $\beta$ dependent. Treatment of primary neurospheres with Tgf- $\beta$ has no effect on Pet1 expression, whereas the inhibition of $\operatorname{Tgf}-\beta$ signaling led to a significant down regulation of Pet1 expression. These results suggest a role of Tgf- $\beta$ in regulating the differentiation of progenitors towards the terminal 5-HT phenotyp via the maintenance of Gata2 and Pet1 expression.

Additionally, the function of the transcription factor Sim1 (Single-minded homolog 1), the murine homologue of sim, a master regulator of CNS midline formation in D. melanogaster, in the development of 5-HT neurons has been analysed. Immunohistological analysis of newborn Sim1 -/- mice compared with wt littermates revealed a significantly reduced number of 5-HT neurons within a 5-HT neuron subpopulation, the dorsal raphe nucleus, at about $30 \%$. The underlying molecular mechanisms were investigated by gain- and loss-offunction experiments using the MN9D cell line. Gene expression changes were analysed after Sim1 overexpression by quantitative Real-Time-PCR. Sim1 overexpression did not result in an upregulation of Gata2. In contrast, a significant upregulation of the expression of Pet1 after Sim1 overexpression has been observed and confirmed after down-regulating Sim1 by transfection using Sim1 specific siRNA. Moreover, an upregulation of Tph2 expression was observed after Sim1 overexpresion. These data suggest a relevance of Sim1 for the differentiation of 5-HT neurons, and allow to position Sim1 upstream Pet1 and Tph2 within the regulatory network directing the formation of $5-\mathrm{HT}$ neurons. In order to identify new members of the regulatory network directing the development of 5-HT neurons, a cDNA 
microarray has been performed, comparing the gene expression pattern of mouse ventral midbrain with that of ventral rostral hindbrain, E11. Three genes highly upregulated in ventral hindbrain, were further investigated by Sim1 overexpression in MN9D cells: Rgs4, a regulator of G-protein coupled receptors, such as 5-HT receptors, and the transcription factors Brn3.2 and Lhx8. Sim1 overepression led to a significant upregulation of Rgs4 and Brn3.2. In summary, the results indicate a role of Sim1 during the late development of $5-\mathrm{HT}$ neurons, at least in a subpopulation of 5-HT neurons, either directly, on Tph2 and Pet1 by regulating their expression, or indirectly via induction of Brn3.2. Furthermore the results suggest an indirect regulation of serotonin release by $\operatorname{Sim} 1$ via Rgs4, and thereby directing the development of 5-HT neurons themself and their target areas.

keywords: primary neurospheres, raphe, rhombencephalon, serotonergic neurons 


\subsection{Zusammenfassung}

Das serotonerge (5-HT) System ist maßgeblich an der Modulation des Verhaltens und der Gemütslage beteiligt. In ihrer Entwicklung sind 5-HT-Neurone des Rhombencephalon von extrinsischen Faktoren wie Fgf4 („Fibroblast growth factor 4“), Fgf8 und Shh („Sonic hedghog") sowie u. a. von den Transkriptionsfaktoren Nkx2.2, Lmx1b, Gata2 und Pet1 abhängig. Bis heute ist, über die genannten extrinsischen und intrinsischen Faktoren hinausgehend, die Steuerung der Entwicklung von 5-HT-Vorläuferzellen hin zum terminalen 5-HT-Phänotyp nicht vollständig aufgeklärt. Ziel der vorliegenden Arbeit war es daher, das regulatorische Netzwerk der 5-HT-Neuronenentwicklung zu ergänzen. Hierzu wurde zunächst das Kultursystem primärer Neurospheres des ventralen rostralen Rhombencephalon der Maus des Embryonaltages (E) 12 etabliert und charakterisiert. Es konnte gezeigt werden, dass diese primären Neurospheres grundlegende Eigenschaften von Vorläuferzellen aufweisen: a) die Fähigkeit zur Proliferation und b) die Möglichkeit, sich in unterschiedliche neurale Zelltypen zu differenzieren. Somit ermöglicht dieses Modellsystem die Anzahl von Vorläuferzellen zu erhöhen und die Zellen in Richtung eines bestimmten zellulären Schicksals zu steuern. Dieses Kulursystem wurde verwendet, um zunächst den Einfluss des extrinsichen Signalmolekül Tgf- $\beta$ („Transforming growth factor- $\beta^{*}$ ) auf die Entwicklung von 5-HT-Neuronen untersucht. Behandlung primärer Neurospheres mit Tgf- $\beta$ führte zu keiner Steigerung der Gata2-Expression. Neutralisation endogen synthetisierten Tgf- $\beta$ resultierte hingegen in einer signifikanten Herabregulation von Gata2. Tgf- $\beta$ Behandlung primären Neurospheres des ventralen rostralen Rhombencephalon der Maus (E12) bedingte keine Erhöhung der Pet1-Expression. Eine funktionelle Blockierung der Tgf- $\beta$-abhängigen Signaltransduktionskaskade führte jedoch zu einer signfikanten Reduktion der Pet1-Transkription. Hieraus kann gefolgert werden, dass Tgf- $\beta$ auf die Differenzierung von neuralen Vorläuferzellen zu 5-HT-Neuronen über die Aufrechterhaltung der Gata2- und Pet1-Expression Einfluss nimmt.

Neben Tgf- $\beta$ wurde die Bedeutung des Transkriptionsfaktors Sim1 („Single-minded homolog 1“) für die Entwicklung von 5-HT-Neuronen analysiert. Die Deletion des Sim1-Gens äußert sich in neugeborenen Sim1-defizienten Mäusen in einer Reduktion der Anzahl 5-HT-Neuronen einer Subpopulation, dem Nucleus dorsalis raphe, um 30\%. Die diesem Befund zugrunde liegenden molekularen Regulationsmechanismen wurden durch Sim1Überexpressions- und Sim1-spezifische siRNA-Experimente in MN9D-Zellen untersucht. Durch Analyse der Änderungen des Genexpressionmusters nach Sim1-Überexpression konnte gezeigt werden, dass Sim1 die Expression von Gata2 nicht induziert. Die Expression der Gene Pet1 und Tph2 wurde im Gegensatz hierzu durch eine Sim1-Überexpression in MN9D-Zellen signifikant gesteigert. Dies zeigt, dass Sim1 zwar keine Bedeutung für die 
Induktion wohl aber für die Differenzierung von 5-HT-Neuronen über eine Regulation von Pet1 sowie Tph2 besitzt. Somit konnte Sim1 eine bisher unbekannte Funktion innerhalb des transkriptionellen Netzwerkes der 5-HT-Neuronenentwicklung zugewiesen werden.

Um bisher unbekannte Elemente des regulatorischen Netzwerkes der Entwicklung 5-HTNeuronen zu identifizieren, wurde ein cDNA-Mikroarray durchgeführt und das Genexpressionsmuster des ventralen rostralen Rhombencephalon mit dem des ventralen Mesencephalon (E11) der Maus verglichen. Drei der im ventralen Rhombencephalon im Vergleich zum ventralen Mesencephalon am stärker exprimierten Gene wurden durch Sim1Überexpessionsversuche auf eine denkbare Sim1-abhängige Expressionsregulation in MN9D-Zellen untersucht: Rgs4, ein Regulator G-Protein-gekoppelter Rezeptoren, wie 5-HT-Rezeptoren, sowie die Transkriptionsfaktoren Brn3.2 und Lhx8. Eine Überexpression von Sim1 führte zu einer signifikanten Steigerung der Expression von Rgs4 und Brn3.2. Zusammenfassend weisen die Ergebnisse daraufhin, dass Sim1 die späte Entwicklungsphase von 5-HT-Neuronen durch Regulation der Expression von Pet1 und Tph2 zumindest in einer Subpopulation steuert. Es ist denkbar, dass dies indirekt über eine Sim1-abhängige Regulation der Expression von Brn2.3 erfolgt. Des Weiteren ist eine funktionelle Regulation der Serotonin-Freisetzung durch Sim1, vermittelt über Rgs4, denkbar, wodurch die Entwicklung von 5-HT-Neuronen selbst und von innen innervierten Gehirnregionen beeinflusst wird.

Schlagwörter: primäre Neurospheres, Raphe, Rhombencephalon, serotonerge Neurone 


\section{Einleitung}

\section{Das serotonerge System des zentralen Nervensystems der Säugetiere}

\subsection{Anatomie und Funktionen des serotonergen Systems}

Das serotonerge (5-HT-) System des zentralen Nervensystems (ZNS) ist von großer Bedeutung für die Modulation und Koordination von Verhaltensweisen sowie verschiedener Bewusstseinslagen. Hierzu zählen u. a. die Regulation des Schlaf-Wach-Rhythmus, die Regulation der Körpertemperatur, die Beeinflussung emotionaler Vorgänge und die Schmerzperzeption. Des Weiteren ist das 5-HT-System an der Steuerung von Entwicklungsprozessen des ZNS beteiligt, einerseits durch autoregulatorische Prozesse (Diefenbach et al., 1995, Lauder et al., 2000), andererseits durch die Beeinflussung innervierter Gehirnareale (Daval et al., 1987; Gaspar et al., 2003; Lauder et al., 1982). Obwohl die Zahl der Serotonin-(5-Hydroxytryptamin, 5-HT)-synthetisierenden Neurone im Vergleich zu anderen Neuronenpopulationen innerhalb des ZNS relativ gering ist, verfügt das 5-HT-System somit über ein überaus breites Funktionsspektrum. Zusammen mit den catecholaminergen (adrenerge, noradrenerge und dopaminerge) Neuronen bilden 5-HTNeurone die Familie der monoaminergen Neurone. 5-HT-Neurone befinden sich in der Formatio reticularis (FR) des Hirnstamms des adulten Gehirns der Säugetiere. Die FR erstreckt sich von der Medulla oblongata über den Pons bis zum kaudalen Mesencephalon. Innerhalb der FR treten 5-HT-Neurone als diffuse Neuronenansammlungen entlang der rostro-kaudalen Achse innerhalb und lateral der Mittellinie auf. Dort bilden sie ein weitverzweigtes, axonales Netzwerk. Eine erste Einteilung der in der FR gelegenen 5-HTNeuronenansammlungen zu Kerngebieten (B1-B9) und Beschreibung ihrer Projektionen nahmen Dahlström und Fuxe 1964 vor. Die Gruppen B1-B4 sind innerhalb der Medulla oblongata lokalisiert. Sie umfassen die kaudalen Kerngebiete, wobei die Gruppe B1 die am weitesten kaudal gelegene Neuronenansammlung bezeichnet. Den kaudalen Kerngebieten steht die Gruppe rostraler Kerngebiete gegenüber, welche die Gebiete B5-B9 beinhaltet. Diese erstrecken sich von dem Pons bis hin zum kaudalen Mesencephalon. Der Großteil der 5-HT-Neurone befindet sich in den Nuclei raphes (Raphe-Kerne), deren Einteilung weitestgehend der zeitlich vorangegangenen B-Gruppenklassifikation entspricht (Jacobs und Azmitia, 1992; Törk, 1990). Eine Zuordnung der B-Gruppen zu den sich aus innen zusammensetzenden Nuclei raphes ist in Tab. 1 (Seite 6) wiedergegeben. 
Tab.1: B-Gruppenklassifikation und Lokalisation der Nuclei raphes des Rhombencephalon der Säugetiere

\begin{tabular}{|l|l|l|l|}
\hline & B-Gruppe & \multicolumn{1}{|c|}{ Nucleus raphe } & \multicolumn{1}{|c|}{ Lokalisation } \\
\hline kaudal & B1 & Nucleus raphe pallidus & Medulla oblongata \\
\hline & B2/B4 & Nucleus raphe obscurus & Medulla oblongata \\
\hline rostral & B5/B8 & $\begin{array}{l}\text { Nucleus raphe magnus } \\
\text { Nucleus paragigantocellularis } \\
\text { reticularis }\end{array}$ & $\begin{array}{l}\text { Pons (kaudal) } \\
\text { Medulla oblongata (rostral) }\end{array}$ \\
\hline & B6/7 & Nucleus raphe dorsalis & $\begin{array}{l}\text { B7-Hauptkern: Mesencephalon } \\
\text { B6: Pons }\end{array}$ \\
\hline & B8 & Nucleus raphe medialis & Pons \\
\hline & B8/B9 & Nucleus raphe pontis & Pons \\
\hline
\end{tabular}

Die in der Medulla oblongata gelegenen Nuclei raphes (B1-B4) projizieren in die Medulla spinalis und in das Cerebellum. Die Kerne B5-B9, lokalisiert innerhalb des Pons und des Mesencephalon, innervieren, wie die Abb. 1 (Seite 7) zeigt, durch ihre aufsteigenden Projektionen nahezu alle Gehirnbereiche. Hierzu zählen Hippocampus, Amygdala, Hypothalamus, Thalamus und die Basalganglien bis hin zum Neocortex (Azmitia und Segal, 1978; Fuxe, 1965; Skagerberg und Björklund, 1985; Waterhouse et al., 1986). Die rostralen und kaudalen Nuclei raphes unterscheiden sich jedoch nicht nur bezüglich ihrer Lokalisation, ihrer Projektionen und damit verbunden in ihren Funktionen voneinander, sondern auch in ihrer zeitlichen Entwicklung. So beginnt die Entstehung der rostralen Nuclei raphes der Maus um den Embryonaltag (E) 10.5, die der kaudalen Nuclei raphes hingegen einen Tag später (Ding et al., 2003). Selbst innerhalb einzelner Nuclei raphes sind Unterschiede der Neuronengruppen und Abstufungen hinsichtlich ihrer pharmakologischen Sensitivität erkennbar (Beck et al., 2004). Darüber hinaus lassen sich gruppen-charakteristische Besonderheiten in den jeweiligen während der Entwicklung erforderlichen Bedingungen feststellen (Brodski et al., 2003; Craven et al., 2004; Pattyn et al., 2003). Somit handelt es sich bei dem 5-HT-System des ZNS, um ein sehr heterogenes System, dessen Entwicklung bisher noch nicht umfassend aufgeklärt werden konnte. 


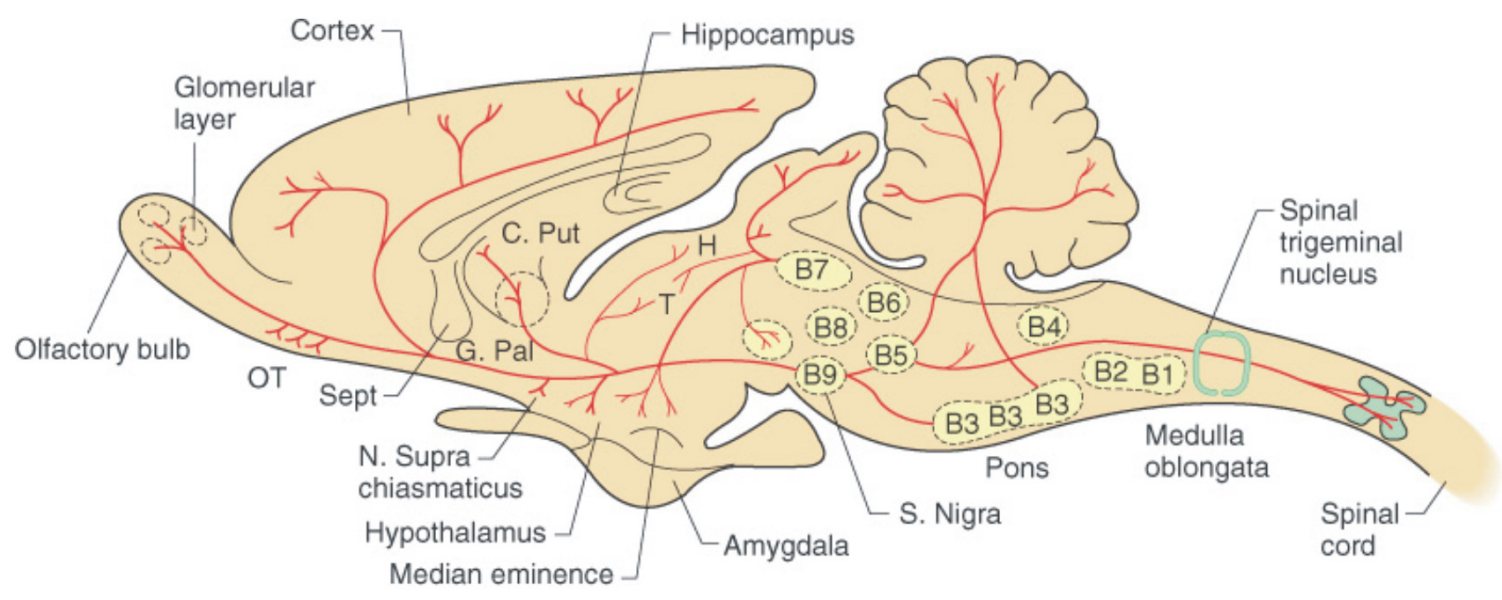

Abb.1: Kaudale und rostrale B-Gruppen serotonerger (5-HT) Neurone des zentralen Nervensystems (ZNS) der Säugetiere und ihre Projektionen am Beispiel der Ratte, aus: The Biology of Serotonergic Transmission, Consolazione, A. und Cuello, A., New York: John Willey \& Sons, 1982, 29-61.

Dysfunktionen des 5-HT-Systems, und damit einhergehend z. B. die Deregulation der Serotonin-Ausschüttung und seine Wiederaufnahme im ZNS, werden mit einer Vielzahl von Erkrankungen in Verbindung gebracht. Hierzu zählen unter anderem Migräne, depressive Erkrankungen, Angst- und Panikzustände bis hin zu Zwangsneurosen, BorderlinePersönlichkeitsstörungen, Schizophrenie und Autismus (Dean und Hayes, 1996; Goodman und New, 2000; Murphy et al., 1989; Nelson und Chiavegatto, 2001; Jones und Blackburn, 2002). Einige psychiatrische Erkrankungen, wie z. B. Formen der Depression, konnten partiell auf genetische Funktionsstörungen des 5-HT-Systems zurückgeführt werden (Carpenter et al., 1993). Eine mögliche Ursache für unterschiedlich ausgeprägte Schweregrade mancher psychiatrischer Erkrankungen, z. B. des Autismus, könnte eine hohe Genvariabilität aber auch eine starke Sensitivität der 5-HT-Neurone gegenüber Veränderungen der direkten Zellumgebung (z. B. nach Alkoholmissbrauch) während der neuronalen Entwicklung sein. Zudem verfügt das 5-HT-System über eine außerordentliche Vielfalt an 5-HT-Rezeptoren (5-HTR). Eine gestörte oder gar fehlende Expression der Rezeptoren hat erheblichen Einfluss auf die Funktionsfähigkeit des 5-HT-Systems. Bisher wurden drei Klassen von 5-HT-Rezeptoren beschrieben, die wiederum jeweils mehrere Familien und Subtypen umfassen. Bis auf 5-HTR3, ein Liganden-gesteuerter Ionenkanal, gehören alle 5-HT-Rezeptoren zur Superfamilie der G-Protein gebundenen Rezeptoren („G-protein coupled receptors“, GCRs; Martin et al., 1998; Pauwels, 2000), deren Signaltransduktion über $G_{i / 0^{-}}$und $G_{q^{-}}$-Proteine vermittelt wird. Diese beinhaltet $z$. B. die Inhibition und Aktivierung der Adenylatzyklase und Proteinkinase A (AC/PKA), die Steuerung der intrazellulären $\mathrm{Ca}^{2+}$-Konzentration, die Aktivierung der NFKB-(„Nuclear factor-KB“)-, der 
PI3K-(„Phosphoinosid 3-kinases”)- oder der ERK1/2-(“Extracellular signal-regulated kinases")-Signaltransduktionskaskade (Baumgarten und Grozdanovic, 1995; Cox und Cohen, 1996, Hoyer et al., 2002). Im Hinblick auf neue therapeutische Ansätze ist die Erforschung der Entwicklung, der Erhaltung und Funktionsregulation zentraler 5-HT-Neurone von größtem Interesse.

\subsection{Die Entwicklung 5-HT-Neurone des ventralen Rhombencephalon der Maus -Zusammenspiel intrinsischer und extrinsischer Faktoren}

\subsubsection{Organisationszentren des ZNS der Vertebraten}

Die Entwicklung 5-HT-Neurone erfolgt in der Maus zwischen dem E10.5 und E12.5. Damit gehören 5-HT-Neurone zu den ersten sich entwickelnden Neuronen des ZNS. Maßgeblich ist ihre Entwicklung von zwei lokalen Organisationszentren abhängig, dem Isthmus-Organizer (IstO) sowie der Grundplatte (siehe Abb. 2, Seite 9). Organisationszentren weisen sich durch die Fähigkeit aus, nach Transplantation in Gewebe anderer regionaler Abstammung ihnen normalerweise benachbarte Gewebestrukturen ektopisch zu induzieren. So ist der IstO nach Transplantation in das kaudale Diencephalon in der Lage, in diesem Gehirnbereich cerebrale und mesencephale Strukturen zu induzieren. IstO und Grundplatte dirigieren die anteriorposterior (A-P) und dorso-ventral (D-V) Achsenbildung innerhalb des sich entwickelnden Gehirns. Die D-V-Achse wird durch die Grundplatte, der Mittelinie des Neuralrohres, bestimmt. Das induzierende Signalmolekül ist Shh („Sonic hedghog“), das Maushomologon zu Hedgehog (hh) aus D. melanogaster (Nüsslein-Volhard und Wieschaus, 1980). Als sogenanntes Segmentpolaritätsgen trägt hh zur Etablierung der A-P-Grenzen der Parasegmente in D. melanogaster bei (Mohler und Vani, 1992). Shh wird zunächst von der Chorda dorsalis, einer embryonalen Struktur mesodermalen Ursprungs, sezerniert. Bereits nach kurzer Zeit beginnen Zellen der Grundplatte indessen selbst Shh zu synthetisieren (Martí et al., 1995; Roelink et al., 1994). Durch Diffusion entsteht ein von ventral nach dorsal gerichteter Hh- bzw. Shh-Konzentrationsgradient. Eine Abhängigkeit der Induktion und Spezifikation 5-HT-Neurone von Shh konnte durch Explantatversuche nachgewiesen werden (Hynes und Rosenthal, 1999; Goridis und Rohrer, 2002). So können 5-HT-Neurone durch externe Applikation von Shh in Explantaten des dorsalen Rhombencephalon des Huhns und der Maus ektopisch induziert werden (Yamada et al., 1991). Diese durch Shh vermittelte Induktion ist nicht in Explantaten aus anderen entlang der A-P-Achse gelegenen Gehirnregionen möglich. Dies lässt auf eine komplizierte, regionale Spezifizierung der 5-HTVorläuferzellen schließen, auf die im nächsten Abschnitt näher eingegangen werden soll. Die 
Dorsalisierung des Neuralrohres wird durch Zytokinsignale der Bmp-(„Bone morphogenetic protein")-Familie vermittelt. Dabei spielen insbesondere Bmp-4, Bmp-5 und Bmp-7, sezerniert vom Ektoderm, eine wichtige Rolle bei der dorsalen Limitierung der ventralisierenden Aktivität von Shh (Barth et al., 1999; Bauer et al., 2001; Timmer et al., 2002).

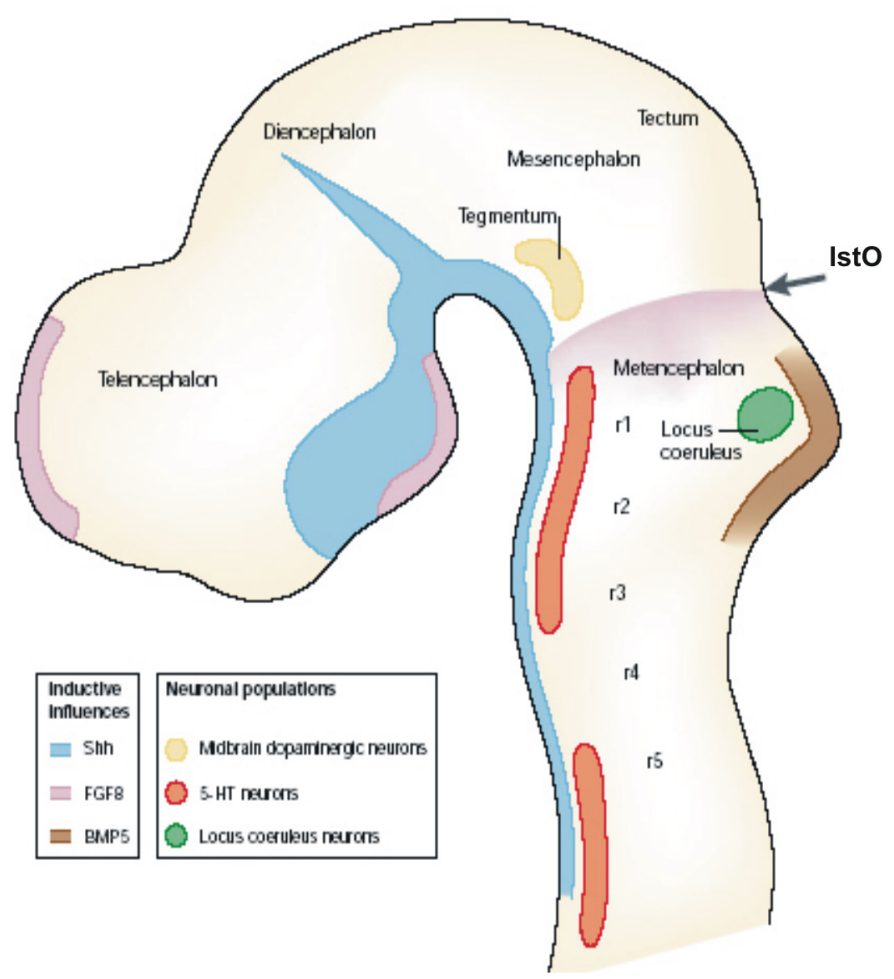

Abb.2: Schematische Darstellung der Lokalisation kaudaler und rostraler serotonerger (5-HT-) Neurone des ventralen Rhombencephalon unter Berücksichtigung der beiden essentiellen Organisationszentren, Isthmus-Organizer (IstO) und Grundplatte, im zentralen Nervensystem (ZNS) der Maus des Embryonaltages (E) 12. (Shh: „Sonic hedghog“, FGF8: „Fibroblast growth factor 8“, BMP5: „Bone morphogenetic protein 5“, Rhombomer: r; aus: Goridis C. \& Rohrer H., Specification of Catecholaminergic and Serotonergic Neurons, Nature Reviews Neuroscience 3, 2002, 531-541.)

Der IstO lässt sich als eine neuroepitheliale Einschnürung zwischen Mesencephalon und Rhombencephalon erkennen - dem Isthmus. Tatsächlich liegt der IstO der Maus leicht kaudal des Isthmus. Die Bildung des IstO ist Teil der A-P-Achsenbildung des Neuralrohres, an der während der Gastrulation Fgf-(„,Fibroblast growth factor")-Signalmoleküle und Wnt(,Wingless-related MMTV integration site")-Signale beteiligt sind (Rhinn et al., 2005; Olander et al., 2006). Der IstO selbst wird im Wesentlichen durch zwei Gene spezifiziert, Otx2 und Gbx2 (siehe Abb. 3, Seite 10). Otx2 („Orthodenticle homeobox homolog 2") wird im Mesencephalon exprimiert (Acampora et al., 1995; Matsuo et al., 1995), während Gbx2 (,Gastrulation brain homeobox 2“) ausschließlich im Rhombencephalon exprimiert wird (Millet et al., 1999; Waters und Levandowski, 2006). Die Deletion des Gens bewirkt im Falle von Otx2 die ausbleibende Bildung des Mesencephalon, im Falle von Gbx2 den Verlust 
rostraler rhombencephaler Strukturen sowie den Verlust dorsaler Anteile des Rhombencephalon. Durch gegenseitige Hemmung der Genexpression von Otx2 und Gbx2 entsteht eine exakt definierte Grenze zwischen Mesencephalon und Rhombencephalon (Glavic et al., 2002).

Eine Vielzahl sich in ihrer Expression überlappender oder gegenseitig reprimierender Gene, En1 und En2 („Engrailed 1/2"), Wnt1, „Paired box gene 2“ (Pax2) und Pax5, sind an der Etablierung und Aufrechterhaltung des IstO beteiligt und nimmt Einfluss auf sich entwickelnde, benachbarte Regionen (Echevarría et al., 2003; Joyner, 1996; Prakash und Wurst, 2004; Wassef und Joyner, 1997). Wichtigstes Signalmolekül der 5-HT-Neurogenese, welches durch den IstO sezerniert wird, ist Fgf8. Dieses wird an der Grenze zwischen den beiden Otx2- bzw. Gbx2-exprimierenden Regionen induziert. Die Expression von Fgf8 überlappt zunächst mit dem Expressionsmuster von Gbx2. Hierbei ist die Fgf8-Expression anfänglich im gesamten anterioren Rhombencephalon zu beobachten, wird jedoch kontinuierlich stärker auf den IstO begrenzt. Damit etabliert sich im Rhombencephalon ein von kaudal zu rostral ansteigender Gradient des Signalmoleküls Fgf8.
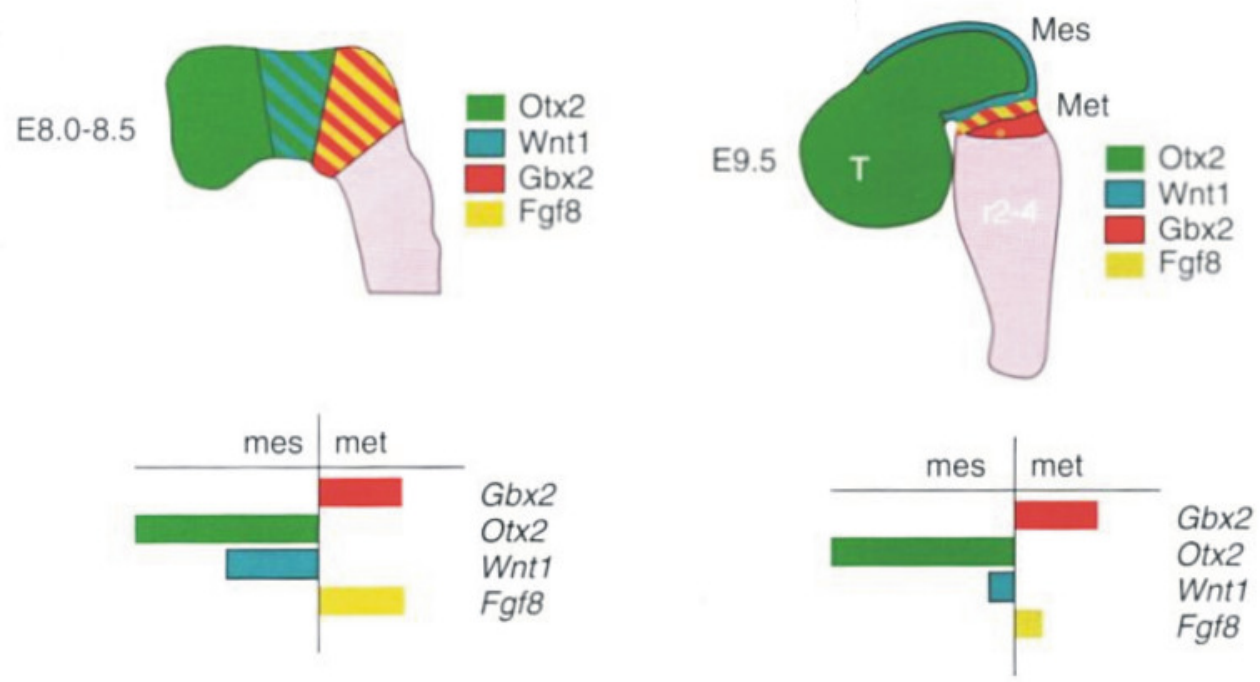

Abb. 3: Schematische Darstellung der Ausbildung des Isthmus-Organizer (IstO) der Maus des Embryonaltages (E) 8-9.5. Gegenseitige Hemmung der Expression der intrinsischen Faktoren Otx2, exprimiert im Mesencephalon (Mes), und Gbx2, exprimiert im frühen rostralen Rombencephalon (Metencephalon, Met), führt zur Ausbildung einer Expressionsgrenze zwischen Mes und Met. Im Zuge der weiteren räumlichen Definierung des IstO wird die Expression extrinsischer Faktoren, u. a. Fgf und Wnt1, zunehmend auf bestimmte Regionen beschränkt. Modifiziert nach: Joyner A., Liu A. und Millet S., Otx2, Gbx2 and Fgf8 Interact to Position and Maintain a Mid-Hindbrain Organizer, Current Opinion in Cell Biology, Volume 12, Issue 6, 2000, 736-741.) 
5-HT-Neurone entstehen kaudal des IstO im Rhombencephalon aus neuroepithelialen Vorläuferzellen der ventrikulären Zone (VZ, Neuroepithelium). Es konnte gezeigt werden, dass Fgf8 für die Induktion der ventralen rostralen 5-HT-Neurone des Rhombencephalon essentiell ist. Dies gilt insbesondere für den Nucleus raphe dorsalis (NRD), ein Abkömmling des ventralen Rhombomers 1 (R1), welches unmittelbar kaudal des IstO lokalisiert ist. Wird die Otx2-Expression nach kaudal ausgedehnt, und damit der IstO nach kaudal verschoben, so bedingt dies eine Verkleinerung des Expressionsgebietes von Fgf8. Hierdurch kommt es zu einer Reduzierung der Anzahl 5-HT-Neurone des NRD. Komplementär hierzu wird die Anzahl der dopaminergen (DA-) Neurone des Mesencephalon erhöht. Wird hingegen durch Verschiebung der Grenze der Gbx2-Expression die Expression von Fgf8 nach rostral ausgedehnt, so hat dies eine Erhöhung der Anzahl 5-HT-Neurone des NRD zur Folge (Brodski et al., 2003). Während der Entwicklung der kaudalen 5-HT-Gruppe scheint, im Gegensatz zur rostralen Gruppe, Retinolsäure (RA, „Retinoid acid"), sezerniert vom paraxialem Mesoderm, wichtige Information bezüglich der räumlichen Lokalisation der Vorläuferzellen zu vermitteln. RA bildet hierbei einen dem Signalmolekül Fgf8 entgegengesetzten Gradienten aus (Durston et al., 1989; Hernandez et al., 2007). Im Unterschied zu 5-HT-Neuronen entstehen DA-Neurone des ventralen Mesencephalon aus rostral des IstO gelegenen Vorläuferzellen der VZ. Beide, DA- und 5-HT-Neuronentypen stehen in enger ontogenetischer Verwandtschaft zueinander. Sowohl rostrale 5-HT- als auch mesencephale DA-Neurone sind während der Induktion auf Fgf8- und Shh-Signale der beiden Organisationszentren IstO und Grundplatte angewiesen. Diese Beobachtung wirft zugleich die Frage auf, durch welches Signal die Entwicklung von Vorläuferzellen zu 5-HTNeurone im Unterschied zur Entwicklung hin zu DA-Neuronen entschieden wird. Die Behandlung von Explantaten des ventralen Mesencephalon der Maus durch externe Gabe von Fgf4 führt zur ektopischen Induktion 5-HT-Neurone und einer gleichzeitigen Abnahme der Anzahl DA-Neurone (Hynes und Rosenthal, 1999; Ye et al., 1998). Somit sind Shh und Fgf8 zwar notwendig, jedoch nicht ausreichend, um 5-HT-Neurone zu induzieren. 5-HTVorläuferzellen bedürfen zudem Fgf4, welches im Primitivstreifen synthetisiert wird. Damit ist die Abhängigkeit von Fgf4 ein wesentlicher Unterschied zwischen 5-HT- und DAVorläuferzellen in ihrer Entwicklung. Aufgrund der frühen Einflussnahme von Fgf4 wird angenommen, dass Fgf4 als ein Signal der vorausgehenden, zellulären Prägung fungiert. Trotz fortschreitender Forschung konnte die Bedeutung extrinsischer Signalmoleküle für die Entwicklung der Gesamtheit 5-HT-Neurone oder einzelner Subpopulationen bisher jedoch nicht eindeutig geklärt werden. 


\subsubsection{Zeitliche und räumliche Entstehung 5-HT-Neurone}

Bevor erste 5-HT-Zellgruppen erkennbar sind, erfährt das Rhombencephalon um E8.5 eine der Segmentierung in D. melanogaster ähnliche, vorübergehende Gliederung in sieben gleichförmige Abschnitte, die sogenannten Rhombomere (R1-7; Lumsden und Krumlauf, 1996). Die Individualität der Rhombomere wird durch die Expression von Hox-(,Homeobox")-Genen in für die einzelnen Rhombomere spezifischer Zusammenstellung bestimmt, die durch den zuvor erwähnten RA-Gradienten induziert wird (Gavalas et al., 1997; Guthrie und Lumsden,1991; Papalopulu et al., 1991). Die Ausbildung der Grenzen der Rhombomere, bedingt durch gegenseitige, durch Zellkontakt vermittelte Repulsion von Grenzzellen, wird durch spezifische Ephrine und ihre Rezeptoren vermittelt. Direkt kaudal des Isthmus liegt das R1. Die rostralen Nuclei raphes entstehen aus den R1-3, wobei aus R1 ausschließlich 5-HTNeurone des Nucleus raphe dorsalis (NRD) hervorgehen. Aus ventralen Vorläuferzellen der R5-7 gehen die 5-HT-Neurone der kaudalen Nuclei raphes hervor.

Beide 5-HT-Gruppen werden anatomisch durch das R4 voneinander getrennt, in dem sich keine 5-HT-Neurone entwickeln (Pattyn et al., 2003). Der Entwicklung 5-HT-Neurone geht die Bildung kranialer branchialer Motoneurone (MNs) und visceraler Motoneurone (MNv) voraus (Pattyn et al., 2003). Wie die Entstehung der 5-HT-Neurone ist auch die Entwicklung von Motoneuronen räumlich und zeitlich exakt festgelegt. Zeitgleich mit der Bildung der MNs in R2-4 und MNv in R5-7 beginnt um E9.5 die Generierung von 5-HT-Neuronen in R1. Wie bereits angedeutet, ist R1 von der Bildung der Motorneuronen ausgenommen. Es folgt um E10.5 die zusätzliche Bildung von 5-HT-Vorläuferzellen in den R1-3. Ungefähr einen Tag später, E11.5, setzt die Entwicklung der kaudalen 5-HT-Neurone ein, während im R4 weiterhin MNv gebildet werden. Das Ausbleiben der Induktion 5-HT-Neurone und die ausschließliche Generierung von Motoneuronen in R4 beruht auf einer gleichbleibenden Expression von Phox2b („Paired-like homeobox-domain protein 2 beta“). Diese wird durch die Homeobox-Transkriptionsfaktoren Hox1b, Nkx6.1 („NK6 transcription factor related, locus 1") und Nkx6.2 bedingt. Während in R1 keine Phox2b-Expression detektierbar ist, wird Phox2b bis zum E10.5 in R2-3 und R5-7 exprimiert. Zu späteren Zeitpunkten wird es in diesen Bereichen durch Nkx2.2 (,NK2 transcription factor related, locus 2") in seiner Expression reprimiert. Diese Hemmung gibt den Weg zur Induktion 5-HT-Neurone frei. Phox2b gilt daher als zentraler Repressor der Entwicklung 5-HT-Neurone (Pattyn et al, 2000). In Phox2b-defizienten Mäusen sind Vorläufer visceraler Motoneurone nicht nachweisbar. Hingegen werden 5-HT-Neurone, obgleich nicht vollständig ausgereift, in diesen Mausmutanten in allen Rhombomeren verstärkt gebildet. 


\subsubsection{Intrinsische Faktoren bestimmen das Vorläuferstadium 5-HT-Neurone}

Die räumlich und zeitlich korrekte Induktion und Differenzierung 5-HT-Neurone steht einerseits unter Kontrolle der bereits erwähnten externen Signalmoleküle Shh, Fgf4 und Fgf8. Andererseits sind diese extrinsischen Faktoren eng mit transkriptionellen Regulationsmechanismen verknüpft, mit denen sie ein kompliziertes Netzwerk bilden. Dabei sind extrinsische Signalmoleküle und intrinsische Transkriptionsfaktoren nicht für alle 5-HTNeurone in gleichem Maße von Bedeutung. Bisher ist es noch nicht gelungen, dieses Netzwerk für die einzelnen Subpopulationen der 5-HT-Neurone vollständig aufzuklären.

Auf transkriptioneller Ebene lässt sich die Entwicklung von 5-HT-Neuronen in zwei Phasen unterteilen. Erstens die Induktion von 5-HT-Vorläuferzellen, zweitens die postmitotische Entwicklung bis hin zur terminalen Differenzierung und Ausbildung des 5-HT-Phänotyps.

Die Expression von Nkx2.2, die dem Shh-Signal der Bodenplatte nachfolgt, besitzt eine essentielle Bedeutung für die Spezifizierung ventraler Zelltypen. Dieser Transkriptionsfaktor wird als einer der ersten Faktoren von allen 5-HT-Vorläuferzellen bis zum Verlassen des Zellzyklus exprimiert (Briscoe et al., 1999). Beobachtungen an Nkx2.2-defizienten Mäusen zeigten, dass Nkx2.2 die Entwicklung der kaudalen, jedoch nicht aller rostralen 5-HTNeurone bestimmt. So sind 5-HT-Neurone des NRD, einem Abkömmling des R1, in Nkx2.2defizienten Mausmutanten weiterhin vorhanden. Es wird vermutet, dass der dem Transkriptionsfaktor Nkx2.2 verwandte Faktor Nkx2.9, welcher in R1 exprimiert wird, möglicherweise einen Verlust von Nkx2.2 kompensiert. Nkx2.2 wiederum induziert Nkx6.1 in Zellen der Vorläuferregion. Eine Deletion von Nkx6.1 führt zum Ausbleiben der Expression von Genen, welche die Differenzierung zu 5-HT-Neuronen kontrollieren, und somit zum vollständigen Verlust aller 5-HT-Neurone. Nkx2.2 und Nkx6.1 regulieren gemeinsam die Expression von Gata-Transkriptionsfaktoren („GATA-binding protein 2/3”, Gata2 und Gata3), die eine bedeutende Rolle in der postmitotischen Entwicklung 5-HT-Neurone spielen. Wie bereits erwähnt, ist Nkx2.2 von essentieller Bedeutung für die zeitliche Kontrolle der Initiierung der 5-HT-Neurogenese zu Lasten der Entwicklung von Motoneuronen durch Hemmung der Expression von Phox2b.

Mash1 („Mouse achaete-scute homolog 1“), ein bHLH-(,Basic helix-loop-helix")Transkriptionsfaktor, wird bereits sehr früh in der VZ exprimiert und gehört zu den proneuralen bHLH-Transkriptionsfaktoren (Bertrand et al. 2002; Guillemot und Joyner, 1993). Mash1 ist nach Herabregulation von Phox2b direkt an der Generierung von postmitotischen 5-HT-Vorläufern beteiligt. Die Bedeutung dieses Transkriptionsfaktors wird anhand von Untersuchungen von Mash1-defizienten Mäusen deutlich (Pattyn et al., 2004). Diese weisen eine gestörte Neurogenese zentraler 5-HT-Neuronen auf. Darüber hinaus lassen sich keine der folgenden, postmitotisch exprimierten Transkriptionsfaktoren nachweisen: Lmx1b 
(„,LIM homeobox transcription factor 1 beta“), Gata2/3 und Pet1 („Plasmacytoma expressed transcript 1“). Die Genexpressionsmuster von Nkx2.2, Nkx2.9 und Phox2b bleiben hingegen unverändert. Interessanterweise werden Nkx2.2 und Mash1 auch in Vorläuferzellen, die nicht den 5-HT-Entwicklungsweg einschlagen, exprimiert. Es ist daher anzunehmen, dass mindestens ein weiterer Faktor zur Festlegung der Entwicklung von 5-HT-Neuronen notwendig ist. Diese Annahme wird durch die Tatsache gestützt, dass eine ektopische Expression von Nkx2.2 und Mash1 nicht in der Lage ist, 5-HT-Neurone zu induzieren (Pattyn et al., 2004). Ein möglicher Transkriptionsfaktor, dem die Rolle der Festlegung von Vorläuferzellen auf die Entwicklung zu 5-HT-Neurone zukommen könnte, ist Foxa2 („Forkhead box $\left.A 2^{\prime \prime}\right)$. Foxa2 wird ventral von jener Vorläuferzellpopulation verstärkt exprimiert, die von der Bildung von MNv zur Entwicklung 5-HT-Neurone umschalten. Dieses Umschalten geht mit einer Herabregulation von Phox2b einher (Jacob et al., 2007).

\subsubsection{Vom postmitotischen Neuron bis zum Erlangen des 5-HT-Phänotyps}

Pet1 ist bislang das einzige identifizierte Markergen, das spezifisch ausschließlich in postmitotischen 5-HT-Neuronen exprimiert wird. Seine beginnende Expression um E10.75 geht der Expression des Gens Tph2 („Tryptophanhydroxylase 2“) um 6-12 h voraus. Auch im adulten Stadium wird Pet1 in seiner Expression aufrecht erhalten. Die Spezifität des Transkriptionsfaktors Pet1 für 5-HT-Neurone lässt sich durch die Tatsache erklären, dass in Promotorregionen der Gene Sert „Plasma membrane serotonin transporter"), Tph2, Aadc (,Aromatic L-aminoacid-decarboxylase“) und des Autorezeptor 5-HTR1a Bindungsstellen für Pet1 identifiziert werden konnten (Hendricks et al., 1999). Pet1-defiziente Mäuse zeigen eine Reduktion 5-HT-Neurone um nahezu 70\% (Hendricks et al., 2003). Die verbleibenden 5-HTNeurone weisen eine verminderte Expression oben genannter, den 5-HT-Phänotyp spezifizierender Gene auf, wodurch die 5-HT-Synthese, seine Wiederaufnahme und Speicherung eingeschränkt werden. Die Tatsache, dass in Pet1-defizienten Mausmutanten dennoch 5-HT-Neurone vorliegen, deutet darauf hin, dass die Funktion von Pet1 in diesen Zellen durch ein weiteres Mitglied der Familie der ETS-Transkriptionfaktoren kompensiert wird. Es könnte sich hierbei auch um 5-HT-Neurone handeln, deren Vorläufer einen späteren, bisher unbekannten und zudem von Pet1 unabhängigen Entwicklungsweg eingeschlagen haben. Im Gegensatz zu anderen Mausmutanten, defizient für Gene der 5-HT-Neuronenentwicklung, sind Pet1-defiziente Mutanten lebensfähig. Jedoch zeigen Mäuse dieses Genotyps ein deutlich gesteigertes Furchtverhalten und Aggressivität ähnlich Mäusen defizient für $L m \times 1 b$ oder für einzelne 5-HT-Rezeptortypen (Gaspar et al., 2003; Gingrich et al., 2003). 
Gata2 und Gata3 verknüpfen das 5-HT-Vorläuferstadium, welches durch eine Expression von Nkx2.2 und Mash1 gekennzeichnet ist, mit der postmitotischen Entwicklungsstufe (Nardelli et al., 1999). Erste postmitotische 5-HT-Neurone lassen sich um E11.5 im rostralen Rhombencephalon immunhistochemisch nachweisen. Ein Ausschalten eines der Gene, Gata2 oder Gata3, führt in Mäusen zum frühen embryonalen Tod (E 9.5-12.5). Hierzu tragen unter anderem gravierende neurogenetische Defekte bei (Pandolfi et al., 1995; Tsai et al., 1994). Gata2 übernimmt eine bedeutende Rolle in der Generierung rostraler und kaudaler rhombencephaler 5-HT-Neurone. Es ist notwendig für die Induktion der Expression von Lmx1b und Pet1. Für die Induktion 5-HT-Neurone des R1 ist Gata2 nicht nur notwendig, sondern auch ausreichend. Dies wird durch Beobachtungen an Gata2-defizienten Mausmutanten gestützt. 5-HT-Neurone, abstammend von Vorläuferzellen des R1, werden in diesen Mutanten nicht ausgebildet, was gegen eine mögliche Kompensation durch Gata3 spricht (Craven et al., 2004). Ob Gata3 in seiner Expression von Gata2 abhängig ist, konnte bisher nicht eindeutig geklärt werden. Gata3, so zeigen konventionelle Gata3Mausmutanten, ist im Gegensatz zu Gata2 für die Entwicklung der kaudalen 5-HT-Neurone essentiell. Zwar wird es auch von rostalen 5-HT-Neuronen exprimiert, jedoch entwickeln sich diese auch in Gata3-defizienten Mäusen in nahezu normaler Anzahl. Fehlt Gata3, so führt dies zu einem Verlust von circa $80 \%$ der kaudalen 5-HT-Neurone, aber nur zu einer Reduktion um circa 30\% der Anzahl rostraler 5-HT-Neurone. Die Expression von Lmx1b und Pet1 ist durch das Fehlen von Gata3 nicht beeinträchtigt, was dafür spricht, dass diese Faktoren parallel zueinander agieren.

Lmx1b ist ein Zink-Finger-Transkriptionsfaktor mit weiter Verbreitung im ZNS. Er ist unter anderem für die weitere postmitotische Entwicklung aller 5-HT-Vorläuferzellen notwendig (Chen et al., 2003; Ding et al., 2003). In Mäusen führt die Gendeletion von Lmx1b zum völligem Fehlen zentraler 5-HT-Neurone und zum perinatalen Tod. Mausmutanten, in denen die $L m x 1 b$-Expression konditionell ausschließlich in Pet1-exprimierenden Zellen aufgehoben ist, weisen dennoch eine vorübergehende Expression von Pet1 in postmitotischen 5-HTVorläuferzellen auf (Zhao et al., 2006). Diese Expression geht jedoch im Zuge der weiteren Entwicklung verloren. Daher ist davon auszugehen, dass Lmx1b nicht die Expression von Pet1 initiiert, jedoch für die Aufrechterhaltung der Pet1-Expression notwendig ist. Ein gänzlicher Verlust von $L m \times 1 b$ führt in Mäusen des Weiteren zu einer räumlichen Ausdehnung der 5-HT-Vorläuferzellregion von ventral zu dorsal. Somit scheint Lmx1b zusätzlich eine regulatorische Funktion bei der Festlegung der regionalen Identität oder direkt bei der Regulation von Migrationsvorgängen zu besitzen. Es sei an dieser Stelle erwähnt, dass Lmx1b während der Entwicklung mesencephaler dopaminerger (DA-) Neurone ebenfalls eine wesentliche Bedeutung zu kommt, was ein weiterer Hinweis auf eine ontogenetische Verwandtschaft beider Neuronengruppen sein könnte. 
Der ausgereifte, terminale 5-HT-Phänotyp wird schließlich durch die Expression der Gene Tph2, eine nur im ZNS exprimierten Isoform des Tryptophanhydroxylase-Gens, des SertGens und des Vmat2-(„Vesicular monoamine transporter 2“)-Gens erreicht.

\subsection{Tgf- $\beta$ (,,Transforming growth factor- $\beta$ ) - Ein extrinsisches Signalmolekül und seine Bedeutung für die Entwicklung ventraler Neuronenpopulationen}

DA-Neurone des ventralen Mesencephalon stehen in enger Verwandtschaft zu 5-HTNeuronen des ventralen Rhombencephalon. So entstehen beide Neuronentypen aus Vorläuferzellen beiderseits des IstO. Kaudal des IstO entstehen 5-HT-Neurone, rostral des IstO befinden sich Vorläuferzellen der mesencephalen DA-Neurone. Neben dieser räumlichen Beziehung zueinander weisen beide Neuronentypen auch bezüglich ihrer Entwicklung Parallelen auf. Hierzu zählt beider Abhängigkeit von Shh, Signalmolekül der Grundplatte, als auch von Fgf8, sezerniert vom IstO. Shh und Fgf8 sind jedoch nicht die einzigen extrinsischen Signalmoleküle die in diesen Strukturen exprimiert werden und in angrenzenden Geweben ihren positionsdefinierenden Einfluss ausüben. Weitere in diesen Regionen endogen exprimierte Moleküle sind zwei Isoformen des Zytokins Tgf- $\beta$ („Transforming growth factor- $\beta$ ), Tgf- $\beta 2$ und Tgf- $\beta 3$. Während der Entwicklung regulieren Tgf- $\beta$ s unter anderem wichtige zelluläre Prozesse wie Proliferation, Differenzierung, Apoptose, aber auch zelluläres Überleben in späteren Stadien. Weitere regulatorische Aufgaben erfüllen Tgf- $\beta$ s in der Regulierung der Synthese extrazellulärer Matrixkomponenten, in der Hämatopoese und in immunologischen Prozessen (Unsicker et al., 1996). Tgf- $\beta$ s werden zunächst als Vorläuferproteine sekretiert und nachfolgend durch proteolytische Spaltung aktiviert. Die Smad-(,Mothers against DPP homolog")-abhängige Signaltransduktion erfolgt, stark vereinfacht, über die Bindung von Tgf- $\beta$ an den homodimeren Tgf- $\beta$-Rezeptor Typ II („Rezeptor serin/threonin kinase Typ II"). Dieser rekrutiert, bindet und aktiviert den Tgf- $\beta$-Rezeptor Typ I („Rezeptor serin/threonin kinase typ I"; „Activin receptor-like kinase 5“, Alk5). Im Anschluss hieran phosphoryliert der Tgf- $\beta$ Rezeptor Typ I Smad2 oder Smad3. Einmal phosphoryliert, dissoziiert der homotrimere Smad-Komplex vom Rezeptorkomplex und bindet Co-Smad/Smad4. Der SmadProteinkomplex transloziert schließlich in den Nucleus und induziert die Expression spezifischer Zielgene. Hierzu zählen auch die Gene der inhibitorischen Smad-Proteine 6 und 7. Diese inhibitorischen Smad-Proteine stehen in Konkurrenz mit aktivierenden SmadProteinen um die Bindung an den zuvor aktivierten Tgf- $\beta$-Rezeptor Typ I. Die beschriebene Smad-abhängige Signaltransduktionskaskade stellt nur einen der durch Tgf- $\beta$ s induzierten 
Signaltransduktionswege dar. Neben diesem sind auch Smad-unabhängige Signaltransduktionskaskaden durch Tgf- $\beta$ s aktivierbar (Moustakas und Heldin, 2005). Die zelluläre Antwort auf Tgf- $\beta$ ist extrem variabel und wird unter anderem durch den jeweiligen Zelltyp und die Zellumgebung determiniert (Rahimi und Leof, 2007; Zhu und Burgess, 2001). Bisher wurden drei Tgf- $\beta$-Isoformen (Tgf- $\beta$ 1/2 und 3) in Säugetieren beschrieben, die innerhalb der Tgf- $\beta$-Superfamilie eine eigenständige Familie bilden. Eine Expression von Tgf- $\beta 1$ konnte in neuralem Gewebe unter normalen, physiologischen Bedingungen nicht beobachtet werden. Im Gegensatz hierzu werden die Tgf- $\beta$-Isoformen 2 und 3 in weiten Teilen des adulten ZNS und peripheren Nervensystem (PNS) exprimiert (Unsicker und Strelau, 2000). Obwohl die Expression der Tgf- $\beta$-Isoformen 2 und 3 häufig überlappen, resultieren beide Gendeletionen in unterschiedlich ausgeprägten Phänotypen der jeweiligen Mausmutanten. Tgf- $\beta 3$-defiziente Mäuse leiden unter anderem an einer ausgeprägten Gaumenspalte. Diese Missbildung bedingt eine Störung der Atmung und der Nahrungsaufnahme und hierdurch den Tod der Mutanten innerhalb eines Tages nach der Geburt (Proetzel et al., 1995). Der Phänotyp einer Gendeletion von Tgf- $\beta 2$ äußert sich weitaus vielfältiger. So lassen sich skelettale Missbildungen, organischen Missbildungen, insbesondere des Herzens, der Lunge, des Auges und Innenohres sowie des Urogenitaltraktes beschreiben. Aufgrund kongenitaler Zyanose tritt bei Tgf- $\beta 2$-defizienten Mäusen der Tod bereits perinatal ein (Dünker und Krieglstein, 2002).

Bedeutsam in Hinblick auf die Entwicklung mesencephaler DA-Neurone ist die Expression der beiden Tgf- $\beta$-Isoformen 2 und 3 in der Substantia nigra (SN). Während früher Embryonalstadien sind diese beiden Tgf- $\beta$-Isoformen zudem in der Chorda dorsalis und der Grundplatte nachweisbar (Böttner et al., 1996; Farkas et al., 2003; Flanders et al., 1991; Unsicker et al., 1996). Darüber hinaus konnten Tgf- $\beta 2$, Tgf- $\beta 3$ und die Tgf- $\beta$-Rezeptoren Typ I und II im ventralen Mesencephalon der Maus ab dem E12 nachgewiesen werden. Eine spezifische Bedeutung der Tgf- $\beta$ s für die Entwicklung und Aufrechterhaltung DA-Neurone des ventralen Mesencephalon konnte durch die Applikation von Tgf- $\beta$ s in vitro an mesencephalen Zellkulturen der Ratte und in vivo an Hühnerembryonen zu unterschiedlichen Zeitpunkten der Entwicklung abgeleitet werden (Farkas et al., 2003). Durch externe Tgf- $\beta$-Gabe konnte die Anzahl Tyrosinhydroxylase-(TH)-exprimierender Zellen in vitro in mesencephalen Zellkulturen der Ratte (E12) signifikant erhöht werden. Dieser Effekt ließ sich durch Blockierung aller endogen exprimierten Tgf- $\beta$-Isoformen mittels eines spezifischen Antikörpers umkehren. Die Expression von TH definiert das Erreichen des terminalen DA-Phänotyps und entspricht damit der Expression von Tph2 in 5-HT-Neuronen. Interessanterweise zeigte sich in den obig beschriebenen in vitro-Versuchen eine starke gegenseitige Abhängigkeit der durch Tgf- $\beta$ s und Shh induzierten Effekte. Trotz endogen 
verfügbarem Shh-Signal resultierte die Blockierung endogen vorliegender TGF- $\beta$ s in vitro in einem Ausbleiben der Induktion DA-Neurone. Eine Blockierung des Shh-Moleküls, nicht aber der endogenen exprimierten Tgf- $\beta$ s, durch einen spezifischen Antikörper führte wiederum zu vergleichbaren Ergebnissen (Farkas et al., 2003). Noch deutlicher wurde die Bedeutung der Tgf- $\beta$ s für die Induktion DA-Neurone anhand ihrer ektopischen Induktion im dorsalen Mesencephalon durch Tgf- $\beta$ s (Roussa et al., 2006). Behandlung von primären Zellkulturen des ventralen Mesencephalon der Ratte (E14) mit Tgf- $\beta$ s über einen längeren Zeitraum hinweg begünstigt das Überleben TH-exprimierender Neurone. Tgf- $\beta$ hat hierbei keinen Einfluss auf die Zellproliferation, sondern reduzieren tatsächlich die Anzahl apoptotischer Zellen. Dieser Effekt lässt sich verstärken, wenn Tgf- $\beta$ in Verbindung mit Shh und Fgf8 appliziert wird (Roussa et al., 2004). Der positive Effekt von Tgf- $\beta$ auf das Überleben DANeurone konnte auch in vivo demonstriert werden. Hierzu wurde in Hühnerembryonen (E6 E10) nach Abschluss der Induktion der Entwicklung von DA-Neuronen endogen synthetisierte Tgf- $\beta$ s durch einen, die Tgf- $\beta$-Funktion blockierenden, Antikörper neutralisiert. Dies führte zu einer deutlichen Abnahme der Anzahl DA-Neurone (Farkas et al., 2003).

Tgf- $\beta 2$ und 3 lassen sich beginnend mit dem Embryonaltag 12 auch im ventralen Rhombencephalon nachweisen (Flanders et al., 1991). Einzelne Applikation der Tgf- $\beta$ Isoformen 2 und 3 führten in vitro jeweils zu einem vergleichbar hohen Anstieg der Anzahl 5-HT-Neurone in primären Zellkulturen des ventralen Rhombencephalon der Ratte, E14 (Galter et al., 1999). Der Anstieg der Anzahl 5-HT-Neurone beschränkte sich hierbei auf 5-HT-Neurone, die dem kaudalen Abschnitt des Rhombencephalon entstammten. Im Gegensatz hierzu blieb die Anzahl der 5-HT-Neurone der rostralen Raphe unverändert. Eine sich über einen längeren Zeitraum erstreckende Einzelbehandlung von Kulturen des rostralen und kaudalen Rhombencephalon früherer Embryonalstadien (E12 und E13) mit Tgf- $\beta$ s zeigte deutlich, dass es sich bei der Empfänglichkeit der Zellen für Tgf- $\beta$-Isoformen um ein zeitlich und räumlich regulierten Effekt handelt. Eine externe Tgf- $\beta 2$ oder 3 Gabe steigerte die Zahl rostraler 5-HT-Neurone um den E12 und E13, während die sich zu entwickeln beginnenden kaudale Population von 5-HT-Neuronen zunächst nicht beeinflusst wurde (Galter et al., 1999). In vivo-Studien von Tgf- $\beta$-Mausmutanten stützen die These, dass Tgf- $\beta$ s sowohl an der Induktion als auch der Aufrechterhaltung von 5-HT-Neuronen beteiligt sind. Interessanterweise deuten in unserem Labor durchgeführte immunhistochemische Untersuchungen an Tgf- $\beta 2$-defizienten Mäusen auf eine Reduktion der Anzahl rostraler 5-HT-Neurone um E11.5 hin (Roussa E., persönliche Mitteilung). Zu diesem Zeitpunkt sind einzelne Nuclei raphes noch nicht identifizierbar. Ebenso sind die kaudalen 5-HT-Neurone noch nicht in die postmitotische Entwicklung eingetreten. Dies deutet auf eine induktive Funktion von Tgf- $\beta 2$ für die Entwicklung rostraler 5-HT-Neurone des ventralen 
Rhombencephalon hin. Zu einem späteren Zeitpunkt, E18.5, lässt sich eine Reduktion von 5-HT-Neurone der paramedianen Raphe (B5/B8) beobachten. Der selektive Verlust dieser Neuronen legt die Vermutung nahe, dass Tgf- $\beta 2$ zumindest für die Aufrechterhaltung diese Subpopulation von 5-HT-Neuronen notwendig ist. Der molekulare Mechanismus einer Tgf- $\beta 2$-abhängigen Induktion und Aufrechterhaltung 5-HT-Neurone ist bisher nicht aufgeklärt.

\subsection{Der Transkriptionsfaktor „Single-minded“ (sim) — Ein intrinsischer Faktor und seine Bedeutung für die Bildung der ventralen Mittellinie in D. melanogaster}

Die Mittellinie von $D$. melanogaster ist ein wichtiges Organisationszentrum für die Ausbildung der D-V-Achse des ZNS (Nambu et al., 1993; Lee et al., 1999). Sie stammt vom Mesektoderm, einer Kette von Einzelzellen ab, welches das Mesoderm vom Neuroektoderm während der Gastrulation trennt (Kosman et al., 1991). "Single-minded" (sim) kodiert für einen bHLH-PAS-Transkriptionsfaktor und stellt ein Hauptregulatorgen der Neurogenese, insbesondere der Bildung der Mittellinie in D. melanogaster, dar. Dabei aktiviert sim die Expression von Genen der Mittellinie, z.B. „rhomboid“ (rho), „engrailed“ (en) und „epidermal growth factor receptor" (egfr). Diese sind notwendig, um die Expression von Genen zu regulieren, die für die D-V-Achsenbildung verantwortlich sind. Gleichzeitig reprimiert Sim in den Mittellinienzellen die Expression von weiter lateral im ZNS zu exprimierenden Genen (Kim, I.O. et al., 2005). Die Zellen der Mittellinie fungieren als Signalzentren für sie umgebendes Gewebe und differenzieren sich in Gliazellen sowie in verschiedene neuronale Zelltypen. Die spezifische Expression von sim in Zellen der Mittellinie wird durch das dorsoventrale Expressionsregulationssystem, bestehend aus dorsal, twist und snail, sowie durch das Notch-Delta-System kontrolliert. In sim-defizienten D. melanogaster lässt sich beobachten, dass sich Zellen der Mittellinie nicht in die entsprechenden, ausgereiften Zelltypen differenzieren und in ihrer Migration beeinträchtig sind, so dass sie ihre endgültige, zugedachte Position innerhalb des ZNS nicht einnehmen können. In der Folge wird keine Mittellinie gebildet (Crews et al., 1988; Thomas et al., 1988). Zudem führt die ektopische Expression von sim in Zellen des lateralen ZNS von $D$ melanogaster zur Ausbildung einer Mittellinienzellen-spezifischen Morphologie und Genexpression (Nambu et al., 1991). Nicht nur an der Ausbildung der Mittellinie in $D$. melanogaster ist sim beteiligt, sondern auch an der Ausformung des visuellen Systems. Nach der hh-abhängigen Induktion der sim-Expression in den Ganglienzellen wird sim benötigt, um die synaptische Assoziation der Axone von Photorezeptorzellen mit den Ganglienzellen zu regulieren (Umetsu et al., 2006). Darüber 
hinaus wirkt sim wesentlich an der korrekten asymetrischen (links-rechts) Entwicklung innerer Organe von D. melanogaster mit (Maeda et al., 2007). In Säugetieren wurden bisher zwei sim-Homologe identifiziert, die als Sim1 und Sim2 bezeichnet werden (Ema et al., 1996; Fan et al., 1996; Moffett et al., 1996; Yamaki et al., 1996). Sim2 wird im embryonalen Diencephalon, einschließlich seiner Mittellinie, exprimiert. Das humane Sim2-Gen wird mit der Ausbildung des Down-Syndrom assoziiert und ist in Tumoren des Colon, der Prostata und des Pankreas nachweisbar (Chen et al., 1995; Dahmane et al., 1995; Woods et al., 2008). Sim1 wird im Gegensatz zu Sim2 direkt lateral zur Mittellinie des Diencephalon und des Rückenmarks sowie in weiteren Bereichen des ZNS und in der sich entwickelnden Niere exprimiert. Während der Entwicklung hypothalamischer neuroendokriner Zellen des Nucleus pariventricularis anterior (aPV), des Nucleus paraventricularis (PVN), der für die Regulation des Körpergewichts von entscheidender Bedeutung ist, und des Nucleus supraopticus (SO) der Maus lassen sich sowohl Sim1 als auch Sim2 nachweisen (Holder et al., 2000; Goshu et al., 2002). Histologische Untersuchungen an Sim1-defizienten Mäusen zeigten, dass der PVN und der SO unterentwickelt sind. Neuroendokrine Zellen dieser Kerne (aPV, PVN, SO), welche für die Neurosekretion von Somatostatin, Vasopressin, Oxytozin, Corticoliberin („Corticotropin releasing hormone“, CHR) und Tyroliberin („Thyrotropin releasing hormone“, $\mathrm{TRH}$ ) verantwortlich sind, sind nicht in der Lage den Zustand der terminalen Differenzierung zu erreichen. Dies führt schließlich kurz nach der Geburt zum Tod der homozygoten Sim1Mutanten (Michaud et al., 1998). Sim2-defiziente Mäuse besitzen hingegen einen normalen PVN und SO (Goshu et al., 2002). Aus diesem Grund wird angenommen, dass nur Sim1 essentiell für die Bildung der oben genannten hypothalamischen Kerne ist und ein Fehlen von Sim1 nicht durch Sim2 kompensiert werden kann. Auch Sim2-Mausmutanten sterben perinatal, spätestens drei Tage nach der Geburt. Der Tod tritt durch gravierende Defekte des respiratorischen Apparates, beruhend auf Missbildungen der Rippen, der Pleurahöhlen und des Diaphragma, ein (Goshu et al., 2002).

Die durch Sim1-vermittelte Transkriptionsaktivierung wird durch die Bindung von Heterodimeren aus Sim1 und Arnt2 („Aryl hydrocarbon receptor nuclear translocator"), dem Orthologon des Tango-Proteins aus D. melanogaster, an die CME-(„CNS midline element")Sequenz vermittelt. Mögliche Zielgene von Sim1 wurden durch Analysen der Genexpression mittels cDNA-Mikroarray anhand eines in vitro-Zellsystems identifiziert (Liu et al., 2003). Sim1- und Arnt2-überexprimierende Neuro2a-Zellen, eine neuronale Säugerzelllinie, wiesen eine gesteigerte Expression einer Vielzahl von Genen auf. Zu diesen möglichen Zielgenen von Sim1 zählten interessanterweise auch Gata2 und Gdnf („Glia cell Line derived neurotrophic factor"), ein Mitglied der Tgf- $\beta$-Superfamilie (Liu et al., 2003), welches für das Überleben von DA-Neuronen des Mesencephalon essentiell ist (Clarkson et al., 1997; ChoiLundberg et al., 1997). Es wäre denkbar, dass der Transkriptionsfaktor Sim1 in die 
Neurogenese ventraler Vorläuferzellen des ZNS der Säuger involviert ist. Hierfür spricht zum einen die Bedeutung von sim in der Ausbildung der Mittellinie in D. melanogaster und damit einhergehend die Beeinflussung der Entwicklung von neuronalen Zelltypen. Zum anderen zeigte ein Vergleich der Genexpression zwischen ventralem und dorsalem Mesencephalon der Maus (E11) mittels Mikroarray-Analyse der Genexpressionsmuster eine deutlich stärkere Sim1-Expression im ventralen Gewebe (persönliche Mitteilung: Roussa E.). Inwieweit Sim1 als ventraler Determinant auch in die Induktion und Spezifikation 5-HT-Neurone involviert ist, ist bisher nicht bekannt. 


\section{Zielsetzung der Arbeit}

Die Entwicklung rostraler 5-HT-Neurone des ventralen Rhombencephalon wird durch ein zeitlich und räumlich genau festgelegtes Zusammenspiel extrinsischer und intrinsischer Faktoren bestimmt, welches bisher nur ansatzweise aufgeklärt werden konnte. Die vorliegende Arbeit soll dazu beitragen, weitere Erkenntnisse über die molekularen Mechanismen der Induktion und Spezifikation 5-HT-Neurone zu gewinnen. Im Fokus wird hierbei die Untersuchung einer denkbaren Beteiligung des extrinsischen Signalmoleküls Tgf- $\beta$ und des Transkriptionsfaktors Sim1, als intrinsischer Faktor, an der Entwicklung 5-HTNeurone des ventralen rostralen Rhombencephalon der Maus (E12) stehen.

Aus diesem Forschungsansatz ergeben sich folgende Ziele der Arbeit:

Die Etablierung und Charakterisierung eines in vitro-Systems des ventralen rostralen Rhombencephalon der Maus (E12), das es ermöglicht, die Induktion und Spezifizierung 5-HT-Neurone in vitro zu untersuchen und gezielt zu beeinflussen.

- Die Untersuchung eines vorstellbaren Einflusses des extrinsischen Signalmoleküls Tgf- $\beta$ auf die Entwicklung und Differenzierung 5-HTNeurone aus Vorläuferzellen des rostralen Rhombencephalon.

- Die Analyse einer möglichen Bedeutung des Transkriptionsfaktors Sim1 für die Entwicklung von 5-HT-Neuronen des ventralen rostralen Rhombencephalon der Maus.

- Die Identifizierung von bisher unbekannten Genen, die an der Induktion und Spezifikation von rostralen 5-HT-Neuronen des ventralen Rhombencephalon der Maus beteiligt sein könnten, und hierdurch die Ergänzung fehlender Elemente innerhalb des transkriptionellen Netzwerkes, welches der Entwicklung rostraler 5-HT-Neurone zugrunde liegt. 


\section{Materialien und Methoden}

\subsection{Materialien}

\subsubsection{Organismen}

\section{Mikroorganismen}

Escherichia coli $\mathrm{DH} 5 \alpha$

Stratagene, La Jolla, California, USA

$D H 5 \alpha\left(F^{\prime}, \varphi 80 d l a c Z \Delta M 15, \Delta(l a c Z Y A-a r g F), U 169\right.$, deoR, recA1, endA1, hsdR17, (rK-,mK+), supE44, $\lambda$-, thi-1, gyrA96, relA1)

\section{Eukaryontische Zelllinien}

MN9D-Zelllinie (,Mouse neuronal cell line clone 9D“)

Durch somatische Zellfusion generierte, immortalisierte, klonale Hybridzelllinie aus Zellen des rostralen mesencephalen Tegmentum der Maus (E14); Choi et al., 1991.

\section{Mausstämme}

\section{NMRI Mausstamm}

Mauslinie des „Naval Medical Research Institute“, Teil des U.S. Navy's National Naval Medical Center. NMRI-Mäuse wurden von der zentralen tierexperimentellen Einrichtung der Universitätsmedizin Göttingen bezogen.

\section{Sim1-defizienter Mausstamm}

Die Sim1-defiziente Mauslinie mit genetischem C57BL/6-Hintergrund (Michaud et al., 1998) wurde freundlicherweise durch Herrn Dr. Chen-Ming Fan (Carnegie Institution, Department of Embryology, Baltimore, Maryland 21218, USA) zur Verfügung gestellt. 


\subsubsection{Medien}

\section{Mikrobiologische Kulturmedien}

Luria-Bertani-(LB)-Flüssigmedium

$$
\begin{array}{rl}
1,0 \mathrm{~g} & \text { Trypton } \\
10,0 \mathrm{~g} & \mathrm{NaCl} \\
0,5 \mathrm{~g} & \text { Hefeextrakt } \\
& \text { ad 1 I A. bidest }
\end{array}
$$

Für die Erstellung von Selektivkulturmedien wurden Ampicillin oder Kanamycin in einer

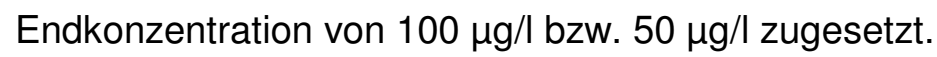

LB-Kulturplattenmedium

\section{Eukaryontische Zellkulturmedien}

Dulbecco's modified Eagle medium-F12

(DMEM-F12)

DMEM-F12-Komplettmedium der Primärkultur

DMEM-F12 MN9D Kulturmedium

CMF (Calcium-Magnesium-freies Medium)

2x Einfriermedium
1,5\% Agar-Agar in LB-Flüssigmedium

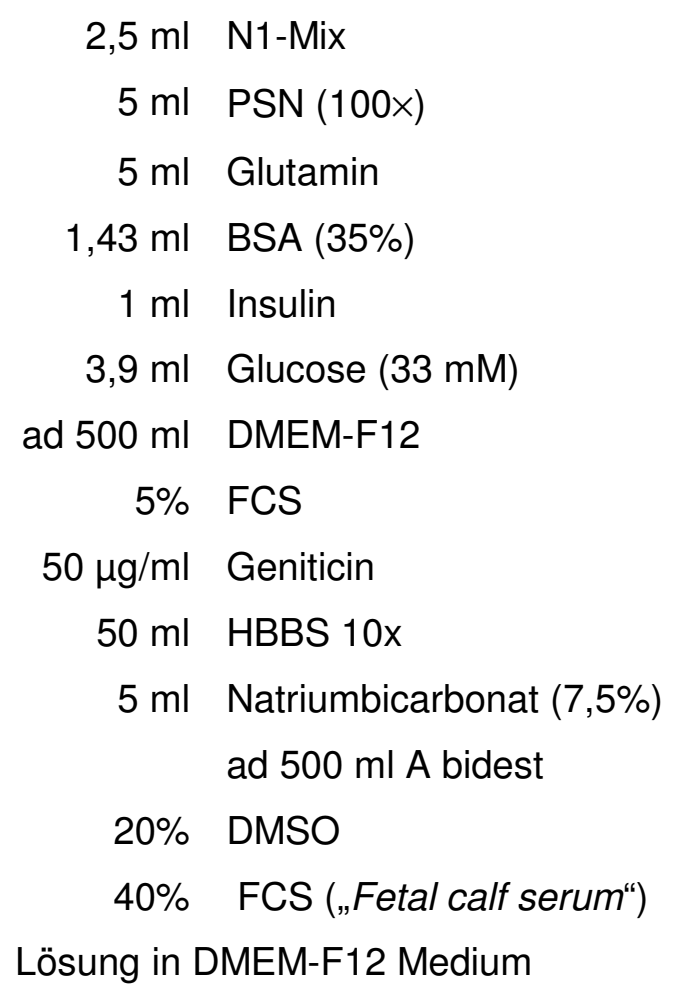


Opti-MEM

(,Reduced serum medium, modification of MEM

Eagle 's")
Gibco/Invitrogen, Karlsruhe, D

\section{Antibiotika und Medienzusätze}

Insulin

N1-Mix Medium Supplement (100x)

Penicillin (100 mg/ml)/Streptomycin $(0,5 \mathrm{mg} / \mathrm{ml}) /$

Neomycin (100 mg/ml); PSN-Lösung (100x)

Geniticin (50 mg/ml)

Ampicilin-Stammlösung $(100 \mathrm{mg} / \mathrm{ml}$ in A. bidest, Lagerung bei $-20{ }^{\circ} \mathrm{C}$ )

Kanamycin-Stammlösung $(50$ mg/ml A. bidest, Lagerung bei $-20^{\circ} \mathrm{C}$ )
Sigma-Aldrich Laborchemikalien

GmbH, Seelze, D

Sigma-Aldrich Laborchemikalien

GmbH, Seelze, D

Sigma-Aldrich Laborchemikalien

GmbH, Seelze, D

Sigma-Aldrich Laborchemikalien

$\mathrm{GmbH}$, Seelze, D

Carl Roth $\mathrm{GmbH}$, Roth, Karlsruhe, D

Carl Roth GmbH, Roth, Karlsruhe, D

\section{Faktoren}

Tgf- $\beta 1$

$\alpha-\operatorname{Tgf}-\beta 1 / 2 / 3$

Fgf2,100 $\mu \mathrm{g} / \mathrm{ml}$

Egf, $100 \mu \mathrm{g} / \mathrm{ml}$
0,5 $\mu \mathrm{g} / \mathrm{ml}$, PeproTech, Hamburg, D

R\&D Systems, Minnesota, USA

Invitrogen $\mathrm{GmbH}$, Karlsruhe, D

Invitrogen $\mathrm{GmbH}$, Karlsruhe, D

\subsubsection{Plasmidvektoren}

(Sequenzangaben siehe Anhang, Punkt 7.4. Plasmide und Sequenzen, Seite 167)

\section{Überexpressionsplasmide}

pcDNA3

Tetsuo Mashima,Cancer Research,Tokyo, J

CMVProm, bla, neo, BGH PolyA 
pcDNA3::Sim1

freundlicher Weise zur Verfügung gestellt von Herrn Dr. Chen-Ming Fan (Carnegie Institution, Baltimore, Maryland 21218, USA)

In situ-RNA-Sondenplasmide

pGEM-T Easy Vector System I

Promega, Mannheim, D pGEM-T Easy::Sim1 (213 bp)

\subsubsection{Oligonukleotide}

Synthetische Oligonukleotid-Primer, wie z.B. Oligo(dT) 12-18 Primer, die in die cDNA-Synthese eingesetzt wurden, wurden von Invitrogen $\mathrm{GmbH}$ (Karlsruhe, D) bezogen. Alle hier angegebenen Oligonukleotide wurden zu einer Konzentration von $100 \mathrm{pmol} / \mu \mathrm{l}$ in DEPC behandeltem $A$. bidest aufgenommen.

\section{Primer der Polymerase-Ketten-Reaktion}

$\begin{array}{lll}\text { Name } & \text { Primer vorwärts 5'-3' } & \text { Primer rückwärts 5'-3’ } \\ \text { Fgf4 } & \text { TCTACTGCAACGTGGGCAT } & \text { AGGAAGGAAGTGGGTTACCTT } \\ \text { Fgf8 } & \text { GTAGTTGAGGAACTCGAAGCG } & \text { TTTACACAGCATGTGAGGGAG } \\ \text { Gapdh } & \text { AGTATGATGACATCAAGAAGG } & \text { ATGGTATTCAAGAGAGTAGGG } \\ \text { Gbx2 } & \text { TCTGGAGAGCGATGTGGATTA } & \text { ATAGCGAACCTGCTAACGTGA } \\ \text { Gfap } & \text { AGGCAGAGAACAACCTGGCT } & \text { CTCCTCCTCCAGCGATTCAA } \\ \text { Lmx1b } & \text { ATGTTGGACGGCATCAAGAT } & \text { TCACAGAGTCAGACTCGTCCG } \\ \text { Nestin } & \text { CAGGCTTCTCTTGGCTTTCCTG } & \text { GGTGAGGGTTGAGGGGTGG } \\ \text { Nkx2.2 } & \text { GAAGCGCCGAGTGCTCTTCTCC } & \text { GCCGAGCTGTACTGGGCGTTGT } \\ \text { Otx2 } & \text { TATGGAGCTTCAAGCTTGGGT } & \text { GTCCATTTCAGGTTGCTGGTT } \\ \text { Shh } & \text { TGATGTGTGGGCCCGGCAGGGGGTTT } & \text { TCAGCCGCCGGATTTGGCCGCC } \\ & & \text { ACG } \\ \text { } \text {-III-Tubulin } & \text { ACCTTGTGTCTGCCACCATGA } & \text { TTACTCTGGATGGCCAGCAT }\end{array}$


Primer der Quantitativen-,,Real-Time“-Polymerase-Ketten-Reaktion

$\begin{array}{lll}\text { Name } & \text { Primer vorwärts 5’3’ } & \text { Primer rückwärts 5’-3’ } \\ \text { Atoh1 } & \text { CACGGGCTGAACCACG } & \text { CGTTGATGTAGATCTGGGCC } \\ \text { Brn3.2 } & \text { ACATCGTCTCCCAGAGTAAGAG } & \text { CACGGGATGGTGTTCTGG } \\ \text { Gapdh } & \text { CGGCCGCATCTTCTTGTG } & \text { TGACCAGGCGCCCAATAC } \\ \text { Gata2 } & \text { CACCCCGCCGTATTGAATG } & \text { CCTGCGAGTCGAGATGGTTG } \\ \text { Meis1 } & \text { CAGTGAGCAAGGTGATGGCTT } & \text { AGATGCCACGCTTTTTGTGAC } \\ \text { Mash1 } & \text { ACTTGAACTCTATGGCGGGTT } & \text { CCAGTTGGTAAAGTCCAGCAG } \\ \text { Lmx1b } & \text { TTCCTGATGCGAGTCAACGAG } & \text { TCCGATCCCGGAAGTAGCAG } \\ \text { Lhx8 } & \text { ACACGAGCTGCTACATTAAGGA } & \text { CCCAGTCAGTCGAGTGGATG } \\ \text { Pet1 } & \text { AGCAAGCCTAACATGAACTACG } & \text { AAGTCAAAGCGGTAGGCG } \\ \text { Rgs4 } & \text { GAGTGCAAAGGACATGAAACATC } & \text { TTTTCCAACGATTCAGCCCAT } \\ \text { Sema5a } & \text { AGGTGCCACTTCCATCAAACA } & \text { TGGGTCATGCTCAGACTCTCC } \\ \text { Sim1 } & \text { CTTTCTTTTATACTTACACCTCACGTTTTC } & \text { AACATAACTTTAAACAGGAGGCTG } \\ & & \text { AAG } \\ \text { Tph2 } & \text { AGTCGAAATCTTCGTGGACTG } & \text { GGCGGATTCAGGGTCACAAT }\end{array}$

Primer der Klonierung von in situ-RNA-Sonden

$\begin{array}{lll}\text { Name } & \text { Primer vorwärts 5' } \mathbf{3} \mathbf{3}^{\prime} & \text { Primer rückwärts 5'-3' } \\ \operatorname{Sim} 1(213 \mathrm{bp}) & \text { CCAGATATCAGCCTCTAAGCC } & \text { TATCAGTCAGGGGACTTCCAC }\end{array}$

siRNA-Oligonukleotide

AllStars Negative Control siRNA Alexa 488, Qiagen GmbH, Hamburg, D $5 \mathrm{nmol}$

Mm_Sim1_1 HP siRNA Cy5 (NM_011376), Q Qiagen GmbH, Hamburg, D $20 \mathrm{nmol}$ 


\subsubsection{Enzyme, Inhibitoren und Beschichtungskomponenten}

\section{Enzyme}

DNase-Lösung (RNase-frei), $10 \mathrm{mg} / \mathrm{ml}$

ProteinaseK-Lösung

RevertAidTM MmuLV Reverse-Transkriptase $200 \mathrm{U} / \mu \mathrm{l}$

Ribonuklease-(RNase)-A-Lösung, $10 \mathrm{mg} / \mathrm{ml} \mathrm{TE}, \mathrm{pH} 8$

Sp6-Polymerase $20 \mathrm{U} / \mu \mathrm{l}$

taq-Polymerase $5 \mathrm{U} / \mu \mathrm{l}$

T4-DNALigase $5 \mathrm{U} / \mu \mathrm{l}$

T7-Polymerase $20 \mathrm{U} / \mu \mathrm{l}$

0,15\% Trypsin $/ 0,02 \%$ EDTA

\section{EcoRI}

Sacll

Sall

\section{Inhibitoren}

Complete $^{\mathrm{TM}}$ Preoteinase Cocktail

Pefa-Block

Ribonuklease-(RNase)-Inhibitor

SB421543 (Alk 4/5/7-Inhibitor 1614)

$10 \mathrm{mM}$ in DMSO, Lagerung bei $-20^{\circ} \mathrm{C}$
Qiagen, Hilden , D

Roche Diagnostics, Mannheim, D

MBI Fermentas, St.Leon-Rot, D

Sigma-Aldrich Laborchemikalien $\mathrm{GmbH}$,

Seelze, D

MBI Fermentas, St.Leon-Rot, D

MBI Fermentas, St.Leon-Rot, D

MBI Fermentas, St.Leon-Rot, D

MBI Fermentas, St.Leon-Rot, D

Gibco/Invitrogen, Karlsruhe, D

MBI Fermentas, St.Leon-Rot, D

MBI Fermentas, St.Leon-Rot, D

MBI Fermentas, St.Leon-Rot, D

\section{Beschichtungskomponenten und Aminosäurederivate}

Laminin $(1 \mathrm{mg} / \mathrm{ml})$

Poly-D-Lysin (1 mg/ml)

Poly-L-Ornithine $(10 \mathrm{mg} / \mathrm{ml} 150 \mathrm{mM}$

$\mathrm{H}_{3} \mathrm{BO}_{3} \mathrm{NaOH}, \mathrm{pH} 8,3$ )
Roche Diagnostics, Mannheim, D

Biomol GmbH, Hamburg, D

MBI Fermentas, St.Leon-Rot, D

Tocris, London, UK 


\subsubsection{Antikörper}

\section{Primäre Antikörper}

$\alpha$-Gapdh hergestellt in Maus, monoklonal $\alpha-\beta$-III-Tubulin, hergestellt in Maus, monoklonal $\alpha$-Nestin, hergestellt in Maus, monoklonal

$\alpha$-Gfap, hegestellt in Kaninchen, polyklonal $\alpha$-O4, hergestellt in Maus, monoklonal $\alpha$-Digoxogenin-(DIG)-AlkalischePhosphatase $\alpha-5-H T$, hergestellt in Kaninchen, polyklonal $\alpha$-Sim1, hergestellt in Kaninchen, polyklonal $\alpha$-Alkalische Phosphatase, hergestellt in Kaninchen, gekoppelt an Alkalische-

Phosphatase

$\alpha$-Alkalische Phosphatase, hergestellt in Maus, gekoppelt an Alkalische-Phosphatase Streptavidin-FITC

\section{Sekundäre Antikörper}

Ziege- $\alpha$-Kaninchen IgG, biotinyliert

Esel- $\alpha$-Maus-IgG-Cy3

Ziege- $\alpha$-Maus-IgG-FITC

Ziege- $\alpha$-Kaninchen-IgG-FITC

Esel- $\alpha$-Kaninchen-HRP

Ziege- $\alpha$-Maus-HRP
Abcam, Cambridge, UK

Developmental Studies Hybridoma Bank, University of lowa, USA

Developmental Studies Hybridoma Bank, University of lowa, USA

Dako, Hamubrg, D

Chemicon/Millipore, Hofheim, D

Roche Diagnostics, Mannheim, D

Sigma-Aldrich Laborchemikalien $\mathrm{GmbH}$, Seelze, D

Chemicon/Millipore, Hofheim, D Nordic Immunological Laboratories, Tilburg, $\mathrm{NL}$

Nordic Immunological Laboratories, Tilburg, $\mathrm{NL}$

Dako Diagnostika GmbH, Hamburg, D
Sigma-Aldrich Laborchemikalien $\mathrm{GmbH}$, Seelze, D Jackson Immuno Research Europe, Newmarket, Suffolk, UK Jackson Immuno Research Europe, Newmarket, Suffolk, UK Jackson Immuno Research Europe, Newmarket, Suffolk, UK GE Healthcare, UK GE Healthcare, UK 


\subsubsection{Molekulare Standards}

Hyperladder II (100 bp-Längenstandard) Bioline GmbH, Luckenwalde, D

„Prestained"-Proteinstandard

BioRad GmbH, Hamburg, D

\subsubsection{Kommerzielle Reinigungs- und Nachweissysteme}

GeneChip $\AA$ 430A Mouse Genome Array

5-Brom-2-desoxyuridin-(BrdU)-

Proliferationsassay

3,3'-Diaminobenzidin (DAB)

NucleoBond ${ }^{\circledR}$ Xtra Midi-Kit

QiaEx-Gelelutionskit

RNAeasy-Kit

\subsubsection{Chemikalien und Biochemikalien}

Azeton

Acrylamid-Bis-Lösung (29:1, 30\%)

Entwickler-Lösung

Fixierlösung

Agarose NEO Ultra 2267

Ammoniumpersulfat (APS)

Bromchloridinolylphosphat $(50 \mathrm{mg} \mathrm{BCIP/ml}$

Dimethylformamid)

$\beta$-Mercaptoethanol

Bovines Serumalbumin (BSA)

Bradford-Reagenz

Chemilumineszenz-Reagenz

Coomassie brilliant blue R250

deionisiertes Formamid
Affymetrix $\mathrm{GmbH}$, München, D

Roche Dignostics, Mannheim, D

Linaris Biologische Produkte $\mathrm{GmbH}$,

Wertheim - Bettingen, D

Macherey-Nagel GmbH \& Co. KG, Düren, D

Qiagen $\mathrm{GmbH}$, Hilden, D

Qiagen $\mathrm{GmbH}$, Hilden, D

Carl Roth GmbH, Roth, Karlsruhe, D

Serva GmbH, Duisburg, D

Adefo Chemie $\mathrm{GmbH}$, Nürnberg, D

Adefo Chemie $\mathrm{GmbH}$, Nürnberg, D

Carl Roth $\mathrm{GmbH}$, Roth, Karlsruhe, D

Carl Roth $\mathrm{GmbH}$, Roth, Karlsruhe, D

Roche, Mannheim, D

Fluka/Sigma, Taufkirchen, D

Sigma-Aldrich Laborchemikalien $\mathrm{GmbH}$,

Seelze, D

Carl Roth $\mathrm{GmbH}$, Roth, Karlsruhe, D

PerkinElmer Life and Analytical Sciences,

Mailand, ITA

BioRad GmbH, München, D

Carl Roth $\mathrm{GmbH}$, Roth, Karlsruhe, D 
Dextransulfat

4',6'-Diamidino-2-phenylindoldihydrochlorid (DAPI)

Diethylpyrocarbonat (DEPC, $\mathrm{C}_{6} \mathrm{H}_{10} \mathrm{O}_{5}$ )

Digoxigenin-(DIG)-Mix labeling 10x

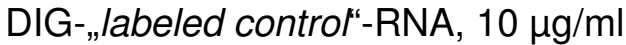

Di-Natriumethylendiamintetra-Acetat (EDTA)

Di-Natriumhydrogenphosphat-dihydrat

$\left(\mathrm{Na}_{2} \mathrm{HPO}_{4} \times 2 \mathrm{H}_{2} \mathrm{O}\right)$

Denhardt's-Lösung 100x

dNTPs (dATP, dCTP, dGTP, dTTP,

Endkonzentration $10 \mu \mathrm{M}$ in $\mathrm{A}$. bidest)

Eisessig/Essigsäure

Entellan

Essigsäureanhydrid

Ethanol, absolut

Ethidiumbromid $\left(\mathrm{C}_{12} \mathrm{H}_{20} \mathrm{BrN}_{3}, \mathrm{EtBr}\right)$;

$10 \mathrm{mg} / \mathrm{ml}$

Formaldehydlösung, 37\%

Glycerol

Glycin

Hefe-Extrakt

Hefe-tRNA $(10 \mathrm{mg} / \mathrm{ml})$

Heringspermien-DNA (10 mg/ml)

HiPerFect

Isopropanol/2-Propanol

Kaliumchlorid $(\mathrm{KCl})$

Kaliumdihydrogenphosphat $\left(\mathrm{KH}_{2} \mathrm{PO}_{4}\right)$

Levamisol

Lipofectamine

Lithiumchlorid ( $\mathrm{LiCl}$ )

Magermilchpulver

Methanol

3-[N-morpholino]propansulfonsäure (MOPS)

Natriumazid $\left(\mathrm{NaN}_{3}\right)$
Carl Roth GmbH, Roth, Karlsruhe, D

$10 \mathrm{mg} / \mathrm{ml} \mathrm{A}$. bidest, Sigma-Aldrich

Laborchemikalien $\mathrm{GmbH}$, Seelze, D

Sigma-Aldrich Laborchemikalien $\mathrm{GmbH}$,

Seelze, D

Roche, Mannheim, D

Roche, Mannheim, D

Carl Roth GmbH, Roth, Karlsruhe, D

Merck, Darmstadt, D

Eppendorf, Hamburg, D

MBI Fermentas, St.Leon-Rot, D

Carl Roth $\mathrm{GmbH}$, Roth, Karlsruhe, D

Merck, Darmstadt, D

Carl Roth GmbH, Roth, Karlsruhe, D

Carl Roth $\mathrm{GmbH}$, Roth, Karlsruhe, D

Sigma-Aldrich Laborchemikalien $\mathrm{GmbH}$,

Seelze, D

Merck, Darmstadt, D

Carl Roth GmbH, Roth, Karlsruhe, D

Carl Roth $\mathrm{GmbH}$, Roth, Karlsruhe, D

Becton, Dickinson \& Company, Sparks, USA

Roche, Mannheim, D

Promega, Mannheim, D

Qiagen, Hilden, D

Carl Roth GmbH, Roth, Karlsruhe, D

Merck, Darmstadt, D

Merck, Darmstadt, D

Sigma-Aldrich Laborchemikalien $\mathrm{GmbH}$,

Seelze, D

Invitrogen $\mathrm{GmbH}$, Karlsruhe, D

Carl Roth $\mathrm{GmbH}$, Roth, Karlsruhe, D

Sucofin, Zeven, D

Carl Roth $\mathrm{GmbH}$, Roth, Karlsruhe, D

Carl Roth GmbH, Roth, Karlsruhe, D

Carl Roth $\mathrm{GmbH}$, Roth, Karlsruhe, D 
Natriumchlorid ( $\mathrm{NaCl})$

Natriumdihydrogenphosphat $\left(\mathrm{NaH}_{2} \mathrm{PO}_{4}\right)$

Natriumdodezylsulfat (SDS)

Natriumhydroxid $(\mathrm{NaOH})$

Natrumzitratdihydrat $\left(\mathrm{C}_{6} \mathrm{H}_{5} \mathrm{Na}_{3} \mathrm{O}_{7} \times 2 \mathrm{H}_{2} \mathrm{O}\right)$

NBT (50 mg Nitroblautetrazolium/ml 70\%

Dimethylformamid)

NBT/BCIP Stock-Solution

Paraformaldehyd (PFA)

Ponceaus

Saccharose

Salzsäure $(\mathrm{HCl})$

Silikonöl

SYBR ${ }^{\circledR}$-GREEN I PCR Master Mix

Tetramethylethylendiamin (TEMED)

Triethanolaminhydrochlorid $\left(\mathrm{C}_{6} \mathrm{H}_{15} \mathrm{NO}_{3} \mathrm{HCl}\right)$

Trishydroxyaminomethan (Tris)

Triton X-100

Trypton

Tween-20

Wasserstoffperoxid $\left(\mathrm{H}_{2} \mathrm{O}_{2}\right)$

Xylol

Vectashield Eindeckmedium

Ziegenserum („Normal goat serum“, NGS)
Fluka, Taufkirchen, D

Merck, Darmstadt, D

Applichem, Darmstadt, D

Carl Roth GmbH, Roth, Karlsruhe, D

Sigma-Aldrich Laborchemikalien $\mathrm{GmbH}$,

Seelze, D

Roche, Mannheim, D

Roche, Mannheim, D

Merck GmbH, Darmstadt, D

Sigma-Aldrich Laborchemikalien $\mathrm{GmbH}$,

Seelze, D

Carl Roth $\mathrm{GmbH}$, Roth, Karlsruhe, D

Carl Roth GmbH, Roth, Karlsruhe, D

Serva $\mathrm{GmbH}$, Duisburg, D

Applied Biosystems, Foster City, CA, USA

Sigma-Aldrich Laborchemikalien $\mathrm{GmbH}$,

Seelze, D

Carl Roth GmbH, Roth, Karlsruhe, D

Carl Roth GmbH, Roth, Karlsruhe, D

Fluka/Sigma, Taufkirchen, D

Becton, Dickinson \& Company, Sparks, USA

Carl Roth $\mathrm{GmbH}$, Roth, Karlsruhe, D

Sigma-Aldrich Laborchemikalien $\mathrm{GmbH}$,

Seelze, D

Carl Roth $\mathrm{GmbH}$, Roth, Karlsruhe, D

Linaris Biologische Produkte $\mathrm{GmbH}$,

Wertheim - Bettingen, D

Dako Diagnostika GmbH, Hamburg, D 


\subsubsection{Lösungen und Puffer}

Alkalische Phosphatase (AP)-Puffer

1\% BSA $/ 0,01 \%$ PBS-Azid

Coomassie-Proteingel-Färbung

DNA-Ladepuffer Orange G (50 bp), 6×

DEPC

0,5 M EDTA-Lösung

50 mM CaCl 2 -Lösung

0,1 M Glycin-Lösung

$50 \mathrm{mM}$ Glycin in Ethanol

Homogenisierungspuffer
$100 \mathrm{mM}$ Tris

$100 \mathrm{mM} \mathrm{NaCl}$

$50 \mathrm{mM} \mathrm{MgCl} 2$

$\mathrm{pH} 8,9$

$66 \mu$ I NBT-Lösung

$33 \mu \mathrm{l}$ BCIP-Lösung

in $10 \mathrm{ml} \mathrm{AP-Puffer}$

$1 \%$ BSA (w/v)

$0,01 \%$ Natriumazid $(w / v)$

in $1 \times$ PBS

0,5\% (w/v) Coomassie brilliant blue R250

$20 \%$ Eisessig

$80 \%$ Ethanol

$0,2 \%(w / v)$ OrangeG

$1 \%(w / v)$ SDS

$50 \%(w / v)$ Saccharose

Lösung in A. bidest

$0,1 \%$ DEPC in A. bidest, ü.N. rühren und anschließend autoklavieren.

$18,11 \mathrm{~g}$ EDTA $\times 2 \mathrm{H}_{2} \mathrm{O}$ unter Rühren und Zuabe von $2 \mathrm{~N} \mathrm{NaOH}$ lösen und auf 1 I mit DEPC-behandeltem $\mathrm{A}$. bidest auffüllen, $\mathrm{pH} 8$

3,75 g Glycin in $500 \mathrm{ml}$ 1× PBS lösen

280 mM Mannitol

$10 \mathrm{mM}$ HEPES

$10 \mathrm{mM} \mathrm{KCl}$

$1 \mathrm{mM} \mathrm{MgCl}_{2}$

0,1 mM Pefablock ( $1 \mathrm{ml}$ einer $100 \mathrm{mM}$

Stammlösung/500ml $\mathrm{H}_{2} \mathrm{O}$ )

$250 \mu$ l Proteinase-Inhibitor-Lösung/500 ml 
Hybridisierungslösung

KCM-Lösung

1M Levamisol-Lösung

$4 \mathrm{mM}$ LiCl-Lösung

MOPS-Puffer, 10x

Paraformaldehyd-Lösung, 4 \%ige

PBS („Phosphat buffered saline“) 10x

\section{PBST}

PonceauS-Lösung

Proteingel-Entfärbelösung
$5 \mathrm{ml} \mathrm{50 \% iges} \mathrm{deionisiertes} \mathrm{Formamid}$

$2 \mathrm{ml} 50 \%$ iges Dexransulfat

$100 \mathrm{ml}$ 100× Denhard`s Lösung

$0,5 \mathrm{ml}$ Lachsspermien-DNA (10 mg/ml)

$0,25 \mathrm{ml}$ Hefe-tRNA $(10 \mathrm{mg} / \mathrm{ml})$

$1,3 \mathrm{ml} 20 \times$ SSC ("Sodium chloride/sodium citrate")

ad $10 \mathrm{ml}$ DEPC-behandeltes A. bidest, Lagerung bei $-20{ }^{\circ} \mathrm{C}$

$500 \mathrm{mM} \mathrm{KCl}$

$100 \mathrm{mM} \mathrm{CaCl}_{2} \times 2 \mathrm{H}_{2} \mathrm{O}$

$250 \mathrm{mM} \mathrm{MgCl}_{2} \times 6 \mathrm{H}_{2} \mathrm{O}$

ad $50 \mathrm{ml} \mathrm{H}_{2} \mathrm{O}$

sterilflitrieren, Lagerung bei $4{ }^{\circ} \mathrm{C}$

$2,4 \mathrm{ng} / \mathrm{ml}$

41,9 g MOPS (säure-frei)

$6,8 \mathrm{~g}$ Natriumacetat

$20 \mathrm{ml} \mathrm{0,5} \mathrm{M}$ EDTA, pH 8

ad 1 | A. bidest, $\mathrm{pH} 7$

lichtgeschützt bei $4{ }^{\circ} \mathrm{C}$ lagern, nicht

autoklavieren

$4 \%(w / v)$ Paraformaldehyd in $1 \times$ PBS bis max. $60^{\circ} \mathrm{C}$ erwärmen und mit $1 \mathrm{~N} \mathrm{NaOH}$

klären und nach Abkühlung abfiltrieren

$2 \mathrm{~g} \mathrm{KCl}$

$2 \mathrm{~g} \mathrm{KH}_{2} \mathrm{PO}_{4}$

$80 \mathrm{~g} \mathrm{NaCl}$

$11,5 \mathrm{~g} \mathrm{Na}_{2} \mathrm{HPO}_{4}$

ad 1 I A. bidest

1x PBS unter Zugabe von 0,1\% Triton X-100

0,25\% PonceauS

$40 \%$ Methanol

15\% Eisessig

$10 \%$ Ethanol

15\% Eisessig 
Proteinproben-Puffer, $6 \times$

Puffer I

Puffer III

RNA-Gel-Laufpuffer

RNA-Gel-Puffer, 10x

RNA-Probenpuffer, 6×

Sammelgel-Puffer

SDS-Elektrophorese-Puffer, 5x
62,5 mM Tris, $\mathrm{pH}$ 6,8

$2 \%$ SDS

10\% Glycin

$5 \% \beta$-Mercaptoethanol

0,001\% Bromphenolblau

$0,1 \mathrm{M}$ Tris

$150 \mathrm{mM} \mathrm{NaCl}$

in $\mathrm{A}$. bidest lösen und auf $\mathrm{pH}$ 7,5 einstellen, autoklavieren

$100 \mathrm{mM}$ Tris

$100 \mathrm{mM} \mathrm{NaCl}$

$50 \mathrm{mM} \mathrm{MgCl} 2 \times 6 \mathrm{H}_{2} \mathrm{O}$

ad $500 \mathrm{ml} \mathrm{H}_{2} \mathrm{O}, \mathrm{pH} \mathrm{9,5}$

nicht autoklavieren

100 ml 10x RNA-Gel-Puffer

$120 \mathrm{ml}$ 37\%ige Formaldehyd-Lösung

$880 \mathrm{ml}$ DEPC-behandeltes $\mathrm{A}$. bidest

$200 \mathrm{mM}$ MOPS

$50 \mathrm{mM}$ Natriumacetat

$20 \mathrm{ml}$ 0,5 M EDTA, pH 8

ad 1 I DEPC-behandeltes A. bidest, $\mathrm{pH} 7$

$25 \mathrm{mg}$ Bromphenolblau

$80 \mu \mathrm{l}$ 0,5 M EDTA, pH 8

$750 \mu \mathrm{l} 37 \%$ Formaldehyd

$2 \mathrm{ml}$ Glycerol

$3084 \mu$ Formamid

$4 \mathrm{ml}$ 10× MOPS-Puffer

ad $10 \mathrm{ml} \mathrm{A}$. bidest

$4 \times$ Tris $/ \mathrm{HCl}, \mathrm{pH} 6,8$

$6,05 \mathrm{~g}$ Tris in $40 \mathrm{ml} \mathrm{A}$. bidest lösen und auf pH 6,8 mit HCL einstellen, hiernach durch $\varnothing 0,45 \mu \mathrm{m}$ Einmalfilter filtrieren und $0,4 \mathrm{~g}$ SDS zugeben

$15,1 \mathrm{~g}$ Tris

72 g Glycin

$5 \mathrm{~g}$ SDS

ad 1 | A. bidest, $\mathrm{pH} 8,3$ 
$1 \%$ SDS/0,01\% PBS-Azid

20× SSC-Lösung

TAE-Puffer, 50X

TE-Puffer

0,1 M Trap-Puffer

Transfer-Puffer

Trenngel-Puffer

$10 \times$ TTBS
$1 \% \operatorname{SDS}(\mathrm{w} / \mathrm{v})$

$0,01 \%$ Natriumazid (w/v)

in $1 \times$ PBS

$87,5 \mathrm{~g} \mathrm{NaCl}$

$44,1 \mathrm{~g}$ Natriumcitrat

in $500 \mathrm{ml} \mathrm{A}$. bidest lösen und mit

Zitronensäure auf $\mathrm{pH} 7$ einstellen

$242 \mathrm{~g}$ Tris

$57,1 \mathrm{ml}$ Eisessig

100ml 0,5 M EDTA, pH 8

ad 1 I A. bidest

$0,6 \mathrm{~g}$ Tris

$019 \mathrm{~g}$ EDTA

in $500 \mathrm{ml} \mathrm{A}$. bidest lösen und $\mathrm{pH} 8$ einstellen

9,3 $\mathrm{g}$ Triethanolaminhydrochlorid in $500 \mathrm{ml}$

A. bidest lösen und auf $\mathrm{pH} 8$ einstellen

$0,25 \mathrm{M}$ Tris

0,19 M Glycin

$10 \%$ Methanol

$\mathrm{pH}$ 8,4-8,6 mit konzentrierter $\mathrm{HCl}$ einstellen

$4 \times \mathrm{Tris} / \mathrm{HCl} \mathrm{pH} 8,8$

$91 \mathrm{~g}$ Tris in $300 \mathrm{ml} \mathrm{A}$. bidest lösen und

pH 8,8 einstellen. Lösung auf $500 \mathrm{ml}$ auffüllen und mit $\varnothing 0,45 \mu \mathrm{m}$ Einmalfilter sterilfiltrieren, hiernach $2 \mathrm{~g}$ SDS zugeben $(0,4 \%)$

$1 \mathrm{M}$ Tris

$1,5 \mathrm{M} \mathrm{NaCl}$

1\% Tween-20

$\mathrm{pH} 7,5$ durch $37 \%$ ige $\mathrm{HCl}$ (ca. $60-70 \mathrm{ml} / \mathrm{l}$ ) einstellen 


\subsubsection{Verbrauchsmaterialien}

Deckgläschen, $\varnothing 12 \mathrm{~mm}$

Easy Flask 75 Filt und 25 Filt

Einmalküvetten (1,5 ml)

Falcon-Röhrchen, $15 \mathrm{ml}$ und $50 \mathrm{ml}$

Kammerkulturplatten, 24 und 48 well plates

Kryoröhrchen, 2 ml

MicroAmp ${ }^{\mathrm{TM}}$ Fast Optical Adhesive Film

MicroAmp ${ }^{\mathrm{TM}}$ Fast Optical 96 well Reaction

Plate

Nitrozellulose Hybond N+Membran

Objektträger

Objektträger SuperFrostPlus

Parafilm'M ${ }^{\circledR}$ LaboratoryFilm

Pasteur-Pipetten, $230 \mathrm{~mm}$

PCR-Softtubes, 0,2 ml

Petrischalen, $\varnothing 10 \mathrm{~cm}$

PVDF-Membran

Röntgenfilm X-Omat Blue

SafeLock-Reaktionsgefäße, 0,5 ml; 1,5 ml und $2 \mathrm{ml}$

Sterilfilter $\varnothing 0,22 \mu \mathrm{m}$ und $\varnothing 0,45 \mu \mathrm{m}$

Whatman-Vliespapier

Zellkulturschalen, $\varnothing 30 \mathrm{~mm}$
Menzel-Gläser, Braunschweig, D

Nunc $^{\mathrm{TM}}$, Roskilde, Dänemark

Brand GmbH \& Co KG, Wertheim, D

Falcon/Becton Dickinson, Heidelberg, D

Falcon/Becton Dickinson, Heidelberg, D

Carl Roth $\mathrm{GmbH}$, Roth, Karlsruhe, D

Applied Biosystems, Foster City, CA, USA

Applied Biosystems, Foster City, CA, USA

Amersham Bioscience, Freiburg, D

Carl Roth $\mathrm{GmbH}$, Roth, Karlsruhe, D

Menzel, Braunschweig, D

American National CAN, Chicago, IL, USA

Pasteurpipetten, Glas WU, Mainz

Biozym Scientific GmbH, Hess. Oldendorf, D

Greiner, Bio-one $\mathrm{GmbH}$, Frickenhausen, D

Amersham Bioscience, Freiburg, D

Kodak/PerkinEImer Life and Analytical

Sciences, Mailand, Italien

Eppendorf, Hamburg, D

Sartorius

Schleicher \& Schuell Biosciences $\mathrm{GmbH}$, Whatman Group, Dassel, D Nunc $^{\text {TM }}$, Roskilde,Dänemark

\subsubsection{Geräte}

Autoklav 5050 ELV

Binokular

BioPhotometer

Brutschrank InCuSafe $\mathrm{Co}_{2}$ Inkubator

Centrifuge 5804R

Einbettautomat Leica ASP200
Systec GmbH, Wettenberg, D

Wild M3Z, Heerbrugg, $\mathrm{CH}$

Eppendorf AG, Hamburg, D

Sanyo FISCHER Sales GmbH, München, D

Eppendorf, Hamburg, D

Leica Mikrosystems GmbH, Wetzlar, D 
Elektrophoresekammer 41-2025

Fluoreszenzmikroskop ECLIPSE E600

FACS (,Fluorescence activated cell sorter")

Gelimager Classico Uno

Heizblock neoBlock II

Homogenisator Ultra-Turrax

Horizontalschüttler Polymax 1040

Hybridisierungsofen Thermo Hyoid

Shak'n'Stack

Kühlzentrifuge 5417R (Rotor FA 45-24-11)

Mikroskop Stemi DV4

Mini-PROTEAN ${ }^{\circledR}$ Elektrophorese-Zelle

Neubauerzählkammer „improved“

Paraffinausgießstation EG 1150C

pH-Meter pH526 Multical

Power Supply Standard Power Pack P25

„Real-Time“-PCR Cycler ABI7500

Rollschüttler CAT RM5

Rotationsmikrotom RM2125RT

Rotationsschüttler Unitron

Sterilbank Heraeus HeraSafe

Termocycler Mastercycler personal

Ultrazentrifuge Sorvall Evolution RC

(Rotor Sorvall SLA-1500 SuperLite)

Ultraschallgerät Sonoplus

Wärmeschrank Modell 600
PeqLab Biotechnologie GmbH, Erlangen, D

Nikon GmbH, Düsseldorf, D

Core Facility, ZFK Freiburg, D

Intas, Göttingen, GmbH, D

NeoLab Migge Laborbedarf-Vertriebs $\mathrm{GmbH}$, Heidelberg, D

IKA Labortechnik AG, Liiau, D

Heidolph Elekro GmbH \% Co KG, Kelheim, D

Thermofischer Scientific GmbH, Ulm, D

Eppendorf AG, Hamburg, D

Carl Zeiss $\mathrm{GmbH}$, Jena, D

BioRad Laboratories GmbH, München, D

Laboroptik $\mathrm{GmbH}$, Friedrichsdorf, D

Leica Mikrosystems GmbH, Wetzlar, D

WTW, Weilheim, D

Biometra, München, D

Applied Biosystems, Foster City, CA, USA

NeoLab, Migge Laborbedarf-Vertriebs $\mathrm{GmbH}$, Heidelberg, D

Leica Mikrosystems GmbH, Wetzlar, D

Infors AG, Bottmingen, D

Kendro Laboratory Products $\mathrm{GmbH}$,

Langenselbold, D

Eppendorf AG, Hamburg, D

Kendro Laboratory Products $\mathrm{GmbH}$,

Langenselbold, D

Bandelin electronics, Berlin, D

Memmert GmbH \& Co. KG, Schwabach, D 


\subsection{Methoden}

\subsubsection{Mikrobiologische Methoden}

\subsubsection{Herstellung von Bakterienkulturplatten}

Zur Herstellung von Bakterienkulturplatten wurden $500 \mathrm{ml}$ Luria-Bertani-(LB)-Medium (1\% Trypton, 0,5\% Hefeextrakt, $1 \% \mathrm{NaCl}, 1,5 \%$ Agar-Agar) nach dem Autoklavieren auf circa $60^{\circ} \mathrm{C}$ abgekühlt. Sofern die Kulturplatten zur Selektion von transformierten $E$. coli $\mathrm{DH} 5 \alpha$, welche eine plasmid-kodierte Ampicillin-(Amp)- oder Kanamycin-(Km)-Resistenz trugen, bestimmt waren, wurden dem Plattenmedium vor dem Gießen $500 \mu l$ einer Amp-Stammlösung (100 mg/ml A. bidest, sterilfiltriert) bzw. $500 \mathrm{ml}$ einer Km-Stammlösung (50 mg/ml A. bidest) zugefügt und diese gleichmäßig im Medium verteilt. Das Medium wurde anschließend auf Plastik-Petrischalen $(\varnothing 10 \mathrm{~cm})$ aufgeteilt und die Platten hiernach verschlossen. Bis zur Verwendung wurden die Kulturplatten nach dem vollständigen Erkalten bei $4{ }^{\circ} \mathrm{C}$ gelagert.

\subsubsection{Herstellung chemisch kompetenter E. coli $\mathrm{DH} 5 \alpha$-Zellen}

Zur Herstellung chemisch kompetenter E.coli-Zellen des Stammes DH5 $\alpha$ wurde mittels einer abgeflammten Impföse einem Glycerol-Stock dieses Bakterienstammes eine geringe Menge entnommen und diese durch Dreistrich auf einer LB-Kulturplatte verteilt. Die Platte wurde anschließend bei $37^{\circ} \mathrm{C}$ ü. N. im Brutschrank inkubiert. Eine Einzelkolonie der Plattenkultur wurde zur Beimpfung von $3 \mathrm{ml}$ LB-Flüssigkulturmedium in einem $15 \mathrm{ml}$ Falcon-Röhrchen verwendet und die Vorkultur bei $37^{\circ} \mathrm{C}$ bei $150 \mathrm{Upm}$ ü. $\mathrm{N}$. inkubiert. Am folgenden Tag wurden $100 \mathrm{ml}$ LB-Flüssigkulturmedium mit $1 \mathrm{ml}$ der Vorkultur inokuliert und diese bis zum Erreichen einer Optischen Dichte (OD) von $0,3-0,4$ bei einer Wellenlänge von $\lambda=600 \mathrm{~nm}$ bei $37^{\circ} \mathrm{C}$ und 150 Upm für circa 3-4h kultiviert. Die Kultur wurde nun in zwei vorgekühlte $50 \mathrm{ml}$ Falcon-Röhrchen überführt. Im Anschluss hieran wurden die Bakterien durch Zentrifugation bei 3500 Upm für 10 min bei $4{ }^{\circ} \mathrm{C}$ sedimentiert und auf Eis gestellt. Das LBKulturmedium wurde vollständig dekantiert und die beiden Zellpellets in jeweils $50 \mathrm{ml}$ einer $50 \mathrm{mM} \mathrm{CaCl}_{2}$-Lösung durch vorsichtiges Auf- und Abpipettieren vollständig resuspendiert. An eine 20minutige Inkubation der Zellsuspension auf Eis schloss sich eine erneute Zentrifugation bei $3500 \mathrm{Upm}$ bei $4{ }^{\circ} \mathrm{C}$ für $10 \mathrm{~min}$ an. Nach Sedimentierung der Zellen wurde der Überstand verworfen und die beiden Pellet zusammen in $9 \mathrm{ml}$ eiskalter $50 \mathrm{mM} \mathrm{CaCl}_{2}-$ 
Lösung aufgenommen. Der Bakteriensuspension wurde nun Glycerol bis zu einem Anteil von $15 \%$ des Gesamtvolumens zugefügt und durch Schwenken im Ansatz verteilt. Die Zellen wurden für weiter $20 \mathrm{~min}$ auf Eis belassen und anschließend zu je $100 \mu \mathrm{l}$ in sterile, vorgekühlte 1,5 ml Eppendorf-Reaktionsgefäße aliquotiert. Nach Schockgefrieren der Zellen in flüssigem $\mathrm{N}_{2}$ wurden diese bei $-80{ }^{\circ} \mathrm{C}$ gelagert.

\subsubsection{Transformation chemisch kompetenter E. coli DH5 $\alpha$ Zellen}

Die Transformation chemisch kompetenter E. coli DH5 $\alpha$ Zellen erfolgte durch Anwendung des Hitzeschockverfahrens. Hierzu wurde pro Transformationsansatz ein $100 \mu$ Aliquot kompetenter E. coli $D H 5 \alpha$-Zellen (Punkt 4.2.1.2., Seite 39) langsam auf Eis aufgetaut. Für Retransformationen wurden $z u$ den Zellen 30 ng Plasmid-DNA zugegeben, für Transformationen durch Ligationsansätze wurden von diesem $10 \mu \mathrm{l}$ zugesetzt. Des Weiteren wurden den Transformationsansätzen jeweils $20 \mu \mathrm{l}$ einer 5 fach konzentrierten KCM-Lösung sowie $70 \mu \mathrm{l}$ autoklaviertes A. bidest zugefügt und die Ansätze durch leichtes Schwenken gemischt. Hiernach wurden die Zellen für $30 \mathrm{~min}$ auf Eis belassen. Die Aufnahme der Plasmid-DNA erfolgte durch einen Hitzeschock bei $42{ }^{\circ} \mathrm{C}$ für $45 \mathrm{~s}$ im Heizblock. Anschließend wurden die Ansätze für 1 min auf Eis abgekühlt. $1 \mathrm{ml}$ auf $37^{\circ} \mathrm{C}$ vorgewärmtes LB-Flüssigkulturmedium wurde nun zu den Transformationsansätzen pipettiert und die Ansätze bei $37^{\circ} \mathrm{C}$ und $65 \mathrm{Upm}$ im Schüttler für 1h inkubiert. Nach Ablauf der Inkubation wurden die Zellen bei 300 Upm für 5 min bei RT abzentrifugiert und der Überstand bis auf $200 \mu \mathrm{l}$ abgenommen. In dem verbleibendem Medium wurden die sedimentierten Zellen resuspendiert und auf geeignete Selektivkulturplatten ausplattiert. Die Kultivierung der Platten erfolgte ü. N. bei $37^{\circ} \mathrm{C}$ im Brutschrank.

\subsubsection{Methoden der eukaryontischen Zellkultur}

\subsubsection{Kultivierung und Passage der Zelllinie MN9D}

Zur Kultivierung der murinen Zelllinie MN9D wurde DMEM-F12-Minimalmedium unter Zusatz von $5 \%$ fetales Kälberserum („Fetal calf serum“, FCS) und $50 \mu \mathrm{g} / \mathrm{ml}$ Geniticin verwendet. Die Zellen wurden in $20 \mathrm{ml}$ dieses Mediums in unbeschichteten $75 \mathrm{~cm}^{2}$ Zellkulturflaschen unter physiologischen Bedingungen, d. h. bei $37{ }^{\circ} \mathrm{C}, 5 \% \mathrm{CO}_{2}, 95 \%$ Luft und einer relativen Luftfeuchtigkeit von 100\%, in einem Brutschrank kultiviert. Eine Passagierung der Zellen wurde nach Erreichen einer Zellkonfluenz von circa $80 \%$ der 
Wachstumsoberfläche vorgenommen. Hierzu wurde das Medium mit einer sterilen PasteurPipette, welche mit einer Pumpe verbunden war, vorsichtig abgesogen. Zur Ablösung der Zellen vom Boden der Kulturflasche wurden $3 \mathrm{ml}$ einer 0,15\%igen Trypsin/Ethylendiamintetraacetat-(EDTA, 0,02\%)-Lösung auf den Zellen gleichmäßig verteilt und diese bei $37{ }^{\circ} \mathrm{C}$ für circa 3 min im Brutschrank inkubiert. Die enzymatische Ablösung der MN9D-Zellen wurde durch Zugabe von $9 \mathrm{ml}$ Kulturmedium inhibiert. Der Boden der Kulturflasche wurde mehrmals durch Auf- und Abpipettieren des Mediums abgespült, und die Zellsuspension in ein steriles $15 \mathrm{ml}$ Falcon-Röhrchen überführt. Nach Zentrifugation bei RT für 5 min und 100 Upm wurde der Überstand vorsichtig abgesogen und das gewonnene Zellpellet in $5 \mathrm{ml}$ Medium resuspendiert. In eine $75 \mathrm{~cm}^{2}$-Zellkulturflasche wurden $20 \mathrm{ml}$ des im Wasserbad auf $37^{\circ} \mathrm{C}$ temperierten Kulturmedium vorgelegt und $500 \mu \mathrm{l}$ der Zellsuspension zugegeben. Die weitere Kultivierung der Zellen erfolgte unter den zuvor beschriebenen physiologischen Bedingungen.

Für die im Rahmen dieser Arbeit vorgenommenen Transfektionen wurde eine Passagenzahl von 20 nicht überschritten, um ein Vorliegen spontan differenzierter MN9D-Zellen in der Kultur zu vermeiden. Sofern eine genaue Bestimmung der Zellzahl erforderlich war, wurde diese unter Verwendung einer Neubauer-Zählkammer ermittelt. Hierzu wurden die Kammer mit $10 \mu \mathrm{l}$ einer homogenen Einzelzellsuspension, basierend auf den zwischen Deckglas und Kammer herrschenden Kapillarkräften, befüllt. Anschließend wurden vier Großquadrate der Zählkammer, bestehend aus jeweils 16 Kleinstquadraten, mäanderförmig ausgezählt. Die Zellzahl pro $\mathrm{ml}$ ergibt sich aus dem Mittelwert für ein Großquadrat multipliziert mit dem Kammerfaktors $10^{4} / \mathrm{ml}$. Für Transfektionen wurden die Zellen in einer Zelldichte von $1 \times 10^{6}$ in $7,5 \mathrm{ml}$ Kulturmedium in $25 \mathrm{~cm}^{2}$ Zellkulturflaschen unter den oben angegebenen Bedingungen kultiviert.

\subsubsection{Kryokonservierung und Auftauen von eukaryontischen Zellen}

Zur dauerhaften Zellkonservierung der Zelllinie MN9D wurden diese wie unter Punkt 4.2.2.1. (Seite 40) dargelegt durch Trypsinierung vom Boden der Kulturflasche abgelöst. Nach Zentrifugation der Zellen wurden diese in $10 \mathrm{ml}$ DMEM-F12-Medium (5\% FCS, $50 \mu \mathrm{g} / \mathrm{ml}$ Geniticin) gewaschen und bei 1000 Upm und RT für 5 min abzentrifugiert. Das Zellpellet wurde in $5 \mathrm{ml}$ DMEM-F12-Medium ohne Zusätze resuspendiert und nach Bestimmung der Zellzahl letztere auf eine Dichte von $1 \times 10^{6}$ Zellen pro ml Medium eingestellt. In $2 \mathrm{ml}$ Kryoröhrchen wurde nun $1 \mathrm{ml}$ des 2fach konzentrierten Einfriermediums $(20 \%$ Dimethylsulfoxid (DMSO), 40\% FCS in DMEM-F12) vorgelegt und $1 \mathrm{ml}$ der Zellsuspension zugegeben. Die Röhrchen wurden verschlossen und $2 \mathrm{~h}$ bei $-20{ }^{\circ} \mathrm{C}$ in einem mit 
Isopropanol gefülltem Einfierbehälter heruntergekühlt. Im Anschluss hieran wurden die Zellen ü. N. bei $-80{ }^{\circ} \mathrm{C}$ gelagert und am darauffolgenden Tag in flüssigem $\mathrm{N}_{2}$ gelagert.

Um MN9D-Zellen in Kultur zu nehmen, wurden diese zügig im Wasserbad aufgetaut und direkt in eine mit 7,5 ml DMEM-F12 (5\% FCS, $50 \mu \mathrm{g} / \mathrm{ml}$ Geniticin) gefüllte $25 \mathrm{~cm}^{2}$ Kulturflasche überführt. Nach Anheftung der Zellen wurde das Kulturmedium ausgewechselt, um das DMSO aus der Kultur zu entfernen.

\subsubsection{Transiente Transfektion von MN9D-Zellen durch Lipofectamine}

Die Untersuchung der regulatorischen Einflussnahme des Transkriptionsfaktors Sim1 auf die Expression von Genen, die in die Entwicklung serotonerger Neurone und ihrer terminale Differenzierung involviert sind, wurde unter Verwendung des MN9D-Zellkulturmodells durch Transfektion des Überexpressionsplamides pcDNA3::Sim1 in vitro analysiert. Zur transienten Transfektion der MN9D-Zellen wurden diese am Vortag der Transfektion in einer Zelldichte von $1 \times 10^{6}$ Zellen pro $7,5 \mathrm{ml}$ in einer $25 \mathrm{~cm}^{2}$-Kulturflasche ausgesät und unter physiologischen Bedingungen kultiviert. Je Zeitpunkt der beabsichtigten Probennahme (24 h, $48 \mathrm{~h}$ und $72 \mathrm{~h}$ nach der Transfektion) und des zu verwendenden Plasmides (pcDNA3 bzw. pcDNA3::Sim1) wurden zwei Kulturflaschen angesetzt. Am nächsten Tag wurde das Kulturmedium gegen 7,5 ml DMEM-F12-Medium ohne Zusätze ausgetauscht und die Zellen im Brutschrank bis zur Transfektion belassen. Für jede Flasche wurden die Transfektionsreagenzien, wie im Folgenden beschrieben, angesetzt. Zu $750 \mu \mathrm{l}$ Opti-MEM in einem sterilen 1,5 ml Eppendorf-Reaktionsgefäß wurden $6 \mu \mathrm{g}$ der Plasmid-DNA gegeben und der Ansatz gemischt. In $750 \mu$ l Opti-MEM wurden $30 \mu \mathrm{l}$ des zuvor gründlich gemischten Lipofectamin sorgfältig suspendiert. Nach einer Inkubation von 5 min bei RT wurden beide Ansätze zusammengefügt und für weitere 20 min bei RT zur Bildung von Liposomen-/DNAKomplexen belassen. Das Transfektionsgemisch wurde anschließend zu den Zellen gegeben und durch Schwenken im Medium verteilt. Die Aufnahme der Plasmid-DNA durch Endozytose erfolgt innerhalb einer vierstündigen Inkubation im Brutschrank. Nach Ablauf dieser Zeit wurde das Medium abgesogen und durch DMEM-F12 (5\% FCS, $50 \mu \mathrm{g} / \mathrm{ml}$ Geniticin) ersetzt. Zum Zeitpunkt der Probennahme wurden die Zellen von je zwei Kulturflaschen, welche mit $p c D N A 3$ als Kontrollprobe bzw. mit $p c D N A 3:: \operatorname{Sim} 1$ transfiziert worden waren, wie unter Punkt 4.2.2.1. (Seite 40) beschrieben trypsiniert. Nach Zentrifugation und Verwerfen des Überstandes wurden die Zellen in $10 \mathrm{ml}$ PBS gewaschen und erneut bei $1000 \mathrm{Upm}$, bei $4{ }^{\circ} \mathrm{C}$ für $5 \mathrm{~min}$ sedimentiert. Das Zellpellet wurde anschließend in $3 \mathrm{ml}$ PBS aufgenommen. $1 \mathrm{ml}$ der Zellsuspension wurde für die Isolation von Gesamt-RNA verwendet und hierzu bei $1000 \mathrm{Upm}$, bei $4{ }^{\circ} \mathrm{C}$ für 5 min sedimentiert. Die 
Isolation der Gesamt-RNA erfolgte wie unter Punkt 4.2.6.4. (Seite 61) beschrieben. $2 \mathrm{ml}$ der Zellsuspension wurden in ein $15 \mathrm{ml}$ Falcon-Röhrchen überführt und wie unter Punkt 4.2.8.1. (Seite 75) erläutert zur Isolation von Gesamt-Protein eingesetzt.

\subsubsection{Liposomen vermittelte Einbringung von „short interfering“-RNA in Zellen der eukaryontischen Zelllinie MN9D}

RNA-Interferenz (RNAi) bietet die Möglichkeit, spezifisch die Expression eines zu untersuchenden Gens in Zellkulturmodellen herunterzuregulieren. Diese „Loss-of-function"Technik kann Hinweise auf die jeweilige Funktion des Gens liefern, da hierdurch der Einfluss des herabregulierten Gens auf nachgeschaltete Gene analysiert werden kann. Die am häufigsten angewendete Methode der RNAi-Technik bedient sich der Transfektion von Zellen mit kurzen, doppelsträngigen RNA-Molekülen. Diese RNA-Moleküle werden als „short interfering"-RNA bezeichnet (siRNA). Die siRNA wird in einen Proteinkomplex aufgenommen, dem RNA induzierten Silencing-Komplex (,RNA induced silencing complex“, RISC). In der Folge leitet der „anti-sense“-Strang den Proteinkomplex RISC zur komplementären mRNA, die anschließend abgebaut wird. Durch den Abbau der mRNA wird die Translation und somit die Bildung des spezifischen Genproduktes verhindert. Wichtig bei der Auswahl der Sequenz des siRNA-Moleküls ist es, dass der "sense“-Strang nicht mit mRNA anderer Gene interagieren kann und somit nicht unbeabsichtigte Nebeneffekte ausgelöst werden. Im Rahmen dieser Arbeit sollte die Expression des für den Transkriptionsfaktor Sim1 kodierenden Gens in MN9D-Zellen durch spezifische siRNA herunterreguliert werden. Hierzu wurden MN9D-Zellen in einer $75 \mathrm{~cm}^{2}$-Kulturflasche, wie unter Punkt 4.2.2.1. (Seite 40) beschrieben, durch Trypsinierung vom Boden der Kulturflasche abgelöst. Nach Sedimentierung und Suspendierung der Zellen in $10 \mathrm{ml}$ DMEM-F12-Kulturmedium (5\% FCS und $50 \mu \mathrm{g} / \mathrm{ml}$ Geniticin) wurde mittels einer NeubauerZählkammer (improved) die Zellzahl bestimmt. Jeweils $1 \times 10^{6}$ Zellen wurden in eine $25 \mathrm{~cm}^{2}$ Zellkulturflasche ausgesät und für $2 \mathrm{~h}$ unter physiologischen Bedingungen inkubiert, um ein Anheften der Zellen an die Oberfläche des Kulturbodens zu ermöglichen. Zur Transfektion wurde eine Sim1-spezifische siRNA (siehe Punkt 4.1.4., Seite 27), welche durch das Fluorophor Cyanin-5 (Cy5) markiert war, sowie eine Kontroll-siRNA (Ctr-siRNA), welche Alexa-488 gebunden vorlag, eingesetzt (siehe Punkt 4.1.4., Seite 27). Die Sequenz der Ctr-siRNA weist keinerlei Homologie zu bekannten Genen der Säuger auf. Je zu verwendender siRNA wurden sechs Kulturflaschen angesetzt. Pro Kulturflasche wurde in einem 1,5 ml Eppendorf-Reaktionsgefäß $1 \mathrm{ml}$ DMEM-F12 ohne weitere Zusätze vorgelegt. Als Transfektionsreagenz wurde HiPerFect verwendet. Nach gründlichem Vortexen des 
Reagenz wurden von diesem $30 \mu \mathrm{l}$ in das vorgelegte Medium pipettiert und dieses sofort gründlich gemischt. Hierzu wurden $30 \mu \mathrm{l}$ einer kurz vor Verwendung angesetzten 1:10 Verdünnung einer $20 \mu \mathrm{M}$ siRNA-Stammlösung in A. bidest hinzugefügt, dies entspricht $750 \mathrm{ng}$ siRNA. Der Transfektionsansatz wurde erneut gevortext und schließlich für 25 min bei RT belassen. Im wässriger Lösung bilden die kationischen Lipide des Transfektionsreagenz Komplexe mit den siRNA-Molekülen welche endozytotisch durch die Zellen aufgenommen werden. Nach Ablauf der Inkubationszeit wurde der Transfektionsansatz langsam auf die Zellen aufgetropft. Um eine optimalen Kontakt der Zellen zum Transfektionsansatz zu erreichen, wurde beim Auftropfen die Kulturflasche schräg gehalten. Im Anschluss wurden die Zellen wieder in horizontaler Lage der Kulturflasche unter normalen, physiologischen Bedingungen für $24 \mathrm{~h}$ kultiviert. Ein Mediumwechsel nach der Transfektion war nicht erforderlich. $24 \mathrm{~h}$ nach der Transfektion wurden die Zellen, wie unter Punkt 4.2.2.1. (Seite 40) erläutert, geerntet und die GesamtRNA der Zellen zur Analyse der Genexpression isoliert (Punkt 4.2.6.4, Seite 61).

\subsubsection{Techniken der Primärkultur}

\subsubsection{Präparation des ventralen rostralen Rhombencephalon der Maus (E12)}

Um die Entwicklung serotonerger Neurone des ventralen rostralen Rhombencephalon der Maus genauer studieren zu können, wurde zunächst ein in vitro-Zellkulturmodell dieses Gehirnbereiches des Embryonaltages (E)12 etabliert. Ausgangspunkt hierzu war die Präparation des ventralen rostralen Rhombencephalon von Embryonen der Maus (E12) der Mauslinie NMRI (,Naval Medical Research Institute“). Diese Mauslinie wurde an der Tierexperimentelle Einrichtung des Universitätsklinikums, Göttingen gehalten und terminiert verpaart. Nach Verpaarung wurden die Weibchen auf die Bildung des vaginalen „Plug“ getestet. Ein positives „Plug“-Ergebnis wurde mit dem Embryonalstadium (E) 1 gleichgesetzt. Am errechneten Embryonaltag 12 wurden trächtige Weibchen durch Genickbruch getötet und im direkten Anschluss die Embryonen entnommen. Hierzu wurde zunächst die Bauchwand des Muttertieres durch 70\%iges Ethanol gesäubert und die Haut im Bereich des Abdomens circa $2 \mathrm{~cm}$ weit aufgeschnitten ohne hierbei das darunter liegende Peritoneum zu verletzen. Dieses wurde mit einer sterilen Pinzette gefasst und leicht angehoben, so dass während der Durchtrennung des Bauchfells mit einer sterilen Schere der Darm nicht verletzt wurde. Innere Organe und Fettgewebe wurden zu Seite geschoben und der Uterus freigelegt. Durch leichtes Anheben eines Uterusschenkels mit der Pinzette konnte die Uterusverankerung lokalisiert und durchtrennt werden, wodurch der Uterus komplett entnommen werden konnte. Der Uterus wurde nun in ein mit Calcium- 
sowie Magnesium-freiem „Hank's balanced salt solution“ (mit 0,04\% Natriumbicarbonat, CMF) gefülltes und auf Eis vorgekühltes $50 \mathrm{ml}$ Falcon-Röhrchen überführt. Zur Entnahme der Embryonen wurde eine $\varnothing 10 \mathrm{~cm}$-Petrischale mit kaltem CMF befüllt, die Unterusschenkel hierin überführt und jeweils ein kleiner Schnitt in die Uteruswandung gesetzt. Die Embryonen wurden leicht aus dem Uterus herausgeschoben und das Amnion entfernt. In dieser Weise isolierte Embryonen wurden in frischem, kaltem CMF gesammelt. Zur Präparation des ventralen rostralen Rhombencephalon wurde, wie Abb. 4A (Seite 46) zeigt, eine sterile Glasplatte mit einigen Tropfen CMF benetzt und ein Embryo darauf gelegt. Die Präparation wurde unter einem Binokular durchgeführt. Die Meningen wurden entfernt und knapp kaudal des Isthmus, welcher anhand einer Gewebeeinschnürung zwischen Mesencephalon und Rhombencephalon zu erkennen ist, ein circa $3 \mathrm{~mm}$ langer Schnitt zum Embryo hin gesetzt (Abb. 4B). Zur Erleichterung der weiteren Präparationsschritte wurde das Mesencephalon leicht nach vorne geschoben. Der zweite Schnitt wurde circa $1 \mathrm{~mm}$ kaudal des ersten Schnittes geführt, was im Gewebe etwa der Höhe des 4. Rhombomers (R) entspricht. Hiernach wurde die geschlossene Schere auf der ventralen Seite des durch beide Schnitte vom umgebenden Gehirngewebe getrennten Bereiches angesetzt und vorsichtig der Gewebeabschnitt herausgeschoben. Der herausgelöste Gehirnbereich wurde im Anschluss hieran auf die Seite gedreht. Hierdurch ließ sich, wie in Abb. 4C dargestellt, das Neuralrohr deutlich als ringförmige Struktur erkennen. Das Neuralrohr wurde dorsal geöffnet und bis auf den Bereich der ventralen Grundplatte das angrenzende Gewebe entfernt (Abb. 4D). Das ventrale Gewebestück wurde vorsichtig mit der Pinzette in ein mit CMF gefülltes $15 \mathrm{ml}$ Falcon-Röhrchen überführt. Die innerhalb einer Stunde präparierten Gewebestücke des ventralen rostralen Rhombencephalon wurden auf Eis gesammelt und sedimentierten am Boden des Falcon-Röhrchens. 

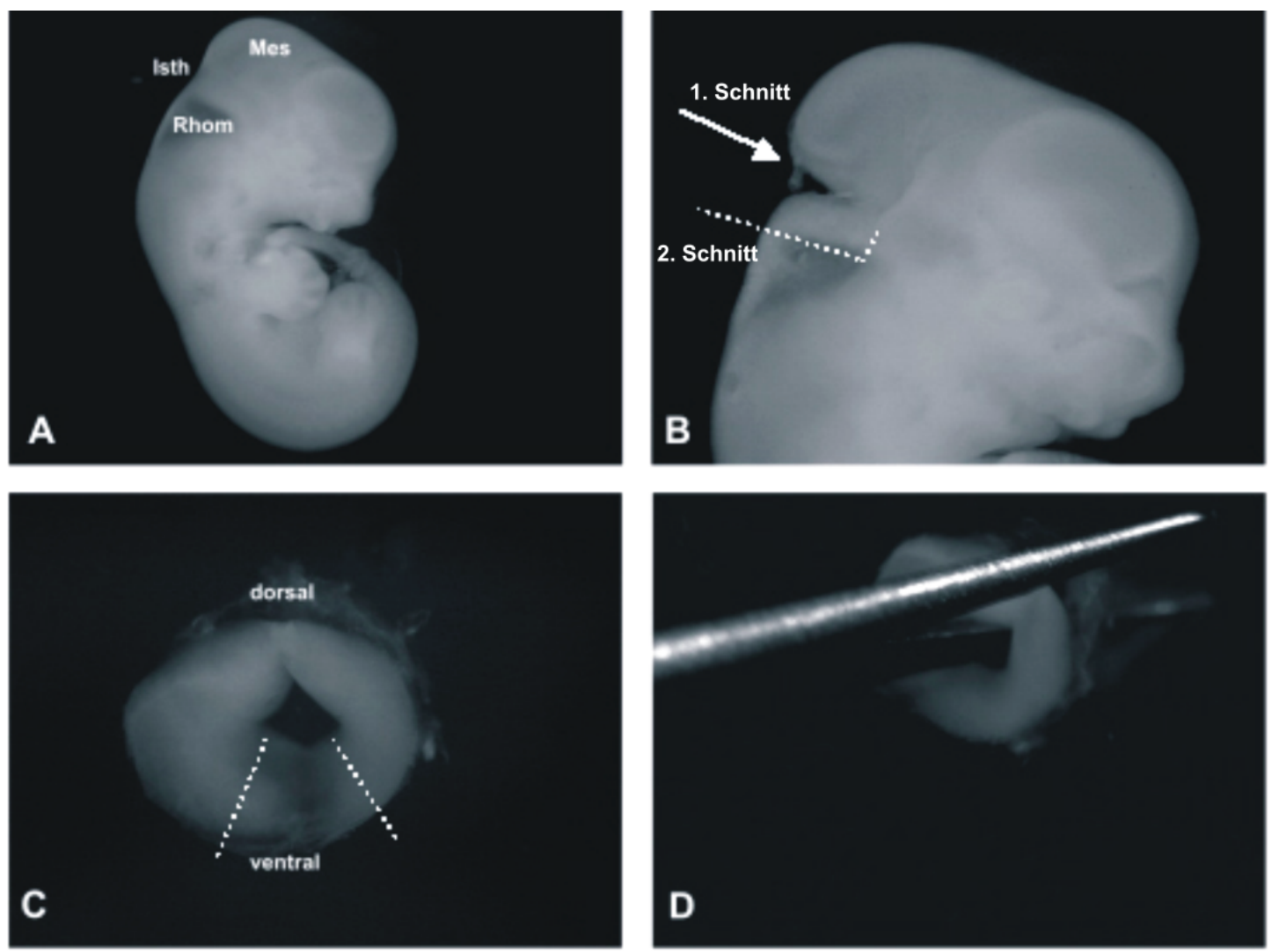

Abb.4: Präparation des ventralen rostralen Rhombencephalon der Maus des Embryonaltages 12 (E12). A: Lateralansicht eines isolierten Mausembryos (E12) nach Entfernung der Meningen. B: Der erste Schnitt (Pfeil) wird knapp kaudal des Isthmus gesetzt, der zweite Schnitt (gestrichelte Linie) erfolgt circa $1 \mathrm{~mm}$ caudal des 1. Schnittes zum Embryo hingerichtet. Das Gewebestück, welches das rostrale Rhombencephalon umfasst, wird mittels Präparationsschere ausgehend von der ventralen Seite herausgeschoben. C: Aufsicht auf den Neuralrohrabschnitt des rostralen Rhombencephalon. Angedeutet ist der die Vorläuferzellen enthaltene Gewebebereich beiderseits der ventralen Mittellinie, der nach Öffnung des Neuralrohres (D) isoliert wird. (Isthmus: Isth, Mesencephalon: Mes, Rhombencephalon: Rhom)

\subsubsection{Silikonisierung von Pasteur-Pipetten}

Um eine Zerstörung sowie ein Anheften der Zellen während ihrer Isolierung aus primärem Gewebe des ventralen rostralen Rhombencephalon der Maus (E12) oder während der Aufarbeitung aus diesen Zellen gebildeter primärer Neurospheres zu verhindern, wurden die zur Titruierung eingesetzten Pasteur-Pipetten silikonisiert. Hierzu wurden diese mit der kleinen Öffnung nach oben gerichtet in einen $250 \mathrm{ml}$-Glaszylinder gestellt und dieser mit Silikonöl gefüllt, bis die Pasteur-Pipetten vollständig bedeckt waren. Nach 10 min wurde das wiederverwendbare Silikonöl abgegossen und die Pasteur-Pipetten fünfmal mit $A$. bidest 
gewaschen. Die Trocknung der Pasteur-Pipetten erfolgte ü. N. bei $50{ }^{\circ} \mathrm{C}$ im Wärmeschrank. Zur Einbrennung der Silikonbeschichtung wurden die Pipetten anschließend bei $150{ }^{\circ} \mathrm{C}$ für eine Stunde gebacken. Nach Auskühlung wurden die weiten Pipettenenden mit Watte gestopft und autoklaviert.

\subsubsection{Aufarbeitung embryonalen Gewebes (E12) des ventralen rostralen Rhombencephalon der Maus zur Gewinnung einer Einzelzellsuspension}

Zur Gewinnung einer Einzelzellsuspension aus dem Gewebe des ventralen rostralen Rhombencephalon der Maus (E12) wurden die in eisgekühltem CMF in einem 15 ml-FalconRöhrchen gesammelten Gewebestücke zunächst durch Zentrifugation für 5 min bei 1000 Upm und $4{ }^{\circ} \mathrm{C}$ sedimentiert. Der Überstand wurde vorsichtig mit einer sterilen, silikonisierten Pasteur-Pipette, deren Öffnung zuvor durch Abschmelzen in der Flamme von scharfen Unebenheiten befreit worden war, abgesogen. Die Auflockerung der Gewebestruktur erfolgte durch enzymatischen Verdau des Gewebes in 300-500 $\mu$ l einer 0,15\%igen Trypsin-/EDTA-(0,02\%)-Lösung, je nach Menge des vorliegenden Gewebes, bei $37^{\circ} \mathrm{C} \mathrm{im} \mathrm{Wasserbad} \mathrm{für} 15 \mathrm{~min}$. Die Inaktivierung des Typsins erfolgte durch Zugabe von $500 \mu$ fetalem Kälberserum (FCS). Durch den enzymatischen Verdau freigesetzte genomische DNA wurde durch Zugabe von $10 \mu \mathrm{l}$ DNase-Lösung (10 mg/ml Stammlösung) abgebaut. Eine silikonisierte, sterile Pasteur-Pipette wurde unmittelbar am Beginn des dünnen Schaftes abgebrochen und die Bruchstellen in einer Flamme glatt geschmolzen. Diese Pipette diente zur gleichmäßigen Durchmischung der Trypsin-Lösung, der darin enthaltenen Gewebestücke und des zugegebenen FCS sowie der DNase-Lösung durch zweimaliges, vorsichtiges Titruieren des Gemisches. Das Falcon-Röhrchen wurde nun für 8 min auf Eis gestellt, währenddessen die Gewebestücke zum Boden absinken konnten. Der Überstand wurde vorsichtig abgesogen und verworfen. Nachdem das Pellet in $1 \mathrm{ml}$ FCS, $2 \mathrm{ml}$ CMF und $10 \mu \mathrm{l}$ DNAse-Lösung gelöst wurde, konnte anschließend mit der mechanischen Vereinzelung der Zellen aus dem Gewebeverband begonnen werden. Hierzu wurden die Gewebestücke mit der gesamten sie umgebenden Flüssigkeit langsam durch den schmalen Schaft der silikonisierten Pasteur-Pipette aufgezogen und vorsichtig zurück in das Falcon-Röhrchen gegeben. Dabei war darauf zu achten, dass keine Schaumbildung auftrat. Dieser als Titruierung bezeichnete Vorgang wurde 8mal wiederholt und anschließend das Röhrchen wiederum für 8 min auf Eis belassen. In dieser Zeit sanken die schwereren Gewebestücke zum Boden des Falcon-Röhrchens; wohingegen Einzelzellen im Überstand verblieben. Dieser Überstand wurde abgehoben und in ein vorgekühltes $15 \mathrm{ml}$ Falcon-Röhrchen überführt. Beginnend mit der Zugabe von FCS, CMF und DNase-Lösung 
auf das verbleibende Pellet wurden die oben aufgeführten Schritte erneut zweimal durchgeführt und alle Überstände zusammen in einem Falcon-Röhrchen gesammelt. Nach insgesamt drei Titruierungsgängen waren in der Regel keine weiteren Gewebestücke mehr zu erkennen, wodurch auf eine erneute Trypsinierung verzichtet wurde. In seltenen Fällen, in denen noch Restgewebe vorlag, wurde der Vorgang mit einer zusätzlichen Inkubation in Trypsin-/EDTA-Lösung wieder aufgenommen. Die gesammelten Überstände, welche die gewonnenen Einzelzellen enthielten, wurden bei $4^{\circ} \mathrm{C}, 1000$ Upm für 10 min abzenrifugiert. Der Überstand wurde verworfen und das Zellpellet in serum-freien DMEM-F12Komplettmedium (siehe Punkt 4.1.2., Seite 24) suspendiert und zentrifugiert. Dieser Vorgang wurde nochmals durchgeführt um das FCS vollständig zu entfernen. Nach erneuter Zentrifugation wurden die Zellen in $3 \mathrm{ml}$ DMEM-F12-Komplettmedium aufgenommen und die Zellzahl pro ml, wie unter Punkt 4.2.2.1. (Seite 40) erläutert, in einer NeubauerZählkammer bestimmt.

Für Experimente an direkt ausplattieren Zellen des ventralen rostralen Rhombencephalon der Maus (E12) wurde die Zellzahl auf $2 \times 10^{5}$ Zellen/100 $\mu$ I DMEM-F12-Komplettmedium eingestellt. Die Zellsuspension wurde nun auf PORN-/Laminin-beschichtete $\varnothing 12 \mathrm{~mm}$ Deckgläschen gleichmäßig aufgetropft. Um die Handhabung zu erleichtern wurden die Deckgläschen vor dem Auftropfen der Zellsuspension auf umgekehrte, sterile Abschlussdeckel von Eppendorf-Reaktionsgefäßen, welche in sterilen $\varnothing 10 \mathrm{~cm}$-Petrischalen verteilt wurden, ausgelegt. Zur Ermöglichung der Anheftung der Zellen an die beschichtete Oberfläche der Deckgläschen wurden die Zellen für $1 \mathrm{~h}$ im Brutschrank inkubiert. Hiernach wurden sie mit den Deckgläschen in eine mit je $650 \mu \mathrm{l}$ DMEM-F12-Komplettmedium pro Kammer befüllte, vorgewärmte 24-Kammerkulturplatte gelegt und in den Brutschrank zurückgestellt.

\subsubsection{Generierung primärer Neurospheres des ventralen rostralen Rhomben- cephalon der Maus (E12)}

Zur Bildung von primären Neurospheres wurden, wie unter Punkt 4.2.3.3. (Seite 47) angegeben, die gesammelten Überstände bei $1000 \mathrm{Upm}$ und $4{ }^{\circ} \mathrm{C}$ für $10 \mathrm{~min}$ abzentrifugiert und die isolierten Einzelzellen aus dem ventralen rostralen Rhombencephalon der Maus (E12) in $3 \mathrm{ml}$ serumfreien DMEM-F12-Medium unter Zusatz von jeweils $20 \mathrm{ng} / \mathrm{ml}$ der Mitogene Fgf2 (,Fibroblast growth factor 2 ) und Egf („Epidermal growth faktor") suspendiert. Hiernach wurde die Zellzahl pro $\mathrm{ml}$ bestimmt. Diese wurde auf $5 \times 10^{5}$ Zellen pro $\mathrm{ml}$ DMEMF12-Medium (inklusive Fgf2 und Egf) eingestellt. In unbeschichtete $\varnothing 35 \mathrm{~mm}$-Petrischalen wurden $2 \mathrm{ml}$ des mitogen-haltigen Kulturmediums vorgelegt und $1 \mathrm{ml}$ der Zellsuspension 
darin verteilt. Die Zellen wurden nun für circa 10 Tage zur Bildung primärer Neurospheres unter einer Atmosphäre von $37{ }^{\circ} \mathrm{C}, 5 \% \quad \mathrm{CO}_{2}$ und $95 \%$ Luft und einer relativen Luftfeuchtigkeit von $100 \%$ kultiviert.

\subsubsection{Dissoziation generierter primärer Neurospheres}

Die Bildungsdauer primärer Neurospheres aus dem ventralen rostralen Rhombencephalon der Maus (E12) betrug 7-10 Tage. Zur Ernte der generierten primären Neurospheres wurden $2 \mathrm{ml}$ des DMEM-F12-Komplettmedium (20 ng Fgf2/ml, $20 \mathrm{ng} \mathrm{Egf/ml)} \mathrm{aus} \mathrm{den,} \mathrm{die}$ primären Neurospheres enthaltenden, Petrischalen ( $\varnothing 30 \mathrm{~mm}$ ) entnommen und in $15 \mathrm{ml}-$ Falcon-Röhrchen gesammelt. Mit dem restlichen in der Petrischale verbliebenen Medium wurden die Petrischale vorsichtig gewaschen, um teilweise adherente primäre Neurospheres zu lösen. In dieser Weise wurden alle Petrischalen behandelt und das primäre Neurospheres enthaltende Medium gesammelt. Die Zellen wurden durch Zentrifugation bei $1000 \mathrm{Upm}$ bei $4^{\circ} \mathrm{C}$ für $10 \mathrm{~min}$ sedimentiert. Zur enzymatischen Vereinzelung der Zellen wurden nach Entfernen des Überstandes $300 \mu \mathrm{l}$ einer 0,15\%igen Trypsin-/EDTA-(0,02\%)-Lösung zugegeben, das Zellpellet aufgewirbelt und schließlich bei $37^{\circ} \mathrm{C}$ im Wasserbad für 15 min inkubiert. Durch Zusatz von $500 \mu$ I FCS sowie $10 \mu$ INaseLösung (Stammlösung: $10 \mu \mathrm{g} / \mathrm{ml}$ ) wurde die Enzymaktivität des Trypsins inhibiert und durch den Verdau freigesetzte, genomische DNA abgebaut. Nach Hinzufügen von 1 ml DMEMF12-Komplettmedium (Punkt 4.1.2., Seite 24) wurden die Zellen achtmal durch langsames Aufziehen und Ablassen mittels einer abgeflammten, silikonisierten Pasteur-Pipette titruiert. Die Zellsuspension wurde nun für 8 min auf Eis belassen und der Überstand in einem $15 \mathrm{ml}-$ Falcon-Röhrchen aufgefangen. Drei weitere Titruierungsgänge schlossen sich, wie unter Punkt 4.2.3.3. (Seite 47) beschrieben, an. Die erhaltenen Überstände wurden dem ersten Überstand zugefügt und bis zur Beendigung der Dissoziation auf Eis belassen. Im Anschluss wurde der gesamte Überstand bei $1000 \mathrm{Upm}$ für 5 min bei $4{ }^{\circ} \mathrm{C}$ zentrifugiert. Der Überstand wurde verworfen und mit $10 \mathrm{ml}$ DMEM-F12-Komplettmedium gewaschen, um das Trypsin vollständig zu entfernen. Das Zellpellet wurde nun in $3 \mathrm{ml}$ Komplettmedium resuspendiert und die Zellzahl durch Auszählung in einer Neubauer-Zählkammer bestimmt (siehe Punkt 4.2.2.1., Seite 40). Sollten die vereinzelten Zellen der Immunzytochemie zugeführt werden, wurden diese in einer Zellzahl von $2 \times 10^{5}$ Zellen in $100 \mu \mathrm{l}$ auf PORN/Laminin-beschichtete $\varnothing 12$ mm-Deckgläschen, wie unter Punkt 4.2.3.3. (Seite 47) beschrieben, ausplattiert („Day in vitro“, DIV0). Zur Isolierung von Gesamt-RNA oder Gesamt-Protein wurden die Zellen in einer Zelldichte von $5-7,5 \times 10^{5}$ Zellen in $3 \mathrm{ml}$ Komplettmedium auf PORN-/Laminin-beschichtete $\varnothing 30 \mathrm{~mm}$-Petrischalen ausgesät. Die 
weitere Vorgehensweise zur Generierung von sekundären Neurospheres aus dissoziierten primärer Neurospheres des ventralen rostralen Rhombencephalon der Maus (E12) ist unter dem nachfolgendem Punkt 4.2.3.6. beschrieben.

\subsubsection{Erzeugung sekundärer Neurospheres aus dissoziierten primären Neuro- spheres des ventralen rostralen Rhombencephalon der Maus (E12)}

Die Fähigkeit von Stamm- und Vorläuferzellen zu proliferieren, lässt sich durch die Generierung sekundärer Neurospheres aus dissoziierten primären Neurospheres demonstrieren. Hierzu wurde, nach Titruierung der primären Neurospheres, der gewonnene Überstand in einem $15 \mathrm{ml}$-Falcon-Röhrchen bei $1000 \mathrm{Upm}$ und $4{ }^{\circ} \mathrm{C}$ für 5 min zentrifugiert (Punkt 4.2.3.5., Seite 49). Der Überstand wurde nun vorsichtig entfernt und das Zellpellet in $3 \mathrm{ml}$ DMEM-F12-Komplettmedium nach Zugabe der Mitogene Fgf2 und Egf (jeweils $20 \mathrm{ng} / \mathrm{ml}$ ) resuspendiert. Die Zellzahl wurde in einer Neubauer-Zählkammer bestimmt. In die Kammern einer unbeschichteten 48-Kammerkulturplatte wurden jeweils $250 \mu$ I DMEM-F12Komplettmedium (20 ng/ml Fgf2, 20 ng/ml Egf) vorgelegt und die Zellen in einer Dichte von $10 \times 10^{3}$ Zellen/100 $\mu \mathrm{l}$ dem vorgelegten DMEM-F12-Komplettmedium hinzugefügt. Die Bildung sekundärer Neurospheres wurde über einer Zeitraum von 22 Tagen hinweg photographisch dokumentiert (Nikon Eclipse TE 200).

\subsubsection{Poly-Ornithine-/Laminin-Beschichtung von Deckgläschen}

Um isolierten Primärzellen des ventralen rostralen Rhombencephalon der Maus (E12) die Differenzierung zu gestatten, wurden $\varnothing 12 \mathrm{~mm}$-Glasdeckgläschen mit Poly-Ornithine und Laminin (PORN/Lam) beschichtet. Hierdurch wurde auf der Oberfläche der Deckgläschen eine etrazelluläre Matrix (EZM) simuliert und die Zelldifferenzierung ermöglicht. Vorbereitend zur Beschichtung der Deckgläschen wurden diese in 100\% Ethanol bei $4{ }^{\circ} \mathrm{C}$ gelagert. Nach kurzem Abflammen wurden die Deckgläschen einzeln in eine 24-Kammerkulturplatte ausgelegt und mit $500 \mu \mathrm{l}$ einer frisch angesetzten Verdünnung von Poly-L-Ornithine in A. bidest in einer Konzentration von 0,1 mg/ml (PORN-Stammlösung: $10 \mathrm{mg} / \mathrm{ml} 150 \mathrm{mM}$ $\left.\mathrm{H}_{3} \mathrm{BO}_{3} \mathrm{NaOH}, \mathrm{pH} 8,3\right)$ bedeckt. Die Platte wurde nun für $1 \mathrm{~h}$ bei RT belassen. Die PORNLösung wurde abgesogen und nicht gebundenes PORN durch dreimaliges Waschen der Deckgläschen in A. bidest entfernt. Die Beschichtung mit Laminin (Lam) erfolgte durch Überschichten der Deckgläschen mit $500 \mu$ l einer Verdünnung der Laminin-Stammlösung $(1 \mathrm{mg} / \mathrm{ml})$ in DMEM-F12 ohne weitere Zusätze in einer Endkonzentration von $1 \mu \mathrm{g} / \mathrm{ml}$. Die 
Kulturplatte wurde ü. N. bei $37^{\circ} \mathrm{C}$ im Brutschrank inkubiert. Zur Verwendung der Kulturplatte wurde die Laminin-Lösung abgesogen und die Kammern dreimal mit DMEM-F12-Medium ohne Zusätze gewaschen und anschließend jede Kammer mit $750 \mu$ LMEM-F12Komplettmedium befüllt.

\subsubsection{5'-Bromodeoxyuridin-(BrdU)-Proliferationsassay}

Zum Nachweis der Fähigkeit von Vorläuferzellen in primären Neurospheres des ventralen rostralen Rhombencephalon zur Proliferation wurde der 5'-Bromodeoxyuridin(BrdU)-Inkorporationsassay angewendet. Als chemisches Analogon des Nukleosids Thymidin wird BrdU nach Phosphorylierung in der Zelle anstelle des Nukleotids Desoxythymidintriphosphat (dTTP) während der mitotischen S-Phase in den neusynthetisierten Strang der Desoxynukleinsäure (DNA) eingebaut. Das BrdU wird anschließend immunzytochemisch nachgewiesen. Für den BrdU-Inkorporationsassay wurden primäre Neurospheres (DIV8) aus primären Zellen des ventralen rostralen Rhombencephalon der Maus (E12) eingesetzt. Zunächst wurde eine 1:1000 Verdünnung der BrdU-Stammlösung (Stammlösung: $10 \mathrm{nmol}$ ) in $1 \mathrm{ml}$ des DMEM-F12 (20 ng/ml Fgf2, $20 \mathrm{ng} / \mathrm{ml}$ Egf) frisch angesetzt, zu den $3 \mathrm{ml}$ DMEM-F12 (20 ng/ml Fgf2, $20 \mathrm{ng} / \mathrm{ml}$ Egf) der Kultur primärer Neurospheres gegeben und durch Schwenken im Medium gleichmäßig verteilt. Die BrdU-Endkonzentration betrug $10 \mu \mathrm{mol} / \mathrm{ml}$ Kulturmedium. Die Zellen wurden bis zur Probenentnahme nach 2 h, 4 h, 6 h und 8 h nach BrdU-Gabe in $\varnothing 30$ mm-Kulturschalen im Brutschrank inkubiert. Zur Probennahme wurden je zwei Kulturschalen verwendet. Das Medium wurde bis auf $1 \mathrm{ml}$ aus den Kulturschalen entnommen und auf Eis in einem $15 \mathrm{ml}$ Falcon-Röhrchen gesammelt. Das restliche in den Petrischalen vorliegende Medium wurde zum Abspülen adherenter primärer Neurospheres verwendet und ebenfalls in das FalconRöhrchen überführt. Die primären Neurospheres wurden bei $1000 \mathrm{Upm}$ und $4{ }^{\circ} \mathrm{C}$ für 5 min sedimentiert und mit $5 \mathrm{ml}$ DMEM-F12-Komplettmedium gewaschen. Nach erneuter Zentrifugation wurden die Zellen in $400 \mu \mathrm{l}$ Komplettmedium überführt. Je $100 \mu \mathrm{l}$ der Zellsuspension wurde auf ein PORN-/Lam-beschichtetes $\varnothing 12 \mathrm{~mm}$-Deckgläschen (Punkt 4.2.3.7., Seite 50) pipettiert und unter normalen Kulturbedingungen im Brutschrank für $1 \mathrm{~h}$ inkubiert, um eine erste Anheftung der undissoziierten primären Neurospheres zu ermöglichen. Hiernach wurden die Deckgläschen in die Kammern einer mit $650 \mu \mathrm{l}$ Komplettmedium pro Kammer befülten 24-Kammerkulturplatte gelegt und für $72 \mathrm{~h}$ im Brutschrank belassen, um ein Eintreten der Zellen in die Differenzierung zu erlauben. Nach drei Tagen wurde das Medium entfernt und die Zellen dreimal in PBS gewaschen. Die azidische Fixierung und Permeabilisierung der Zellen erfolgte durch eine 20minutige 
Inkubation der Zellen in einer kalten $50 \mathrm{mM}$ Glycin-Lösung in Ethanol bei $-20{ }^{\circ} \mathrm{C}$. Das Fixanz wurde durch dreimalige Waschung mit PBS entfernt. Im Anschluss wurden die Deckgläschen in eine mit Parafilm ausgekleidete Feuchtkammer gelegt und mit $100 \mu \mathrm{l}$ der Anti-BrdULösung bedeckt. Die Anti-BrdU-Lösung enthält neben einem monoklonalem, gegen BrdU gerichteten und in Maus hergestellten Antikörper unbekannter Konzentration zusätzlich $200 \mathrm{nM} \beta$-Mercaptoethanol sowie Nukleasen zur Denaturierung der DNA. Inkorporiertes BrdU wird hierdurch für die Bindung des primären Antikörpers zugänglich. Die AntikörperLösung wurde für $30 \mathrm{~min}$ bei $37^{\circ} \mathrm{C}$ in einem Wärmeschrank auf den Deckgläschen belassen. Die Deckgläschen wurden anschließend dreimal in PBS gewaschen. Als sekundärer Antikörper wurde ein im Schaf hergestellter, gegen Maus gerichteter und mit Fluorescein markierter Antikörper der Immunoglobinklasse G verwendet. Dieser wurde 1:10 in PBS verdünnt und jeweils $100 \mu \mathrm{l}$ der Verdünnung auf ein Deckgläschen aufpipettiert. Die Bindung des sekundären Antikörpers erfolgte während einer 30 minutigen Inkubation bei $37{ }^{\circ} \mathrm{C}$ im Wärmeschrank in einer Feuchtkammer. Zum Abschluss des Nachweises von BrdU wurden die Deckgläschen dreimal in PBS gewaschen.

Für den Nachweis spezifische Markerproteine neuraler Zelltypen in Zellen, die von proliferierenden Vorläuferzellen innerhalb primärer Neurospheres abstammten, wurden wie unter Punkt 4.2.4. (Seite 53) erläutert, weitere immunzytochemische Analysen angeschlossen. Sofern keine weiteren immunzytochemischen Analysen angeschlossen werden sollten, wurden die Zellen in Vectashield eingedeckt, mit Klarlack versiegelt und am Fluoreszenzmikroskop (Nikon Eclipse E600) das Ergebnis dokumentiert.

\subsubsection{Behandlung von Primärkulturen und primären Neurospheres des ventralen rostralen Rhombencephalon der Maus (E12) durch Faktorengabe}

Eine Behandlung durch externe Faktorengabe wurde sowohl an Primärzellen als auch an primären Neurospheres des ventralen rostralen Rhombencephalon der Maus (E12) vorgenommen. Hierzu wurden die nach Aufarbeitung embryonalen Gewebes (E12) des ventralen rostralen Rhombencephalon der Maus gewonnene Einzelzellsuspension auf PORN-/Lam-beschichtete $\varnothing 12 \mathrm{~mm}$-Deckgläschen in einer Zelldichte von $2 \times 10^{5}$ Zellen/750 $\mu \mathrm{l}$ DMEM-F12-Komplettmedium ausplattiert und ü. N. im Brutschrank unter Normalbedingungen kultiviert (Punkt 4.2.3.4, Seite 48). Primäre Neurospheres wurden, wie unter Punkt 4.2.3.5. (Seite 49) erläutert, in PORN-/Lam-beschichtete $\varnothing 30 \mathrm{~mm}$-Kulturschalen in einer Zelldichte von $5 \times 10^{5} / 3 \mathrm{ml}$ DMEM-F12-Komplettmedium ausgesät. Die Faktorengabe wurde am darauffolgenden Tag (DIV1) durchgeführt. Hierzu wurden 2/3 des Medium 
abgezogen und durch frisches Komplettmedium ersetzt, in welchem der jeweilige Faktor in der sich auf das Gesamtvolumen beziehenden Konzentration verdünnt war. Verwendet wurde Tgf- $\beta 1$ in einer Endkonzentration von $1 \mathrm{ng} / \mathrm{ml}$. Des Weiteren kam zur Blockierung endogen synthetisierter Tgf- $\beta$ s ein alle drei Tgf- $\beta$-Isoformen neutralisierender Antikörper (anti TGF $\beta 1 / 2 / 3$ ), in einer Endkonzentration von $10 \mu \mathrm{g} / \mathrm{ml}$ zum Einsatz. Ein synthetischer Inhibitor der Rezeptoren Alk-(„Activin receptor-like kinase“)-4/5 und 7 (SB431542) wurde in einer Endkonzentration von $15 \mu \mathrm{M}$ verwendet, durch welchen unter anderem die Tgf- $\beta$ induzierte Signaltransduktionskaskade blockiert wurde. Als Negativkontrollen wurden parallel nicht behandelte Kulturen der gleichen Zellpräparation verwendet, bei denen lediglich das DMEM-F12-Komplettmedium zu 2/3 ausgetauscht wurde. An Tag 3 nach der Faktorengabe (DIV3) wurden die Zellen der Isolation von Gesamt-RNA bzw. Gesamt-Protein zugeführt (Punkt 4.2.6.4. und Punkt 4.2.8.1., Seite 61 sowie Seite 75).

\subsubsection{Immunzytochemische Charakterisierung von Primärzellen und primärer Neurospheres des ventralen rostralen Rhombencephalon der Maus (E12)}

Der immunzytochemische Nachweis von spezifischen Markerproteinen neuraler Zelltypen wurden an Einzelzellen des ventralen rostralen Rhombencephalon der Maus (E12) sowie an dissoziierten primären, aus Einzelzellsuspensionen generierten Neurospheres desselben Gehirnbereiches durchgeführt. Hierzu wurden die Zellen an Tag 3 (DIV3) nach Ausplattierung auf PORN-/Lam-beschichtete Deckgläschen in einer 24-Kammerkulturplatte durch Überschichtung mit einer 4\%igen PFA-Lösung für $30 \mathrm{~min}$ bei RT fixiert. Das Fixierungsmittel wurde durch dreimalige Waschung in PBS für jeweils 5 min entfernt. Im Anschluss wurde das PBS abgesogen und die Zellen durch Inkubation in eiskaltem Azeton für 10 min bei $-20{ }^{\circ} \mathrm{C}$ permeabilisiert. Nach Entfernung des Azetons wurden die Deckgläschen wie zuvor in PBS gewaschen und in eine mit Parafilm ausgekleidete, lichtundurchlässige Feuchtkammer überführt. Unspezifische Bindungsstellen wurden durch eine Inkubation in $100 \mu$ leiner 10\%igen Ziegenserum-Lösung („Normal goat serum“, NGS) in PBS für $1 \mathrm{~h}$ bei RT blockiert. Die Bindung des jeweiligen primären Antikörpers erfolgte ü. $\mathrm{N}$. bei $4{ }^{\circ} \mathrm{C}$ in $100 \mu$ l einer Verdünnung in PBST (10\% NGS und 0,1\% Triton-X 100) pro Deckgläschen. Die verwendeten Antikörper und ihre spezifische Verdünnung sind in nachfolgender Tabelle (Tab. 2, Seite 54) zusammengefasst: 
Tab. 2: Zur immunzytochemischen Charakterisierung von Primärzellen und primären Neurospheres des ventralen rostralen Rhombencephalon der Maus (E12) eingesetzte, primäre Antikörper

\begin{tabular}{|l|c|c|c|}
\hline \multicolumn{2}{|l|}{} & Ursprungsorganismus & Verdünnungsstufe \\
\hline$\alpha$-Nestin & monoklonal & Maus & $1: 20$ \\
\hline$\alpha$ - $\beta$-III-Tubulin & monoklonal & Maus & $1: 20$ \\
\hline$\alpha$-Gfap & polyklonal & Kaninchen & $1: 1000$ \\
\hline$\alpha$-O4 & monoklonal & Maus & $1: 400$ \\
\hline
\end{tabular}

Nicht gebundene Antikörper wurden am folgenden Tag durch dreimaliges Waschen für 5 min in PBS entfernt. Anschließend erfolgte die Bindung des gegen die Ursprungsspezies des primären Antikörpers gerichteten und im Esel hergestellten, sekundären Antikörpers der Immunoglobinklasse G. Die sekundären Antikörper waren entweder an das Fluorophor Сy3 (Verdünnung 1:600) oder an das Fluorophor Fluorecein (FITC, Verdünnung 1:100) gekoppelt und wurden, wie in obiger Tab. 2 angegeben, in PBS verdünnt. Verwendet wurden jeweils $100 \mu \mathrm{l}$ der Antikörper-Lösung pro Deckgläschen. Nach einstüngiger Inkubation bei RT wurden die Deckgläschen wie zuvor beschrieben in PBS gewaschen und eine Kernfärbung mittels 4',6-Diamidino-2-phenylindol (DAPI) durch eine 5minutige Inkubation mit $100 \mu$ leiner 1:1000 Verdünnung (DAPI-Stammlösung: $10 \mathrm{mg} / \mathrm{ml}$ ) in PBS angeschlossen. Im Falle zuvor BrdU-behandelter Zellen wurde auf eine zusätzliche Kernfärbung verzichtet. Schließlich wurden die Deckgläschen einmal in PBS gewaschen, in Vectashield eingedeckt und mit Klarlack versiegelt.

Für den immunzytochemischen Nachweis von 5-HT musste das oben aufgeführte Protokoll wie folgt modifiziert werden. Die 5-HT-Detektion in Zellpräparaten des ventralen rostralen Rhombencephalon der Maus (E12) erforderte eine Fixierung der Zellen in Methanol/Azeton (1:1) auf Eis für 10 min. Die Deckgläschen wurden dreimal für je 5 min in PBS gewaschen und in eine Feuchtkammer überführt. Die Blockierung erfolgte in $100 \mu \mathrm{l}$ einer 10\%igen NGSLösung in PBS für $1 \mathrm{~h}$ bei RT. Als primärer Antikörper wurde ein in Kaninchen hergestellter, gegen 5-HT gerichteter, polyklonaler Antikörper verwendet. Dieser wurde 1:1000 in PBS verdünnt und jeweils $100 \mu \mathrm{l}$ der Verdünnung auf die Deckgläschen aufpipettiert. Nach einer Inkubation ü. N. bei $4{ }^{\circ} \mathrm{C}$ wurde nicht gebundener Antikörper durch dreimaliges Waschen mit PBS für 5 min entfernt. Als Verstärkung des späteren Fluoreszenzsignals wurde als sekundärer Antikörper ein in der Ziege hergestellter, biotinylierter und gegen Kaninchen gerichteter Antikörper der Immunglobulinklasse G verwendet. Dieser wurde 1:200 in PBS verdünnt und je $100 \mu$ l dieser Verdünnung zur einstündigen Inkubation der Deckgläschen bei RT benutzt. Die Deckgläschen wurden wie zuvor beschrieben in PBS gewaschen und nachfolgend mit Streptavidin-FITC in einer Verdünnung von 1:200 in PBS für 30 min bei RT 
inkubiert. Durch die mehrfache Bindung des FITC-markierten Streptavidins an das Biotin des sekundären Antikörpers wurde eine Verstärkung des Fluoreszenzsignals erreicht. Die Deckgläschen wurden im Anschluss dreimal in PBS gewaschen und zum Abschluss eine DAPI-Kernfärbung durchgeführt. Nach Eindeckung der Zellen in Vectashield und Versiegelung der Deckgläschen mit Klarlack wurden die Zellpräparate am Fluoreszenzmikroskop (Nikon Eclipse E600) ausgewertet.

\subsubsection{Histologische Methoden}

\subsubsection{Fixierung von Mausembryonen unterschiedlicher Entwicklungsstadien für die Herstellung von Gewebeschnitten}

Im Rahmen dieser Arbeit kamen zur Untersuchung von Genexpressionsmustern immunhistochemische Verfahren und die Methode der in situ-RNA-Hybridisierung an Paraffinschnitten sowie Mausembryonen zum Einsatz. Hierzu wurden frisch entnommene Embryonen von NMRI-Mäusen des Embryonaltages (E) 12 oder E14.5 und präparierte Gehirne von neugeborenen NMRI-Mäusen (postnatales Stadium, P0) in einer 4\%igen Paraformaldehyd (PFA)-Lösung immersionsfixiert, wodurch eine Quervernetzung der Proteine erfolgte. Die Fixierungsdauer richtete sich nach dem Stadium der zu fixierenden Embryonen, beginnend mit einer Dauer von $3 \mathrm{~h}$ bei RT unter sanftem Schütteln für Embryonen des Embryonaltages (E) 12 bis hin zur Fixierung ü. N. bei $4{ }^{\circ} \mathrm{C}$ von Präparaten des Gesamtgehirns neugeborener NMRI-Mäuse. Die weitere Behandlung des Gewebes richtete sich nach der anzuwendenden Analysetechnik und wird daher unter dem jeweiligen Unterpunkt erläutert.

\subsubsection{Paraffineinbettung von PFA-fixierten Mausembryonen}

Nach Immersionsfixierung der Mausembryonen durch eine 4\%ige PFA-Lösung wurde das Gewebe bis zur Einbettung in Paraffin zur Herstellung von Gewebeschnitten mehrmals in $70 \%$ igem Ethanol gewaschen und ebenfalls in $70 \%$ igem Ethanol bei $4{ }^{\circ} \mathrm{C}$ gelagert. Die Einbettung in Paraffin erfolgte in einem Paraffineinbett-Automaten beginnend mit einer Entwässerung des Gewebes über eine aufsteigende Ethanolreihe. Diese gliederte sich in folgende Schritte: 


$\begin{array}{rr}80 \mathrm{~min} & 70 \% \text { Ethanol } \\ 80 \mathrm{~min} & 85 \% \text { Ethanol } \\ 80 \mathrm{~min} & 95 \% \text { Ethanol } \\ 80 \mathrm{~min} & 95 \% \text { Ethanol } \\ 120 \mathrm{~min} & 100 \% \text { Ethanol } \\ 120 \mathrm{~min} & 100 \% \text { Ethanol }\end{array}$

Als Intermediärmedium zwischen Ethanol und flüssigem, $60{ }^{\circ} \mathrm{C}$ warmen Paraffin wurde Xylol verwendet, wodurch dem Gewebe zusätzlich noch vorhandenes Restwasser entzogen wurde.

$\begin{array}{ll}80 \text { min } & \text { Xylol } \\ 80 \text { min } & \text { Xylol } \\ 60 \text { min bei } 60{ }^{\circ} \mathrm{C} & \text { Paraffin } \\ 60 \text { min bei } 60^{\circ} \mathrm{C} & \text { Paraffin }\end{array}$

Nach Abschluss der Paraffinierung wurde das Gewebe an einer Paraffin-Ausgießstation in passenden Metallformen in der gewünschten Ausrichtung der späteren sagittalen bzw. frontalen Schnittebene ausgerichtet und die Form mit Paraffin vollständig ausgegossen. Die Metallformen wurden im direkten Anschluss auf einer Kühlplatte positioniert, um eine gleichmäßige und schnelle Abkühlung des Paraffins, welche die Schneideeigenschaften des Paraffins maßgeblich beeinflusst, zu erreichen.

\subsubsection{Herstellung von Gewebeschnitten}

Die Herstellung von Gewebeschnitten nach Einbettung der Mausembryonen in Paraffin (siehe Punkt 4.2.5.2., Seite 55) erfolgte an einem Rotationsmikrotom generell unter RNAsefreien Bedingungen, um sowohl immunhistochemische Untersuchungen als auch in situRNA-Hybridisierungen an dem selben Präparat durchühren zu können. Das Gewebe wurde in Schnitteserien einer Schnittdicke von $10 \mu \mathrm{m}$ geschnitten und anschließend je zwei Schnitte auf silanisierte SuperFrostPlus-Objektträger aufgezogen. Auf einer $37^{\circ} \mathrm{C}$ warmen Metallplatte wurden die Schnitte vorgetrocknet. Die vollständige Trocknung der Schnitte erfolgte ü. N. im Wärmeschrank bei $37{ }^{\circ} \mathrm{C}$. Die Schnitte wurden im Anschluss bis zur Verwendung trocken gelagert. 


\subsubsection{Immunhistochemische Untersuchungen an Schnittpräparaten des zentralen Nervensystems de Maus (E14.5 und P0)}

Für den immunhistochemischen Nachweis von 5-HT-Neuronen der Raphe in wt-Mäusen und Sim1-defizienten Mäusen des gleichen Wurfes wurden serielle, $10 \mu \mathrm{m}$ dicke, frontale Paraffinschnittserien (siehe Punkt 4.2.5.3., Seite 56) des murinen Gehirns unterschiedlicher Entwicklungsstadien (E14.5 und P0) zunächst wie folgt entparaffiniert:

$$
\begin{array}{rc}
2 \times 10 \text { min } & \text { Xylol } \\
2 \times 10 \text { min } & 100 \% \text { Ethanol } \\
5 \text { min } & 95 \% \text { Ethanol } \\
5 \text { min } & 80 \% \text { Ethanol } \\
5 \text { min } & 75 \% \text { Ethanol }
\end{array}
$$

Hieran schloss sich ein dreimaliges Waschen der Schnitte in PBS für jeweils 5 min bei RT an. Um die Zugänglichkeit der zu detektierenden Antigene zu erhöhen, wurden die Schnitte in eine abgedeckte Glasschale umgebettet und für 5 min in $0,1 \mathrm{M}$ Citrat-Puffer (pH 6) in einer Mikrowelle bei $600 \mathrm{~W}$ erwärmt. Nach 20minutiger Abkühlung auf RT wurden die Schnitte $5 \mathrm{~min}$ in PBS gewaschen und ein Blockierung endogener Peroxidasen angeschlossen, um eine unspezifische Hintergrundsfärbung durch die spätere DABReaktion zu vermeiden. Hierfür wurden die Schnitte in $3 \% \mathrm{H}_{2} \mathrm{O}_{2}$ in Methanol für 30 min bei RT inkubiert und im Anschluss erneut für $5 \mathrm{~min}$ in PBS gewaschen. Zur Absättigung unspezifischer Bindungsstellen wurden die Gewebeschnitte für $3 \mathrm{~h}$ in PBS (10\% NGS, 0,1\% Triton-X 100) bei RT blockiert. Die Detektion von 5-HT-Neuronen im Gewebe erfolgte unter Verwendung eines spezifischen, gegen Serotonin gerichteten, polyklonalen und in Kaninchen hergestellten Antikörpers in einer Verdünnung von 1:1000 in PBS (10\% NGS, 0,1\% Triton-X 100). Die Antikörperbindung erfolgte ü. N. bei $4^{\circ} \mathrm{C}$. Als Negativ-Kontrolle wurde der primäre Antikörper durch PBS ersetzt und die nachfolgend beschriebenen Schritte ebenfalls durchgeführt. Am darauffolgenden Tag wurde ungebundener, gegen 5-HT-gerichteter Antikörper durch dreimaliges Waschen in PBS für jeweils 5 min entfernt. Als sekundärer Antikörper wurde ein in der Ziege hergestellter, Peroxidase-gekoppelter und gegen Kaninchen gerichteter Antikörper der Immunglobulinklasse G eingesetzt. Dieser wurde in einer Verdünnung von 1:100 in PBS verwendet und die Schnitte mit der Verdünnung des sekundären Antikörpers für $1 \mathrm{~h}$ bei RT inkubiert. Nach wiederholtem Waschen in PBS wurde ein gegen Peroxidase gerichteter und selbst Peroxidasegekoppelter, im Kaninchen hergestellter Antikörper in einer Verdünnung von 1:800 in PBS 
verwendet. Die Inkubation wurde nach Ablauf von $1 \mathrm{~h}$ durch dreimaliges, 5minutiges Waschen in PBS beendet. Hieran schloss sich die 3,3'Diaminobenzidin Tetrahydrochlorid(DAB)-vermittelte Visualisierung der Peroxidase-Reaktion an. Zur Verstärkung des Signals wurde die Reaktion durch Zugabe von $\mathrm{NiCl}_{2}$ zur DAB-Lösung gemäß den Angaben des Herstellers (Vectashield) intensiviert. Nach kurzer Inkubation in PBS, um die Reaktion abzustoppen, wurden die Schnitte der aufsteigenden Ethanolreihe zugeführt und schließlich in Entellan eingedeckt. Die Auszählung der 5-HT-immunpositiven Neurone in Gewebeschnitten der wt- und Sim1-defizienten Mäuse erfolgte lediglich an jedem fünften Schnitt, um mehrfach Zählung derselben Zelle in aufeinanderfolgenden Schnitten zu umgehen. Es wurden nur jene Zellen als positiv angesehen, die keine unspezifische Kernfärbung erkennen ließen und deren Zytoplasma eine relativ dunkle, Nickel-bedingte Färbung aufwiesen. Die statistische Auswertung der Ergebnisse der Zählungen ist unter Punkt 4.2.9. (Seite 78) dargelegt.

Für den gleichzeitigen immunhistologischen Nachweis der Expression des Transkriptionsfaktors Sim1 und Serotonin (5-HT) wurde das oben beschrieben Protokoll wie folgt modifiziert. Zum spezifischen Nachweis von Serotonin-positiven Neuronen in Frontalschnitten der Maus (wt) des postnatalen Stadiums P0 wurde ein in Maus hergestellter, monoklonaler Primärantikörper in einer Verdünnung von 1:100 in PBS (10\% NGS, 0,1\% Triton-X 100) eingesetzt. Für den Nachweis von Sim1 wurde ein polyklonaler, in Kaninchen hergestellter primärer Antikörper in einer Verdünnung von 1:200 in PBS (10\% NGS, 0,1\% Triton-X 100) verwendet. Hierdurch wurde eine gleichzeitige Inkubation der Gewebeschnitte mit beiden primären Antikörpern ermöglicht. Nach Bindung der primären Antikörper ü. .N. bei $4{ }^{\circ} \mathrm{C}$ wurden die Schnittpräparate zunächst dreimal für jeweils 5 min in PBS gewaschen. Als sekundärer Antikörper wurde ein in der Ziege hergestellter, gegen Maus gerichteter und FITC-markierter Antikörper der Immunoglobinklasse G (1:100 in PBS) bzw. ein in der Ziege hergestellter, Cy3-gekoppelter und gegen Kaninchen gerichteter sekundärer Antikörper (IgG, 1:600 in PBS) benutzt. Die Bindung der sekundären Antikörper erfolgte während einer $1 \mathrm{~h}$ Inkubation bei RT. Hiernach wurden die Gewebeschnitte dreimal für $5 \mathrm{~min}$ in PBS gewaschen und schließlich in Vectashield eingedeckt. Die Auswertung und Dokumentation der Doppelimmunfärbung wurde an einem Fluoreszenzmikroskop (Nikon Eclipse 600) vorgenommen. 


\subsubsection{Molekularbiologische Methoden}

\subsubsection{Isolierung von Plasmid-DNA}

Die Isolierung von Plasmid-DNA aus Bakterienkulturen in größerem Maßstab erfolgte durch klassische alkalische SDS-Lyse transformierter E. coli DH5 $2.200 \mathrm{ml}$ LB $_{\text {Amp }}$-Medium wurden mit einer Einzelkolonie inokuliert und die Flüssigkultur ü. N. bei 250 Upm und $37^{\circ} \mathrm{C}$ inkubiert. Die Kultur wurde in sterile $50 \mathrm{ml}$-Falcon-Röhrchen aufgeteilt und durch 10minutige Zentrifugation bei $6000 \mathrm{Upm}$ und $4{ }^{\circ} \mathrm{C}$ die Zellen geerntet. Die alkalische SDS-Lyse und die Aufreinigung der Plasmid-DNA erfolgte unter Verwendung des QiagenTip100-Systems. Die Zellpellets wurden zusammen in $10 \mathrm{ml} 4^{\circ} \mathrm{C}$ kaltem Puffer 1 resuspendiert und vorsichtig $10 \mathrm{ml} \mathrm{P2}$ zugegeben. Der Ansatz wurde fünfmal leicht gekippt und für maximal 5 min bei RT belassen. Die Neutralisation erfolgte durch Zugabe von $10 \mathrm{ml}$ kaltem Puffer 3. Das Zelllysat wurde in eine Filterspritze gefültt und hierin 10 min bei RT ruhen gelassen. Das Lysat wurde filtriert und in einem 50 ml-Falcon-Rörchen aufgefangen. Zur Bindung der Plasmid-DNA an die Silika-Matrix der Aufreinigungssäule wurde die Anionenaustauschersäule mit $10 \mathrm{ml}$ QBT equilibriert. Nach Durchlauf des Puffers wurde das Filtrat nochmals gemischt und auf die Säule aufgetragen. Zur Entfernung von Proteinen wurde die Säule nach vollständigem Durchlauf des Lysates zweimal mit jeweils $30 \mathrm{ml}$ OC gewaschen. Die Elution der gebundenen Plasmid-DNA erfolgte durch $15 \mathrm{ml}$ QF. Das Eluat wurde in einem $50 \mathrm{ml}$-FalconRöhrchen aufgefangen und mit 12,5 ml Isopropanol (RT) zur Fällung der Plasmid-DNA versetzt. Hierzu wurde die Lösung der Plasmid-DNA in zwei 15 ml-Falcon-Röhrchen gefüllt und eine Zentrifugation bei $14000 \mathrm{Upm}$ für $30 \mathrm{~min}$ bei $4{ }^{\circ} \mathrm{C}$ angeschlossen. Die Überstände wurden vorsichtig dekantiert und die DNA-Pellets mit jeweils $500 \mu \mathrm{l} 70 \%$ igem Ethanol gewaschen. Nach einer erneuten Zentrifugation für 15 min bei $14000 \mathrm{Upm}$ und $4{ }^{\circ} \mathrm{C}$ wurde das Ethanol weitestgehend entfernt und die DNA luftgetrocknet. Jedes DNA-Pellet wurde zunächst in $50 \mu \mathrm{l} \mathrm{A}$. bidest aufgenommen und die Lösungen anschließend in einem 1,5 mlEppendorf-Reaktionsgefäß zusammen gefügt. Nach photometrischer Bestimmung der Nukleinsäurekonzentration (Punkt 4.2.6.7., Seite 64) wurde die Plasmid-DNA bei $-20{ }^{\circ} \mathrm{C}$ gelagert.

\subsubsection{Präparation von Plasmid-DNA in analytischen Mengen}

Zur Gewinnung von Plasmid-DNA im kleineren Maßstab, z.B. zur Identifizierung positiver, transformierter $E$. coli $D H 5 \alpha$-Klone mittels anschließender Restriktionskontrolle, wurde eine Einzelkolonie in $3 \mathrm{ml}$ einer LB $_{\mathrm{Amp}}$-Flüssigkultur in $15 \mathrm{ml}$-Falcon-Röhrchen suspendiert und 
ü. N. bei $37^{\circ} \mathrm{C}$ und 150 Upm inkubiert. $1,5 \mathrm{ml}$ der Bakterienkultur wurden in ein $2 \mathrm{ml}-$ Eppendorf-Reaktionsgefäß überführt und bei 6000 Upm für 3 min sedimentiert. Der Überstand wurde verworfen und das Pellet in $80 \mu \mathrm{l}$ 1 suspendiert. Nach Zugabe von $80 \mu \mathrm{l}$ P2 und leichtem Kippen der Lösung wurden die Zellen bei RT für 5 min lysiert. Die Neutralisation erfolgte durch Zugabe von $80 \mu \mathrm{l} 3$ zum Lysat. Zur Fällung von Proteinen und Membranbestandteilen wurde der Ansatz für 10 min auf $-20{ }^{\circ} \mathrm{C}$ gekühlt und anschließend für 15 min bei 13000 Upm abzentrifugiert. Der Überstand wurde in ein 1,5 ml-EppendorfReaktionsgefäß überführt und mit $600 \mathrm{ml}$ 100\%igem Ethanol zur Fällung der Plasmid-DNA versetzt. Dieser Vorgang wurde durch Inkubation bei $-20{ }^{\circ} \mathrm{C}$ für 30 min unterstützt. Durch einstündige Zentrifugation bei $4{ }^{\circ} \mathrm{C}$ und 13000 Upm wurde die Plasmid-DNA sedimentiert. Der Überstand wurde verworfen und die DNA mit $200 \mu \mathrm{l}$ 70\%igem Ethanol gewaschen. Nach Zentrifugation bei 13000 Upm für 20 min und $4{ }^{\circ} \mathrm{C}$ wurde das Ethanol entfernt und das DNA-Pellet luftgetrocknet. Die DNA wurde in $30 \mu$ DEPC-behandeltem A. bidest gelöst und bei $-20{ }^{\circ} \mathrm{C}$ gelagert.

\subsubsection{Restriktionsverdau von Plasmid-DNA}

Die sequenzspezifische Aufspaltung von Plasmid-DNA durch Endonukleasen wurde sowohl zur Identifizierung positiver E. coli $\mathrm{DH} 5 \alpha$-Klone (siehe Punkt 4.2.1.3., Seite 40 und Punkt 4.2.6.2., Seite 59) als auch zur Vorbereitung der RNA-Sonden-Plasmid-DNA für die in vitroTranskription eingesetzt (Punkt 4.2.7.2., Seite 70). Daher werden an dieser Stelle beide Verfahren erläutert.

Zur Kontrolle der isolierten Plasmid-DNA auf korrekte Insertion wurden verschiedene Restriktionsspaltungen vorgenommen und positive Klone anhand des Fragmentenmusters identifiziert. Das Reaktionsvolumen betrug jeweils $10 \mu \mathrm{l}$.

Zusammensetzung der Reaktionsansätze:

\begin{tabular}{|c|c|}
\hline Plasmid-DNA & $4,0 \mu \mathrm{l}$ \\
\hline A. bidest & $4,5 \mu \mathrm{l}$ \\
\hline Puffer (10x) & $1,0 \mu \mathrm{l}$ \\
\hline 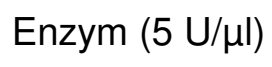 & 0,5 \\
\hline
\end{tabular}

Der Ansatz erfolgte auf Eis. Die DNA-Probe wurden vorgelegt, die restlichen Reaktionskomponenten als Master-Mix zugefügt und der Ansatz kurz anzentrifugiert. Die Spaltungsreaktion erfolgte während einer Inkubation ü. N. bei $37^{\circ} \mathrm{C}$ und wurde hiernach 
durch Zusatz von 6x DNA-Probenpuffer gestoppt. Die Auftrennung der Restriktionsprodukte erfolgte in $2 \%$ igen Agarosegelen bei $120 \mathrm{~V}$.

Zur Vorbereitung der in vitro-Transkription (Punkt 4.2.7.2., Seite 70) zur Herstellung von Sim1-RNA-Sonden für die in situ-Hybridisierung (Punkt 4.2.7.4., Seite 72) wurden die folgenden Restriktionsansätze verwendet:

$\begin{array}{lr}\text { pGemTEasy::Sim1 } & 5 \mu \mathrm{g} \\ \text { Puffer }(10 \times) & 5 \mu \mathrm{l} \\ \text { Enzym }(5 \mathrm{U} / \mu \mathrm{l}) & 2 \mu \mathrm{l} \\ \text { A. bidest ad } & 50 \mu \mathrm{l}\end{array}$

Zur Linearisierung des pGemTEasy::Sim1 Vektors vor dem T7-Promotor, zur Herstellung der „sense“-Sim1-RNA-Sonde wurde das Enzym Sacll eingesetzt, zur Linearisierung vor dem Sp6-Promotor, zur Herstellung der „anti-sense“-Sim1-RNA-Sonde das Restriktionsenzym Sall. Die Spaltungsreaktionen verliefen ü. N. bei $37{ }^{\circ} \mathrm{C}$ und wurde durch 20 minutige Hitzedenaturierung der Enzyme bei $65^{\circ} \mathrm{C}$ beendet.

\subsubsection{Isolierung von Gesamt-RNA aus eukaryontischen Zellkulturen und embryonalem Gewebe der Maus des Embryonaltages (E) 11 und E12}

Zur Gewinnung der Gesamt-RNA wurde der RNA-Isolationskit RNEasy der Firma Qiagen verwendet. Die Zellen wurden wie unter Punkt 4.2.2.1. (Seite 40) beschrieben trypsiniert, für die RNA-Isolation durch Zentrifugation pelletiert und in $600 \mu$ l Lysepuffer (Zugabe von $1 \mu$ l $\beta$-Mercaptoethanol pro $100 \mu \mathrm{l}$ „Rapid lysis buffer", RLB) aufgenommen. Sollte aus embryonalem Gewebe die Gesamt-RNA isoliert werden, so wurde das Gewebe während der Präparation (Punkt 4.2.3.1., Seite 44) in einem 2 ml-Eppendorf-Reaktionsgefäß in $600 \mu \mathrm{l}$ RLB mit $\beta$-Mercaptoethanol auf Eis gesammelt. Das Gewebe wurde für $40 \mathrm{~s}$ im Homogenisator zerkleinert und danach sofort auf Eis gestellt. Die weitere Vorgehensweise unterschied sich für beide Ausgangsproben nicht. Das Lysat wurde durch mehrmaliges Aufund Abziehen durch eine Spritze (Kanülendurchmesser: $\varnothing 0,025 \mu \mathrm{m}$ ) bis zur vollständigen Auflösung des Gewebeverbandes aufgeschlossen und mit $600 \mu \mathrm{l} 70 \%$ igem Ethanol in DEPC-behandeltem A. bidest versetzt. Das Lysat wurde nun auf eine Säule zur Bindung an deren Silikatmatrix aufgetragen und bei 10000 Upm für $30 \mathrm{~s}$ abzentrifugiert. Der Durchfluss 
wurde verworfen und der Vorgang bis zur vollständigen Auftragung des Lysates wiederholt. Die Säule wurde mit $350 \mu$ RW1-Puffer gewaschen und erneut abzentrifugiert. Der Durchfluss wurde verworfen und direkt auf der Säule ein Verdau der genomischen DNA vorgenommen. Hierzu wurden $10 \mu$ der DNase-Stammlösung (10 mg/ml Stammlösung) in $70 \mathrm{ml} \mathrm{RDD-Puffer} \mathrm{verdünnt} \mathrm{und} \mathrm{die} \mathrm{Lösung} \mathrm{direkt} \mathrm{auf} \mathrm{die} \mathrm{Säulematrix} \mathrm{pipettiert.} \mathrm{Nach} \mathrm{einer}$ Inkubation von 15 min bei RT wurden die durch den DNA-Verdau freigesetzten Nukleotide durch Waschung mit $350 \mu \mathrm{l}$ RW1 Puffer von der Säule entfernt. Im Anschluss wurden $600 \mu \mathrm{l}$ RPE-Puffer auf die Säule aufgetragen, diese erneut zentrifugiert und der Durchfluss entfernt. Dieser Vorgang wurde mit $200 \mu \mathrm{l}$ RPE-Puffer wiederholt und die Dauer der Zentrifugation auf 2 min erhöht, um die Säulenmatrix zu trocknen. Die Säule wurde nun auf ein steriles 1,5 ml-Eppendorf-Reaktionsgefäß gesetzt. Durch Aufragung von 20-40 $\mu \mathrm{l}$ RNase-freien A. bidest auf die Säule (je nach zu erwartender RNA-Menge), wurde die RNA durch Zentrifugation bei 10000 Upm für 1 min eluiert. Zur Erhöhung der RNA-Ausbeute wurde das Eluat erneut auf die Säule aufgetragen und der Vorgang wiederholt. Die Konzentration der RNA-Lösung wurde photometrisch (Punkt 4.2.6.7., 64) Seite bestimmt und bis zur weiteren Verwendung die Proben bei $-80{ }^{\circ} \mathrm{C}$ gelagert.

\subsubsection{Gelelektrophoretische Auftrennung von RNA-Proben}

Die erfolgreiche Durchführung eines cDNA-Mikroarray ist abhängig von Qualität und Reinheit der verwendeten RNA-Proben. In dieser Arbeit wurden, wie unter Punkt 4.2.6.4. (Seite 61) beschrieben, die Gesamt-RNA aus Gewebepräparationen des ventralen rostralen Rhombencephalon und des ventralen Mesencephalon der Maus (E11) isoliert. Nach photometrischer Bestimmung der Konzentration und Reinheit der RNA-Proben (Punkt 4.2.6.7., Seite 64) wurde die Integrität der isolierten RNA-Proben mittels denaturierender Formaldehyd-Agarose-Gelelektrophorese überprüft. Hierbei lässt die Detektion intakter 28Sund 18S-r-(ribosomale)-RNA-Banden im Gel indirekt auf eine nicht degradierte GesamtRNA schließen. mRNA-Moleküle sind zu klein und in ihrer Größe zu heterogen, um als Bande sichtbar zu sein. Je RNA-Probe wurden 0,5 $\mu \mathrm{g}$ RNA, mit 6x RNA-Probenpuffer versetzt, diese bei $65^{\circ} \mathrm{C}$ für $10 \mathrm{~min}$ denaturiert und der Ansatz sofort auf Eis gestellt. Jeder RNA-Probe wurde $1 \mu \mathrm{l}$ der Ethidium-(EtBr)-Stammlösung einer Konzentration von 10 mg/ml zugesetzt, um die RNA später unter UV-Licht dokumentieren zu können. Die elektrophoretische Auftrennung erfolgte in einem 1,2\%igem Agarosegel. Hierzu wurden $0,6 \mathrm{~g}$ Agarose mit $36 \mathrm{ml}$ DEPC-behandeltem A. bidest und $5 \mathrm{ml}$ 10fach konzentriertem 3 -[N-morpholino]propansulfonsäure-(MOPS)-Puffer aufgekocht. Nach Abkühlung auf $60{ }^{\circ} \mathrm{C}$ wurden $9 \mathrm{ml}$ 37\%ige Formaldehyd-Lösung unter dem Abzug zugesetzt und das Gel sofort 
gegossen. Nach Erkalten des Gels wurde dieses in eine Gelapparatur, welche mit Paraformaldehyd-haltigem RNA-Laufpuffer gefüllte war, eingesetzt, das Gel mit Laufpuffer überschichtet und der Probenkamm entnommen. Nach Beladung des Gels wurde der Lauf bei $40 \mathrm{~V}$ für circa $1 \mathrm{~h}$ gestartet. Die Integrität der RNA-Proben wurde im Anschluss an dem UV-Transilluminator überprüft.

\subsubsection{6. cDNA-Synthese aus Präparationen von Gesamt-RNA durch Reverse- Transkription (RT-PCR)}

Die Synthese komplementärer DNA („complementary DNA“, cDNA) erfolgte mittels reverser Transkription ausgehend von $1 \mu \mathrm{g}$ einer Präparation von Gesamt-RNA (4.2.6.4., Seite 61). Der Ansatz der Reaktion erfolgte in 0,2 ml-,PCR-Softtubes“ (Biozym) auf Eis. Zur Denaturierung der RNA wurde das $1 \mu \mathrm{g}$ entsprechende Volumen der RNA-Lösung auf ein Gesamtvolumen von 19,8 $\mu$ l durch RNase-freies A. bidest ergänzt und im Thermozykler für 10 min bei $70{ }^{\circ} \mathrm{C}$ die Sekundärstruktur der RNA aufgebrochen. Der Ansatz wurde auf Eis gekühlt und die folgenden Reaktionskomponenten hinzugefügt, wodurch sich ein Gesamtvolumen des Reaktionsansatzes von $30 \mu \mathrm{l}$ ergab. Analog hierzu wurde als Negativkontrolle, welche den Nachweis von genomischer DNA mittels PCR erlaubte, ein Ansatz ohne Zugabe der Reversen-Transkriptase vorbereitet.

$\begin{array}{ll}5 \times \text { Reaktionspuffer } & 6,0 \mu \mathrm{l} \\ \text { dNTP-Mix (10 mM) } & 2,0 \mu \mathrm{l} \\ \text { Oligo-dT-Primer }(100 \mathrm{pmol}) & 1,0 \mu \mathrm{l} \\ \text { RNase-Inhibitor }(40 \mathrm{U} / \mu \mathrm{l}) & 0,5 \mu \mathrm{l} \\ \text { M-MuLV Reverse-Transkriptase }(20 \mathrm{U} / \mu \mathrm{l}) & 0,7 \mu \mathrm{l}\end{array}$

Die Reaktionsansätze wurde im Thermozykler bei $42{ }^{\circ} \mathrm{C}$ für $1 \mathrm{~h}$ inkubiert. Hieran schloss sich eine Inaktivierung der reversen Transkiptase durch Erhitzung des Ansatzes auf $70{ }^{\circ} \mathrm{C}$ für $10 \mathrm{~min}$ an. Sofern keine Analyse der Genexpression im direkten Anschluss vorgenommen wurde, wurden die cDNA-Proben bei $-20{ }^{\circ} \mathrm{C}$ dauerhaft gelagert. 


\subsubsection{Photometrische Konzentrationsbestimmung von wässrigen Nukleinsäure-} Lösungen

Die Konzentration von Nukleinsäure-Präparationen wurde durch photometrisch Messung der Lichtabsorption (A) der Lösung bei einer Wellenlänge von $\lambda=260 \mathrm{~nm}$ bestimmt. Hierzu wurde eine Verdünnung von 1:100 der Nukleinsäure-Lösung in A. bidest angesetzt. Die Messungen erfolgten in einer Quarzküvette (Schichtdicke $10 \mathrm{~mm}$, Probenvolumen $100 \mu \mathrm{l}$ ) gegen A. bidest, dessen Absorption gleich Null gesetzt wurde. Die Konzentration der Nukleinsäure-Lösung ergibt sich unter Berücksichtigung der Verdünnungsstufe wie folgt:

$$
\begin{array}{ll}
\mathrm{A}_{260}= & 1,0=50 \mu \mathrm{g} \text { doppelsträngige DNA } / \mathrm{ml} \\
\mathrm{A}_{260}= & 1,0=40 \mu \mathrm{g} \mathrm{RNA} / \mathrm{ml}
\end{array}
$$

Zur Abschätzung der Reinheit wurde der Quotient $A_{260} / A_{280}$ errechnet. Werte für reine Proben liegen zwischen 1,8 und 2,0. Stärker abweichende Werte weisen auf eine Verunreinigung z. B: durch Proteine oder Lösungsmittel hin.

\subsubsection{Analyse der Genexpression mittels Polymerase-Ketten-Reaktion (PCR)}

Der Nachweis der Expression von Genen erfolgte nach Synthese der cDNA aus Gewebe und Zellkulturproben (Punkt 4.2.6.6., Seite 63) mittels der exponentiellen Amplifikation eines als Matrize dienenden, einzelsträngigen cDNA Abschnittes mittels genspezifischer Primer durch Polymerase-Ketten-Reaktion (PCR). Der Ansatz der PCR-Reaktionen mit einem Gesamtvolumen von $30 \mu \mathrm{l}$ erfolgte auf Eis in sterilen 0,2 ml-„PCR-Softtubes“ (Biozym). Der PCR-Reaktionsansatz umfasste die folgenden Komponenten:

$\begin{array}{lc}\text { 10x Reaktionspuffer } & 3,0 \mu \mathrm{l} \\ \text { dNTP-Mix (10 mM) } & 1,2 \mu \mathrm{l} \\ \mathrm{MgCl}_{2}(25 \mathrm{mM}) & 1,8 \mu \mathrm{l} \\ \text { vorwärts-Primer (100 pmol) } & 1,2 \mu \mathrm{l} \\ \text { rückwärts-Primer (100 pmol) } & 1,2 \mu \mathrm{l} \\ \text { cDNA-Matrize } & 1-2 \mu \mathrm{l} \\ \text { taq-Polymerase }(5 \mathrm{U} / \mu \mathrm{l}) & 0,3 \mu \mathrm{l} \\ \text { A. bidest ad } & 30 \mu \mathrm{l}\end{array}$


Die PCR wurde in einem Thermozykler durchgeführt und gliederte sich in die nachstehenden Schritte. Einer initialen Denaturierung der cDNA für 3 min bei $95{ }^{\circ} \mathrm{C}$ folgte die zyklische Abfolge einer Denaturierung bei $95{ }^{\circ} \mathrm{C}$ für $30 \mathrm{~s}$, gefolgt von der Anlagerung der Primermoleküle an die cDNA-Matrize bei spezifischer, optimaler Bindungstemperatur $\left(T_{m}\right.$-Werte, $\left.T_{m}=4(G+C)+2(A+T)\right)$ des Primerpaares für $30 \mathrm{~s}$ und die Amplifikation des gesuchten Genabschnittes während einer $40 \mathrm{~s}$ bis 1 min dauernden Elongationsphase bei $72{ }^{\circ} \mathrm{C}$ durch die taq-Polymerase. Dabei richtete sich die Dauer dieser Phase nach der Größe es zu amplifizierenden cDNA-Abschnittes. Die Wiederholung dieser drei Schritte umfasste 30 bis maximal 35 Zyklen. Hiernach wurde zur finalen Elongation der Amplifikate eine Erhitzung auf $72{ }^{\circ} \mathrm{C}$ für 5 min vorgenommen und im Anschluss die Reaktion durch Abkühlung des Ansatzes auf $10{ }^{\circ} \mathrm{C}$ beendet. Zur Analyse der PCR wurden die Amplifikationsprodukte gelelektrophoretisch gemäß ihrer Größe aufgetrennt (siehe hierzu Punkt 4.2.6.10., Seite 67).

\subsubsection{Quantitative-“Real-Time“-Polymerase-Ketten-Reation (qRT-PCR)}

Die Quantitative-,,Real-Time“-PCR (qPCR) kommt vorwiegend für vergleichende Genexpressionsanalysen zum Einsatz. Im Gegensatz zur herkömmlichen PCR erlaubt die qRT-PCR die Amplifikation von cDNA-Abschnitten mittels spezifischer Primerpaare und deren zeitgleiche Detektion. Hierdurch wird es möglich, unter Verwendung eines Referenzgenes („Housekeeping gene“, Haushaltsgen), welches in seiner Expression nicht durch die experimentellen Bedingungen beeinflusst ist, eine relative Quantifizierung der Expression eines Gens in einer oder mehrerer Proben im Vergleich zu einer Kontrollprobe durchzuführen. Das Referenzgen hat hierbei die Aufgabe, einen mathematischen Ausgleich der Variationen in der Ausgangsmenge der eingesetzten DNA zu ermöglichen. Die Detektion der Amplifikate erfolgt über die Emission eines in die amplifizierte, doppelsträngige DNA interkalierenden Fluoreszenzfarbstoffes. In der vorliegenden Arbeit wurde SYBR Green I verwendet. Beginnend mit einer initialen Denaturierung der als Template dienenden cDNA bei $95{ }^{\circ} \mathrm{C}$ schließen sich wie bei der klassischen PCR zyklische Wiederholungen der Denaturierung, der Primer-Anlagerung (,Anealing“) und der Elongation des komplementären DNA-Stranges durch die taq-Polymerase an. In den nach Ablauf der Elongation vorliegenden doppelsträngigen DNA-Strang interkaliert der Fluoreszenzfarbstoff während der Synthese. Zu diesem Zeitpunkt wird die Emission des SYBR Green I-DNAKomplexes nach Anregung bei einer Wellenlänge $(\lambda)$ von $521 \mathrm{~nm}$ gemessen. Mit jedem Zyklus verstärkt sich hierdurch das detektierbare Fluoreszenzsignal proportional zur Menge der amplifizierten Fragmente. Nach Ablauf von max. 40 Zyklen, wird eine Schmelzkurven- 
analyse der Amplifikate angeschlossen, um Fehlamplifikate, die anhand eines abweichenden Schmelzpunktes von dem des spezifisch amplifizierten DNA-Fragmentes unterscheidbar sind, angeschlossen. Die Schmelztemperatur („Melting temperature“, $\mathrm{T}_{\mathrm{m}}$ ) gibt die jeweilige Temperatur an, bei der $50 \%$ der Menge eines spezifische amplifizierten DNA-Fragmentes als Einzelstrang vorliegt. Für die Erstellung der Schmelzkurve werden zunächst alle doppelsträngigen DNA-Moleküle denaturiert und bei $60{ }^{\circ} \mathrm{C}$ hybridisiert. Hierbei interkaliert wiederum der SYBR Green I-Fluoreszenzfarbstoff in die doppelsträngigen DNAMoleküle. Denaturierung und Hybridisierung wechseln miteinander ab, wobei die Hybridisierungstemperatur sukzessive erhöht wird. Infolgedessen bleiben doppelsträngige Amplifikate der selben Fragmentlänge bei einer für sie spezifischen Temperatur, über dem eigentlichen $\mathrm{T}_{\mathrm{m}}$-Wert, in Einzelstränge getrennt und das Fluoreszenzsignal nimmt proportional $\mathrm{ab}$.

Die qRT-PCR wurde unter Verwendung des RT-PCR-Thermozyklers ABI Prism 7500, des SYBR Green I-Mastermix und speziellen 96-Kammerplatten, die eine Messung des Fluoreszenzsignals zulassen, der Firma Applied Biosystems $\mathrm{GmbH}$ durchgeführt. Der Reaktionsansatz pro Kammer und das PCR-Programm sind im folgenden wiedergegeben:

\section{Reaktionsansatz}

\begin{tabular}{|c|c|c|c|c|}
\hline 2× SYBR Green I-Mix & $12,5 \mu \mathrm{l}$ & 1. Intitiale Denaturierung & $10 \mathrm{~min}$ & $95^{\circ} \mathrm{C}$ \\
\hline $\begin{array}{l}\text { vorwärts-Primer } \\
\text { (10 pmol) }\end{array}$ & $2,5 \mu \mathrm{l}$ & 2. Denaturierung & $30 \mathrm{~s}$ & $95^{\circ} \mathrm{C}$ \\
\hline $\begin{array}{l}\text { rückwärts-Primer } \\
\text { (10 pmol) }\end{array}$ & $2,5 \mu l$ & 3. Primer-Anlagerung & $30 \mathrm{~s}$ & $\mathrm{~T}_{\mathrm{m} \text { (Primer). }}$ \\
\hline cDNA Template & $2,5 \mu l$ & 4. Elongation & $40 \mathrm{~s}$ & $72{ }^{\circ} \mathrm{C}$ \\
\hline $\mathrm{H}_{2} \mathrm{O}$ & $5 \mu l$ & Zyklen (2-4) & 40 & \\
\hline Gesamtvolumen & $25 \mu \mathrm{l}$ & & & \\
\hline
\end{tabular}

\section{Schmelzkurve:}
A: 15 s $95{ }^{\circ} \mathrm{C}$
$1 \min 60^{\circ} \mathrm{C}$
B: 15 s $95{ }^{\circ} \mathrm{C}$
$1 \min x^{\circ} \mathrm{C}-0,5^{\circ} \mathrm{C}$

Die Amplifikation des DANN-Templates wird in drei Abschnitte untergliedert, einer Basisphase, in der die Zahl der Ausgangskopien noch zu gering ist, um quantitativ auswertbar zu sein, die exponentielle Phase, in der die der amplifizierten DNA-Fragmente exponentiell und daher quantifizierbar ansteigt, sowie die dritte Phase, die stationäre Phase, in der Substratverbrauch, multiple Produkte und nachlassende Enzymaktivität zu suboptimalen Reaktionsbedingungen führen. Um die Messung für die einzelnen Proben 
stets zu Beginn der exponentiellen Phase durchführen zu können, bedient man sich des CtWertes („Threshold cycle"). Der Ct-Wert beschreibt den jeweiligen Zyklus, bei dem das Fluoreszenzsignal erstmals signifikant über die Hintergrundsfluoreszenz ansteigt. Die Auswertung der Genexpressionsdaten, die auf diese Weise gemessen werden, lässt sich nur unter der Voraussetzung durchführen, dass die Amplifikation des Reverenzgenes, hier Gapdh, und des Zielgens eine nicht zu stark voneinander abweichende Effizienz besitzen.

Die Effizienz $(E)$ wird mittels einer Standardkurve für jedes Primerpaar bestimmt und ergibt sich wie folgt aus der Steigung $(m)$ der Standardkurve:

$$
E=10^{-1 / m}-1
$$

Eine Effizienz von 100\% entspricht einer Steigung von -3,32 und einer Verdopplung der Amplifikate pro Zyklus.

Die unterschiedliche Expression eines Gens lässt sich als n-fache Expression $\left(2^{-\Delta \Delta \mathrm{Ct}}\right)$ durch den $\Delta \Delta$ Ct-Wert angeben. Hierzu wird die Differenz des Ct-Wertes des Zielgens und des Ct-Wertes des Referenzgens gebildet $(\Delta \mathrm{Ct})$ wodurch Unterschiede in der Ausgangsmenge des Templates kompensiert werden (1). Im nächsten Schritt wird die Differenz aus dem $\Delta$ CtWert einer Probe und dem $\Delta \mathrm{Ct}$-Wert der Kontrollprobe errechnet (2), der durch $2^{-\Delta \Delta \mathrm{Ct}}$ auch als absoluter Wert angegeben werden kann (3). Die Standardabweichungen $(s)$ ergeben sich aus den unten aufgeführten mathematischen Formeln (5), welche ebenfalls als Absolutwerte angegeben werden können.

$$
\begin{aligned}
& \Delta \mathrm{Ct}=\mathrm{Ct}_{\text {Zielgen }}-\mathrm{Ct}_{\text {Reterenzgen }} \\
& \Delta \Delta \mathrm{Ct}=\Delta \mathrm{Ct}_{\text {Probe }}-\Delta \mathrm{Ct}_{\text {Kontrollprobe }} \\
& 2^{-\Delta \Delta \mathrm{Ct}} \\
& s=\sqrt{{s_{\text {Zielgen }}{ }^{2}+S_{\text {Referenzgen }}^{2}}^{2}} \\
& 2^{-(\Delta \Delta \mathrm{Ct}+s)} ; 2^{-(\Delta \Delta \mathrm{Ct}-s)}
\end{aligned}
$$

\subsubsection{DNA-Agarosegelelektrophorese}

Die elektrophoretische Größenauftrennung von DNA-Fragmenten nach DNA-Restriktion oder aus PCR-Reaktionen (Punkte 4.2.6.3. und Punkt 4.2.6.8., Seiten 60 und 64) wurde in $2 \%$ igen Submers-Agarosegelen vorgenommen. Hierzu wurden zunächst $8 \mathrm{~g}$ Agarose in 
$400 \mathrm{ml} 1 \times$ TAE-Puffer durch Aufkochen gelöst, verdunstete Flüssigkeit ergänzt und die Lösung unter Schwenken auf ca. $60{ }^{\circ} \mathrm{C}$ abgekühlt. Zur Detektion der DNA-Fragmente unter UV-Licht wurde dem Gel Ethidiumbromid (EtBr) in einer Konzentration von 0,4 $\mu \mathrm{g} / \mathrm{ml}$ zugesetzt. Die Agarose-Lösung wurde gründlich gemischt, in eine abgedichtete Gelträgerwanne gefüllt und die Probenkämme zur Bildung der Auftragstaschen eingesetzt. Nach Erstarren des Agarosegels wurde dieses mit dem Träger in die Elektrophoresekammer eingesetzt, mit 1× TAE-Puffer überschichtet und vorsichtig die Probenkämme entfernt. Die DNA-Proben wurde mit dem entsprechenden Volumen DNAProbenpuffer $(6 \times)$ versetzt und vollständig aufgetragen. Zur Größenbestimmung der Fragmente wurde das Agarosegel mit $6 \mu$ des 100 bp-DNA-Größenstandards beschickt. Die elektrophoretische Auftrennung der DNA-Fragmente erfolgte bei $120 \mathrm{~V}$ und wurde anschließend unter UV-Licht photographisch dokumentiert.

\subsubsection{Aufreinigung von DNA-Fragmenten aus Agarosegelen}

Die PCR-Produkte der Sim1-Amplifikation zur Generierung eines RNA-Sonden-Plasmides für den Einsatz in die in situ-RNA-Hybridisierung wurden elektrophoretisch in einem $2 \%$ igen TAE-Agarosegel bei $120 \mathrm{~V}$ aufgetrennt. Die Elution der zu ligierenden Fragmente wurde unter Verwendung des QIAEX II-Elutionskits vorgenommen. Hierzu wurden die DNA-Bande einer Fragmentgröße von 213 bp im Gel auf dem Transilluminator mit einem sterilen Skalpell markiert und anschließend entnommen. Nach Gewichtsbestimmung wurden 3 VT QX1 sowie 2 VT DEPC-behandeltes A. bidest zugesetzt und der Ansatz bis zur Auflösung des Gels gevortext. Es wurden nun $10 \mu \mathrm{l}$ der gründlich suspendierten Silika-Matrix (QIAX2) zugesetzt, gemischt und der Ansatz für $10 \mathrm{~min}$ bei $50{ }^{\circ} \mathrm{C}$ und 14000 Upm zur DNA-Bindung an die Matrix im Thermomixer inkubiert. Zur Sedimentierung der matrixgebundenen DNAFragmente wurde der Ansatz $30 \mathrm{~s}$ bei 14000 Upm abzentrifugiert und der Überstand gründlich abpipettiert. Es folgte ein Waschschritt mit $500 \mu \mathrm{l}$ QX1 sowie eine zweimaliges Waschen mit $500 \mu \mathrm{l}$ PE-Puffer. Nach Verwerfen des Überstandes wurde das Pellet luftgetrocknet. Zur Elution der DNA-Fragmente wurde das Matrix-Pellet in $15 \mu \mathrm{l}$ DEPC-behandeltes A. bidest sowie $5 \mu 10 \mathrm{mM}$ Tris- $\mathrm{HCl}(\mathrm{pH} 7,5)$ resuspendiert und 5 min bei $50{ }^{\circ} \mathrm{C}$ unter gelegentlichem Invertieren inkubiert. Durch Zentrifugation bei 14000 Upm für 1 min wurde die Matrix abgetrennt und der die DNA enthaltende Überstand in ein neues Eppendorf-Reaktionsgefäß überführt. $1 / 3$ des Eluates wurden zur Abschätzung der Konzentration nochmals elektrophoretisch aufgetrennt (Punkt 4.2.6.10, Seite 67). Bis zur Ligation in einen geeigneten Vektor wurden die DNA-Lösung bei $-20{ }^{\circ} \mathrm{C}$ gelagert. 


\subsubsection{Genexpressionsstudie mittels cDNA-Mikroarray-Analyse}

Zur Identifizierung bisher unbekannter Kandidatengene, die Einfluss auf die Entwicklung von 5-HT-Neuronen des ventralen rostralen Rhombencephalon der Maus nehmen könnten, wurde die Tatsache genutzt, dass Vorläuferzellen mesencephaler DA-Neurone und rhombencephaler 5-HT-Neurone in enger ontogenetischer Verwandtschaft zueinander stehen. Somit sollte ein Vergleich der Genexpressionen beider Gewebegebiete zu einem geeigneten, frühen Zeitpunkt der Entwicklung Unterschiede in der Expression von Genen aufweisen, die bisher nicht in diesem entwicklungsbiologischen Kontext untersucht wurden. Als geeignet Stadium wurde der Embryonaltag (E11) gewählt, da zu diesem Zeitpunkt nur vereinzelt differenzierte rostrale 5-HT-Neurone im Rhombencephalon detektierbar sind. Der Vergleich der Genexpression wurde durch cDNA-Mikroarray-Analyse durchgeführt. Hierfür wurde Gesamt-RNA sowohl des ventralen Mesencephalon als auch des ventralen rostralen Rhombencephalon, wie unter Punkt 4.2.6.4. (Seite 61) erläutert, isoliert. Die MikroarrayAnalyse erforderte eine hochwertige Präparation der Gesamt-RNA, so dass vor der Durchführung zunächst die Integrität der RNA mittels denaturierender FormaldehydGelelektrophorese überprüft wurde (Punkt 4.2.6.5., Seite 62). Zum Vergleich des Genexpressionsmusters wurde der GeneChip ${ }^{\circledR}$ Mouse Genome 430A 2.0-Array von Affimetrix verwendet, auf welchem synthetisch hergestellte Oligonukleotide in definierter Position („Slide“) auf der Oberfläche gebunden vorliegen, die spezifisch für 22000 gut charakterisierten Genen des Mausgenoms sind. Je RNA-Probe wurden $11 \mu \mathrm{g}$ für die Synthese der cDNA verwendet. Die cDNA-Synthese wurde am Steinbeis-Transferzentrum für Proteom-Analysen, Rostock durchgeführt. Hierbei wurden die beiden zu vergleichenden cDNA-Proben, ventrales Mesencephalon und ventrales rostrales Rhombencephalon der Maus (E11) durch zwei unterschiedliche Fluoreszenzfarbstoffe markiert. In der anschließenden Hybridisierungsreaktion wurden die cDNA-Proben an die synthetischen Oligonukleotide des Mikrochip gebunden. Nach Abschluss der Hybridisierung wird der Mikrochip durch Laser ausgelesen. Hierbei werden die in die cDNA inkorporierten Fluorophore der beiden Proben bei spezifischer Wellenlänge angeregt. Die hierbei ausgelöste Emission jedes Fluorophors eines „Slides“ wird gemessen und anschließend der Quotient beider Werte errechnet. Der Quotient der Emissionen beider Proben gibt an, ob das Gen, welches durch das hybrdisierte Oligonukleotid repräsentiert wird, in einer Probe relativ zur zweiten Probe herauf- oder herunterreguliert ist oder keine Unterschiede bezüglich der Expression vorliegen. Die Normalisierung der Daten erfolgt durch den Vergleich der Expression von verschiedenen „Housekeeping“-Genen in beiden cDNA-Proben. 


\subsubsection{In situ-RNA-Hybridisierung}

\subsubsection{Klonierung von in situ-RNA-Sondenplasmiden — Ligation von DNA-Molekülen}

Zur Klonierung eines Sim1-Sondenplasmides wurde das pGEM-T Easy Vektor-System verwendet. Der liniearisierte Vektor trägt an den 3'-Enden eine Thymidin-Überhang wodurch die Insertion von PCR-Produkten, welche in Abhängigkeit der verwendeten taq-Polymerase einen Adenin-Überhang an den 5'-Enden besitzen, erleichtert wird. Zur Ligation des eluierten Sim1-Genfragments (213 bp) in den pGEM-T Easy Vektor wurde ein Verhältnis des Inserts zum Vektor von nahezu 3:1 gewählt.

Zusammensetzung des Ligationsansatzes in einem 0,5 ml-Eppendorf-Reaktionsgefäß:

$\begin{array}{lr}2 \times, \text {,Rapid ligation buffer" } & 5 \mu \mathrm{l} \\ \text { PCR Produkt } & 3 \mu \mathrm{l} \\ \text { pGEM-T Easy Vektor } & 1 \mu \mathrm{l} \\ \text { T4 DNA-Ligase }(5 \mathrm{U} / \mu \mathrm{l}) & 1 \mu \mathrm{l} \\ \text { A. bidest ad } & 50 \mu \mathrm{l}\end{array}$

Die Ligationsreaktion verlief ü. N. bei $4^{\circ} \mathrm{C}$ und wurde am folgenden Tag zur Transformation chemisch kompetenter E. coli DH5 $\alpha$ eingesetzt (Punkt 4.2.1.3., Seite 40).

\subsubsection{Herstellung von in situ-RNA-Sonden durch in vitro-Transkription}

Zur in vitro-Transkription wurde jeweils $1 \mu \mathrm{g}$ des geschnittenen pGem-T Easy::Sim1(213 bp)-Sondenplasmides eingesetzt. Wurde der Vektor vor dem T7-Promotor linearisiert, wurde für die in vitro-Transkription die Sp6-Polymerase verwendet. Für eine in vitroTranskription des vor dem Sp6-Promotor linearisierten Vektors wurde entsprechend die T7Polymerase benutzt. Hierdurch wurden beide komplementären DNA-Stränge des Sim1Inserts in mRNA transkribiert und auf diese Weise eine „sense“-(Sp6) und eine „anti-sense“(T7)-RNA-Hybridisierungssonde gegen Sim1-mRNA der Größe von 301 bp bzw. 322 bp gewonnen.

Im Folgenden ist der Ansatz der in vitro-Transkriptiosreaktion dargelegt: 


$\begin{array}{lr}\text { DIG-Labeling Mix } & 2 \mu \mathrm{l} \\ \text { 5× Transkriptionspuffer } & 4 \mu \mathrm{l} \\ \text { RNase-Inhibitor } & 1 \mu \mathrm{l} \\ \text { linearisierte Plasmid-DNA } & 10 \mu \mathrm{l} \\ \text { T7- bzw. Sp6 Polymerase }(10 \mathrm{U} / \mu \mathrm{l}) & 1 \mu \mathrm{l} \\ \text { DEPC-behandeltes A. bidest } & \text { ad } 20 \mu \mathrm{l}\end{array}$

Die in vitro-Transkription verlief bei $37^{\circ} \mathrm{C}$ im Wärmeblock für $150 \mathrm{~min}$. Zur Fällung der RNA-Sonden wurde der Ansatz mit $5 \mu$ einer 4M LiCl-Lösung sowie $150 \mu$ l 100\%igem Ethanol versetzt und bei $-80{ }^{\circ} \mathrm{C}$ für 30 min inkubiert. Die RNA wurde durch Zentrifugation bei $12000 \mathrm{Upm}$ und $4{ }^{\circ} \mathrm{C}$ für $30 \mathrm{~min}$ sedimentiert. Hiernach wurde die RNA in $200 \mu \mathrm{l}$ $70 \%$ igem Ethanol gewaschen und bei $12000 \mathrm{Upm}$ und $4{ }^{\circ} \mathrm{C}$ für 15 min abzentrifugiert. Nach Lufttrocknung der RNA-Sondenproben wurden diese in $20 \mu$ DEPC-behandeltem A. bidest gelöst und bei $-80{ }^{\circ} \mathrm{C}$ gelagert.

\subsubsection{Effizienzbestimmung von in situ-RNA-Sonden}

Um die Effizienz der in vitro-Transkription (Punkt 4.2.7.2., Seite 70) zu bestimmen und die in die in situ-RNA-Hybridisierung einzusetzenden Volumina der "sense“- und „anti-sense“-DIGmarkierten RNA-Sonde zu bestimmen, wurde von jeder RNA-Sonde eine Verdünnungsreihe in DEPC-behandeltem A. bidest angesetzt. Verwendet wurden je eine 1:10, 1:50, 1:100, 1:1000 und 1:10000 Verdünnungsstufe. Zur späteren Konzentrationsabschätzung der transkribierten RNA-Sonden wurde eine DIG-markierte Kontroll-RNA einer Konzentration von $1 \mu \mathrm{g} / \mu \mathrm{l}$ in gleicher Weise verdünnt. Von jeder Verdünnungsstufe der Sonden-RNA bzw. Kontroll-RNA wurde $1 \mu \mathrm{l}$ auf eine Nitrozellulose-Membran aufgetropft und diese $10 \mathrm{~min}$ luftgetrocknet. Die Bindung der RNA-Moleküle an die Membran erfolgte durch 2minutige Fixierung durch UV-Bestrahlung („Cross-linking“). Die Membran wurde in eine $\varnothing 10 \mathrm{~cm}$ Petrischale gelegt und diese 3 min lang in Puffer I äquilibriert. Unspezifische Bindungsstellen wurden durch Inkubation in Magermilchpulver-gesättigtem Puffer I (4\% Milchpulver, MP) für 15 min auf einem Horizontalschüttler erreicht. Hiernach erfolgte die Bindung des gegen DIG-gerichteten und an alkalische Phosphatase gebundenen Antikörpers in einer Verdünnung von 1:5000 in MP-gesättigtem Puffer I für 30 min bei RT. Nach zweimaligem Waschen in Puffer I für jeweils 10 min wurde die Membran in Puffer III umgepuffert. Die alkalische Phosphatase-vermittelte Farbreaktion wurde durch Inkubation in 5-Brom-4-chlor-3-indoxylphosphat-(BCIP)/Nitroblau-Tetrazoliumchlorid-(NBT)-Lösung (1:50 
in Puffer III) unter Lichtabschluss gestartet. Nach deutlicher Farbentwicklung wurde der Puffer entfernt, die Membran mehrmals in Leitungswasser gewaschen und die Membran luftgetrocknet.

\subsubsection{In situ-RNA-Hybridisierung an embryonalen Gewebeschnitten der Maus (E12)}

Der in situ-Nachweis der Expression des für den Transkriptionsfaktor Sim1 kodierenden Gens erfolgte durch Hybridisierung genspezifischer, DIG-markierter RNA an $10 \mu \mathrm{m}$ dicken Paraffinschnitten der Maus des Embryonaltages (E) 12, welche durch PFA fixiert worden waren. Zum direkten Vergleich der, wie unter Punkt 4.2.7.2. (Seite 70) erläutert, hergestellten "sense"- und "anti-sense"-RNA-Sonden gegen Sim1-mRNA wurden je zwei direkt aufeinander folgende Objektträger mit jeweils zwei Schnitten verwendet. Die in situRNA-Hybridisierung wurde unter RNAse-freien Bedingungen in sterilen Glasküvetten sowie unter Verwendung RNAse-freier, DEPC-behandelter und autoklavierter Lösungen durchgeführt. Zunächst wurden die Paraffinschnitte durch zweimalige, 10minutige Inkubation in Xylol entparaffiniert. Hieran schloss sich eine Rehydrierung des Gewebes durch eine absteigende Ethanolreihe und anschließende Waschung in PBS an.

$\begin{array}{rr}10 \mathrm{~min} & 100 \% \text { Ethanol } \\ 10 \mathrm{~min} & 100 \% \text { Ethanol } \\ 5 \mathrm{~min} & 95 \% \text { Ethanol } \\ 5 \mathrm{~min} & 80 \% \text { Ethanol } \\ 5 \mathrm{~min} & 70 \% \text { Ethanol } \\ 3 \times 5 \mathrm{~min} & \text { PBS }\end{array}$

Nach Rehydrierung wurden die Schnitte zur Absättigung freier Aldehydgruppen für 5 min in einer 0,1 M Glycin-Lösung inkubiert. Während einer dreimaligen Waschung der Schnitte in PBS für jeweils 5 min wurde der Raum um die Schnitte mittels eines Fettstiftes begrenzt, um das in späteren Schritten einzusetzende Volumen von Enzymlösungen und der, die RNASonden enthaltende, Hybridisierungslösung zu verringern. Nach Abschluss der Waschung in PBS wurden die beiden Gewebeschnitte eines Objektträgers mit $100 \mu \mathrm{l}$ einer Proteinase K-Lösung $(10 \mu \mathrm{g} / \mathrm{ml}$ in TE-Puffer, $\mathrm{pH}$ 8) bedeckt. Die Schnitte wurden nun in einer mit angefeuchtetem Fliespapier ausgekleideten Kammer bei $37{ }^{\circ} \mathrm{C}$ für $30 \mathrm{~min}$ inkubiert. Durch die Proteinase K-Behandlung werden intrazelluläre Proteine abgebaut, darunter auch DNasen und RNasen. Des Weiteren werden durch diese enzymatische 
Behandlung Nukleinsäuren für die späteren Hybridisierung der RNA-Sonden zugänglich. Nach Ablauf der Inkubation wurden die Schnitte erneut in 4\%igem PFA für 3 min in einer Glasküvette fixiert und hierdurch die Aktivität der Proteinase K inhibiert. Zur Reduktion einer später auftretenden Hintergrundsfärbung durch endogene Phosphatasen wurde eine Inkubation in 0,1 M Trap-Puffer unter Zusatz von 0,25\% Essigsäureanhydrid für $10 \mathrm{~min}$ unter Lichtabschluss angeschlossen. Die Schnitte wurden nun in einer Feuchtkammer mit je $100 \mu \mathrm{l}$ der Hybridisierungslösung bedeckt und für $1 \mathrm{~h}$ bei RT prähybridisiert. Kurz vor Beendigung der Prähybridisierung wurden 50 ng der DIG-markierten, gegen Sim1gerichteten "sense"- bzw. "anti-sense"-RNA-Sonde in einem Gesamtvolumen von jeweils $10 \mu$ in DEPC-behandeltem A. bidest verdünnt und die RNA bei $65^{\circ} \mathrm{C}$ für 3 min denaturiert. Danach wurden die RNA-Proben für 2 min auf Eis gestellt, wodurch eine spontane Hybridisierung der RNA-Moleküle mit sich selbst oder miteinander unterbunden wurde. Den RNA-Proben wurden nun $90 \mu \mathrm{l}$ Hybridisierungslösung zugegeben. Je ein Objektträger wurde mit einer RNA-Probe nach Entfernen der Prähybridisierungslösung bedeckt. Die Hybridisierung der RNA-Sonden an mRNA des Sim1-Gens erfolgte ü. N. bei $42{ }^{\circ} \mathrm{C}$ im Wärmeschrank in einer Feuchtkammer.

Am folgenden Tag wurden die Schnitte zunächst in einer Glasküvette mit 4fach konzentrierter, auf $42{ }^{\circ} \mathrm{C}$ temperierten SSC-Lösung gewaschen. Nicht gebundene oder unvollständig gebundenen RNA-Sondenmoleküle wurden durch eine anschließende RNase A-Behandlung $(10 \mu \mathrm{g} / \mathrm{ml}$ RNase $\mathrm{A}$ in TE-Puffer, $\mathrm{pH}$ 8) entfernt. Die nachfolgenden Waschungen wurden ebenfalls bei $42{ }^{\circ} \mathrm{C}$ in vorgewärmten SSC-Lösungen absteigender Konzentration durchgeführt.

$\begin{array}{rr}15 \text { min } & 2 \times S S C \\ 15 \text { min } & 0,1 \times S S C \\ 5 \text { min } & 0,05 \times S S C\end{array}$

Hieran schloss sich eine Äquilibrierung der Gewebeschnitte in Puffer I für 10 min an. Unspezifischer Bindungsstellen wurden durch eine 30minutige Inkubation der Gewebeschnitte in Magermilchpulver-gesättigtem (4\% MP) Puffer I blockiert. Die Verdünnung des anti-DIG, alkalische Phosphatase-gebundenen Antikörpers zum Nachweis der DIG-markierten, hybridisierten RNA-Sonde erfolgte im gleichen Puffer, im Verhältnis 1:400. Hiervon wurden jeweils $100 \mu \mathrm{l}$ auf die beiden Gewebeschnitte eines Objektträgers verteilt und diese zur Bindung des Antikörpers in einer Feuchtkammer bei $4{ }^{\circ} \mathrm{C}$, ü. N. inkubiert. 
Der indirekte Nachweis gebundener DIG-markierter, gegen Sim1-mRNA-gerichteter RNASondenmoleküle erfolgte am darauffolgenden Tag durch alkalische Phosphatase-(AP)vermittelte Farbreaktion. Hierzu wurden nicht gebundene, gegen DIG-gerichtete, AP-markierte Antikörper durch dreimalige Waschung der Gewebeschnitte in Puffer I entfernt. Durch 5minutige Inkubation der Gewebeschnitte in Puffer III wurden die optimalen Pufferbedingungen der AP im Gewebe hergestellt. Je $20 \mu \mathrm{l}$ NBT- und BCIP-Lösung als Substrat der AP-Reaktion sowie $1 \mu$ l einer Levamisol-Stammlösung $(2,4 \mathrm{mg} / \mathrm{ml})$ zur Inhibierung endogener alkalischer Phosphatasen wurden in einem Gesamtvolumen von $1 \mathrm{ml}$ in Puffer III verdünnt. $100 \mu \mathrm{l}$ der Reaktionslösung wurden auf die Gewebeschnitte eines Objektträgers pipettiert. Die Farbreaktion wurde in einer lichtgeschützten Feuchtkammer durchgeführt und gelegentlich unter dem Mikroskop beobachtet. Nachdem eine deutliche bläulich-violette, zytoplasmatische Färbung zu erkennen war, wurde die Farbreaktion der mit "anti-sense"- und der entsprechenden "sense"-RNA-Sonde hybridisierten Gewebeschnitte durch einen 5minutigen Waschschritt in TE-Puffer abgestoppt. Anschließend wurden die Gewebeschnitte kurz in A. bidest getaucht und durch eine aufsteigende Ethanolreihe dehydriert.

\begin{tabular}{|c|c|}
\hline $1 \mathrm{~min}$ & $70 \%$ Ethanol \\
\hline $1 \mathrm{~min}$ & $80 \%$ Ethanol \\
\hline $1 \mathrm{~min}$ & $95 \%$ Ethanol \\
\hline $2 \times 2 \min$ & $100 \%$ Ethano \\
\hline
\end{tabular}

Die Entwässerung des Gewebes wurde durch zweimalige Inkubation in Xylol für jeweils 3 min abgeschlossen. Zur permanenten Konservierung der gefärbten Gewebeschnitte wurden diese in Entellan eingedeckt. 


\subsubsection{Proteinbiochemische Methoden}

\subsubsection{Isolierung des Gesamtproteins aus Gewebe und Zellkulturproben}

Wie unter Punkt 4.2.2.1. (Seite 40) beschrieben wurden MN9D-Zellen zur Proteinisolation nach Transfektion der Zellen trypsiniert und durch Zentrifugation in einem 15 ml-FalconRöhrchen sedimentiert. Das Zellpellet wurde nun in $5 \mathrm{ml}$ kaltem Homogenisierungspuffer resuspendiert und bei $250 \mathrm{~g}$ und $4{ }^{\circ} \mathrm{C}$ für $5 \mathrm{~min}$ abzentrifugiert. Dieser Vorgang wurde zweimal wiederholt und schließlich das Zellpellet in $100 \mu$ l Homogenisierungspuffer (siehe Punkt 4.1.10., Seite 33) aufgenommen. Die Zellprobe wurde an einem Stab-Ultraschallgerät für dreimal $5 \mathrm{~s}$ zur Zerstörung von Komponenten der Zellmembran beschallt. Durch die Hitzeentwicklung war eine Kühlung der Probe auf Eis zwischen den einzelnen UltraschallGaben notwendig. Die Proteinkonzentration wurde gemäß Punkt 4.2.8.2. (Seite 75) photometrisch bestimmt. Bis zur gelelektrophoretischen Auftrennung wurden die Proteine bei $-80{ }^{\circ} \mathrm{C}$ gelagert.

\subsubsection{Photometrische Bestimmung der Proteinkonzentration nach Bradford}

Die Konzentration von Proteinlösungen (Punkt 4.2.8.1., Seite 75) erfolgte gemäß der Konzentrationsbestimmung nach Bradford. Diese Methode basiert auf der proportionalen Anlagerung des Coomassie-Farbstoffes an Proteine. Die Absorption des Farbstoffes wird anschließend photometrisch bei einer Wellenlänge $(\lambda)$ von $595 \mathrm{~nm}$ gemessen und anhand einer parallel erstellten Standardkurve die Proteinkonzentration errechnet. Für Gesamtprotein-proben, isoliert aus MN9D-Zellen, wurde eine 1:20, eine 1:40 sowie eine 1:80 Verdünnung in A. bidest verwendet. Stammte die Probe von primären Neurospheres, so wurde aufgrund der erwarteten geringen Konzentration ein 1:5 und eine 1:10 Verdünnung in A. bidest verwendet. Die Regressionsgerade wurde anhand der Absorptionen $\left(A_{595 \mathrm{~nm}}\right)$ einer BSA-Reihe bekannter Konzentration erstellt $(0,1 \mathrm{mg} / \mathrm{ml}, 0,3 \mathrm{mg} / \mathrm{ml}, 0,5 \mathrm{mg} / \mathrm{ml}, 0,7 \mathrm{mg} / \mathrm{ml}$ sowie $1 \mathrm{mg} / \mathrm{ml} \mathrm{A}$. bidest). Zu jeweils $25 \mu \mathrm{l}$ der Verdünnung wurde $1 \mathrm{ml}$ des 1 fach konzentrierten Bradford-Reagenz zugegeben und die Ansätze gut gemischt. Nach einer Inkubation von 10 min bei RT wurden die Proben in Einwegküvetten überführt, Luftblasen entfernt und die Absorption der Proben bei einer Wellenlänge von $\lambda=595 \mathrm{~nm}$ gemessen. 


\subsubsection{Größenabhängige Auftrennung von Proteinen durch diskontinuierliche SDS- Polyacrylamidgelelektrophorese (SDS-PAGE)}

Die Auftrennung der Proteinproben erfolgte durch diskontinuierliche SDS-PAGE in einer Mini-Protean-Gelapparatur (Bio-Rad). Nach Entfettung der beiden Glasplatten $(7 \times 8,3 \mathrm{~cm} \times 0,1 \mathrm{~cm})$ wurden Abstandhalter $(0,5 \mathrm{~cm}$ Breite $\times 0,15 \mathrm{~cm}$ Tiefe) links und rechts zwischen die Glasplatten eingefügt, die Glasplatten in die Gelhalterung eingesetzt und schließlich in die Gießvorrichtung eingespannt. Die vorbereitete Lösung des Trenngels wurde zum Starten der Polymerisationsreaktion mit $50 \mu \mathrm{l}$ APS (10\% Ammoniumpersulfat) und $20 \mu$ l TEMED versetzt, gut gemischt und bis zu einem Abstand von ca. $2 \mathrm{~cm}$ zur oberen Glaskante zwischen die Glasplatten pipettiert. Bis zur vollständigen Polymerisation wurde das Trenngel mit Butanol überschichtet. Nach $20 \mathrm{~h}$ wurde das Butanol durch mehrmaliges Spülen mit A. bidest entfernt und restliche Flüssigkeit mit etwas Vliespapier abgesogen. Danach wurde der Probenkamm zur Bildung der Auftragstaschen zwischen die Glasplatten eingesetzt. Der angesetzten Lösung des Sammelgels wurden $50 \mu \mathrm{l}$ APS (10\%) und $20 \mu \mathrm{l}$ TEMED (Tetramethylethylendiamin) zugefügt, die Lösung gevortext und mit einer $1 \mathrm{ml}$ Pipette langsam an der Seite des Probenkammes auf das Trenngel pipettiert.

\section{9\%iges Trenngel}

\begin{tabular}{|c|c|c|c|}
\hline $4 \times$ Tris/HCl-SDS; pH 8,8 & $3,75 \mathrm{ml}$ & $4 \times$ Tris/HCl-SDS pH 6,8 & $3,50 \mathrm{ml}$ \\
\hline A. bidest & $6,75 \mathrm{ml}$ & A. bidest & 7,16 \\
\hline Bisacrylamid (30\%) & $4,50 \mathrm{ml}$ & Bisacrylamid (30\%) & 0,65 \\
\hline $10 \%$ APS & $50 \mu \mathrm{l}$ & $10 \%$ APS & 50 \\
\hline TEMED & $20 \mu \mathrm{l}$ & TEMED & 20 \\
\hline
\end{tabular}

Nach erfolgter Polymerisation des Sammelgels wurde das Gel aus der Gießapparatur genommen, in die Elektrophoresekammer eingesetzt und diese mit $1 \times$ Laufpuffer bis zur oberen Gelkante gefüllt. Der Probenkamm wurde vorsichtig entfernt und die Geltaschen mittels einer $25 \mu \mathrm{l}$-Hamilton-Spritze mit Laufpuffer gespült. Die Proteinproben wurden nun mit $6 \times$ Protein-Probenpuffer versetzt und bei $95^{\circ} \mathrm{C}$ für 5 min denaturiert und direkten an die Denaturierung anschließend auf Eis gekühlt. Die Volumina der Proteinproben wurden nun in die Geltaschen pipettiert. Zur Abschätzung des Molekulargewichtes wurden $8 \mu \mathrm{l}$ des „prestained“-Protein-Standards (BioRad) mitaufgetragen. Die Elektrophorese wurde bei $90 \mathrm{~V}$ begonnen und nachdem die Proben das Trenngels erreicht hatten, wurde die 
Spannung auf 120 V erhöht. Sobald die Lauffront die untere Gelkante erreicht hatte, wurde die Elektrophorese beendet.

\subsubsection{Western-Blot-Analyse}

Gegen Ende der elektrophoretischen Auftrennung der Proteinproben wurde eine PVDF-Membran in der Größe des Trenngels zugeschnitten und für den Proteintransfer vorbereitet. Hierzu wurde die Membran zunächst für $1 \mathrm{~min}$ in Methanol gelegt und schließlich bis zum Aufbau des Transfers in Transferpuffer äquilibriert. Nach Beendigung der SDS-PAGE wurde das Gel der Kammer entnommen und das Trenngel mittels Skalpell vom Sammelgel getrennt. Der Blot wurde von Kathode zu Anode in einem „Blotsandwich“ wie folgt aufgebaut: Begonnen wurde mit einem puffergetränkten Schwämmchen, hierauf wurde ein angefeuchtetes Whatman-Papier gegeben und auf dieses die PVDF-Membran. Nun wurde auf die Membran das Trenngel gelegt und die obere linke Kante der Membran gekennzeichnet. Auf das Trenngel wurde ein weiteres, puffergetränktes Whatman-Papier gegeben. Zur Entfernung möglicher Luftblasen wurde vorsichtig eine Pipette über den Transferaufbau gerollt. Zuletzt wurde ein nasses Schwämmchen aufgelegt und der „Blotsandwich“ geschlossen. Dieser wurde nun in die Blotapparatur zwischen Anode und Kathode so eingesetzt, dass das Trenngel sich auf der Seite der Kathode befand. Die Kammer wurde vollständig mit Transferpuffer gefüllt. Mit Hilfe eines Magnetrührers wurde das Durchmischen des Transferpuffers sichergestellt. Der Transfer erfolgte ü. N. bei $18 \mathrm{~V}$ und $4{ }^{\circ} \mathrm{C}$.

Nach Beendigung des Proteintransfers wurde die PVDF-Membran entnommen und zur Überprüfung des Transfers für $1 \mathrm{~min}$ in Ponceau S-Lösung geschwenkt. Nach unspezifischer Anfärbung der Proteine wurde die Membran solange in A. bidest gewaschen, bis einzelne Banden sichtbar wurden. Zur Entfärbung der Membran wurde diese dreimal kurz in PBS $(0,1 \%$ Tween-20) gewaschen. Die nachfolgenden Inkubationsschritte und Waschungen des Western-Blots erfolgten unter stetigem, leichtem Schwenken auf einem Horizontalschüttler bei 200 Upm. Die PVDF-Membran wurde zweimal für 5 min in TTBS $(0,1 \% \mathrm{MP})$ gewaschen, woran sich ein 15 minutiger Waschschritt anschloss. Die Absättigung der Membran wurde durch Inkubation in TTBS mit $3 \%$ MP für $8 \mathrm{~h}$ bei $4^{\circ} \mathrm{C}$ vorgenommen. Hiernach erfolgte die Bindung des primären Antikörpers. Es wurde ein polyklonaler, in Kaninchen hergestellter und gegen Sim1 gerichteter Antikörper in einer Verdünnung von 1:1000 in TTBS $(0,1 \% \mathrm{MP})$ benutzt. Die Bindung des Primärantikörpers an das Sim1-Epitop erfolgte ü. N. bei $4^{\circ} \mathrm{C}$ unter kontinuierlichem, leichten Schwenken. Am darauffolgenden Tag wurde die Membran mehrmals wie zuvor beschrieben gewaschen. Als sekundärer 
Antikörper wurde ein an HRP-gebundener, in Ziege hergestellter Antikörper und gegen Kaninchen gerichteter Antikörper der Immunglobulinklasse $G$ benutzt, der in einer Verdünnung von 1:10000 in TTBS verwendet wurde. Zur Antikörperbindung wurde die Membran in dieser Lösung für $1 \mathrm{~h}$ bei RT unter Schwenken inkubiert. Nach mehrmaligem Waschen in TTBS wurde die indirekte Detektion der Proteine durch Peroxidase-vermittelter Chemilumineszenz durchgeführt. Hierzu wurde der Puffer abgegossen, überschüssige Feuchtigkeit mit Filterpapier abgesogen und mit der ECL-(„Enhanced chemiluminescense“)Reaktionslösung bedeckt. Nach einer Inkubation von 1 min bei RT wurde die Membran zwischen zwei Folien gelegt und mit einem weichen Tuch entstandene Luftblasen beseitigt. Herausfließende Flüssigkeit wurde entfernt und die Membran in eine Filmkassette gelegt. Je nach Signalintensität wurde bei Verwendung von X-Omat/Blue (Kodak) für eine Dauer von $1 \mathrm{~min}$ bis $\mathrm{zu} 1 \mathrm{~h}$ exponiert und die Filme manuell entwickelt. Zur Überprüfung der Gleichmäßigkeit der verwendeten Proteinproben wurde ein Western-Blot für das „Housekeeping"-Gen Gapdh in gleicher Weise durchgeführt. Zur Anwendung kam hierbei ein gegen Gapdh gerichteter, monoklonaler und in Maus hergestellter Primärantikörper in einer Verdünnung von 1:1000. Als sekundärer Antikörper wurde ein gegen Maus gerichteter, an HRP-gebundener Antikörper der Immunoglobinklasse G verwendet, welcher 1:1000 in TTBS verdünnt wurde. Die Entwicklung des Western-Blot erfolgte wie oben beschrieben, die Belichtungszeit lag im Sekundenbereich.

\subsubsection{Statistische Auswertung}

Die in dieser Arbeit dargestellten Daten der Zellzählung und qRT-PCR sind als Mittelwert \pm SEM („Standard error of the mean“) wiedergegeben. Die Unterschiede in der Anzahl der 5-HT-immunpositiven Zellen in den experimentellen Gruppen, wt- und Sim1defiziente Mäuse sowie Unterschiede der Expressionswerte der cDNA-Proben eines Zeitpunktes aus „Gain-of-function“- und "Loss-of-function“-Experimenten und ihrer entsprechenden Kontrollen, wurden mit Hilfe des zweiseitigen "Student's t-test" unter Annahme einer Normalverteilung auf ihre Signifikanz hin untersucht. Unterschiede zwischen mehreren experimentellen Gruppen, wie z. B. Expressionsdaten nach Behandlung von primären Zellkulturen mit Faktoren, wurden durch den „One-Way“-Anova- und Bonferronipost-hoc-Test bestimmt. Statistische Signifikanz wurde wie folgt angenommen: ${ }^{*} P<0,05$, ${ }^{* *} P<0,01,{ }^{* *} P<0,001 . P>0,05$ wurde als statistisch nicht signifikant angesehen (n. s.). 


\section{Ergebnisse}

\subsection{Etablierung und Charakterisierung eines Kultursystems primärer Neurospheres aus dem ventralen rostralen Rhombencephalon der Maus (E12)}

\subsubsection{Morphologie primärer Neurospheres aus dem ventralen rostralen Rhomben- cephalon der Maus (E12)}

Pluripotente neurale Vorläuferzellen besitzen die Fähigkeit zu proliferieren und sich in unterschiedliche neurale Zelltypen, d. h. Neurone, Astrozyten und Oligodendrozyten, zu differenzieren (Uchida et al., 2000; Weissman, 2000). Aufgrund ihres Proliferationsvermögens bilden sie unter Einfluss von Mitogenen Neurospheres (Reynolds und Weiss, 1992; Morshead et al., 1994; Palmer et al., 1997; Gage, 2000; Roisen et al., 2001; Roussa et al., 2006). Um zu untersuchen, ob isolierte Zellen aus dem ventralen rostralen Rhombencephalon in der Lage sind, primäre Neurospheres zu bilden, wurde Gewebe dieser Gehirnregion mechanisch und enzymatisch in Einzelzellen dissoziiert (siehe hierzu Punkt 4.2.3.1., Seite 44). Eine auf diese Weise gewonnene Zellsuspension wurde in Gegenwart der Mitogene Fgf2 und Egf unter serumfreien Bedingungen kultiviert. Hierbei wurde den Zellen keine die extrazelluläre Matrix (EZM) nachahmende Oberfläche geboten. In Abb. 5 (Seite 80) sind die sich bildenden, primären Neurospheres aus dem ventralen rostralen Rhombencephalon der Maus (E12) als kugelförmige Zellaggregate unterschiedlicher Größe zu erkennen. Diese Zellaggregate ließen sich bereits nach vier Tagen in Kultur beobachten. Zum Großteil lagen die primären Neurospheres aus dem ventralen rostralen Rhombencephalon der Maus (E12), wie in Abb. 5A dargestellt, freischwimmend vor. Lediglich vereinzelt traten adherente, primäre Neurospheres auf, wie es in Abb. 5A exemplarisch durch einen Pfeil angezeigt ist. Die Bildung primärer Neurospheres beruht möglicherweise auf der Proliferationsaktivität vereinzelter, in der Zellsuspension enthaltener neuraler Stamm- und Vorläuferzellen als Antwort auf Fgf2 und Egf. Nur selten, wie in Abb. 5B durch einen Stern markiert, befanden sich in der Kultur neben primären Neurospheres auch Zellen, die aufgrund der mechanischen und enzymatischen Dissoziation des Ausgangsgewebes nicht überlebten. 

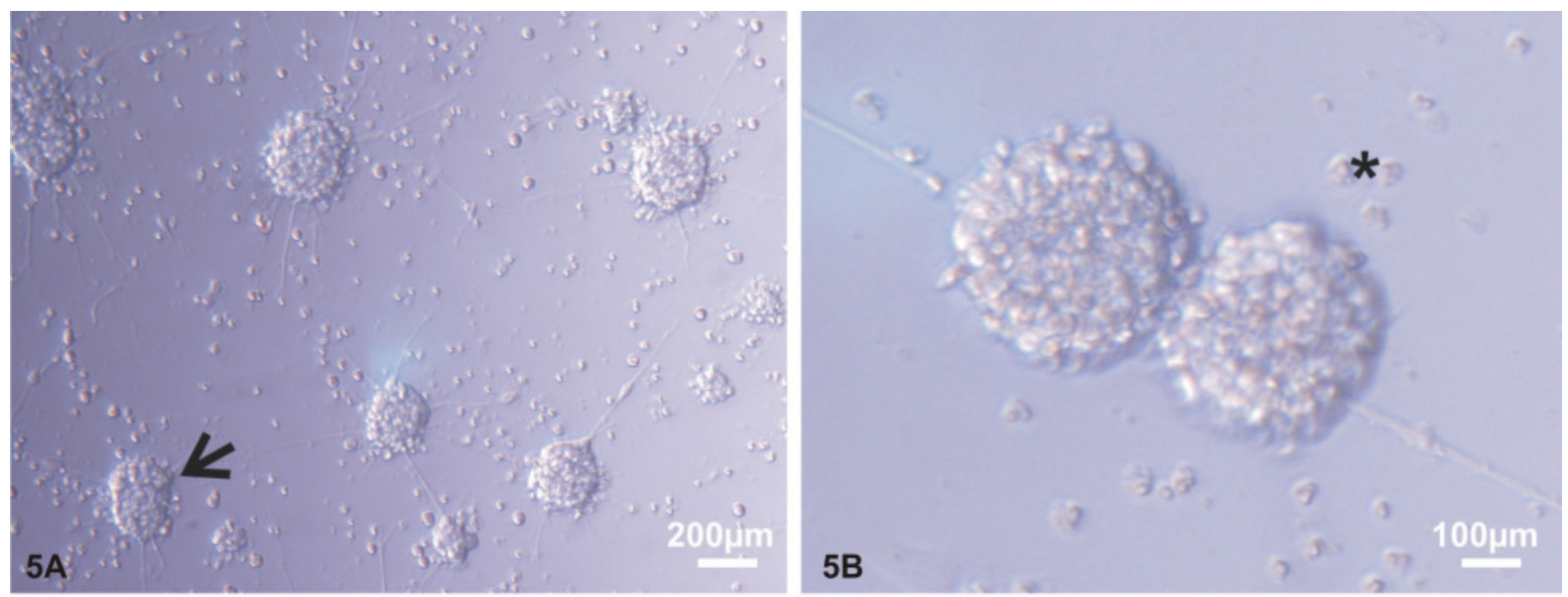

Abb. 5: Zellen des ventralen rostralen Rhombencephalon der Maus des Embryonaltages (E) 12 besitzen die Fähigkeit zur Bildung primärer Neurospheres A: Unter serumfreien Kulturbedingungen in Gegenwart von Fgf2 und Egf entstehen frei-schwimmende, primäre Neurospheres. Vereinzelt treten adherente Neurospheres auf (Pfeil). B: Morphologie primärer Neurospheres in höherer Vergrößerung. Nur wenige nicht vitale Zellen sind zu erkennen (Stern).

\subsubsection{Bildung sekundärer Neurospheres}

Um zu überprüfen, ob primäre Neurospheres des ventralen rostralen Rhombencephalon der Maus E12 aufgrund der Proliferation von pluripotenten, zur Selbsterneuerung befähigten Vorläuferzellen, entstanden, wurden die primären Neurospheres enzymatisch und mechanisch in einzelne Zellen dissoziiert (siehe Punkt 4.2.3.6, Seite 50). Die hierdurch erhaltenen Zellen wurden erneut unter serum-freien Bedingungen in Anwesenheit der Mitogene Fgf2 und Egf kultiviert. Die Kultur in einer geringen Zelldichte von $5 \times 10^{3}$ Zellen/Kammer einer 48-Kammerplatte ermöglichte die zeitliche Verfolgung einzelner, jedoch nicht klonaler Zellen. Abb. 6 (Seite 81) zeigt die Entwicklung eines sekundären Neurosphere über einen Zeitraum von 22 Tagen hinweg. Ließen sich primäre Neurospheres des ventralen rostralen Rhombencephalon bereits nach vier Tagen beobachten, so konnten im Gegensatz hierzu sekundäre Neurospheres, wie in Abb. 6A gezeigt, erst nach einer Kulturdauer von 12 Tagen festgestellt werden. Diese sekundären Neurospheres sind zunächst noch sehr klein. Abb. 6B gibt das Entwicklungsstadium des selben sekundären Neurospheres (Abb. 6A) nach weiteren drei Tagen ( „Day in vitro“ 15, DIV15) wieder. Deutlich ist die Größenzunahme aufgrund eine Erhöhung der Zellzahl erkennbar. Noch offensichtlicher ist diese Zellzahlzunahme sieben Tage später (DIV22) wie sie in Abb. 6C aufgezeigt ist. Die Bildung sekundärer Neurospheres ist ein weiterer Hinweis auf die Existenz neuraler Vorläuferzellen in Zellpräparationen aus dem ventralen rostralen Rhombencephalon der Maus (E12). 


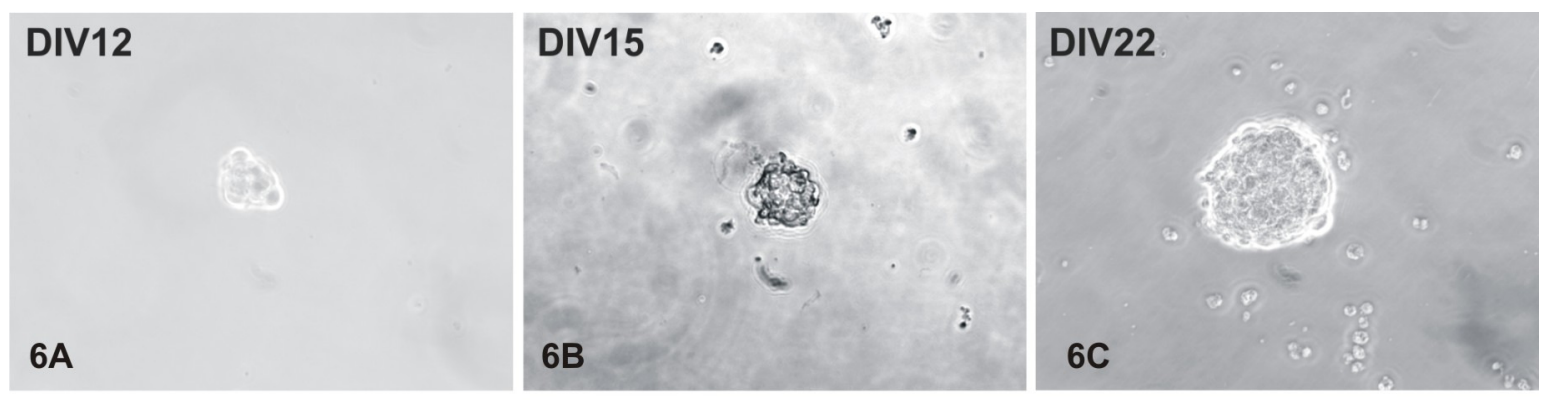

Abb.: 6A-C: Darstellung der zeitlichen Entwicklung (DIV "Day in vitro" 12-22) eines sekundären Neurospheres aus dissoziierten, primären Neurospheres des ventralen rostralen Rhombencephalon der Maus (Embryonaltag, E12) unter Einfluss der Mitogene Fgf2 und Egf sowie serumfreier Kulturbedingungen.

\subsubsection{Primäre Neurospheres aus dem ventralen rostralen Rhombencephalon der Maus (E12) besitzen Proliferationspotential}

Um nachzuweisen, dass Zellen primärer Neurospheres aus dem ventralen rostralen Rhombencephalon der Maus (E12) zur Proliferation befähigt sind, wurde zusätzlich ein Bromdesoxyuridin-(BrdU)-Inkorporationsassay durchgeführt. BrdU ist ein chemisches, putativ mutagenes und zytotoxisches Analogon des Nukleosids Thymidin. Dieses Analogon wird in der Zelle phosphoryliert und anstelle des Nukleotids Desoxythymidintriphosphat (dTTP) im Zuge der Chromatiden-Replikation während der mitotischen S-Phase in die neu zu synthetisierende DNA eingebaut. Nach Denaturierung der genomischen DNA ermöglicht eine anschließende, immunzytochemische Nachweisreaktion die Markierung proliferierender, BrdU-positiver Zellen.

Primäre Neurospheres des ventralen rostralen Rhombencephalon der Maus (E12) wurden für eine Zeitspanne von 2 h, 4 h, 6 h und 8 h nach Zugabe von BrdU (Endkonzentration: $10 \mu \mathrm{M})$ zum Medium ohne Serum, unter Fgf2 und Egf Einfluss inkubiert (siehe Punkt 4.2.3.8., Seite 51). Um die BrdU-Inkorporation zu beenden, wurden die primären Neurospheres auf PORN-/Laminin-beschichtete Deckgläschen ohne eine vorangegangene Dissoziation plattiert. Nach Fixierung durch Ethanol/Glycin, und somit gleichzeitige Denaturierung der genomischen DNA, wurden die primären Neurospheres schließlich der immunzytochemischen Detektion des BrdU zugeführt. Verwendet wurde hierzu ein spezifisch gegen BrdU gerichteter monoklonaler, in Maus hergestellter primärer Antikörper. Als sekundärer Antikörper dienten im Esel hergestellte und gegen Maus gerichtete Immunglobuline der Klasse G, welche an FITC-gekoppelt waren. Die Abbildungen 7A-C (Seite 83) zeigen BrdU-positive Zellen (grün), wie sie nach 2 h, 4 h und 6 h BrdUBehandlung immunzytochemisch nachgewiesen werden konnten. Deutlich ließen sich zu 
allen drei Zeitpunkten eine Vielzahl proliferierender, BrdU-positiver Zellen feststellen. Darüber hinaus konnten auch nicht-fluoreszierende und somit sich nicht in der Zellteilung befindliche Zellen beobachtet werden. Neurale Vorläuferzellen lassen sich auch durch den immunzytochemischen Nachweis des spezifischen Neurofilaments, Nestin (Lendahl et al., 1990), markieren. Um Nestin exprimierende Vorläuferzellen in primären Neurospheres nachzuweisen, wurden primäre Neurospheres aus dem ventralen rostralen Rhombencephalon der Maus (E12), wie unter Punkt 4.2.3.3. (Seite 47) beschrieben, dissoziiert und auf PORN-/Laminin-beschichtete Deckgläschen ausplattiert. Nach dreitägiger Kultur wurden die Zellen durch PFA fixiert und immunzytochemisch untersucht (Punkt 4.2.4., Seite 53). Als primärer Antikörper wurde ein monoklonaler, gegen Nestin gerichteter, in Maus hergestellter Antikörper verwendet. Als sekundärer Antikörper dienten in der Ziege hergestellte und gegen Maus gerichtete Immunglobuline der Klasse $G$, welche an Cy3-gebunden vorlagen. Das Ergebnis des immunzytochemischen Nachweises von Nestin ist in Abb. 7D dargestellt. Eine hohe Anzahl Nestin-positiver Zellen konnte in der dissoziierten Kultur primärer Neurospheres beobachtet werden. Diese Zellen wiesen die für das Neurofilament Nestin charakterisitische, zytoplasmatische Immunreaktivität auf. Es handelt sich somit wahrscheinlich um Vorläuferzellen. Neben diesen Zellen konnten auch Nestin-immunnegative Zellen in der Kultur festgestellt werden. 


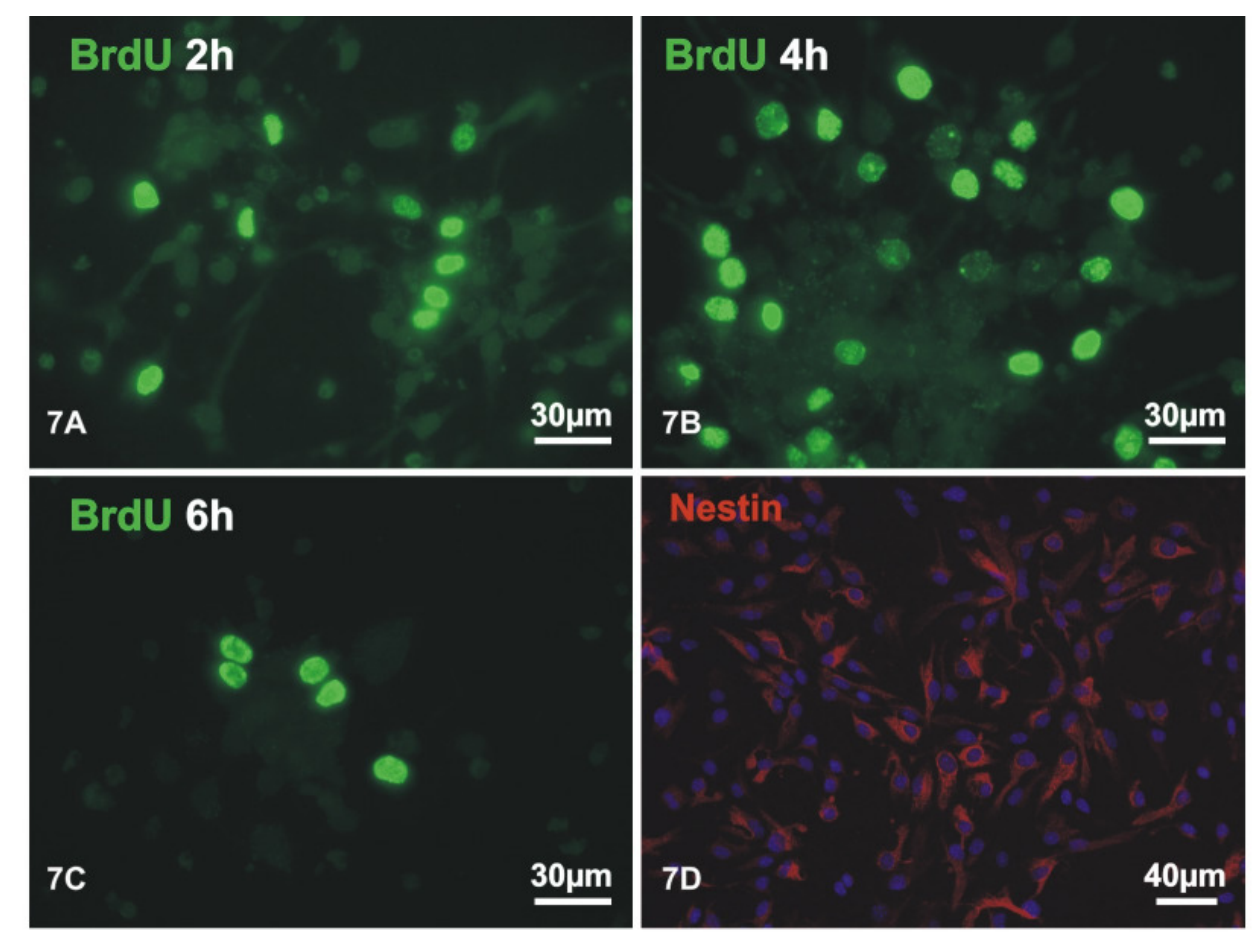

Abb. 7: Zellen primärer Neurospheres des ventralen rostralen Rhombencephalon der Maus (E12) besitzen die Fähigkeit zur Proliferation. A-C: Immunzytochemische BrdU-Detektion (grün) in ausplattierten primären Neurospheres 2 h, 4 h und 6 h nach externer BrdU-Gabe (Endkonzentration $10 \mu \mathrm{M})$. D: Darstellung von Vorläuferzellen innerhalb dissoziierter, primärer Neurospheres DIV („Day in vitro") 3 des ventralen rostralen Rhombencephalon (Maus, E12) mittels immunzytochemischer Detektion des spezifischen, neuralen Vorläuferzellmarkers Nestin (rot).

\subsubsection{Zelluläre Zusammensetzung primärer Neurospheres aus dem ventralen rostralen Rhombencephalon der Maus (E 12)}

Um eine exakte und durch angrenzende Gewebe nicht kontaminierte Präparation des verwendeten ventralen rostralen Gewebes des Rhombencephalon der Maus (E12) sicherzustellen, wurde zunächst die Expression der Gene Otx2 und Gbx2 (Millet et al., 1999; Wassarman et al., 1997) in primären Neurospheres und entsprechendem, primärem Gewebe des ventralen rostralen Rhombencephalon der Maus (E12) mittels Polymerasekettenreaktion und spezifischen Primern (Punkt 4.1.4., Seite 26) nach vorangegangener reverser Transkription (RT-PCR) analysiert. Abb. 8A (Seite 86) zeigt das Ergebnis der Amplifikation des Otx2- bzw. Gbx2-Gens in cDNA-Proben primärer Neurospheres und entsprechendem primärem Gewebe. Weder in primären Neurospheres (Spur 4), noch in primärem Gewebe (Spur 5) ließ sich eine Expression des mesencephalen Markergens Otx2 (334 bp) nachweisen. Gbx2 ist ein spezifisches Markergen des Rhombencephalon und, wie Otx2, an 
der Ausbildung des IstO beteiligt. In Abb. 8A (Spur 6) konnte deutlich eine Gbx2-Expression (407 bp) in primären Neurospheres aus dem ventralen rostralen Rhombencephalon detektiert werden. Ebenso ließ sich in Abb. 8A (Spur 7) eine deutliche Gbx2-Expression in primärem Gewebe erkennen. Diese Ergebnisse belegen, dass die Präparation primären Gewebes des ventralen rostralen Rhombencephalon der Maus (E12) nicht durch angrenzende mesencephale Gewebebereiche verunreinigt war.

Obwohl primäre Neurospheres hinsichtlich der in innen enthaltenen Vorläuferzellen angereichert sind, besitzen primäre Neurospheres eine heterogene zelluläre Zusammensetzung. Dies basiert nicht zuletzt auf der charakteristischen Fähigkeit neuraler Vorläuferzellen, sich in unterschiedliche neurale Zelltypen, d. h. in Neurone und gliale Zellen, zu differenzieren (Uchida et al., 2000; Weissman, 2000). Um die zelluläre Zusammensetzung primärer Neurospheres des ventralen rostralen Rhombencephalon der Maus (E12) näher zu untersuchen, wurde ein Vergleich der Genexpressionen zwischen diesen primären Neurospheres und primärem Gewebe des gleichen rhombencephalen Ursprunges vorgenommen. Die Genexpression bekannter Markergene unterschiedlicher neuraler Zelltypen wurde hierzu ebenfalls mittels RT-PCR bestimmt (siehe Punkt 4.2.6.8, Seite 64). Die Ergebnisse der RT-PCR-Analyse sind in den Abbildungen 8B-D dargestellt.

Die Expression des für neurale Vorläuferzellen spezifischen Gens Nestin (438bp) konnte, wie in Abb. 8B dargestellt, sowohl in primären Neurospheres (Spur 2), als auch in primärem Gewebe des ventralen rostralen Rhombencephalon (Spur 3) in gleicher Stärke nachgewiesen werden. Abb. 8B zeigt des Weiteren die Expression von $\beta$-III-Tubulin, einem Neuronen spezifischen Anteil der Mikrotubuli und frühestes Markergen der neuronalen Differenzierung (Caccamo et al., 1989). $\beta$-III-Tubulin (327 bp) konnte mittels RT-PCR in primären Neurospheres (Spur 4) und in primärem Gewebe des ventralen rostralen Rhombencephalon der Maus (E12, Spur 5) detektiert werden. Hierbei lag eine deutlich stärkere Expression dieses Gens in der primärem Gewebepräparation (Spur 5) vor. Eine Expression von Gfap („Glial fibrillic acid protein“, 97 bp), charakteristisch für Astrozyten, konnte hingegen, wie der Abb. 7A zu entnehmen ist, weder in cDNA-Proben primärer Neurospheres (Spur 9), noch im primären Gewebe des ventralen rostralen Rhombencephalon der Maus (E12, Spur 10) detektiert werden.

Aufgrund der Tatsache, dass die Induktion 5-HT-Neurone des ventralen rostralen Rhombencephalon maßgeblich durch Shh, Fgf8 und Fgf4 bestimmt wird (Ye et al., 1998), wurden sowohl primäre Neurospheres als auch primäres Gewebe des ventralen rostralen Rhombencephalon auf eine endogene Genexpression dieser Faktoren hin untersucht. Abb. 8C gibt die Ergebnisse der Analyse der Shh-, Fgf4- und Fgf8-Genexpression in beiden cDNA-Proben wieder. Das Amplifikationsprodukt für Shh (523 bp) konnte in beiden Proben detektiert werden. Die Expression des Gens Shh war jedoch in primären Neurospheres 
(Spur 4) im Vergleich zu primärem Gewebe (Spur 5) deutlich stärker. Fgf4 (355 bp) konnte in seiner Expression hingegen in beiden Proben (Spuren 6 und 7) in gleichem Maße schwach nachgewiesen werden. Im Gegensatz hierzu war die Detektion einer endogenen Expression von Fgf8 (494 bp) nur im primärem Gewebe des ventralen rostralen Rhombencephalon der Maus (E12, Spur 10), nicht jedoch in primären Neurospheres (Spur 9), möglich.

Um zu untersuchen, ob mitotische Vorläuferzellen, welche dem Entwicklungsweg 5-HT-Neurone folgen könnten, vorhanden waren, wurden cDNA-Proben primärer Neurospheres des ventralen rostralen Rhombencephalon (E12) und primären Gewebes gleichen Ursprungs auf die Expression von Genen charakteristischer Transkriptionsfaktoren hin untersucht. Zu diesen Genen zählen Nkx2.2 und Lmx1b. Die Abb. 8C zeigt die Ergebnisse des Expressionsvergleiches dieser Gene zwischen beiden cDNA-Proben. Eine erhöhte Genexpression von Nkx2.2 (374 bp) konnte in primären Neurospheres des ventralen rostralen Rhombencephalon der Maus (E 12, Spur 10) im Vergleich zu primärem Gewebe (Spur 11) gezeigt werden. Ebenfalls gesteigert im Vergleich zu primärem Gewebe (Spur 13) erscheint die Expression von $L m x 1 b$ (492 bp) in primären Neurospheres (Spur 12).

Die Analyse der Expression von Markergenen der postmitotischen Entwicklungsstufe der 5-HT-Neurone zeigte weitere Unterschiede zwischen primären Neurospheres und primärem Gewebe des ventralen rostralen Rhombencephalon von Mausembryonen (E12) auf. Zu den analysierten Markergenen zählten Gata2, als mitotisch und postmitotisch exprimiertes Markergen der rostralen 5-HT-Neuronen Entwicklung, Pet1, als einziges spezifisches, postmitotisches Markergen für 5-HT-Neuronen, und Tph2, als Determinant der terminalen Spezifizierung des 5-HT-Phänotyps. Wie die Abb. 8D veranschaulicht, wurde Gata2 (129 bp) sowohl in primärer Neurospheres (Spur 2) als auch in primärem Gewebe (Spur 3) in gleicher Stärke exprimiert. Hingegen konnte, wie in Abb. 8D dargestellt, sowohl für Pet1 (109 bp, Spur 4) als auch für Tph2 (99 bp, Spur 6) in primären Neurospheres eine erhöhte Genexpression im Vergleich zu primären Gewebe des ventralen rostralen Rhombencephalon von Mausembryonen (E12, Spur 5 bzw. Spur 7) aufgezeigt werden. 

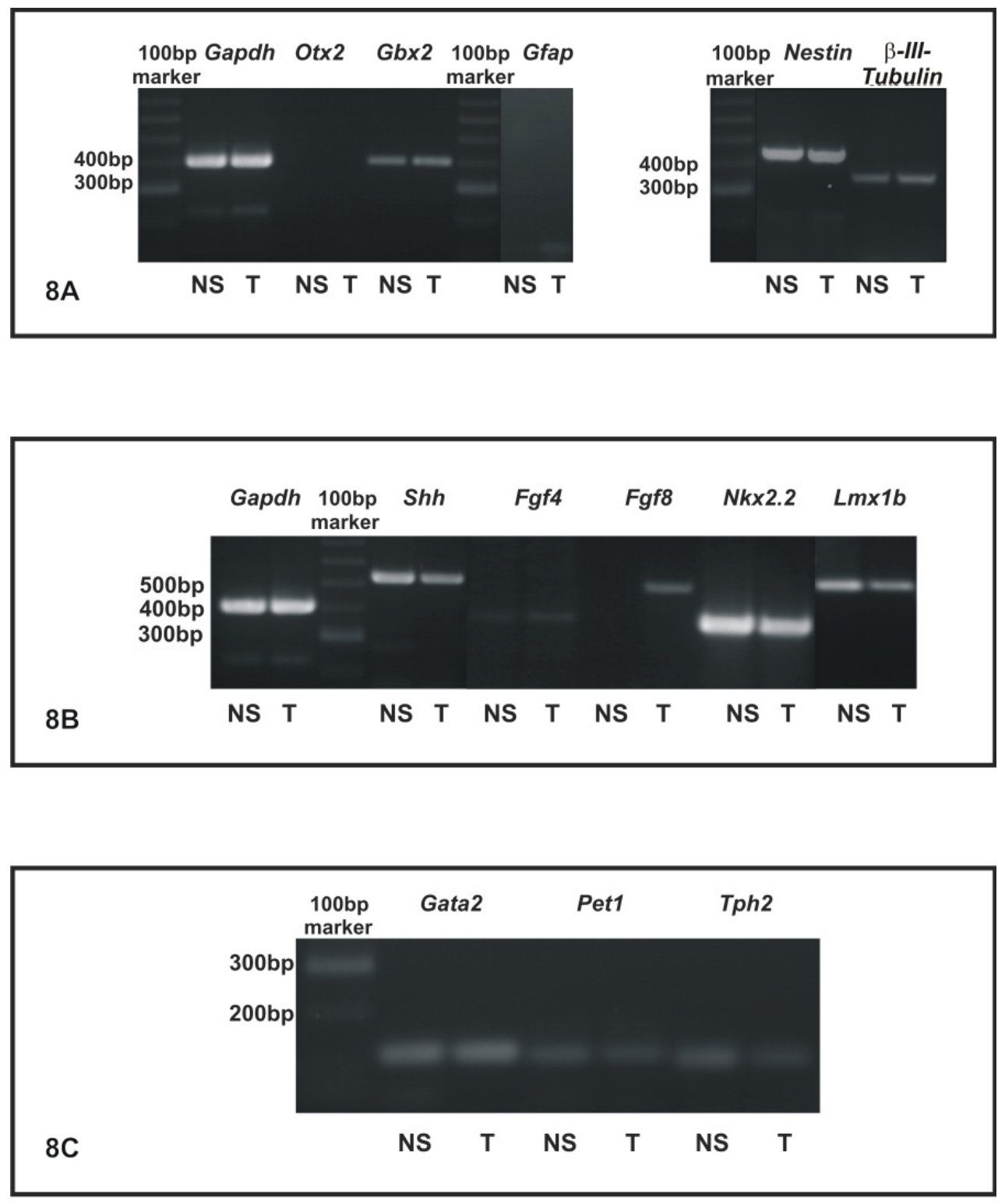

Abb. 8: Vergleich der Genexpression zwischen primären Neurospheres (NS) und primärem Gewebe $(T)$ des ventralen rostralen Rhombencephalon der Maus (E12) mittels Polymerasekettenreaktion und genspezifischer Primer nach vorangegangener reverser Transkription (RT-PCR) A-B: Expression der den Isthmus (IstO) determinierenden Gene Otx2 (Mesencephalon) und Gbx2 (Rhombencephalon) sowie Expression der spezifischen Markergene Gfap (Astrozyten), Nestin (neurale Vorläuferzellen), und $\beta$-III-Tubulin (Neurone). C : Endogene Expression der Signalmoleküle Fgf4, Fgf8 und Shh sowie Expression der Transkriptionsfaktoren $N k x 2.2$ und $L m \times 1 b$ als frühe Determinanten der Entwicklung serotonerger (5-HT-) Neurone D: Analysis der Genexpression von Gata2, frühes postmitotisches Markergen der rostralen 5-HTNeuronenentwicklung, sowie Pet1 und Tph2 als Determinanten der terminalen Differenzierung serotonerger Neuronen. 


\subsubsection{Zellen primärer Neurospheres aus dem ventralen rostralen Rhombencephalon der Maus (E12) besitzen die Fähigkeit zur Differenzierung in unterschiedliche zelluläre Abstammungslinien}

Um die gemischte zelluläre Zusammensetzung primäre Neurospheres des ventralen rostralen Rhombencephalon der Maus (E12) auch auf Ebene der Proteinexpression nachzuweisen, wurden immunzytochemische Färbungen vorgenommen. Hierzu wurden primäre Neurospheres des ventralen rostralen Rhombencephalon der Maus (E12) in Einzelzellen dissoziiert und auf PORN-/Laminin-beschichtete Deckgläschen plattiert (siehe hierzu Punkt 4.2.3.3., Seite 47). Für eine Dauer von drei Tagen wurden die Zellen unter serumfreien Bedingungen kultiviert, wodurch ihre Differenzierung ermöglicht werden sollte. Hiernach wurden die Zellen fixiert und immunzytochemisch die Expression zelltypspezifischer Markerproteine nachgewiesen (Punkt 4.2.4., Seite 53). Die Ergebnisse der immunzytochemischen Untersuchungen sind in den Abb. 9A-C sowie in Abb. 9E (Seite 88) wiedergegeben. Wie der Abb. 9A zu entnehmen ist, waren, wie für diesen Zeitpunkt der Differenzierung zu erwarten, in den dissoziierten Kulturen primärer Neurospheres des ventralen rostralen Rhombencephalon der Maus (E12) nahezu keine Gfap-positiven (rot) Zellen zu beobachten. Im Gegensatz hierzu war, wie die Abb. 9B zeigt, eine hohe Anzahl Vorläuferzellen, repräsentiert durch Nestin-positve (rot) Zellen, innerhalb der Kulturen zu erkennen. In Abb. 9C sind jene Zellen dargestellt, die bereits in die Differenzierung zu Neuronen eingetreten waren, und aufgrund ihrer charakteristischen Immunreaktivität für $\beta$-IIITubulin (grün) markiert werden konnten. Ebenso konnten bereits differenzierte, 5-HTpositive (grün) Zellen, wie Abb. 9D zeigt, innerhalb der Kulturen dissoziierter, primärer Neurospheres nachgewiesen werden.

Um nachzuweisen, ob die sich in Neurone differenzierenden Zellen von proliferierenden Vorläuferzellen innerhalb primärer Neurospheres abstammen, wurde durch BrdU-Inkorporationsversuche in primären Neurospheres und anschließende immunzytochemische Nachweisreaktionen für BrdU sowie für spezifische Markerproteine neuraler Zelltypen untersucht (siehe Punkt 4.2.3.8. und 4.2.4., Seite 51 und Seite 53). Abb. 9E zeigt eine deutliche, zelluläre Kolokalisation von $\beta$-III-Tubulin (rot) und BrdU (grün). Zudem weisen diese Zellen eine deutlich ausgereifte, neuronale Morphologie auf. In Abb. 9F sind Oligodendrozyten, hier repräsentiert durch O4-positive (rot) Zellen, dargestellt. O4 steht für einen Antikörper, der an ein Oligodendrozyten spezifisches, sulfatiertes Glycolipid („Proligodendrocyte antigene“, POA) bindet (Gard und Pfeiffer, 1989). Neben O4-positiven, BrdU-negativen Zellen zeigen einige O4-positive Zellen zugleich eine deutliche BrdU-positive Immunreaktivität (grün). Somit weisen primäre Neurospheres des ventralen rostralen Rhombencephalon der Maus (E12) einerseits eine heterogene zelluläre Zusammensetzung 
auf, und andererseits besitzen die in innen nachgewiesene Vorläuferzellen die Fähigkeit, sich in unterschiedliche neurale Zelltypen zu differenzieren.
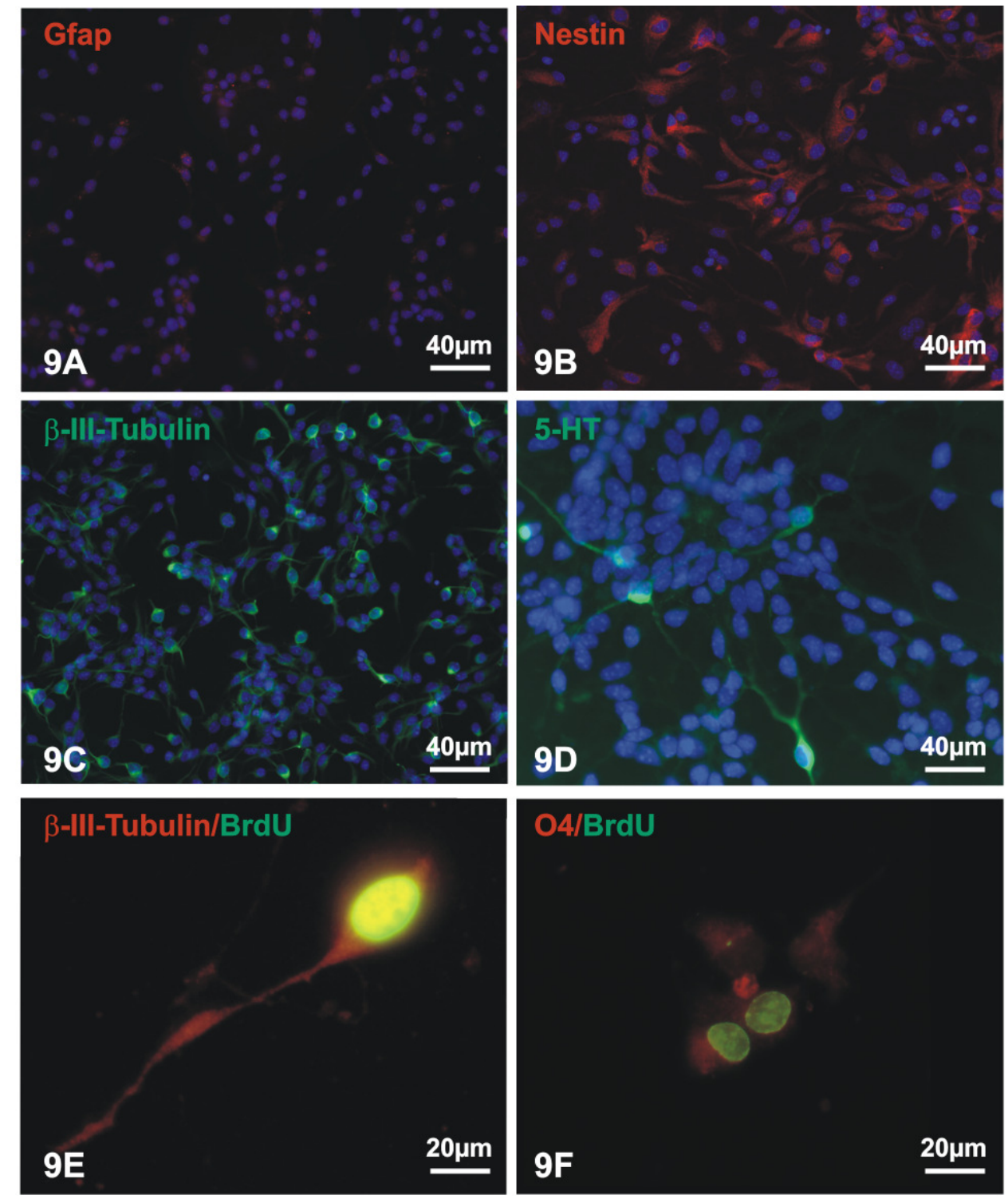

Abb. 9: Primäre Neurospheres des ventralen rostralen Rhombencephalon der Maus (E12) zeigen eine heterogene zelluläre Zusammensetzung. Vorläuferzellen aus primären Neurospheres des ventralen rostralen Rhombencephalon der Maus (E12) besitzen die Fähigkeit zur Differenzierung in gliale und neuronale Zelltypen. A-C: Immunzytochemische Untersuchung von Kulturen dissoziierter, primärer Neurospheres an DIV3 („Day in vitro“ 3), Nachweis von Gfap-positiven Gliazellen (A, rot), von Nestin-immunpositiven Vorläuferzellen (B, rot) und $\beta$-III-Tubulin-immunreaktiven Neuronen (C, grün) D: $\beta$-III-Tubulin-positive Zellen (rot) sind häufig BrdU-positiv (grün) und weisen zudem eine ausgereifte neuronale Morphologie auf (in höherer Vergrößerung) E: Innerhalb der Kulturen finden sich auch Serotonin-(5-HT)-immunpositive Zellen (grün). F: Oligodendrozyten (O4immunpositiv, rot) sind teils BrdU-positiv (grün), teils BrdU-negativ. A-C und E: Kerngegenfärbung durch DAPI (blau). 


\subsection{Einfluss des extrinsischen Signalmoleküls Tgf- $\beta$ auf die Induktion und Spezifikation rostraler serotonerger Neurone des ventralen Rhombencephalon der Maus (E12)}

\subsubsection{In vitro-Beeinflussung der Genexpression von primären Neurospheres des ventralen rostralen Rhombencephalon der Maus E12 durch Behandlung mit Faktoren}

Eine Einflussnahme von Tgf- $\beta$ auf die Steuerung der Induktion und Spezifizierung von 5-HTNeuronen des ventralen rostralen Rhombencephalon der Maus (E12) wurde durch die Behandlung primärer Neurospheres dieses Bereiches durch externe Tgf- $\beta$-Gabe bzw. Blockierung endogener Tgf- $\beta$ s und anschließende qRT-PCR-Analyse der Genexpression der Gene Lmx1b, Gata2 und Pet1 untersucht. Hierzu wurden primäre Neurospheres nach einer Generationszeit von acht Tagen enzymatisch und mechanisch dissoziiert und in einer Zelldichte von $5 \times 10^{5}$ Zellen auf PORN-/Lam-beschichtete $\varnothing 30 \mathrm{~mm}$-Zellkulturschalen ausplattiert (Punkt 4.2.3.9., Seite 52). Am folgenden Tag (DIV1) wurde die Behandlung der Zellen aus primären Neurospheres des ventralen rostralen Rhombencephalon der Maus E12 vorgenommen. Hierzu wurden Zellen mit Tgf- $\beta 1$, in einer Endkonzentration von $1 \mathrm{ng} / \mathrm{ml}$ Komplettmedium, behandelt. Eine weitere Zellprobe erhielt eine Gabe eines gegen alle drei Tgf- $\beta$-Isoformen gerichteten Antikörpers, $\alpha$-Tgf- $\beta 1 / 2 / 3$, in einer Endkonzentration von $10 \mu \mathrm{g} / \mathrm{ml}$ Komplettmedium. Hierdurch wurden endogen synthetisierte Tgf- $\beta \mathrm{s}$ in dieser Zellkultur neutralisiert. Als Kontrolle wurden jeweils Zellen der gleichen Gewebepräparation, aus welcher die primären Neurospheres generiert wurden, eingesetzt, die keiner Behandlung unterzogen wurden. Nach einer Kulturdauer von drei Tagen (DIV3) wurden die Zellen zur Gewinnung der Gesamt-RNA lysiert (Punkt 4.2.6.4., Seite 61).

Zunächst wurde die Änderung der Expression des mitotisch in 5-HT-Progenitoren exprimierten Gens Lmx1b mittels qRT-PCR bestimmt (Punkt 4.2.6.9., Seite 65). Die Änderung der Genexpression drei Tage nach Behandlungsbeginn der dissoziierten und ausplattierten primären Neurospheres des ventralen rostralen Rhombencephalon der Maus (E12) im Vergleich zu unbehandelten Kontrollen (Ctr, blau) ist in Abb. 10 (Seite 90) dargestellt. Die Behandlung durch Tgf- $\beta 1$ (rot: $0,57+0,03 /-0,025 ; P=0,3014$ ) führte nach drei Tagen zu keiner signifikanten Änderung der Expression von $L m x 1 b$ im Vergleich zur Expression in unbehandelten Kontrollen (blau: $1+0,284 /-0,221)$. Eine Behandlung durch $\alpha$-Tgf- $\beta 1 / 2 / 3$ (grün) bedingte in behandelten Zellen eine nahezu vollständige, signifikante Reduktion der Expression von $L m \times 1 b$ auf das 0,09 fache $\left(+0,019 /-0,019 ;{ }^{*} P=0,009\right)$ in Bezug auf unbehandelte Zellen (1+0,284/-0,221). 


\section{$L m \times 1 b$}

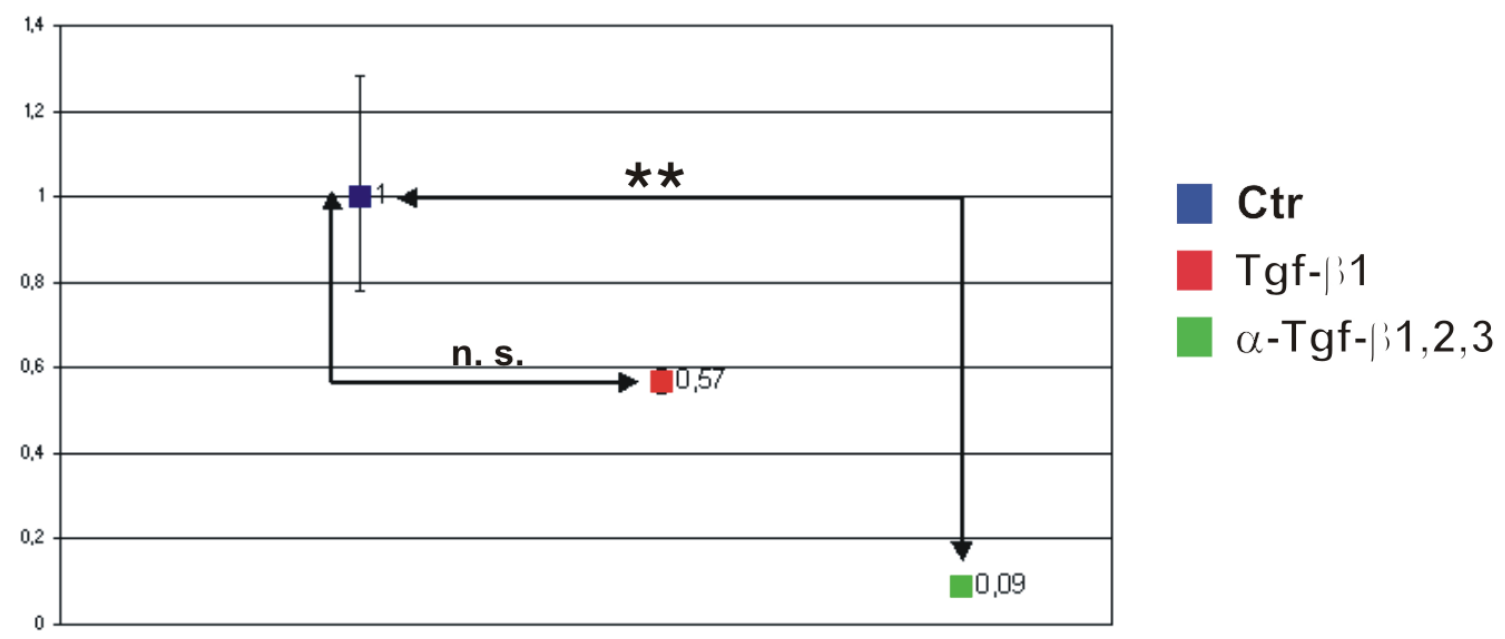

Abb. 10: Quantitative-,,Real-Time“-PCR-(qRT-PCR)-Analyse der Expression des mitotisch in Progenitoren zentraler serotonerger (5-HT-) Neuronen exprimierten Gens $L m \times 1 b$ in einem repräsentativen Versuch. Analysiert wurde cDNA aus dissoziierten und auf PORN-/Lamininbeschichtete $\varnothing 30 \mathrm{~mm}$-Kulturschalen ausplattierte primäre Neurospheres des ventralen rostralen Rhombencephalon der Maus des Embryonaltages (E) 12 nach externer Faktorengabe, Tgf- $\beta 1$ $(1 \mathrm{ng} / \mathrm{ml}$; rot)) und des funktionsblockierenden, gegen alle drei Tgf- $\beta$-Isoformen gerichteten Antikörpers $\alpha$-Tgf- $\beta 1 / 2 / 3$ (10 $\mu \mathrm{g} / \mathrm{ml}$; grün) drei Tage nach Behandlungsbeginn („Day in vitro“ 3 , DIV3). (Bestimmung der relativen RNA-Mengen mittels mathematischer Anwendung der vergleichenden $\Delta \Delta \mathrm{Ct}$ Methode, $\left(2^{-\Delta \Delta \mathrm{Ct}}\right)$, statistische Signifikanz: ${ }^{*} P<0,05 ;{ }^{*} P<0,01 ;{ }^{* *} P<0,001$; statistisch nicht signifikant (n. s.) $P \geq 0,05$ ).

Die Analyse der Expression des frühen, mitotisch und postmitotisch in 5-HT-Neuronen des rostralen Rhombencephalon der Maus exprimierten Transkriptionsfaktors Gata2 wurde ebenfalls mittels qRT-PCR anhand von cDNA-Proben behandelter Zellen aus dissoziierten und ausplattierten primären Neurospheres im Vergleich zu unbehandelten Zellen gleichen Ursprungs vorgenommen. Drei Tage nach Behandlungsbeginn der Zellen durch Tgf- $\beta 1$ (1 ng/ml Komplettmedium) zeigten diese keine wesentliche Veränderung der Expression von Gata2 (rot: 0, $96+0,004 /-0,049 ; P=0,988$ ) im Vergleich zu unbehandelten Zellen (blau: $1+0,081 /-0,075)$. Eine signifikante Reduktion der Gata2-Expression auf das 0,21fache (grün: $\pm 0,002 ;{ }^{* \star *} P=0,0006$ ) in Bezug auf unbehandelte Kontrollen (blau: $1+0,081 /-0,075$ ) ließ sich, wie Abb. 11 (Seite 91) graphisch wiedergibt, nach drei Tagen nach Behandlung der Zellen durch $\alpha$-Tgf- $\beta 1 / 2 / 3$ (10 $\mu \mathrm{g} / \mathrm{ml}$ Komplettmedium, grün) feststellen. 


\section{Gata2}

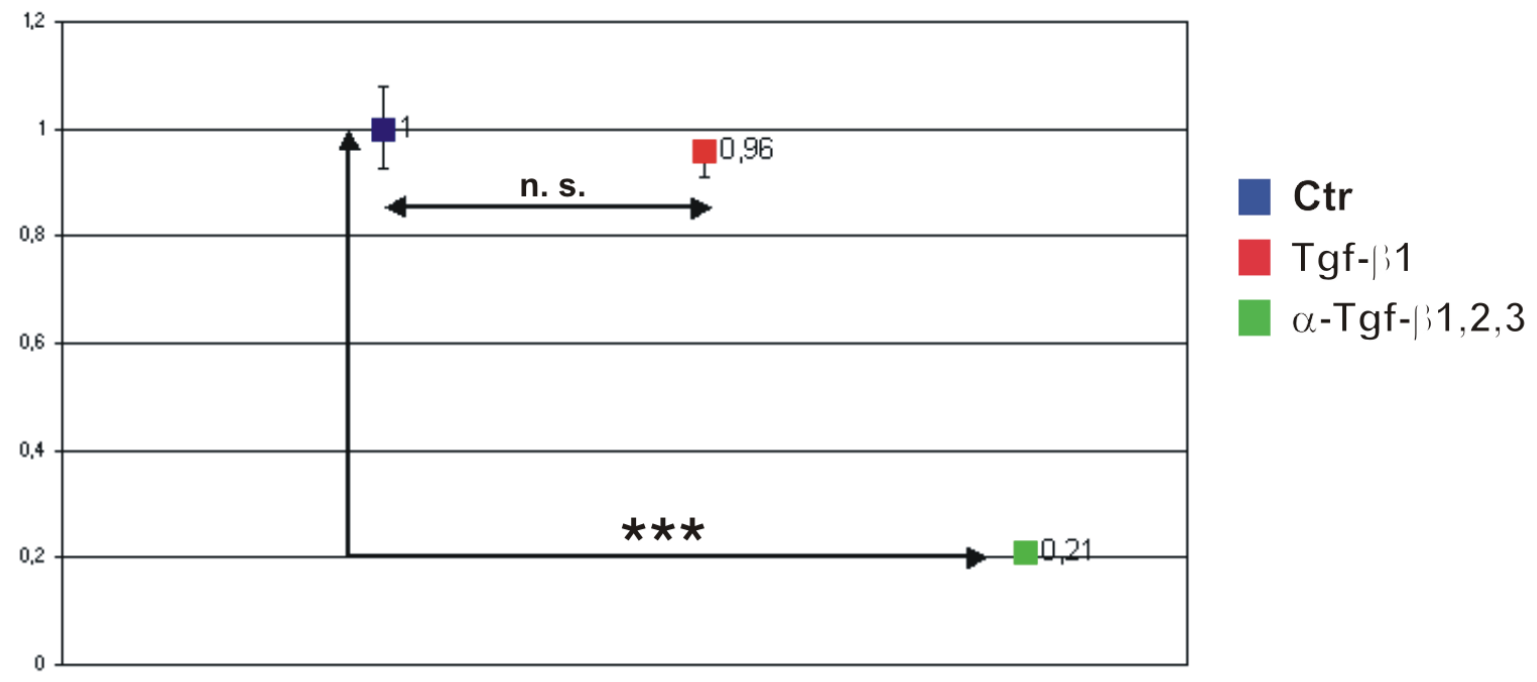

Abb. 11: Quantitative-,,Real-Time“-PCR-(qRT-PCR)-Analyse eines repräsentativen Versuchs der Expression des Gen Gata2 als frühes Markergen der Entwicklung serotonerger (5-HT-) Neuronen in cDNA aus dissoziierten und ausplattierten primären Neurospheres des ventralen rostralen Rhombencephalon der Maus des Embryonaltages (E)12 nach externer Faktorengabe. Als externe Faktoren wurden Tgf- $\beta 1$ ( $1 \mathrm{ng} / \mathrm{ml}$ Komplettmedium; rot) als auch der funktionsblockierende, gegen alle drei Tgf- $\beta$-Isoformen gerichteten Antikörper $\alpha$-Tgf- $\beta 1 / 2 / 3$ (10 $\mu \mathrm{g} / \mathrm{ml}$ Komplettmedium; grün) verwendet. Als Kontrolle dienten unbehandelte Zellen (blau). Drei Tage nach Behandlungsbeginn (,Day in vitro“ 3, DIV3) wurden die Zellen zur Expressionsanalyse eingesetzt. (Bestimmung der relativen RNA-Mengen mittels mathematischer Anwendung der vergleichenden $\Delta \Delta \mathrm{Ct}$ Methode, $\left(2^{-\Delta \Delta C t}\right)$, statistische Signifikanz: ${ }^{*} P<0,05 ;{ }^{* *} P<0,01$; ${ }^{* *} P<0,001$; statistisch nicht signifikant (n. s.) $P \geq 0.05)$.

Zusätzlich zu Gata2 als mitotisch in 5-HT-Vorläuferzellen exprimierter Transkriptionsfaktor wurde auch das 5-HT-Neuronen-spezifische, postmitotisch exprimierte Gen Pet1 in seiner Expression durch Behandlung der Zellen beeinflusst. Wie Abb. 12 (Seite 92) zeigt, kam es in Zellen aus dissoziierten, ausplattierten primären Neurospheres durch Tgf- $\beta 1$ (rot: 0,69 $+0,032 /-0,035 ; P=0,1524)$ zu keiner Änderung der Pet1-Expression im Vergleich zu unbehandelten Zellen (blau: $1+0,254 /-0,203$ ). Hingegen führte die Gabe von $\alpha-$ Tgf- $\beta 1 / 2 / 3$ (grün) nach drei Tagen nach Behandlungsbeginn zu einer signifikanten Reduktion der Expression von Pet1 in den behandelten Zellen im Vergleich zur unbehandelten Kontrolle (blau). Die Reduktion erfolgte auf das 0,3fache $\left(+0,028 /-0,019 ;{ }^{* *} P=0,0054\right)$ des Expressionswertes der unbehandelten Kontrolle $(1+0,254 /-0,203)$. 


\section{Pet1}

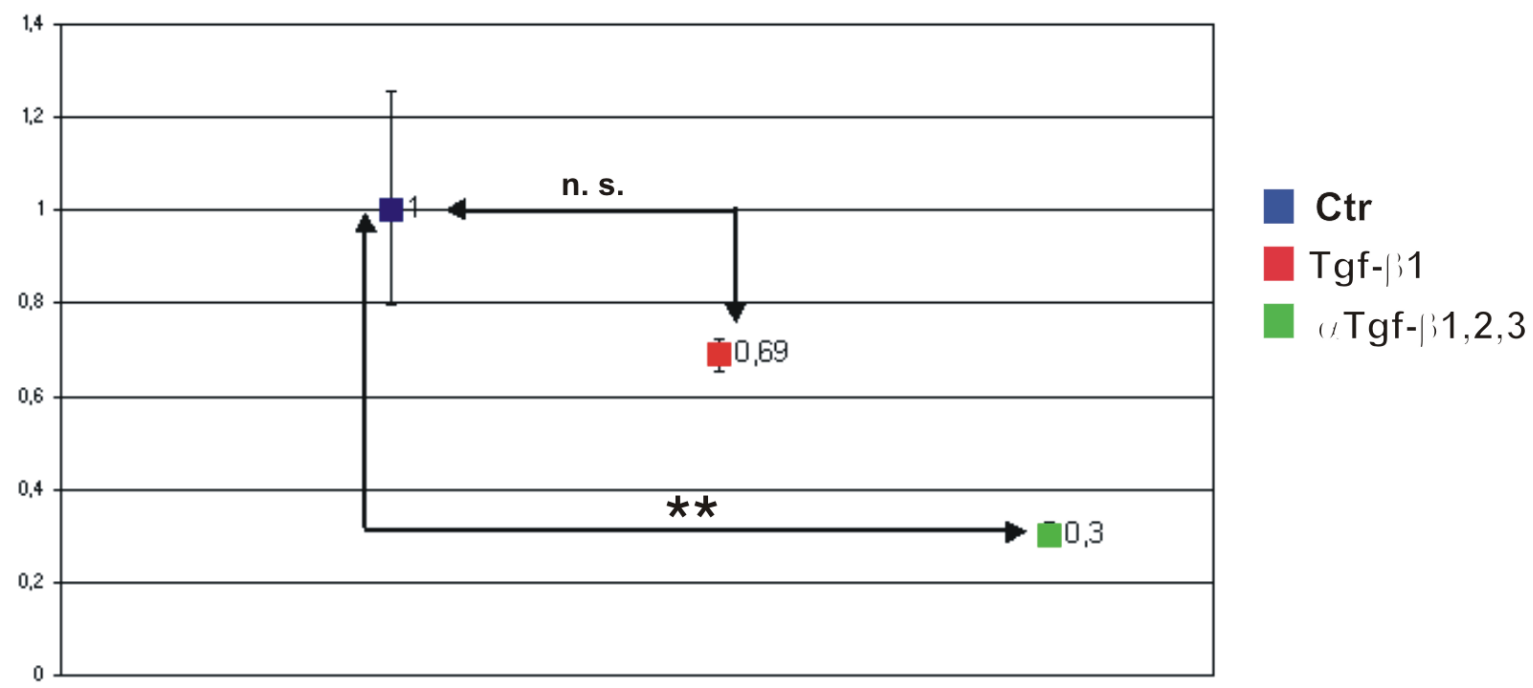

Abb. 12: Quantitative-,,Real-Time“-PCR-(qRT-PCR)-Analyse der Expression eines repräsentativen Versuchs des Gen Pet1 als frühstes spezifisches Markergen serotonerger (5-HT-) Neurone an cDNA aus dissoziierten und ausplattierten primären Neurospheres des ventralen rostralen Rhombencephalon der Maus des Embryonaltages (E)12 nach externer Faktorengabe. Als externe Faktoren wurden Tgf- $\beta 1$ ( $1 \mathrm{ng} / \mathrm{ml}$ Komplettmedium) als auch der funktionsblockierende, gegen alle drei Tgf- $\beta$-Isoformen gerichteten Antikörper $\alpha$-Tgf- $\beta 1 / 2 / 3$ $(10 \mu \mathrm{g} / \mathrm{ml}$ Komplettmedium) verwendet. Drei Tage nach Behandlungsbeginn („Day in vitro“ 3 , DIV3) wurden die Zellen zur Expressionsanalyse eingesetzt. (Bestimmung der relativen RNAMengen mittels mathematischer Anwendung der vergleichenden $\Delta \Delta \mathrm{Ct}$ Methode, $\left(2^{-\Delta \Delta \mathrm{Ct}}\right)$, statistische Signifikanz: ${ }^{*} P<0,05 ;{ }^{* *} P<0,01 ;{ }^{* *} P<0,001$; statistisch nicht signifikant (n. s.) 


\subsubsection{Beeinflussung der Genexpression in vitro von Primärzellen des ventralen rostralen Rhombencephalon der Maus (E12) durch externe Faktoren}

Um zu analysieren, auf welchem molekularen Mechanismus der Einfluss von Tgf- $\beta 2$ auf die Entwicklung von 5-HT-Neurone basiert, wurden die folgenden in vitro-Behandlungen an Primärzellen des ventralen rostralen Rhombencephalon der Maus E12 durchgeführt. Nach Dissoziation des Gewebes des ventralen rostralen Rhombencephalon wurden die Einzelzellen, wie ausführlich unter Punkt 4.2.3.3. (Seite 47) beschrieben, in einer Zelldichte von $3 \times 10^{5}$ Zellen auf PORN-/Lam-beschichtete $\varnothing 12 \mathrm{~mm}$-Deckgläschen ausplattiert, wodurch den Zellen der Eintritt in die Differenzierung ermöglicht wurde. Am folgenden Tag wurden die Zellen, wie unter Punkt 4.2.3.9. (Seite 52) erläutert, durch eine externe Faktorengabe behandelt. Als Kontrolle wurden Zellen der gleichen Präparation verwendet, die jedoch unbehandelt blieben. Eine Zellprobe wurde durch die Gabe von Tgf- $\beta 1$ in einer Konzentration von $10 \mathrm{ng} / \mathrm{ml}$ Komplettmedium behandelt und die Zellen unter serumfreien Bedingungen kultiviert. Des Weiteren erhielt eine dritte Zellprobe eine Gabe des synthetischen Inhibitors SB431242, in einer Endkonzentration von $15 \mu \mathrm{M}$. Diese Inhibitor blockiert die Rezeptoren Alk4 („Activin receptor-like kinase typ l“), Alk5 („,TGF- $\beta$ receptor typ /") und Alk7, wodurch die durch Tgf- $\beta$-induzierte Signaltransduktionskaskade unterbrochen wird (Inman et. al, 2002). Drei Tage nach externer Faktorengabe (DIV3) wurden die Zellen der Isolation der Gesamt-RNA zugeführt (siehe hierzu Punkt 4.2.6.4., Seite 61). Die Veränderung der Genexpression der Gene Gata2 und Pet1 in cDNA-Proben behandelter Primärzellen des ventralen rostralen Rhombencephalon der Maus (E12) im Vergleich zu unbehandelten Zellen wurde durch qRT-PCR ermittelt und sind in nachfolgenden Abb. 13-14 dargestellt.

Abb. 13 (Seite 94) gibt das Ergebnis der Expressionsänderung von Gata2 in dissoziierten Zellen des ventralen rostralen Rhombencephalon der Maus (E12) ohne Expansion der Progenitoren vor dem Ausplattieren der Zellen auf PORN-/Lam-beschichtete Deckgläschen durch Behandlung externer Faktoren wieder. Eine Behandlung der Zellen mit Tgf- $\beta 1$ (rot) führt zu keiner signifikanten Änderung der Gata2-Expression (2,52 +0,128/-0,117; $P=0,1246)$ im Vergleich zur unbehandelten Kontrolle (blau: $1+0,654 /-0,395)$. Wurden die direkt ausplattierten Zellen des ventralen rostralen Rhombencephalon der Maus (E12) mit dem synthetischen Alk4/5/7-Inhibitor SB431542 (violett) behandelt, so führte dies zu einer deutlichen, signifikanten Reduktion der Expression von Gata2 auf das 0,17fache $\left(+0,0016 /-0,003 ;{ }^{*} P=0,0016\right)$ im Bezug auf die Expression von Gata2 in unbehandelten Kontrollen (blau, $1+1,035 /-0,509)$. 


\section{Gata2}

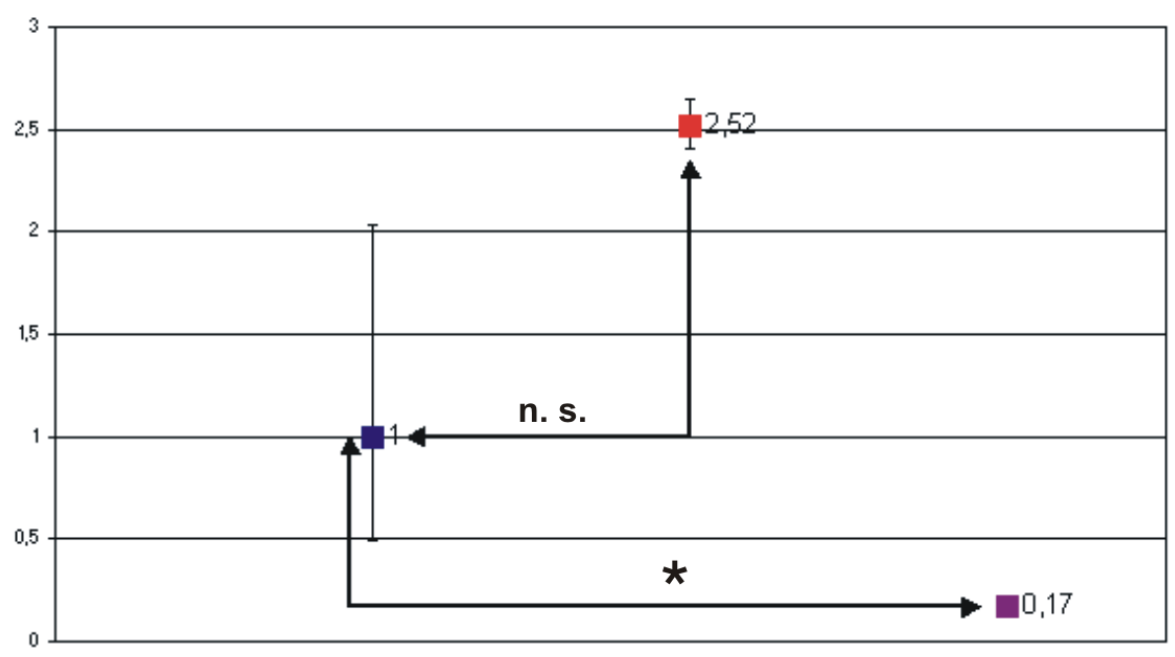

Ctr

Tgf- $\mid 1$

SB431542

Abb. 13: Quantitative-„Real-Time“-PCR-(qRT-PCR)-Analyse eines repräsentativen Versuchs der Expression des Gen Gata2 als frühes Markergen der Entwicklung serotonerger (5-HT-) Neuronen in cDNA aus Primärzellen des ventralen rostralen Rhombencephalon der Maus des Embryonaltages (E)12 nach externer Faktorengabe, Tgf- $\beta 1$ ( $1 \mathrm{ng} / \mathrm{ml}$, rot) und des synthetischen Alk4/5/7-Inhibitors SB431542 (15 $\mu \mathrm{M}$, violett) drei Tage nach Behandlungsbeginn (,Day in vitro 3, DIV3). (Bestimmung der relativen RNA-Mengen mittels mathematischer Anwendung der vergleichenden $\Delta \Delta \mathrm{Ct}$ Methode, $\left(2^{-\Delta \Delta \mathrm{Ct}}\right)$, statistische Signifikanz: ${ }^{*} P<0,05 ;{ }^{* *} P<0,01 ;{ }^{* * *} P<0,001$; statistisch nicht signifikant (n. s.) $P \geq 0,05$ ).

Wie im Falle behandelter, dissoziierter primärer Neurospheres des ventralen rostralen Rhombencephalon der Maus (E12) wurde auch Pet1, als frühestes spezifisches Markergen der 5-HT-Neurone bezüglich einer Expressionsänderung in direkt ausplattierten Zellen des ventralen Rhombencephalon nach drei Tagen nach Behandlung mit Tgf- $\beta 1$ bzw. dem Inhibitor SB431542 analysiert. Das Ergebnis der ermittelten Expressionsänderung ist graphisch in Abb. 14 (Seite 95) dargestellt. Eine Gabe von Tgf- $\beta 1$ (rot) über einen Zeitraum von drei Tagen (DIV3) führte in ausplattierten Primärzellen, ohne vorangehende Expansion, zu keiner signifikanten Heraufregulation der Pet1-Expression $\left(2,42 \pm 0,117,{ }^{\star} P=0,0573\right)$ des Kontrollwertes (blau: $1+0,597 /-0,374$ ). Durch die Behandlung mit dem Inhibitor SB431542 (violett) wurde ebenfalls keine Änderung der Expression von Pet1 $(0,76+0,2541 /-0,1962$; $P=0,428)$ in direkt ausplattierten Primärzellen nach deren Ausplattieren im Vergleich zu unbehandelten Zellen ausgelöst. 


\section{Pet1}

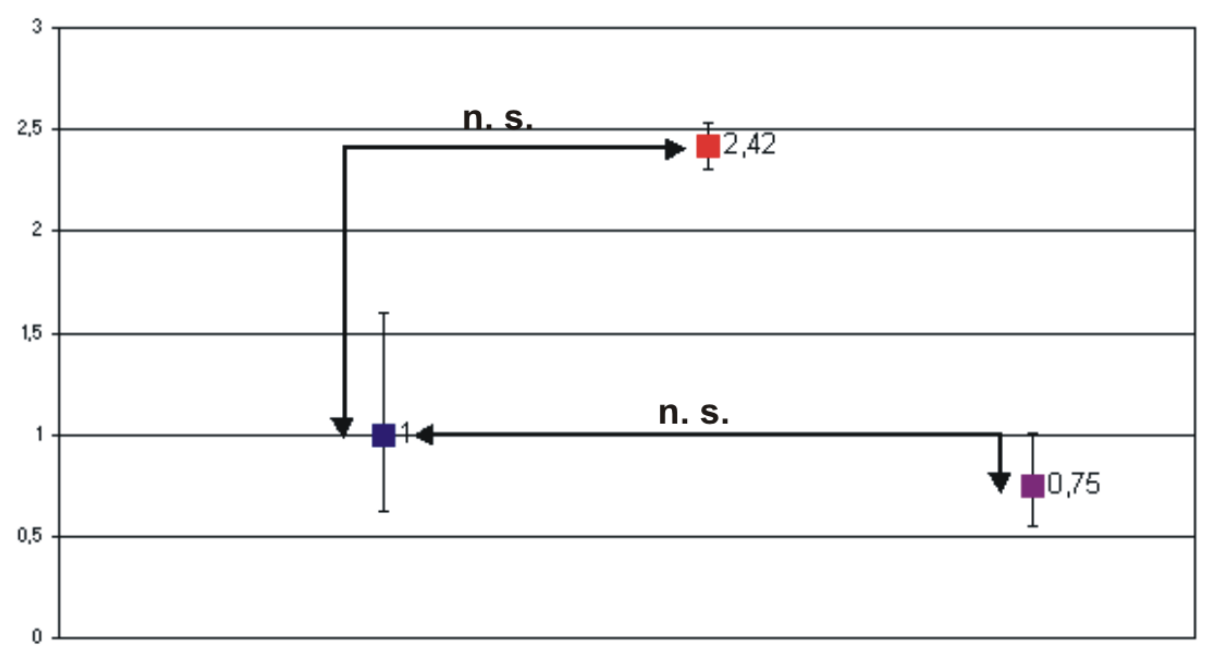

Ctr

Tgf- $/ 1$

SB431542

Abb. 14: Quantitative-,,Real-Time“-PCR-(qRT-PCR)-Analyse der Expression des Gen Pet1 als frühestes Markergen der Entwicklung serotonerger (5-HT-) Neuronen in cDNA aus Primärzellen des ventralen rostralen Rhombencephalon der Maus des Embryonaltages (E)12 nach externer Faktorengabe, Tgf- $\beta 1$ (1 ng/ml, rot) und des synthetischen Alk4/5/7-Inhibitors SB431542 (15 $\mu \mathrm{M}$, violett) drei Tage nach Behandlungsbeginn in einem repräsentativen Versuch („Day in vitro“ 3 , DIV3). Als Vergleich wurden unbehandelte Zellen, gleichen präparativen Ursprungs verwendet (Ctr, blau). (Bestimmung der relativen RNA-Mengen mittels mathematischer Anwendung der vergleichenden $\Delta \Delta \mathrm{Ct}$ Methode, $\left(2^{-\Delta \Delta \mathrm{Ct}}\right)$, statistische Signifikanz: ${ }^{\star} P<0,05 ;{ }^{* *} P<0,01$; ${ }^{* *} P<0,001$; statistisch nicht signifikant (n. s.) $P \geq 0,05$ ). 


\subsection{Analyse der Bedeutung des Transkriptionsfaktors Sim1 für die Entwicklung von 5-HT-Neuronen des ventralen Rhombencephalon der Maus}

\subsubsection{Nachweis der Expression von Sim1 im ventralen Rhombencephalon an verschiedenen Embryonalstadien der Maus}

Der Transkriptionsfaktor sim ist maßgeblich an der Ausbildung und Differenzierung von Zellen der ventralen Mittellinie von D. melanogaster beteiligt (Crews et al., 1988; Thomas et al., 1988). Zudem zeigte ein Vergleich der Genexpressionsmuster des ventralen und dorsalen Mesencephalon der Maus (E11) mittels cDNA-Mikroarray eine deutlich höhere Expression des sim-Homologon der Säuger, Sim1, im ventralen Gewebe. Diese Beobachtungen führten zu der Vermutung, dass Sim1 eine Rolle in der Induktion und Spezifikation ventraler Neuronenpopulationen, wie jener der 5-HT-Neurone, in Säugetieren spielen könnte. Um dies zu überprüfen, wurde zunächst immunhistochemisch untersucht, ob Sim1 in vivo in 5-HT-Neuronen im Rhombencephalon der Maus exprimiert wird (siehe hierzu 4.2.5.4, Seite 57). Abb. 15 zeigt exemplarisch eine Immunfluoreszenzfärbung des im Zellkern lokalisierten Transkriptionsfaktors Sim1 (rot) und des zytoplasmatischen Markers für 5-HT-Neuronen, Serotonin (5-HT, grün), in einem frontalem Paraffinsschnitt des postnatalen rostralen Rhombencephalon (P0) der Maus. Dargestellt ist der ventrale Bereich des Rhombencephalon an welchen das Lumen des IV. Ventrikels grenzt. Deutlich ist eine Kolokalisation von 5-HT und $\operatorname{Sim} 1$ in 5-HT-Neuronen zu erkennen. Darüber hinaus sind auch Sim1-immunpositive Zellen festzustellen, welche 5-HT nicht exprimieren.

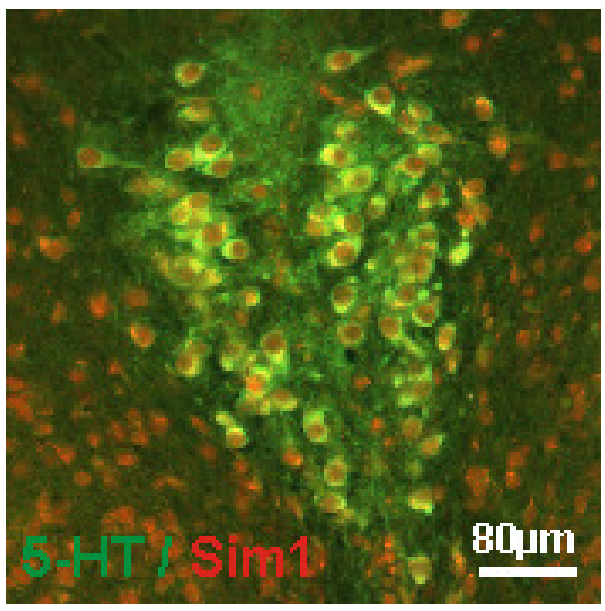

Abb. 15: Immunhistochemischer Nachweis der Expression von Sim1 („Single-minded homologon 1", rot) und Serotonin (5-HT, grün) in Zellen des Rhombencephalon der Maus des Postnataltages (P) 0. Sim1 wird in ventralen Neuronenpopulationen exprimiert, darunter auch in serotonergen (5-HT-) Neuronen, wie die Kolokalisation von $5-\mathrm{HT}$ und Sim1 in diesen Neuronen bestätigt. (frontaler Paraffinschnitt, Schnittdicke $10 \mu \mathrm{m}$ ). 
Um zu untersuchen, ob das Expressionsmuster die These einer Beteiligung des Transkriptionsfaktors Sim1 an der Induktion 5-HT-Neurone unterstützt, wurde zeitnah zum Beginn der Entstehung 5-HT-Neurone (E11) die Expression von Sim1-m(messenger)RNA mittels nicht-radioaktiver in situ-RNA-Hybridisierung (ISH) nachgewiesen (siehe Punkt 4.2.7.4, Seite 72). Verwendet wurden hierzu aufeinanderfolgende sagittale Paraffinschnitte der Maus E12, um einen direkten Vergleich der Hybridisierun von Sim1-,,sense“- (Sp6) und „anti-sense“-RNA-Sonde (T7) zu ermöglichen (Punkt 4.2.7.2, Seite 70). Die Ergebnisse der Sim1-RNA-ISH sind in Abb. 16A-D (Seite 98) zusammengefasst. Abb. 16A zeigt die durch alkalische Phosphatase katalysierte Farbreaktion nachgewiesene Hybridisierung der Sim1„anti-sense"-RNA-Sonde. Deutlich ist eine Färbung im Bereich des ventralen Rhombomer 1 (R1) festzustellen, die zum ventralen R2 hin schwächer wird. Dies deutet auf eine graduelle Expression von Sim1 hin. Darüber hinaus lässt sich eine stärkere Färbung im ventralen Gewebe im Vergleich zum dorsalen Gewebe des Rhombencephalon erkennen. Abb. 16B gibt das Hybridisierungsergebnis in einer höheren Vergrößerung wieder, in der eindeutig eine zytoplasmatische Färbung (blau) erkennbar ist. Zum Vergleich ist die ISH der „sense“RNA-Sonde gegen Sim1 am direkt nachfolgenden Schnitt in Abb. 16C und Abb. 16D aufgezeigt. Die ISH der „sense“-RNA-Sonde von Sim1 erbrachte keine Sim1-spezifische, zytoplasmatische Färbung. Zu beobachten ist lediglich eine bräunliche Hintergrundsfärbung. Eine Aussage bezüglich der Bedeutung von Sim1 für die Entstehung 5-HT-Neurone einzelner Nuclei raphes lässt sich aufgrund des frühen Zeitpunktes (E12) nicht treffen. In diesem Stadium, in dem sich rostrale 5-HT-Neurone zu differenzieren beginnen, ist die endgültige Lokalisation und Gruppierung 5-HT-Neurone zu abgrenzbaren, rostralen rhombencephalen Kerngebieten noch nicht erreicht. Jedoch zeigt die ISH, dass Sim1 graduell in Regionen des rostalen Rhombencephalon, insbesondere des R1, exprimiert wird, aus deren Vorläuferzellen ventraler 5-HT-Neurone hervorgehen. 


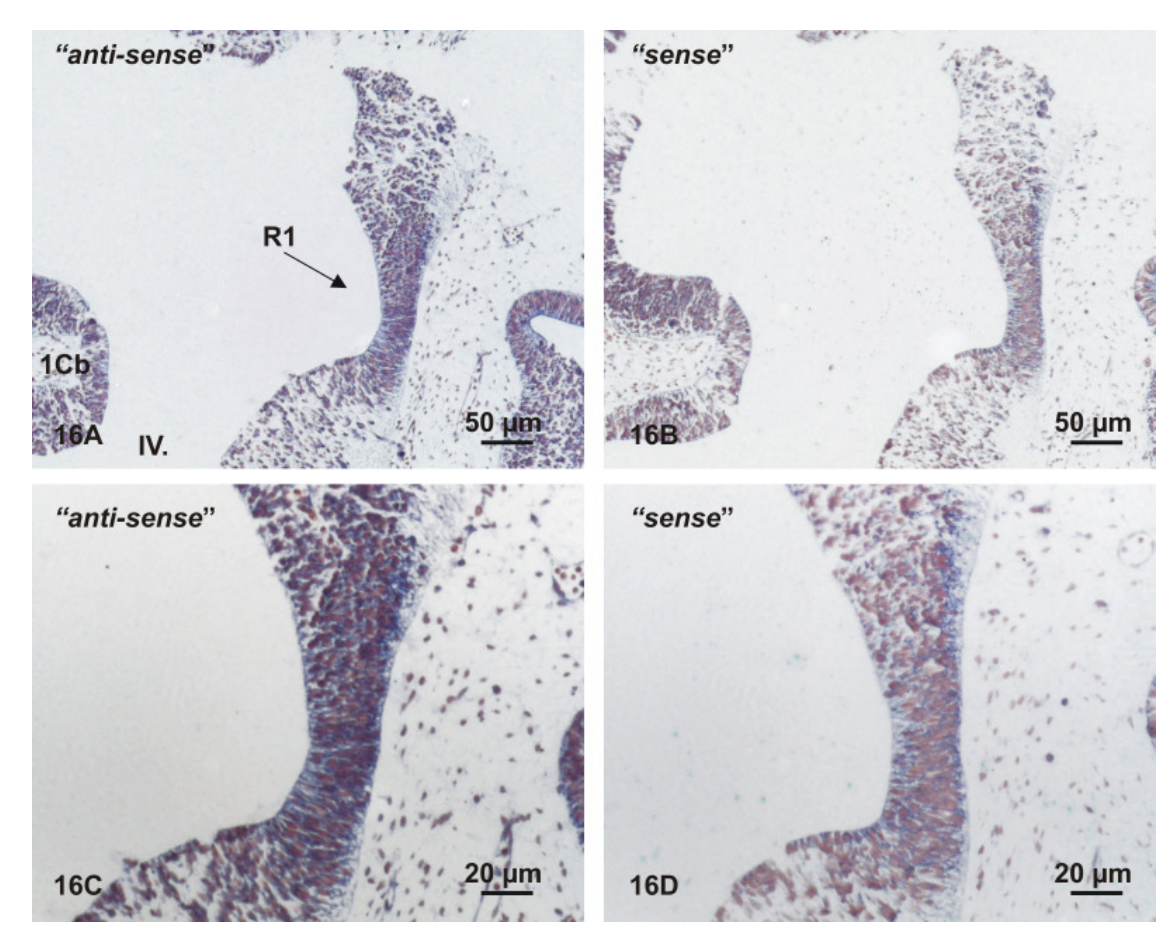

Abb.16 A-D: Nachweis der Sim1-Expression durch nicht-radioaktive in situ-RNA-Hybridisierung (ISH) an sagittalen Paraffinschnitten (Schnittdicke $10 \mu \mathrm{m}$ ) der Maus des Embryonaltages (E) 12. A: Die Sim1-,anti-sense“-RNA-Sondenhybridisierung zeigt eine Sim1-Expression im ventralen Rhombomere (R)1 und einen von R1 zu R2 schwächer werdenden Expressionsgradienten C: Sim1Expression in höherer Vergrößerung. Die ISH der „anti-sense“-RNA-Sonde gegen Sim1 zeigt eine deutliche zytoplasmatische Färbung (blau). B und D: Kontrolle der Sim1-ISH mittels „sense“RNA-Sondenhybridisierung (Cb: Cerebellum; IV.: IV. Ventrikel)

Um zu untersuchen, ob die Expression von Sim1 im Rhombencephalon während einem früheren Zeitpunkt für die Entwicklung 5-HT-Neuronen in vivo relevant ist, wurde nach immunhistochemischem Nachweis von Serotonin mittels Peroxidase-vermittelter Farbreaktion (Diaminobenzidin-Tetrahydrochlorid, DAB) die Anzahl 5-HT-positiver Neurone in Frontalschnitten des ventralen Rhombencephalon (E14.5) in wt- und Sim1-defizienten Mausembryonen bestimmt (siehe Punkt 4.2.5.4., Seite 57). Verglichen wurden jeweils wtEmbryonen und homozygote, Sim1-defiziente Embryonen eines Muttertieres. Es wurden je Genotyp mindesten drei Embryonen untersucht $(n=3)$. Das Ergebnis des quantitativen Vergleiches der Anzahl 5-HT-Neurone ist graphisch in Abb. 17 (Seite 99) dargestellt. Die Gesamtzahl 5-HT-Neurone im Rhombencephalon von Sim1-defizienten Embryonen (Säule 2) ist im Vergleich zu wt-Embryonen (Säule 1) reduziert, jedoch ist diese Reduktion nicht signifikant $(P=0,027 ; \mathrm{n}=4)$. Inwieweit jedoch Subpopulationen 5 -HT-Neurone durch die Deletion von Sim1 selektiv in ihrer Induktion und Spezifikation betroffen sind, lässt sich aufgrund der nicht möglichen Abgrenzung einzelner Kerngebiete in diesem Stadium nicht beurteilen. 


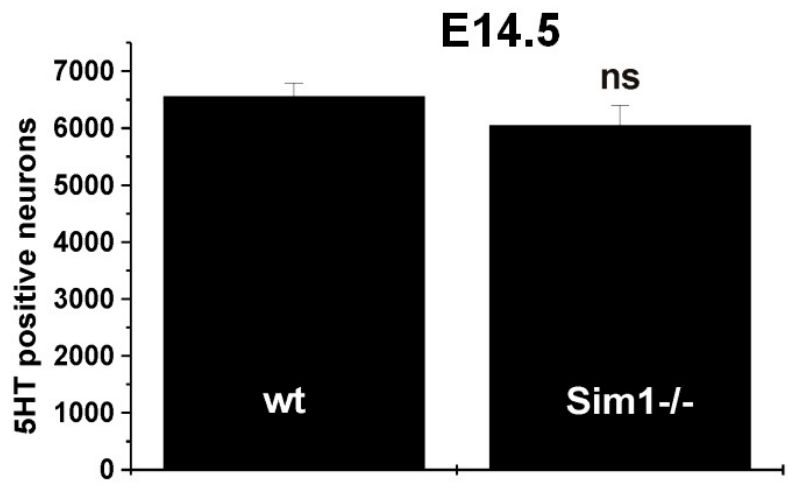

Abb. 17: Quantitativer Vergleich der Gesamtzahl serotonerger (5-HT-) Neurone des rostralen Rhombencephalon der Maus in Wildtyp (wt) und homozygoten Sim1-Mutanten des Embryonaltages (E) 14.5. Der Vergleich der Gesamtzahl 5-HT-Neurone der rostralen Kerngebiete B4-9 zwischen wt und Sim1 -/- (Anzahl $\mathrm{n}=3$ ) ergab keinen signifikanten Unterschied $(P \geq 0,05)$. (Statistische Auswertung mittels zweiseitigen "Student's t-test", Darstellung als Mittelwert der Gesamtzahlen Serotonin-(5-HT)immunpositiver Neurone \pm Standardfehler des Mittelwertes (MW \pm SEM), statistische Signifikanz: ${ }^{*} P<0,05 ;{ }^{* *} P<0,01 ;{ }^{* \star *} P<0,001$; statistisch nicht signifikant (n. s.) $P \geq 0,05$ )

\subsubsection{Sim1-defiziente Mausmutanten (P0) weisen eine signifikante Reduktion der 5-HT- Neuronenpopulation des Nucleus raphe dorsalis auf}

Um zu bestimmen, ob der Sim1 für die Differenzierung einzelner Nuclei raphes bzw. für die Aufrechterhaltung 5-HT-Neurone notwendig ist, wurde die Anzahl 5-HT-immunpositiver Neurone zum Zeitpunkt PO bestimmt. Hierzu wurden in Frontalschnitten des rostralen Rhombencephalon von wt-Mäusen und Sim1-defizienten Mäusen (P0) 5-HT-Neurone immunhistochemisch über eine Peroxidase-vermittelte DAB-Farbreaktion nachgewiesen (Punkt 4.2.5.4., Seite 57). Abb. 18 (Seite 100) gibt die statistischen Auswertung des Vergleiches der 5-HT-Neuronen des rostralen Rhombencephalon in Wildtyp (wt) und homozygoten Sim1-Mausmutanten graphisch wieder. Zur Auswertung wurden jeweils die Ergebnisse von drei Tieren der entsprechenden Genotypen $(n=3)$ gemittelt, wobei Sim1defiziente Mäuse jeweils mit wt-Mäusen des gleichen Wurfes verglichen wurden. Wie der Abb. $18 \mathrm{zu}$ entnehmen ist, konnte bezogen auf die Gesamtzahl der 5-HT-Neurone im rostralen Rhombencephalon, welches die Kerngebiete B4-B9 umfasst, kein signifikanter (n. s.; $P=0,08$ ) Unterschied zwischen wt (Säule 1, 11792,5 $\pm 1060,9 ; \mathrm{n}=4$ ) und Sim1defizienten Mäusen (Säule 2, $9870 \pm 170,4 ; n=3$ ) festgestellt werden. Der Vergleich einzelner rostraler Nuclei raphes (B4-B9) bezüglich der Anzahl der in ihnen enthaltenen 5-HT Neurone machte hingegen deutlich, dass die Anzahl 5-HT-Neurone des Nucleus raphe dorsalis (NRD, B6/B7) in Sim1-defizienten Mausmutanten (Säule 4, $3803 \pm 31,8 ; n=3$ ) im 
Vergleich zum wt (Säule 3, $5440 \pm 298 ; n=4$ ) zum Zeitpunkt P0 signifikant um circa 30\% $\left({ }^{* *} P 0,0057\right)$ reduziert ist. Dieses Ergebnis lässt auf eine Bedeutung von Sim1 für die Differenzierung und/oder die Aufrechterhaltung dieser Subpopulation rostraler 5-HTNeurone schließen. Aufgrund der perinatalen Letalität der homozygoten Sim1-Mutanten konnten spätere Zeitpunkte nicht untersucht werden.

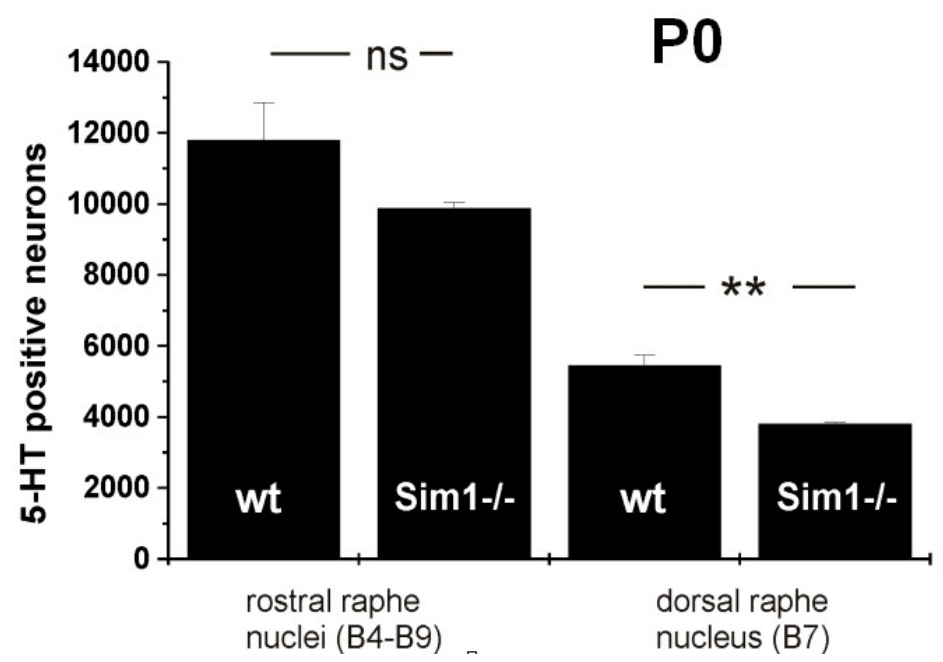

Abb. 18: Vergleich der Gesamtzahl serotonerger (5-HT-) Neurone des rostralen Rhombencephalon der Maus zum postnatalen Zeitpunkt (P) 0 in Wildtyp (wt) und homozygoten Sim1-Mutanten. Der Vergleich der Gesamtzahl 5-HT-Neurone der rostralen Kerngebiete B4-B9 zwischen wt und Sim1 -/- ergab keinen signifikanten Unterschied ( $P>0,05)$. Die Anzahl 5-HTNeurone des Nucleus raphe dorsalis (NRD, B7) ist in Sim1 -l- hingegen im Vergleich zum wt signifikant um circa $30 \%\left({ }^{\star *} P<0,0057\right)$ reduziert. (Statistische Auswertung mittels zweiseitigen "Student's t-test", Darstellung als Mittelwert der Gesamtzahlen Serotonin (5-HT)-immunpositiver Neurone \pm Standardfehler des Mittelwertes $\left(M W \pm\right.$ SEM), statistische Signifikanz: ${ }^{*} P<0,05$; ${ }^{* \star} P<0,01 ;{ }^{* \star *} P<0,001$; statistisch nicht signifikant (n. s.) $P \geq 0,05$ )

\subsection{3. “Gain-of-function” Experimente}

Um die molekularen Grundlagen einer auf in vivo-Beobachtungen (Punkt 5.3.1., Seite 96 und Punkt 5.3.2., Seite 99) gestützten, denkbaren Funktion von Sim1 während der Entwicklung rostraler Subpopulationen 5-HT-Neuronen zu untersuchen, wurden „Gain-of-function“Experimente durchgeführt. Zellen der Zellinie MN9D wurde hierbei als in vitro-Kulturmodell eingesetzt. Es handelt sich bei diesen Zellen um Fusionszellen aus embryonalen Zellen des ventralen Mesencephalon der Maus und Neuroblastoma-Zellen (Choi et al., 1991). Da diese Zelllinie insbesondere als Modell für DA-Neurone verwendet wird, wurde zunächst die Expression von Genen, die für die Entwicklung 5-HT-Neurone mitverantwortlich sind, durch 
RT-PCR und spezifische Primer (Punkt 4.1.4., Seite 26), wie unter Punkt 4.2.6.8. (Seite 64) beschrieben, überprüft. Die Ergebnisse der Expressionsanalyse sind der Abb. 19 (Seite 101) zu entnehmen. Deutlich ist zu erkennen, dass MN9D-Zellen sowohl frühe als auch späte Determinanten der Entwicklung 5-HT-Neurone exprimieren. Hierzu zählen Gata2 (Spur 3) und das 5-HT-spezifische Markergen Pet1 (Spur 4). Ebenfalls detektiert werden konnte in cDNA-Proben von MN9D-Zellen die Expression des Gens Tph2 als Marker der terminalen Differenzierung von 5-HT-Neuronen (Spur 5). Darüber hinaus konnte das Amplifikationsprodukt von Sim1, als ventral exprimierter Transkriptionsfaktor schwach aber deutlich nachgewiesen werden (Spur 6). Hieraus konnte geschlossen werden, dass sich MN9D-Zellen als in vitro-Modell für Untersuchung des Einflusses von Sim1 auf die Entwicklung 5-HT-Neurone mittels Überexpression des Sim1-Gens eignen würden.

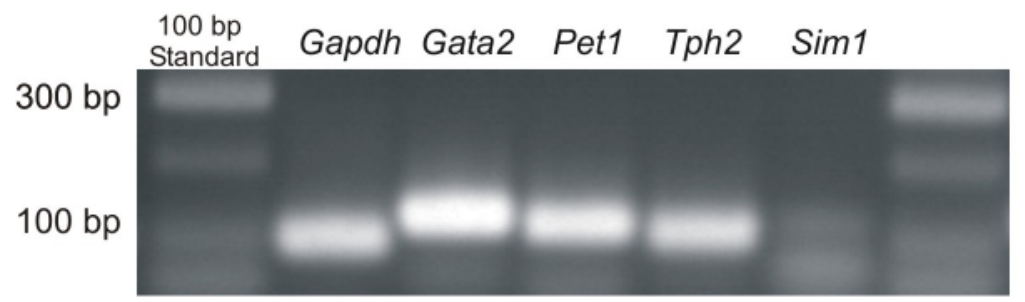

Abb. 19: Analyse der Expression von Gata2, Pet1 und Tph2 als Vertreter von Markergenen der Entwicklung serotonerger (5-HT-) Neurone und des ventral exprimierten Transkriptionsfaktors Sim1 in MN9D-Zellen mittels Reverser-Transkriptions-(RT)-PCR. Sowohl Gata2, ein frühes postmitotisches Markergen der Entwicklung rostraler rhombencephaler 5-HT-Neurone, als auch Pet1 und Tph2 als Determinanten der terminalen Differenzierung von 5-HT-Neuronen sind in MN9D-Zellen exprimiert. Eine schwache Expression von Sim1 ließ sich ebenfalls nachweisen.

Die Durchführung der Überexpression von Sim1 in MN9D-Zellen ist unter Punkt 4.2.2.3. (Seite 42) im Detail erläutert. $1 \times 10^{6}$ MN9D-Zellen wurden in $25 \mathrm{~cm}^{2}$-Kulturflaschen ausplattiert und am folgenden Tag mittels des Transfektionsreagenz Lipofectamine mit dem Überexpressionsplasmid pcDNA3::Sim1 transfiziert. Als Kontrollplasmid wurde pcDNA3 verwendet und dieses analog zum Überexpressionsplasmid transfiziert. Nach $4 \mathrm{~h}$ wurde die Reaktion durch Wechsel des Kulturmediums gestoppt und die Expression des Sim1-Gens nach $24 \mathrm{~h}, 48 \mathrm{~h}$ und $72 \mathrm{~h}$ durch Probennahme unterbrochen. Aus MN9D-Zellen, die mit dem Sim1-Überexpressionsplasmid transfiziert worden waren und aus pcDNA3-transfizierten MN9D-Zellen des gleichen Zeitpunktes wurde sowohl Gesamt-RNA (siehe Punkt 4.2.6.4.; Seite 61) als auch Gesamt-Protein (Punkt 4.2.8.1., Seite 75) isoliert. Die Proben wurden anschließend hinsichtlich einer erfolgten Sim1-Überexpression auf RNA- bzw. Protein-Ebene analysiert. Nachfolgende Abb. 20 zeigt exemplarisch die Überexpression des Sim1-Gens in 
MN9D-Zellen auf RNA-Ebene nach $24 \mathrm{~h}, 48 \mathrm{~h}$ und $72 \mathrm{~h}$ im Vergleich zu Zellproben der Kontrollen, wie sie nach RT-PCR Analyse der Genexpression bestimmt werden konnte. Wie die RT-PCR für Gapdh (Spuren 2-7) zeigt, wurde von allen Proben die gleiche Menge cDNA (ausgehend von $1 \mu \mathrm{g}$ Gesamt-RNA) in der PCR-Reaktion eingesetzt, wodurch ein direkter Vergleich der relativen Expression des Sim1-Gens in MN9D-Vergleichsproben (Ctr) und in Proben von pcDNA3::Sim1-transfizierten MN9D-Zellen (Sim1) möglich ist. Bereits nach einer Dauer von $24 \mathrm{~h}$ konnte in der Probe von pcDNA3::Sim1-transfizierten MN9D-Zellen (Spur 10) eine gesteigerte Expression von Sim1 im Vergleich zur Probe der Kontrolle (Spur 9) nachgewiesen werden. Die Überexpression von Sim1 ließ sich nach 48 h (Spur 12) und 72 h (Spur 14) noch deutlich im Vergleich zu Kontrollproben (Spuren 11 und 13) bestimmen.

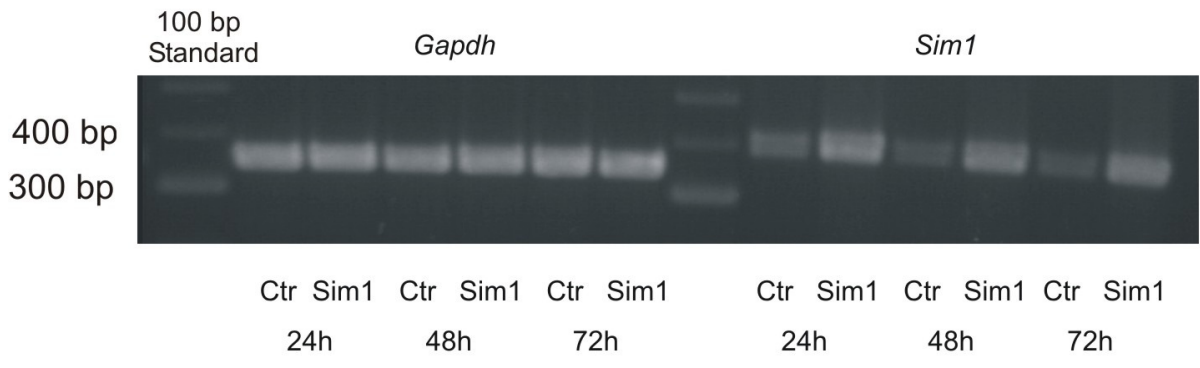

Abb. 20: Reverse Transkriptions-(RT)-PCR-Analyse der Überexpression von Sim1 (Sim1) in MN9DZellen nach 24 h, 48 h und 72 h nach Transfektion mit pcDNA3::Sim1 im Vergleich zu pcDNA3transfizierten Kontrollen (Ctr) unter Berücksichtigung der jeweils für die PCR eingesetzten cDNAMenge (Gapdh).

Um sicherzustellen, dass eine Sim1-Überexpression auf Protein-Ebene erreicht wurde, wurde dies mittels Western-Blot-Analyse (siehe Punkt 4.2.8.4., Seite 77) überprüft. Abb. 21 (Seite 103) gibt die Ergebnisse des Western-Blot von drei „Gain-of-function“-Experimente wieder. Aufgetragen wurden jeweils $20 \mu \mathrm{g}$ Gesamt-Protein der Probe aus pcDNA3transfizierten MN9D-Zellen (Ctr) und der entsprechenden Probe von pcDNA3::Sim1transfizierten MN9D-Zellen (Sim1). Gewählt wurde jeweils der Zeitpunkt, zu dem die Expression von Sim1 innerhalb eines Versuches zuvor auf RNA-Ebene als am höchsten bestimmt worden war. Als Vergleichsprotein wurde erneut Gapdh (36 kDa), welches nicht durch eine Sim1-Überexpression in seiner eigenen Expression beeinflusst wurde, gewählt (Abb. 21A). Der Nachweis des Sim1-Proteins (85,5 kDa, Abb. 21B) erfolgte durch Bindung eines, im Kaninchen hergestellten polyklonalen Antikörper (1:1000), welcher durch einen, an HRP („Horseradish peroxidase“) gekoppelten, gegen Kaninchen gerichteten, sekundären Antikörper gebunden wurde. Im Anschluss an die Bestimmung des Sim1-Proteins mittels Chemilumineszenz-Reaktion wurde die Proteinexpression des „Housekeeping“-Gens Gapdh 
durch einen in Maus hergestellten, monoklonalen Antikörper (1:10000) und anschließende Bindung eines, an HRP gebundenen, gegen Maus gerichteten, sekundären Antikörper nachgewiesen. Dies ermöglichte einen direkten Vergleich der Proteinmengen von den Proben der Kontrollen und den jeweils korrespondierenden Proben von Sim1überexprimierender MN9D-Zellen. Wie in Abb. 21A ersichtlich wurden von den beiden Proben eines Versuches vergleichbare Proteinmengen eingesetzt. Die Expression des Sim1Proteins zeigt Abb. 21B. Eine prominente Bande von circa 85,5 kDa konnte in den Proben der Kontrollen nachgewiesen werden, was der Molmasse von „full-length“-Sim1 entspricht. Versuch 1 (1. V.) konnte nach einer Expressionsphase von $24 \mathrm{~h}$ eine deutlich gesteigerte Expression des Sim1-Proteins in der Probe von pcDNA3::Sim1-transfizierten MN9D-Zellen (Spur 2) im Vergleich zur Probe pcDNA3-transfizierter Zellen (Spur 1) festgestellt werden. Auch in den Versuchen 2 und 3 konnte $48 \mathrm{~h}$ nach der Transfektion eine gesteigerte Expression des Sim1-Proteins in Proben pcDNA3::Sim1-transfizierter Zellen (Spuren 4 und 6) im Vergleich zu den entsprechenden pcDNA3-transfizierter MN9D-Zellen (Spur 3 und 5) bestimmt werden.

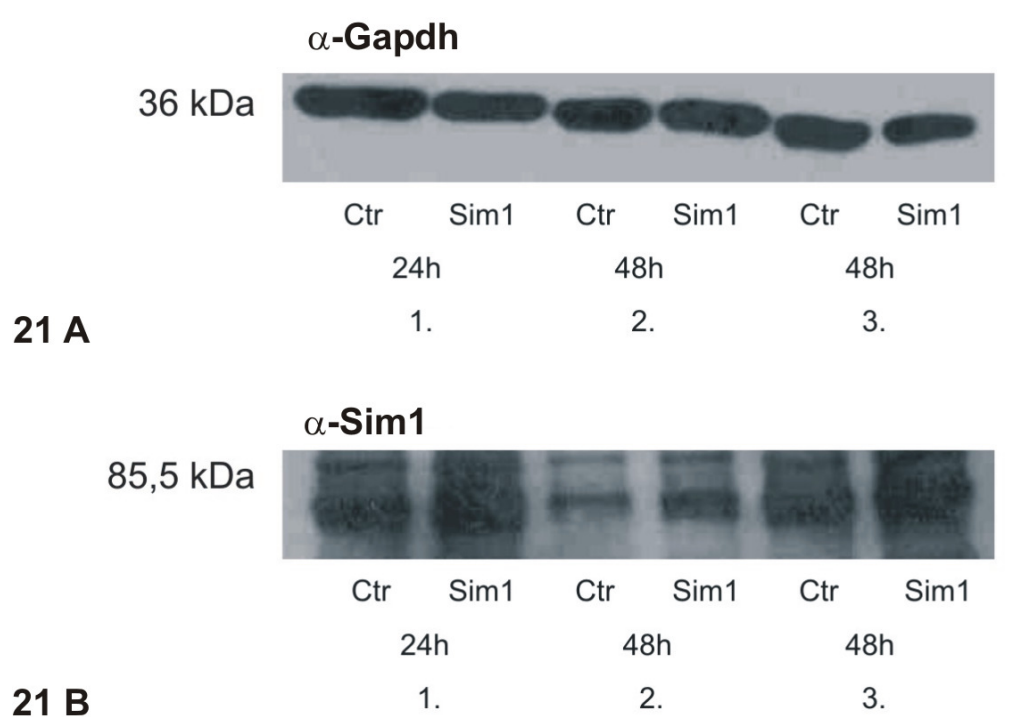

\begin{abstract}
Abb. 21: Western-Blot-Analyse repräsentativer „Gain-of-Function"-Versuche, (V)1-3, zum Zeitpunkt der jeweils höchsten Sim1-Proteinexpression. A: Nachweis des Gapdh-Proteins (36 kDa) durch einen gegen Gapdh gerichteten, monoklonalen Antikörper aus Maus ( $\alpha$-Gapdh) und anschließende Chemilumineszenz-Reaktion des sekundären, Merretich-Peroxidase-(HRP, Horseradish Peroxidase)konjugierten Antikörpers B: Chemilumineszenz-basierter Nachweis der Expression des Sim1-Proteins (85,5 kDa) durch einen polyklonalen, gegen Sim1 gerichteten Antikörper aus Kaninchen ( $\alpha$-Sim1) (Ctr: Probe der als Kontrolle dienenden pcDNA3-transfizierten MN9D-Zellen; Sim1: Probe der pcDNA3::Sim1-transfizierten MN9D-Zellen)
\end{abstract}


Um eine mögliche Regulation der Expression von Genen, die für die transkriptionelle Kontrolle der 5-HT-Neuronen Differenzierung bekannt sind, durch den Transkriptionsfaktor Sim1 zu analysieren, wurde, wie unter Punkt 4.2.6.9. (Seite 65) beschrieben, die Genexpression von Mash1, Gata2, Pet1 und Tph2 mittels qRT-PCR in cDNA-Proben Sim1überexprimierender MN9D-Zellen zu drei unterschiedlichen Zeitpunkten nach der Transfektion (24 h, 48 h, 72 h) ermittelt. Diese wurde mit der Expression dieser Gene in zeitlich entsprechenden, als Kontrolle dienenden, pcDNA3-transfizierten MN9D-Zellen verglichen. In nachfolgender Abb. 22 ist die Expression von Mash1, als allgemeines Markergen für neurale Vorläuferzellen (Lo et al., 1991), nach Überexpression von Sim1 in MN9D-Zellen (rot) nach 24 h, $48 \mathrm{~h}$ und $72 \mathrm{~h}$ im Vergleich zu nicht Sim1-überexprimierenden Kontrollen (blau) dargestellt $(n=3)$. Hier zeigt sich, dass eine Überexpression von Sim1 zu keinem der drei genannten Zeitpunkte einen signifikanten Einfluss auf die Expression von Mash1 im Vergleich zu den Kontrollen ausübt (nach 24 h: $\operatorname{Ctr} 1+0,35 /-0,27$; Sim1 0,94 $+0,6 /-0,34 ; P=0,4$, nach 48 h: $\operatorname{Ctr} 1+0,24 /-0,2 ; \operatorname{Sim} 10,88+0,31 /-0,38 ; P=0,26$ und nach 72 h: Ctr Ctr $1+0,29 /-0,32$; $\operatorname{Sim} 10,84+0,24 /-0,29 ; P=0,29$, statistische Signifikanz: ${ }^{\star} P<0,05,{ }^{* *} P<0,01,{ }^{* * *} P<0,001$; statistisch nicht signifikant (n. s.) $P \geq 0,05$ ).

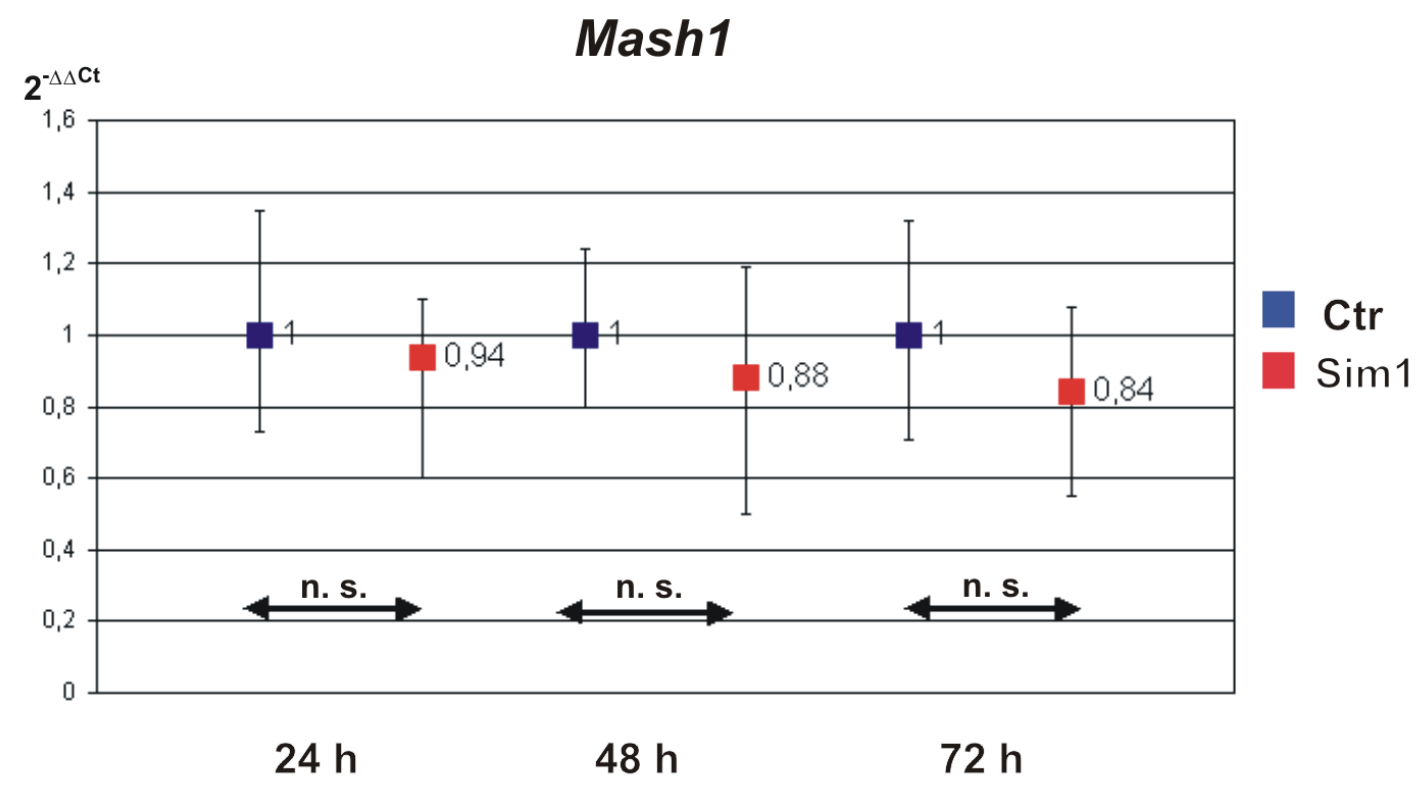

Abb. 22: Quantitative-,,Real-Time“-PCR-(qRT-PCR)-Analyse der Mash1-Expression in cDNA aus MN9D-Zellen nach Überexpression des Transkriptionsfaktors Sim1(rot) im Vergleich zu cDNA aus MN9D-Kontrollansätzen (blau) zu verschiedenen Zeitpunkten (24 h, 48 h, 72 h). Sim1Überexpression in MN9D-Zellen führt zu keiner signifikanten Änderung der Expression von Mash1 im Vergleich zu den nicht Sim1-überexprimierenden Kontrollen. (Bestimmung der relativen RNAMengen mittels mathematischer Anwendung der vergleichenden $\Delta \Delta \mathrm{Ct}$ Methode $\left(2^{-\Delta \Delta \mathrm{Ct}}\right)$, statistische Signifikanz: ${ }^{\star} P<0,05 ;{ }^{\star *} P<0,01$; ${ }^{\star * *} P<0,001$; statistisch nicht signifikant (n. s.) $P \geq 0,05$, $\mathrm{n}=3$.) 
In Abb. 23 ist die Expressionsanalyse des Gens Gata2, ein in 5-HT-Vorläuferzellen des rostralen Rhombencephalon der Maus exprimiertes Gen, exemplarisch dargestellt. $24 \mathrm{~h}$, $48 \mathrm{~h}$ und ebenso $72 \mathrm{~h}$ nach Transfektion der MN9D-Zellen durch pcDNA3::Sim1 (rot) führt die Überexpression des Sim1-Gens verglichen zu nicht Sim1-überexprimierenden Zellen (pcDNA3, blau) zu keiner signifikanten Änderung der Expression von Gata2 (nach 24 h: Ctr 1 $+0,186 /-0,157 ; \operatorname{Sim} 10,97+0,05 /-0,04 ; P=0,81$, nach 48 h: Ctr $1+0,15 /-0,13 ; \operatorname{Sim} 10,77$ $+0,18 /-0,15 ; P=0,17$ und nach 72 h: $\operatorname{Ctr} 1+0,018 /-0,189 ; \operatorname{Sim} 10,62 ;+0,29 /-0,19$; $P=0,15)$.

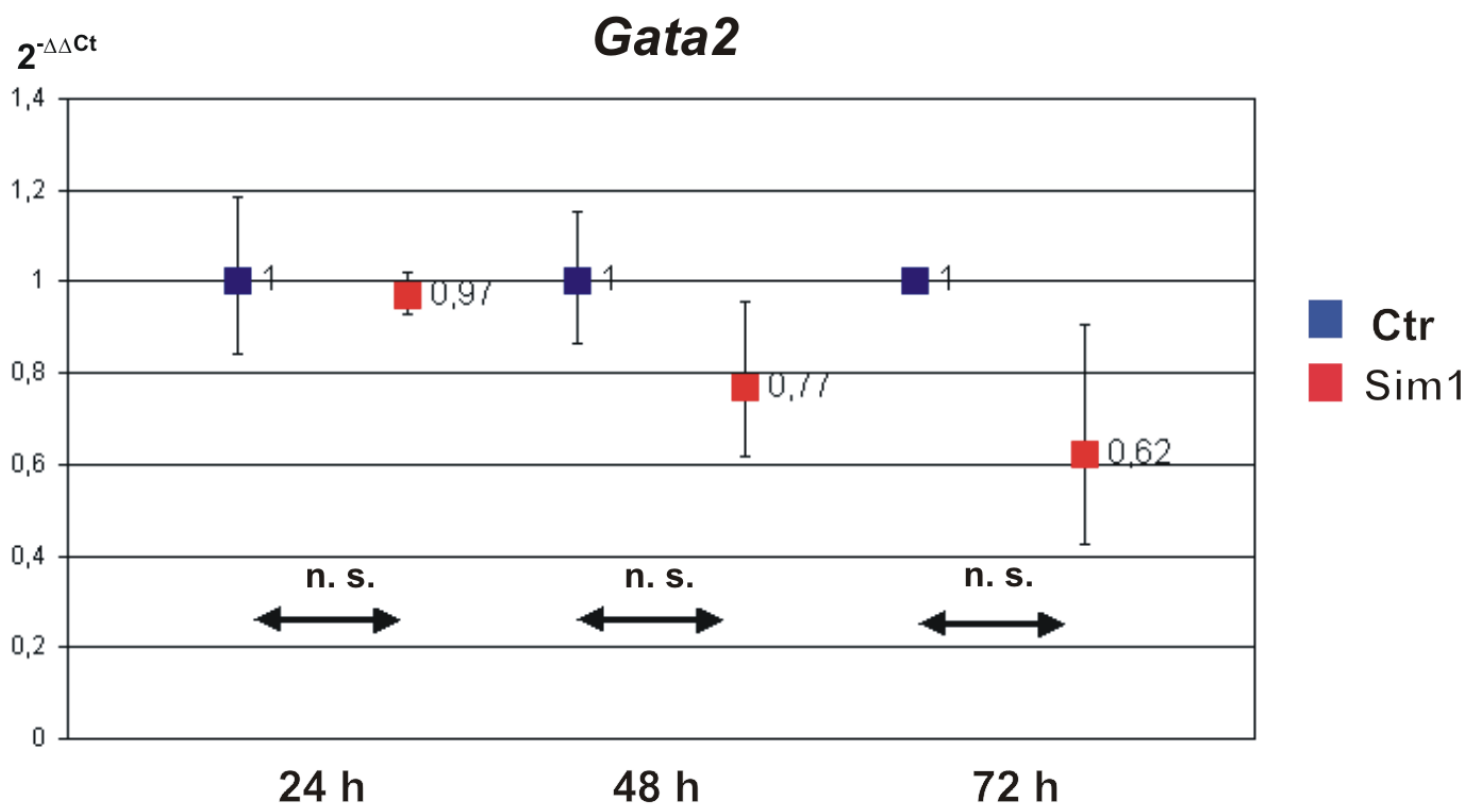

Abb. 23: Repräsentative, quantitative-,,Real-Time“-PCR-(qRT-PCR)-Analyse der Expression von Gata2 in cDNA aus MN9D-Zellen nach Überexpression des Transkriptionsfaktors Sim1 ( $p c D N A 3:: S i m 1$, rot) im Vergleich zu cDNA aus MN9D-Kontrollansätzen ( $p c D N A 3$, blau) zu verschiedenen Zeitpunkten ( $24 \mathrm{~h}, 48$ h, 72 h). Sim1-Überexpression in MN9D-Zellen führt zu keinem Zeitpunkt nach der Transfektion (24 h, $48 \mathrm{~h}$ und 72 h) zu einer signifikanten Expressionsänderung von Gata2 im Vergleich zu nicht Sim1-überexprimierenden Kontrollen. (Bestimmung der relativen RNA-Mengen mittels mathematischer Anwendung der vergleichenden $\Delta \Delta \mathrm{Ct}$ Methode $\left(2^{-\Delta \Delta \mathrm{Ct}}\right)$, statistische Signifikanz: ${ }^{*} P<0,05 ;{ }^{*} P<0,01 ;{ }^{* *} P<0,001$; statistisch nicht signifikant (n. s.) $P \geq 0,05$, 
In Abb. 24 ist die Expression des Gens Pet1 in cDNA-Proben von Sim1-überexprimierenden (pcDNA3::Sim1) MN9D-Zellen (Sim1, rot) in Relation zu pcDNA3-transfizierten MN9D-Zellen (Ctr, blau) zu unterschiedlichen Zeitpunkten wiedergegeben. Deutlich zu erkennen ist, dass eine Sim1-Überexpression nach $24 \mathrm{~h}$ zu keiner Änderung der Pet1-Expression des Kontrollwertes auf RNA-Ebene führt (Ctr $1+0,43 /-0,31$; $\operatorname{Sim1} 1,14 \pm 0,10 ; P=0,127)$. Die Expression von Pet1 nimmt jedoch nach einem Zeitraum von $48 \mathrm{~h}$ signifikant auf das 3,16fache (Ctr $1+0,52 /-0,35$; $\left.\operatorname{Sim} 13,16+1,14 /-1,23 ;{ }^{* *} P=0,003\right)$ des Kontrollwertes zu und erreicht nach $72 \mathrm{~h}$ eine signifikante Steigerung um das 4,2fache $(\operatorname{Ctr} 1+0,09 /-0,1 ; \operatorname{Sim} 1$ $\left.+2,4 /-1,65 ;{ }^{*} P=0,01\right)$ der Expression in pcDNA3-transfizierten MN9D-Zellen. Hieraus kann geschlossen werden, dass Sim1 in vitro die Pet1-Expression in MN9D-Zellen positiv reguliert.

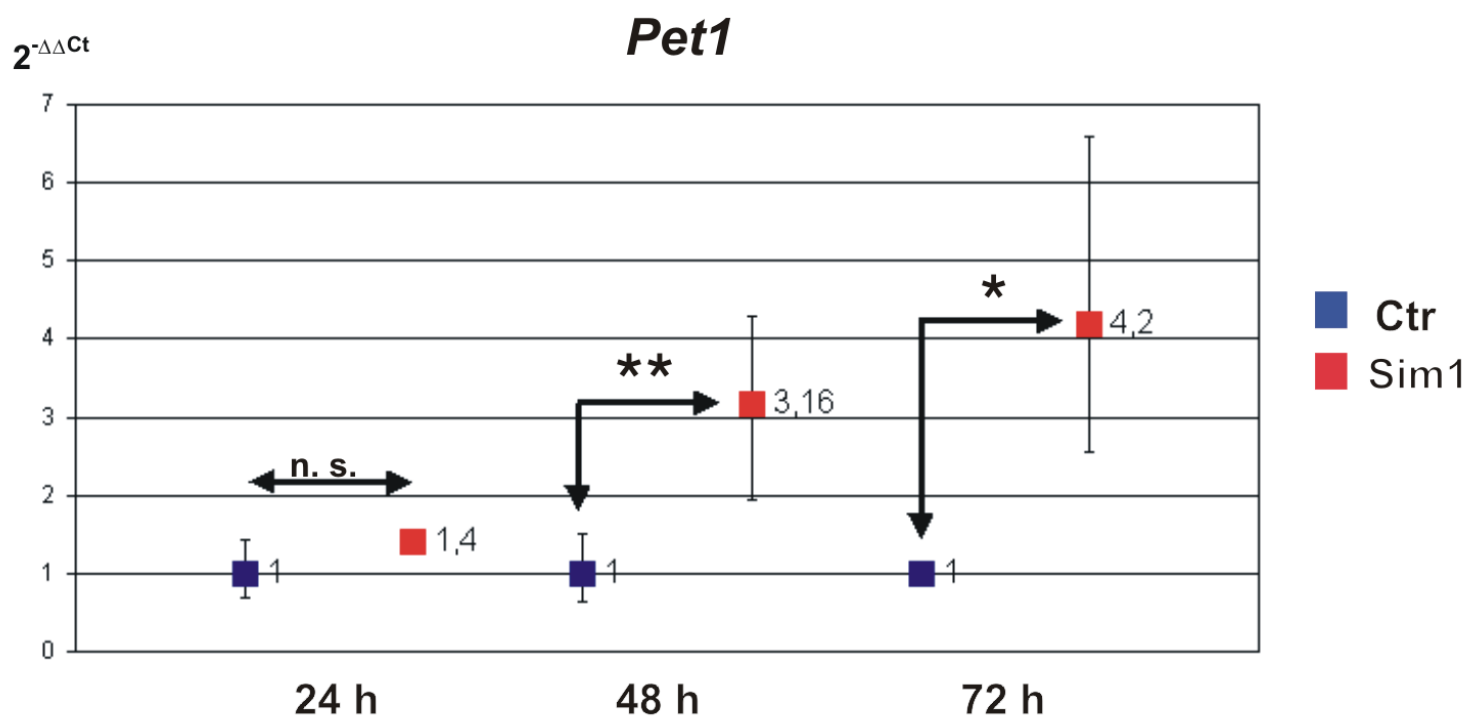

Abb. 24: Quantitative-„Real-Time“-PCR-(qRT-PCR)-Analyse der Pet1-Expression in cDNA aus MN9D-Zellen nach Überexpression des Transkriptionsfaktors Sim1(rot) im Vergleich zu cDNA aus MN9D-Kontrollansätzen (blau) zu verschiedenen Zeitpunkten (24 h, 48 h, 72 h). Sim1Überexpression in MN9D-Zellen führt zu einer signifikanten Heraufregulation nach $48 \mathrm{~h}$ $\left({ }^{\star *} P=0,003\right)$ und $72 \mathrm{~h}\left({ }^{*} P=0,01\right)$ der Pet1-Expression im Vergleich zu den nicht Sim1überexprimierenden Kontrollen. (Bestimmung der relativen RNA-Mengen mittels mathematischer Anwendung der vergleichenden $\Delta \Delta \mathrm{Ct}$ Methode $\left(2^{-\Delta \Delta \mathrm{Ct}}\right)$, statistische Signifikanz: ${ }^{*} P<0,05 ;{ }^{* *} P<0,01$; *** $P<0,001$; statistisch nicht signifikant (n. s.) $P \geq 0,05, \mathrm{n}=2$ ). 
In gleicher Weise wurde die relative Expression des Tph2-Gens nach Überexpression von Sim1 in MN9D-Zellen mittels qRT-PCR untersucht. Wie Abb. 25 graphisch veranschaulicht, konnte $24 \mathrm{~h}$ nach Transfektion des Überexpressionsplasmides pcDNA3::Sim1 (rot) keine Änderung der Tph2-Expression in Sim1-überexprimierenden Zellen im Vergleich zu der Tph2-Expression in der entsprechenden cDNA der Kontrolle nachgewiesen werden. Nach $48 \mathrm{~h}$ jedoch wurde eine signifikante Steigerung der Tph2-Expression auf das 1,82fache $\left(+/-0,37 ;{ }^{\star *} P=0,006 ; \operatorname{Ctr} 1+0,04 /-0,05\right)$ und nach weiteren $24 \mathrm{~h}$ um das 2,47 fache (+ $\left.0,76 /-0,51 ;{ }^{* \star *} P=0,0009 ; \operatorname{Ctr} 1 \pm 0,11\right)$ des Kontrollwertes ermittelt. Eine Überexpression des Sim1-Proteins in vitro führt somit zu einer deutlichen, signifikanten Steigerung der Expression des Tph2-Gens nach $48 \mathrm{~h}$ und $72 \mathrm{~h}$.

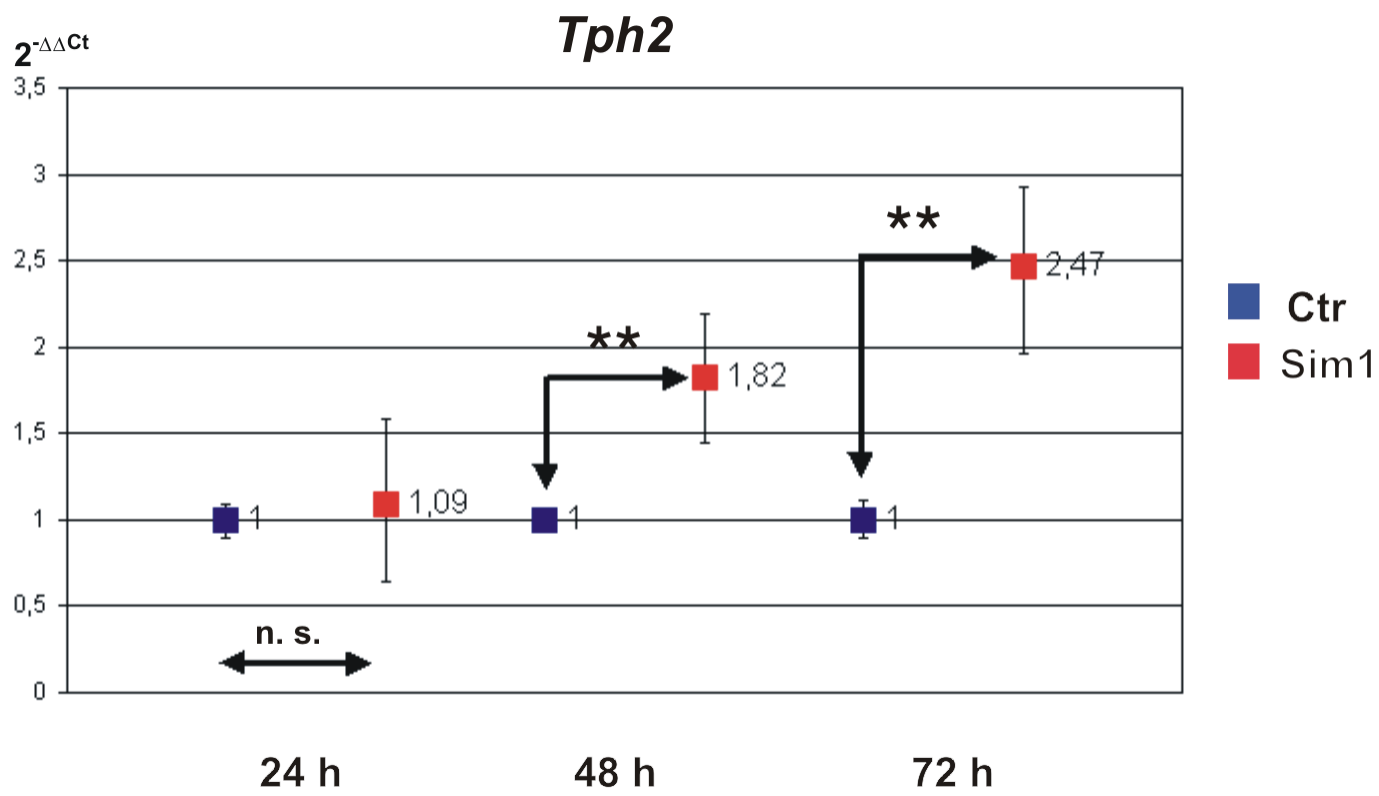

Abb. 25: Quantitative-„Real-Time“-PCR-Analyse der Genexpression von Tph2 in cDNA aus Sim1überexprimierenden $M N 9 D$-Zellen (Sim1, rot) im Vergleich zu cDNA-Proben aus pcDNA3transfizierten MN9D-Zellen (blau) zu unterschiedlichen Zeitpunkten (24 h, $48 \mathrm{~h}$ und $72 \mathrm{~h}$ ). Überexpression von Sim1 führt zu einer gesteigerten, signifikanten Expression von Tph2 in MN9DZellen innerhalb von $48 \mathrm{~h}\left({ }^{* *} \mathrm{P}=0,006\right)$ und $72 \mathrm{~h}\left({ }^{* *} \mathrm{P}=0,0009\right)$ nach erfolgter pcDNA3::Sim1Transfektion. (Bestimmung der relativen RNA-Mengen mittels mathematischer Anwendung der vergleichenden $\Delta \Delta \mathrm{Ct}$ Methode $\left(2^{-\Delta \Delta \mathrm{Ct}}\right)$, statistische Signifikanz: ${ }^{*} P<0,05 ;{ }^{* *} P<0,01 ;{ }^{* *} P<0,001$; statistisch nicht signifikant (n. s.) $P \geq 0,05, \mathrm{n}=2$ ). 


\subsection{4. „Loss-of-function“-Experimente}

Um die Wirkung von Sim1 auf die Regulation der Expression von Genen, die für die Entwicklung und Differenzierung von 5-HT-Neuronen relevant sind, zu analysieren, wurden „Loss-of-function"-Experimente durchgeführt. Diese Experimente beruhen auf der Blockierung der Translation der Sim1-mRNA mittels spezifischer siRNA-Moleküle. Als Kultursystem wurden wiederum MN9D-Zellen verwendet, deren Transfektion mit Fluorophormarkierten siRNA-Molekülen verfolgt werden konnte. Dabei handelte es sich zum einen um Cy5-gekoppelte siRNA, mit komplememtärer Sequenz zu einem Sequenzabschnitt der mRNA des Sim1-Gens (Sim1-siRNA-Cy5, siehe Punkt 4.1.4., Seite 27). Zum anderen wurde als Kontrolle eine FITC-konjugierte siRNA zum Einsatz, welche aufgrund ihrer pflanzlichen Ursprungssequenz keine Komplementarität zu mRNA-Sequenzen der Maus aufweist und im weiteren als Kontroll-siRNA (Ctr-siRNA-Alexa488, Punkt 4.1.4., Seite 27) bezeichnet wird. Die Transfektion wurde wie unter Punkt 4.2.2.4. (Seite 43) beschrieben durchgeführt. Nachfolgende Abb. 26 (Seite 109) zeigt exemplarisch MN9D-Zellen in einer Dichte von $1 \times 10^{5}$ Zellen/Poly-D-Lysin-beschichtetem Deckgläschen $(\varnothing 12 \mathrm{~mm})$ nach erfolgter Transfektion. Nach Ablauf von $24 \mathrm{~h}$ wurden die Zellen durch eine 4\%ige PFA-Lösung fixiert und die Zellkerne durch DAPI (blau) markiert. In Abb. 26A ist die deutlich als rote, zytoplasmatische Fluoreszenz erkennbare Transfektion der MN9D-Zellen durch siRNASim1-Cy5 (37,5 ng/1×10 5 Zellen) nach $24 \mathrm{~h}$ zu erkennen (rot). Die Effizienz der Transfektion lag bei circa 40\%. Demgegenüber, war die Effizienz der Transfektion der FITC-konjugierten Ctr-siRNA-Alexa 488 (grün) geringer und betrug circa 30\%. Abb. 26B zeigt die Transfektion des als Kontrolle verwendeten Ctr-siRNA-FITC-Moleküls $\left(37,5 \mathrm{ng} / 1 \times 10^{5}\right.$ Zellen) ebenfalls $24 \mathrm{~h}$ nach Transfektion der Zellen. 

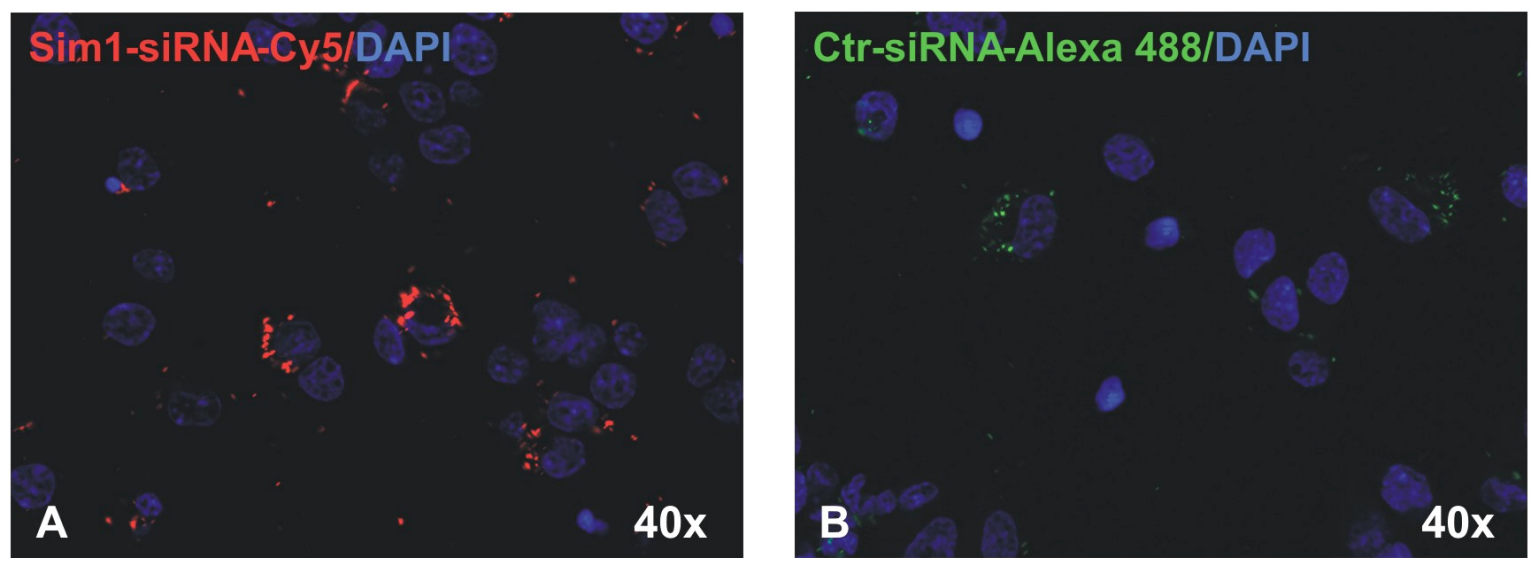

Abb. 26: Transfektion von MN9D-Zellen mit Sim1-mRNA-spezifischer siRNA (A: Sim1-Cy5, rot) bzw. einer nicht zur komplementären Sequenzbindung fähigen Kontroll-siRNA (B: Ctr-siRNAAlexa 488, grün). MN9D-Zellen wurden unmittelbar vor der Transfektion in einer Dichte von $1 \times 10^{5}$ Zellen/Poly-D-Lysin beschichtetem, $\varnothing 12 \mathrm{~mm}$-Deckgläschen plattiert und mit $70 \mathrm{ng}$ siRNA pro Deckgläschen transfiziert. Die Aufnahme und zytoplasmatische Lokalisation der Fluorophormarkierten siRNA-Moleküle wurde fluoreszenzmikroskopisch ausgewertet. Kernfärbung durch DAPI (blau).

Die Abnahme der Expression von Sim1 in MN9D-Zellen auf RNA-Ebene durch spezifische Sim1-siRNA wurde, wie unter Punkt 4.2.6.8. (Seite 64) beschrieben, durch RT-PCR Nachweis des Sim1-Amplifikationsproduktes bestätigt. Hierzu wurde die Expression des Sim1-Gens in cDNA-Proben aus siRNA-Sim1-Cy5-transfizierten MN9D-Zellen mit der Expression von Sim1 in parallel gewonnenen cDNA-Proben aus Ctr-siRNA-Alexa488transfizierten Zellen verglichen. Die Ergebnisse der Sim1-Expression zu unterschiedlichen Zeitpunkten nach siRNA-Transfektion sind der Abb. 27 (Seite 110) zu entnehmen. Abb. 27A zeigt eine vergleichbar starke Gapdh-Expression in cDNA-Proben der mit Ctr-siRNA-Alexa 488-transfizierten MN9D-Zellen (Ctr) und in entsprechenden cDNA-Proben Sim1-siRNACy5-transfizierter Zellen (Spur 2 bzw. Spur 3), 48 h nach erfolgter Transfektion. Ebenso ist die jeweilige dazugehörige Gapdh-Expression 72 h nach Transfektion der Zellen durch Sim1siRNA-Cy5 bzw. Ctr-siRNA-Alexa488 (Spur 4 bzw. 5) einander vergleichbar. Die Analyse der Expression von Sim1 ist in Abb. 27B dargestellt. Hier wird deutlich, dass durch die eingesetzte Sim1-siRNA-Cy5 bereits nach $48 \mathrm{~h}$ nach Transfektion eine Absenkung der Sim1Expression (Spur 2) auf RNA-Ebene im Vergleich zur Probe der mit Ctr-siRNA-Alexa 488transfizierten MN9D-Zellen (Spur 1) erzielt werden konnte. Deutlicher ist die Minderung der Sim1-Expression $72 \mathrm{~h}$ nach der Transfektion zu erkennen. So lässt sich in Spur 4 eine Amplifikation von Sim1 im Vergleich zur entsprechenden Kontrolle (Spur 3) nur schwach nachweisen. 
Gapdh
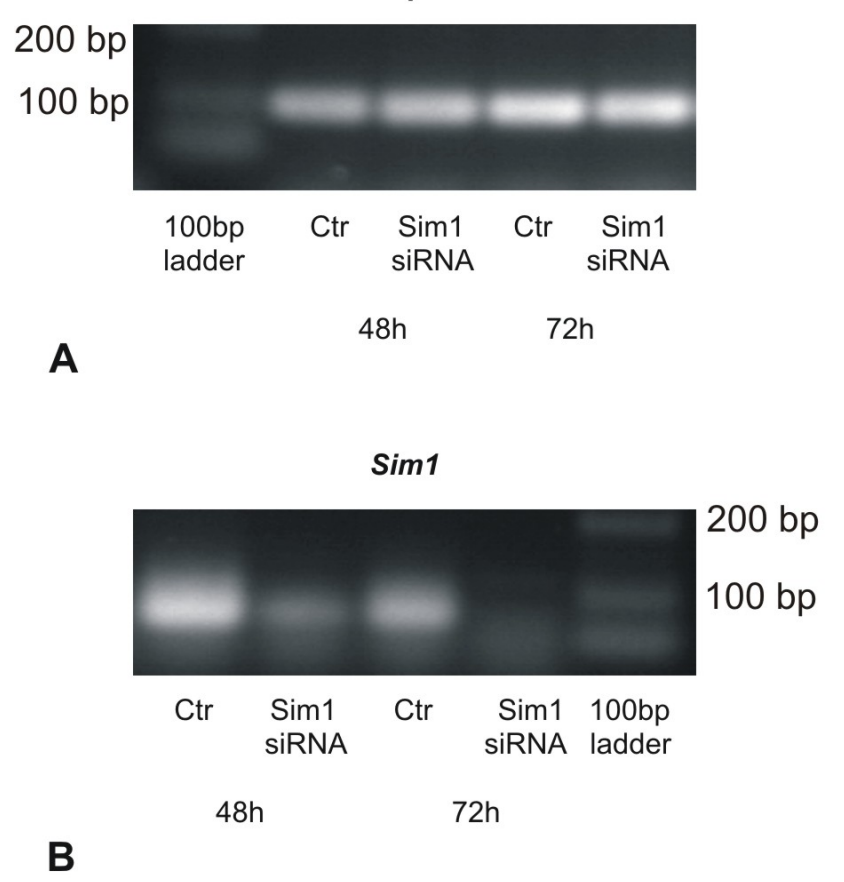

Abb. 27: Analyse der Herabregulation der Sim1-Expression mittels spezifischer siRNA (Sim1-Cy3) in MN9D Zellen durch Reverse-Transkriptions(RT)-PCR. A: Expression des Gapdh-Gens in cDNAProben von MN9D-Zellen, die mit einer Alexa 488-markierten Kontroll-siRNA (Ctr-siRNA-Alexa 488) transfiziert wurden im Vergleich zu cDNA-Proben von mit siRNA-Sim1-Cy5-transfizierten MN9DZellen des selben Zeitpunktes, $48 \mathrm{~h}$ bzw. 72 h, nach der Transfektion. B: Nachweis des Sim1Amplifikationsproduktes in cDNA Proben der siRNA-Sim1-Cy3-transfizierten MN9D-Zellen im Vergleich zu cDNA-Proben von Ctr-siRNA-Alexa 488-transfizierten Zellen. $48 \mathrm{~h}$ nach der Transfektion konnte eine eindeutige Reduktion der Sim1-Expression auf RNA-Ebene erzielt werden, die nach weiteren $24 \mathrm{~h}$ nahezu vollständig war. (Ctr: Ctr-siRNA-Alexa 488; Sim1 siRNA: siRNASim1-Cy5).

Wie in Abb. 24 (Seite 106) dargelegt wurde, führt eine Überexpression von Sim1 in MN9DZellen zu einer gesteigerten Expression des 5-HT-spezifischen Transkriptionsfaktors Pet1. Dieser Befund wurde nun durch „Loss-of-function“-Experimente mittels Sim1-spezifischer siRNA und anschließende Analyse der Änderung der Expression von Pet1 durch qRT-PCR untermauert. Hierzu wurden MN9D-Zellen wie unter Punkt 4.2.2.4. (Seite 43) erläutert mittels Sim1-spezifischer siRNA (siRNA-Sim1-Cy5) transfiziert und anschließend transfizierte Zellen durch FACS (,Fluorescense activated cell sorting“) bei einer Wellenlänge $(\lambda)$ von $670 \mathrm{~nm}$ aus der Gesamtzellpopulation herausgefiltert. Als Kontrollen wurden mit Ctr-siRNA-Alexa 488transfizierte MN9D-Zellen aus der gleichen Passage verwendet. Wie nachfolgender repräsentativer Versuch, wiedergegeben in Abb. 28 (Seite 111), zeigt, führt eine Blockierung der Translation der Sim1-mRNA zu einer signifikanten Minderung der Expression von Pet1 
nach $24 \mathrm{~h}$ in siRNA-Sim1-Cy5-transfizierten und FACS-sortierten MN9D-Zellen $\left(0,08+0,181 /-0,056 ;{ }^{\star} P=0,0163\right)$ im Vergleich zu Kontrollen (Ctr-siRNA-Alexa 488, $1+0,138 /-0,121)$. Somit ist Pet1 ein potentielles Zielgen von Sim1.

$$
2^{-\Delta \Delta \mathrm{Ct}} \quad \text { Pet1 }
$$

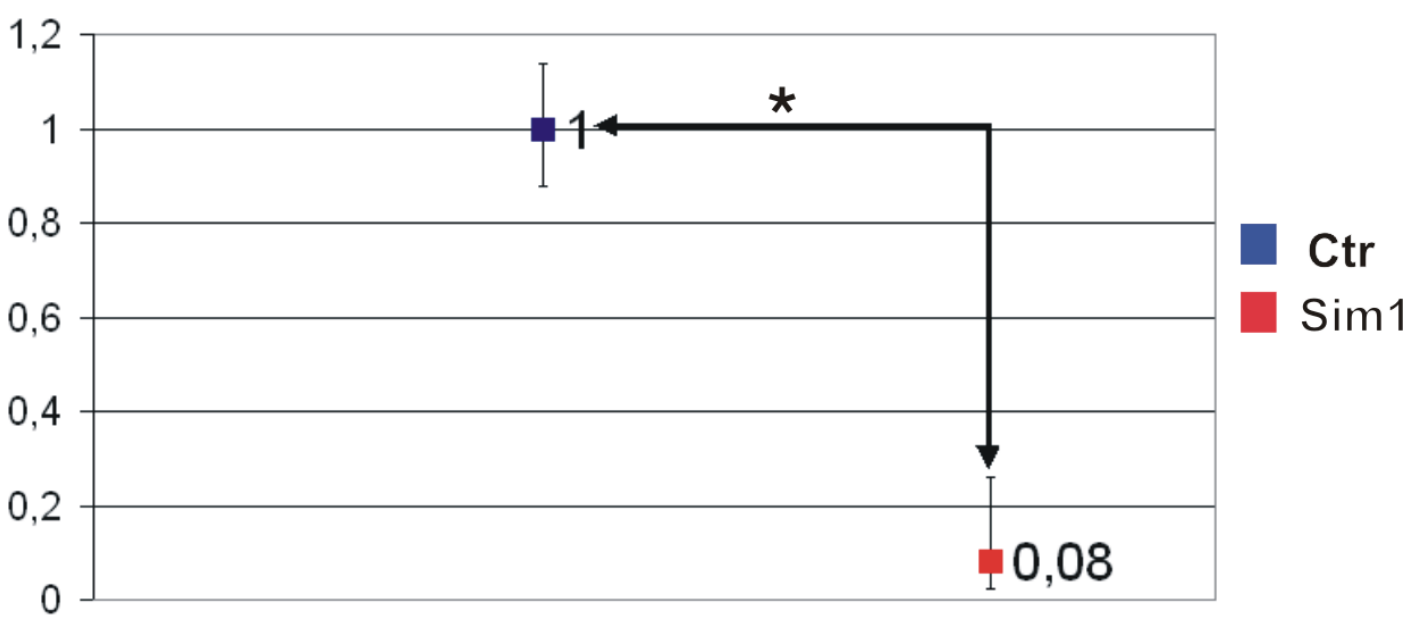

$24 \mathrm{~h}$

Abb. 28: Repräsentative Analyse der Genexpression von Pet1 mittels Quantitativer-„Real-Time“PCR in MN9D-Zellen nach Herabregulation der Expression von Sim1 mittels spezifischer siRNA (Sim1-Cy5) nach $24 \mathrm{~h}$ im Vergleich zu Ctr-siRNA-Alexa 488-transfizierten MN9D-Zellen. Pet1 wird nach Reduktion der Translation der Sim1-mRNA signifikant herunterreguliert. Statistische Signifikanz: ${ }^{\star} P<0,05,{ }^{* *} P<0,01,{ }^{* \star *} P<0,001$; statistisch nicht signifikant (n. s.) $P \geq 0,05$.

\subsubsection{Die Einflussnahme von Tgf- $\beta$ auf die Entwicklung von 5-HT-Neurone verläuft unabhängig von Sim1}

Basierend auf der Identifizierung von möglichen Zielgenen des Transkriptionsfaktors Sim1 als Mitglieder der Tgf- $\beta$-Superfamilie (Liu et al. 2003) wurde untersucht, ob Sim1 einen denkbaren, regulatorischen Einfluss auf die Expression endogener Tgf- $\beta$ s ausübt. Zu diesem Zweck wurde die cDNA Sim1-überexprimierender MN9D-Zellen bezüglich ihrer Tgf- $\beta 2$ Expression mittels qRT-PCR mit nicht Sim1-überexprimierenden MN9D-Zellen verglichen. Tgf- $\beta 2$ wurde aufgrund seines in vivo beobachteten Einflusses auf die Induktion rostraler 5-HT-Neurone des ventralen Rhombencephalon und Aufrechterhaltung 5-HT-Neurone der Paramedianen Raphe (B5/B8, siehe hierzu Punkt 2.3., Seite 16) als relevanteste Tgf- $\beta$ Isoform gewählt. Abb. 29 (Seite 112) zeigt die Ergebnisse des Expressionsvergleiches von cDNA-Proben aus Sim1-überexprimierenden (pcDNA3::Sim1) MN9D-Zellen (rot) mit 
entsprechenden cDNA-Proben, der als Kontrolle dienenden, mit pcDNA3-transfizierten Zellen (blau) in graphischer Darstellung der Expression $2^{-\Delta \Delta C t} \mathrm{zu}$ drei unterschiedlichen Zeitpunkten, 24 h, 48 h und 72 h nach Transfektion. Lediglich nach 24 h war durch die Überexpression von Sim1 eine signifikante Steigerung der Tgf- $\beta 2$-Expression auf das 1,42 fache $\left(+0,12 /-0,08 ;{ }^{*} P=0,016\right)$ des Kontrollwertes $(1+0,06 /-0,03)$ zu bestimmen. $\mathrm{Zu}$ späteren Zeitpunkten (48 h und 72 h) nach Transfektion der Zellen konnte jedoch keine weitere signifikante Änderung der Expression von Tgf- $\beta 2$ im Vergleich zu entsprechenden Kontrollen auf RNA-Ebene festgestellt werden.

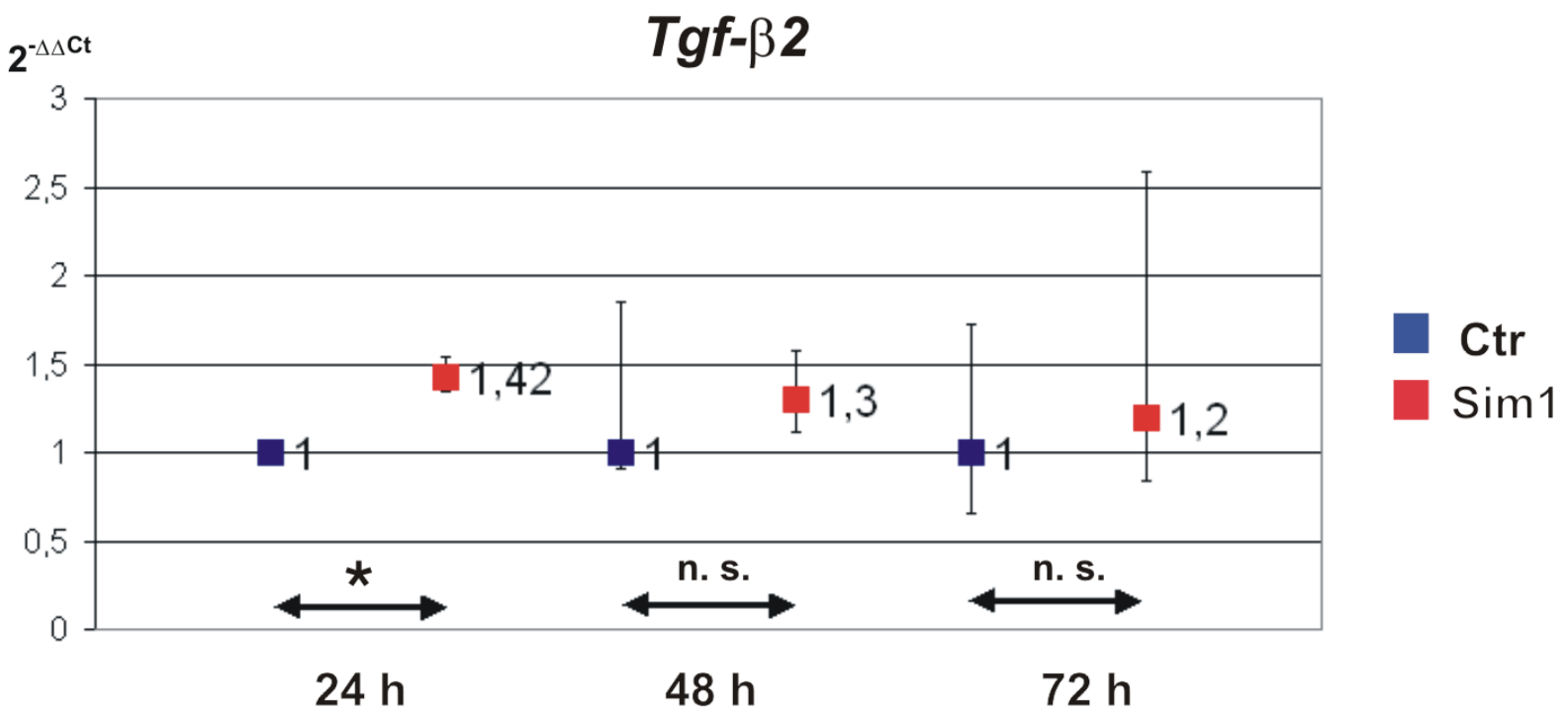

Abb. 29: Quantitative-,,Real-Time“-PCR-Analyse der Genexpression von Tgf- $\beta 2$ in cDNA-Proben aus Sim1-überexprimierenden MN9D-Zellen ( $p c D N A 3:: \operatorname{Sim1}$, rot) im Vergleich zu cDNA-Proben nicht Sim1-überexprimierender Zellen ( $p c D N A 3$, blau) zu unterschiedlichen Zeitpunkten. Überexpression von Sim1 führte zu einer vorübergehenden, signifikanten Änderung der Expression von Tgf- $\beta 2$ auf RNA-Ebene in MN9D-Zellen innerhalb von $24 \mathrm{~h}\left({ }^{*} P=0,02\right)$ nach der Transfektion. $48 \mathrm{~h}$ und $72 \mathrm{~h}$ nach Transfektion der Plasmid-DNA erfolgt signifikante keine Änderung der Tgf- $\beta 2$ Expression. (Bestimmung der relativen RNA-Mengen mittels mathematischer Anwendung der vergleichenden $\Delta \Delta \mathrm{Ct}$ Methode, $\left(2^{-\Delta \Delta \mathrm{Ct}}\right)$, statistische Signifikanz: ${ }^{*} P<0,05 ;{ }^{* \star} P<0,01 ;{ }^{* \star *} P<0,001$; statistisch nicht signifikant (n. s.) $P \geq 0,05, \mathrm{n}=2$ ).

Die durch qRT-PCR erhaltenen Daten der Tgf- $\beta 2$-Expression zeigen, dass eine Überexpression von Sim1 in MN9D-Zellen in keiner langfristigen Regulation der endogenen Expression von Tgf- $\beta 2$ resultiert. 


\subsection{Identifizierung von Kandidatengenen der Entwicklung von 5-HT-Neuronen durch Vergleich des Genexpressionsmusters von ventralem rostralen Rhombencephalon und ventralem Mesencephalon der Maus (E11)}

\subsection{1. Überprüfung der präparierten Gehirnregionen des ventralen Mesencephalon und ventralen Rhombencephalon der Maus, E11}

Basierend auf der ontogentischen Verwandtschaft rostraler 5-HT-Neurone des ventralen Rhombencephalon mit DA-Neurone des ventralen Mesencephalon wurde ein Genexpressionsvergleich dieser beiden Gehirnbereiche mittels cDNA-Mikroarray durchgeführt. Als Ausgangsmaterial diente hierzu Gesamt-RNA aus Gewebe des ventralen Mesencephalon und des ventralen rostralen Rhombencephalon am E11 der Maus, dem Zeitpunkt des Beginns der Induktion von 5-HT-Neuronen und DA-Neuronen. Hierdurch sollte es ermöglicht werden, erste Hinweise auf jene wesentlichen Unterschiede in der Genexpression intrinsischer Faktoren ventraler Vorläuferzellen beider Neuronenpopulationen zu gewinnen, die zur Entwicklung des einen bzw. des anderen Neuronentyps führen. Nach Isolation der Gesamt-RNA und Überprüfung der RNA-Integrität (siehe hierzu Punkte 4.2.6.4. und 4.2.6.5., Seite 61 bzw. Seite 62) wurden die Proben zur cDNA-Synthese eingesetzt. Letztere sowie die Mikroarray-Analyse wurden im Steinbeis-Transferzentrum für ProteomAnalysen (Rostock) durchgeführt. Für den Vergleich der Genexpression zwischen ventralem Mesencephalon und ventralem, rostralem Rhombencephalon wurde der GeneChip® Mouse Genome 430A 2.0 Array von Affimetrix verwendet.

Abb. 30 (Seite 114) zeigt eine graphische Auftragung der Expressionsdaten, welche zur Überprüfung der präparierten Gewebebereiche herangezogen wurden. Auf der y-Achse ist die relative Expression, $2^{-\Delta \Delta c t}$ (rot), im ventralen Rhombencephalon im Vergleich zum ventralen Mesencephalon der Maus E11 aufgetragen. Ebenfalls angegeben ist der $P$-Wert (Überschreitungswahrscheinlichkeit) der ermittelten Expressionswerte, wobei Expressionswerte mit einem $P$-Wert (blau) von $\leq 0,05$ als signifikant eingestuft wurden. Deutlich zu erkennen ist die fehlende Expression des mesencephalen Transkriptionsfaktors Otx2 im ventralen Rhombencephalon der Maus am Embryonaltag E11. Demgegenüber ist das rhombencephale Markergen Gbx2 um das 2fache stärker im ventralen Rhombencephalon exprimiert als im ventralen Mesencephalon der Maus (E11). Somit kann davon ausgegangen werden, dass es während der Präparation der beiden Ausgangsgewebe zu keiner Gewebekontamination und damit Verfälschung der Expressionsdaten gekommen ist. Um darüber hinaus die kaudale Grenze des präparierten ventralen Rhombencephalon festzulegen, wurden die relativen Expressionswerte einzelner Hox-Gene graphisch aufgetragen, welche die Rhombomere 1-7 determinieren (Krumlauf et al., 1993) Die 
Zuordnung der exprimierten Hox-Gene Hoxb1, Hoxa2, Hoxb2, Hoxa3, Hoxb3, Hoxd3 und Hoxa4 zu den Rhombomeren ist in einer Farbtafel widergespiegelt. Hier zeigt sich, dass einzelne Hox-Gene in mehreren Rhombomeren zum Zeitpunkt E11 exprimiert werden, so z.B. Hoxa2 oder Hoxd3. Hierdurch lassen sich auch die stark variierenden Expressionswerte der Hox-Gene untereinander erklären. Anhand der Darstellung der Expressionsdaten in Bezug auf die einzelnen Rhombomere konnte bestimmt werden, dass die in den Mikroarray eingesetzte cDNA des ventralen Rhombencephalon einer präparierten Geweberegion der R1-R6 entspricht. Aufgrund eines sehr hohen $P$-Wertes $(P=0,15)$, wurde der Expressionswert des Gens Hoxa4 als nicht zuverlässig eingestuft. Ein höherer $P$-Wert der detektierbaren Expression hängt unter anderem mit einer sehr schwachen Signalstärke zusammen, so dass davon auszugehen ist, dass das Gebiet des R7 nicht vollständig in der Gewebepräparation erfasst wurde.

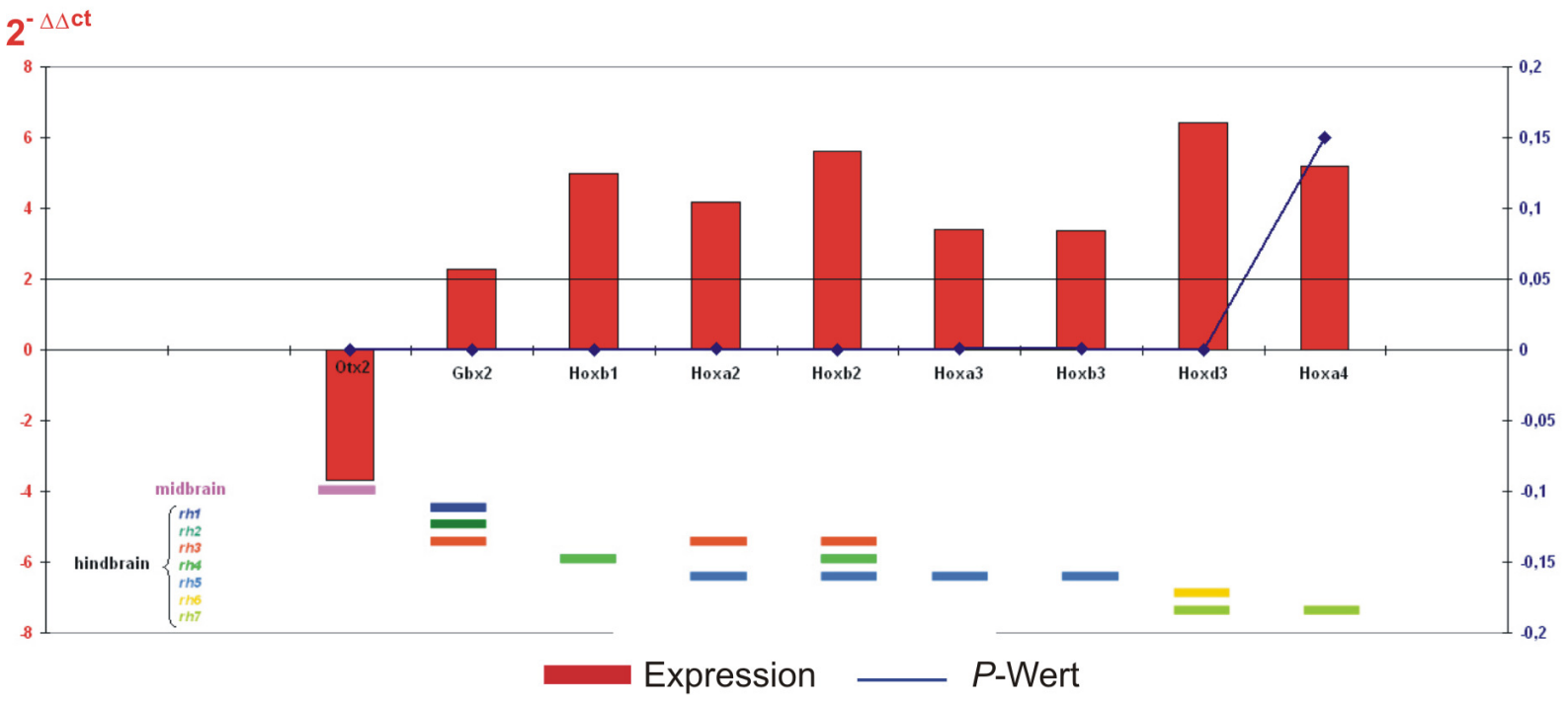

Abb. 30: Graphische Darstellung der relativen Werte der Genexpression im ventralen Rhombencephalon im Vergleich zum ventralen Mesencephalon der Maus des Embryonaltages (E) 11, ermittelt durch Vergleich der entsprechenden Genexpressionsmuster mittels cDNA-Mikroarray. Dargestellt ist die relative Expression $2^{-\Delta \Delta \mathrm{ct}}$ (rot) sowie der $P$-Wert $(P$, blau) für Gbx2 und Otx2, als Determinanten des ventralen Rhombencephalon bzw. des ventralen Mesencephalon, sowie Vertreter der Hox-Genfamilie als Determinanten der Rhombomere 1-7. Expressionswerte mit einem $P$-Wert $(P)$ $\geq 0,05$ wurden als nicht signifikant eingestuft und nicht in die Beurteilung der Qualität der, dem cDNAMikroarray zugrunde liegenden, Gewebepräparationen einbezogen. Eine Expression Otx2 im ventralen Rhombencephalon lag nicht vor. Gbx2 wurde hingegen im Vergleich zum ventralen Mesencephalon über das 2fache erhöht im ventralen Rhombencephalon exprimiert. Eine Zuordnung der Expression repräsentativer Hox-Gene zu den einzelnen Rhombomeren (R) spiegelt die präparierte Geweberegion des Rhombencephalon wieder, welche die R1-6 umfasst. 


\subsubsection{Validierung der durch cDNA-Mikroarray ermittelten Genexpressionsdaten}

Um die durch die cDNA-Mikroarray-Analyse gewonnenen Daten der relativen Genexpression zu überprüfen, wurden die Expressionswerte für einzelne Genen durch qRT-PCR überprüft, wie es unter Punkt 4.2.6.9. (Seite 65) beschrieben ist. Eingesetzt wurden hierbei die, mit den für den cDNA-Mikroarray verwendeten, identischen RNA-Proben des ventralen Rhombencephalon und ventralen Mesencephalon der Maus, E11. Nachfolgende Tab. 3 zeigt die durch qRT-PCR ermittelten, relativen Expressionswerte der Gene, Atoh1, Cyp26B1, Meis1 sowie Sema6d im ventralen Rhombencephalon im Vergleich zum ventralen Mesencephalon der Maus (E11). Die Gegenüberstellung der durch Mikroarray-Analyse erhaltenen Expressionsdaten für diese Gene im ventralen Rhombencephalon (E11) zeigt weitgehend eine Übereinstimmung der durch beide Methoden ermittelten, relativen Expressionswerte. Somit kann davon ausgegangen werden, dass die Daten des cDNAMikroarray als eine Grundlage für die Ermittlung von bisher unbekannten Kandidatengenen der Induktion und Spezifizierung 5-HT-Neurone des ventralen Rhombencephalon der Maus dienen können.

Tab. 3: Gegenüberstellung der durch Quantitative-,,Real-Time“-PCR (qRT-PCR) bzw. cDNAMikroarray erhaltenen, relativen Genexpressionsdaten des ventralen Rhombencephalon im Vergleich zum ventralen Mesencephalon der Maus des Embryonaltages (E) 11. Die Expressionswerte der qRT-PCR sind mit denen des cDNA-Mikroarray vergleichbar.

\begin{tabular}{l|c|c|c}
\multicolumn{1}{c|}{ Gen } & qRT-PCR & cDNA-Mikroarray & $\boldsymbol{P}$-Wert \\
\hline Atoh1 & 3,64 & 2,89 & $\mathbf{2}^{-\Delta \Delta \mathrm{Ct}}$ \\
\hline Cyp26B1 & 4,57 & 4,38 & 0,000244 \\
\hline Meis1 & 3,4 & 3,98 & 0,001221 \\
\hline Sema6d & 3,67 & 3,55 & 0,005859 \\
\hline
\end{tabular}




\subsubsection{Auswahl von Kandidatengenen auf Grundlage der mittels cDNA-Mikroarray ermittelten Genexpresssionsdaten}

Literaturrecherchen führte zu einer ersten, vorläufigen Selektion von Kandidatengenen, welche im ventralen Rhombencephalon im Vergleich zum ventralen Mesencephalon der Maus (E11) mindestens um das 2,5fache heraufreguliert waren. Auswahlkriterien waren hierbei in erster Linie bisherige Erkenntnisse über eine Beteiligung des jeweiligen Gens in generelle, entwicklungsbiologische Prozesse. Hierzu gehört z. B. eine nachgewiesene Beteiligung an der Neurogenese oder Zellmigration. Darüber hinaus wurden ebenfalls Gene in die Auswahl aufgenommen, die im Bezug zu neurologischen Erkrankungen stehen, welche Ähnlichkeiten zu Erkrankungen basierend auf einer Dysfunktion des 5-HT-Systems aufweisen. Gene mit erhöhtem Fehlerwert $(P \geq 0,05)$ wurden zu diesem Zeitpunkt noch nicht von der Auswahl ausgeschlossen. Die Auswahl beschränkte sich zunächst nur auf Gene, die im ventralen Rhombencephalon im Vergleich zum ventralen Mesencephalon heraufreguliert waren. Interessante Gene, die jedoch eine geminderte Expression im ventralen Rhombencephalon aufwiesen, wurden zu diesem Zeitpunkt nicht berücksichtigt. Nachfolgende Abb. 31 (Seite 117) gibt eine erste Auswahl von Genen wieder, welche im Vergleich zu einer Expression im ventralen Mesencephalon zu den 300 am höchsten im ventralen Rhombencephalon der Maus (E11) exprimierten Genen gehören. 


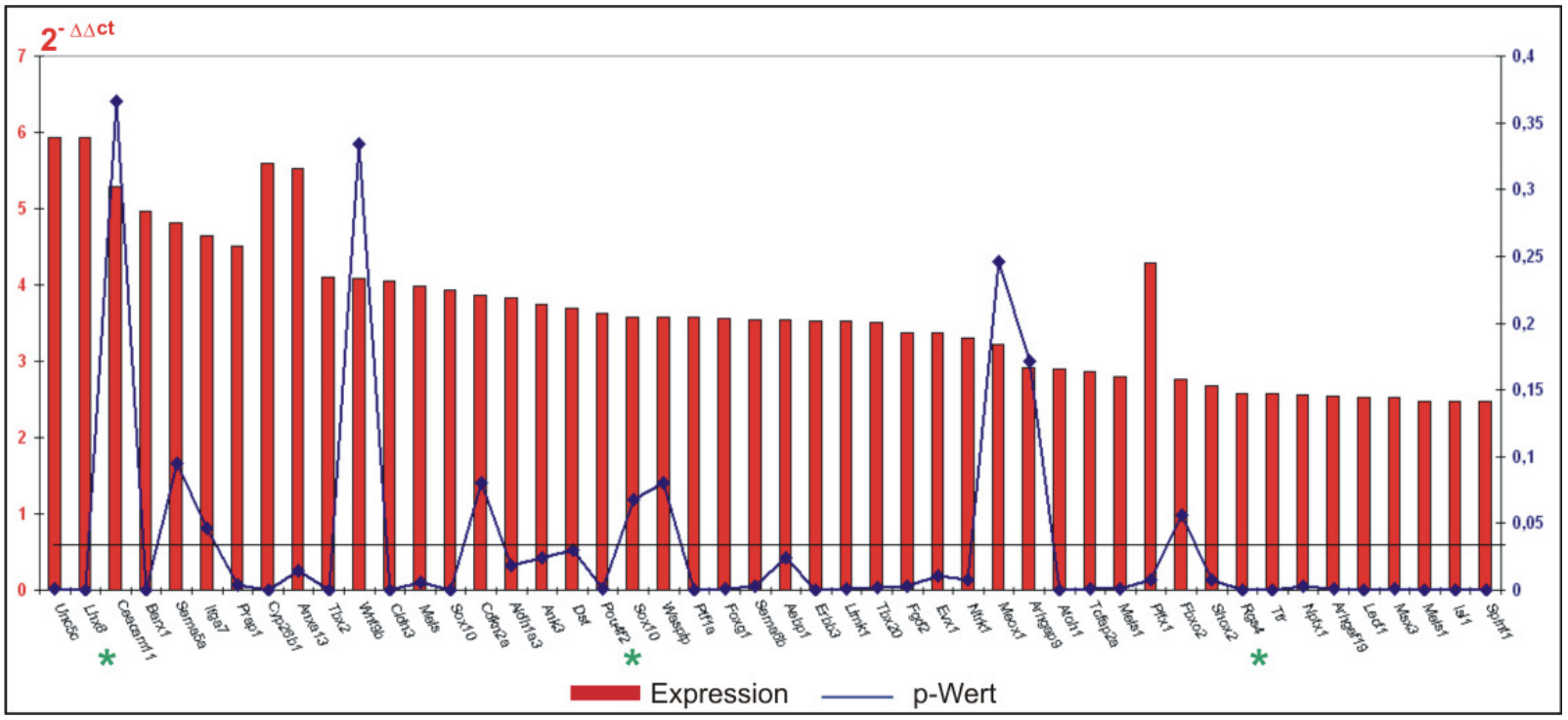

Abb. 31: Graphische Darstellung der relative Genexpression, 2- ${ }^{\Delta c t}$, von ausgesuchten Genen, basierend auf einem Genexpressionsvergleich des ventralem Rhombencephalon mit dem ventralem Mesencephalon der Maus des Embryonaltages (E) 11. Angegeben sind Gene mit u. a. bekanntem Bezug zu entwicklungsbiologischen Prozessen und einer denkbaren Beteiligung an der Induktion und Spezifikation serotonerger (5-HT-) Neurone des ventralen Rhombencephalon der Maus. Ebenfalls angegeben ist der $P$-Wert $(P)$ der Expression jedes Gens, welcher jedoch zunächst nicht in die Auswahl miteinbezogen wurde. $\left({ }^{*}=\right.$ gewählte Kandidantengene)

Die, sich aus den in Abb. 31 angegebenen Genen zusammensetzende, Auswahl wurde in Hinblick auf mögliche regulatorische Interaktion dieser Genprodukte mit Tgf- $\beta$ s und Sim1 weiter eingegrenzt (* in Abb. 31). Auf drei Kandidatengene soll im Weiteren näher eingegangen werden: Brn3.2, Rgs4 und Lhx8.

\section{Der Transkriptionsfaktor Brn3.2 -- Ein Zielgen von Sim1}

Der Transkriptionsfaktor Brn3.2 („Brain-specific homeobox/POU domain protein 3b“, Pou4f2) gehört zur Klasse der Pou-Homeodomänen Proteine (Schonemann et al., 1998) und wies im cDNA-Mikroarray eine um das 3,62fache höhere Expression im ventralen Rhombencephalon der Maus (E11) im Vergleich zum ventralen Mesencephalon auf. Der im ZNS exprimierte Transkriptionsfaktor Brn3.2 ist z. B. an der terminalen Differenzierung neuronaler Phänotypen beteiligt. Interessanter Weise konnte gezeigt werden, dass in Teratocarcinoma and Neuroblastoma Zellen Brn3.2 in seiner Expression durch Retinolsäure (RA) reguliert wird (Turner et al., 1994). Des Weiteren ist Brn3.2 z. B. zusammen mit Islet1 („Insulin related protein 1"), einem LIM-Homeodomänen Transkriptionsfaktor, an der Differenzierung der 
retinalen Ganglionzellen („Retinal ganglion cells“, RGC) beteiligt ( Mu et al., 2008; Pan et al., 2008). Darüber hinaus nimmt es nicht nur Einfluss auf die Differenzierung der Vorläuferzellen in Richtung zu RGC, sondern erfüllt auch eine wesentliche Funktion bei der Unterdrückung anderer Entwicklungsprogramme in den Vorläuferzellen (Qiu et al., 2008).

\section{Das Regulatorprotein Rgs4 - Ein Zielgen von Sim1}

Ebenfalls in die Auswahl aufgenommen wurde Rgs4 („Regulator of G-protein signalling 4“) mit einer relativen, um 2,58 höheren Expression im ventralen Rhombencephalon im Vergleich zum ventralen Mesencephalon der Maus (E11). Es wird stark im zentralen Nervensystem exprimiert. Eine deutlich geringere Expression findet sich in Herz, Lunge, Leber und skeletaler Muskulatur (Nomoto et al., 1997). Rgs4 ist ein GTPase-aktivierendes Protein, spezifisch für Gi- und $\mathrm{G}_{\mathrm{q}}$ - $\alpha$ Untereinheiten von G-Proteinen, die duch Rgs4 negativ reguliert werden. Obwohl kein Transkriptionsfaktor, weist Rgs4 mehrere interessante Bezüge zur Regulation des 5-HT-System und seiner Dysfuktionen, z. B. der Schizophrenie auf, entweder durch genetische Polymorphismen oder durch eine Veränderung seiner regulatorischen Funktion (Ding et al., 2007)

\section{Der Transkriptionsfaktor Lhx8 - Ein Zielgen von TGF- $\beta$ und Sim1}

Der Transkriptionsfaktor Lhx8 („LIM homeobox 8“, L3) gehört mit einer relativen Expression von 5,94 zu den am stärksten hochregulierten Gene im ventralen Rhombencephalon der Maus (E11) im Vergleich zum ventralen Mesencephalon. Er gehört zur Klasse der LIMHomeobox-Transkriptionsfaktoren, die an verschiedenen Entwicklungsprogrammen beteiligt sind, hierzu gehören die Organisation des Zytoskeletts, zelluläre Spezifikation, Muskelzellenund Neuronendifferenzierung sowie die Bildung des Auges. Lhx8 ist in die Spezifikation und Differenzierung unterschiedlicher neuronaler Zelltypen, wie cholinergen Neuronen des basalen Telencephalon, während der embryonalen Entwicklung beteiligt (Manabe et al., 2007) sowie der Determinierung des GABAergen Phänotyps (Manabe et al., 2005). Neben diesen, das Gehirn betreffenden Funktionen, konnte eine Bedeutung von Lhx8 auch in der Zahnentwicklung (Shibaguchi et al., 2003) und in der embryonalen Entwicklung des Gaumens gezeigt werden (Zhao et al., 1999). 
Die Angaben der Genexpression der drei Kandidatengene Brn3.2, Rgs4 und Lhx8 im ventralen rostralen Rhombencephalon im Vergleich zum ventralen Mesencephalon der Maus (E11) wie sie nach dem cDNA-Mikroarray erhalten worden waren, wurden ebenfalls durch qRT-PCR unter Verwendung der selben, in den cDNA-Mikroarray eingesetzten cDNAProben, überprüft (Punkt 4.2.6.9., Seite 65). Nachfolgende Abb. 32 zeigt die durch qRT-PCR ermittelten, relativen Expressionswerte der drei Kandidatengene Brn3.2, Rgs4 sowie Lhx8 im ventralen Rhombencephalon im Vergleich zum ventralen Mesencephalon. Eine deutlich erhöhte Expression im ventralen rostralen Rhombencephalon im Vergleich zum ventralen Mesencephalon der Maus (E11) konnte für alle drei Gene bestätigt werden.

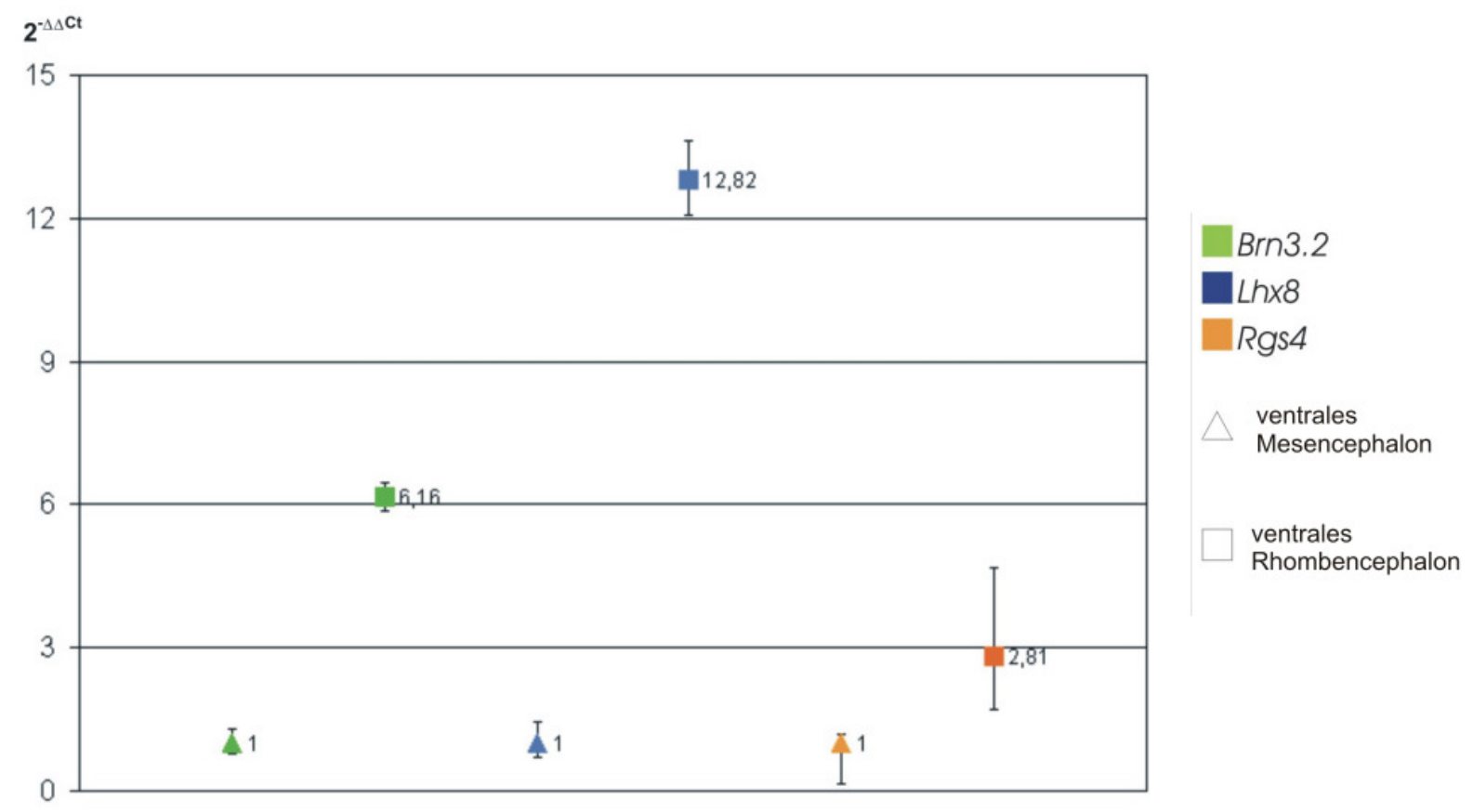

\footnotetext{
Abb. 32: Gegenüberstellung der durch Quantitative-,Real-Time“-PCR (qRT-PCR) bzw. cDNAMikroarray-Analyse erhaltenen, relativen Genexpressionsdaten der Kandidatengene Brn3.2, Lhx8 und Rgs4 im ventralen Rhombencephalon im Vergleich zum ventralen Mesencephalon der Maus des Embryonaltages (E) 11. Die gesteigerte Expression der drei Kandidatengene im ventralen rostralen Rhombencephalon der Maus (E11), wie sie die Auswertung des cDNA-Mikroarray zeigte, konnte mittels qRT-PCR-Analyse bestätigt werden.
} 


\subsubsection{Sim1-Überexpression in MN9D-Zellen führt zu einer signifikanten Steigerung der Expression der Kandidatengene Brn3.2 und Rgs4}

Um eine vorstellbare Regulation der Gene Brn3.2 und Rgs4 durch Sim1 zu untersuchen, wurden „Gain-of-function“-Experimente durchgeführt. Zum Einsatz kamen hierbei Zellen der Zelllinie MN9D, die wie unter Punkt 4.2.2.3. (Seite 42) beschrieben, mit dem Überexpressionsplasmid pcDNA3::Sim1 bzw. zum Zwecke der Kontrolle mit pcDNA3 transfiziert wurden. $1 \times 10^{6} \mathrm{MN} 9 \mathrm{D}$-Zellen wurden in $25 \mathrm{~cm}^{2}$-Kulturflaschen ausplattiert und am folgenden Tag mittels des Transfektionsreagenz Lipofectamine transfiziert. $24 \mathrm{~h}, 48 \mathrm{~h}$ und $72 \mathrm{~h}$ nach erfolgter Transfektion der Zellen wurde aus beiden experimentellen Gruppen die Gesamt-RNA isoliert und diese in gleich hoher Konzentration in die cDNA-Synthese eingesetzt (siehe Punkt 4.2.6.6., Seite 63). Des Weiteren wurde aus dem gleichen Zellmaterial Gesamt-Protein isoliert (Punkt 4.2.8.1., Seite 75) um eine Sim1-Überexpression auch auf Proteinebene nachweisen zu können. Konnte eine Überexpression von Sim1 in MN9D-Zellen durch Western-Blot-Analyse, wie unter Punkt 4.2.8.4. (Seite 77) erläutert, bestimmt werden, wurde der Einfluss dieser Sim1-Überexpression auf die Expression der Gene Rgs4 und Brn3.2 durch qRT-PCR untersucht. In Abb. 33 (Seite 121) ist die Expression des Rgs4-Gens in cDNA-Proben von Sim1-überexprimierenden (pcDNA3::Sim1) MN9DZellen (Sim1, rot) und von pcDNA3-transfizierten MN9D-Zellen (Ctr, blau) dargestellt. $24 \mathrm{~h}$ nach Transfektion der MN9D-Zellen mit pcDNA3::Sim1 ist im Vergleich zur Expression des Rgs4-Gens in mit pcDNA3-transfizierten MN9D-Zellen eine Heraufregulation der Rgs4Expression festzustellen (Ctr $1+0,06 /-0,07 ; \operatorname{Sim} 11,7+0,15 /-0,16 ;{ }^{*} P=0,003$ ). Eine Heraufregulation von Rgs4 konnte in cDNA aus pcDNA3::Sim1-transfizierten MN9D-Zellen im Vergleich zu pcDNA3-transfizierten Zellen nach $48 \mathrm{~h}$ (Ctr $1+0,32 /-0,24 ; \operatorname{Sim} 1$ 1,29 $+0,39 /-0,12 ; P=0,0998)$ sowie 72 h $(C \operatorname{tr} 1+0,85 /-0,46$; $\operatorname{Sim} 11,63+0,83 /-0,15 ; P=0,21)$ nach der Transfektion nicht dokumentiert werden. Hieraus kann geschlossen werden, dass Sim1 in vitro die Expression von Rgs4 in MN9D-Zellen innerhalb von $24 \mathrm{~h}$ nach Transfektion positiv reguliert. 


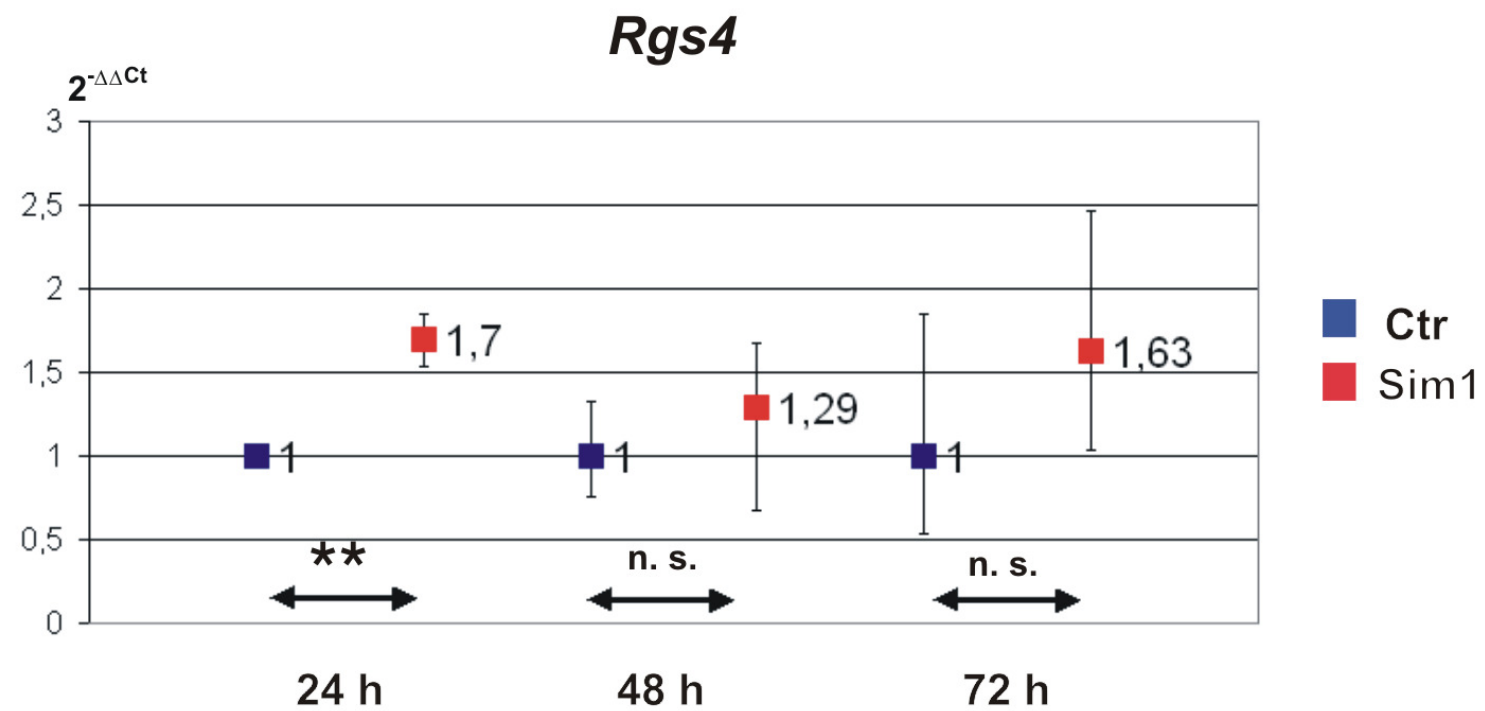

Abb. 33: Quantitative-,,Real-Time“-PCR-(qRT-PCR)-Analyse der Expression von Rgs4 in cDNA aus MN9D-Zellen nach Überexpression des Transkriptionsfaktors Sim1(rot) im Vergleich zu cDNA aus MN9D-Kontrollansätzen (blau) zu verschiedenen Zeitpunkten (24 h, 48 h, 72 h). Sim1Überexpression in MN9D-Zellen führt zu einer signifikanten Heraufregulation der Expression von Rgs4 nach $24 \mathrm{~h}$ im Vergleich zu nicht Sim1-überexprimierenden Kontrollen. Bestimmung der relativen RNA-Mengen mittels mathematischer Anwendung der vergleichenden $\Delta \Delta \mathrm{Ct}$ Methode, $\left(2^{-\Delta \Delta C t}\right)$, statistische Signifikanz: ${ }^{*} P<0,05 ;{ }^{*} P<0,01 ;{ }^{* *} P<0,001$; statistisch nicht signifikant (n. s.) $P \geq 0,05, \mathrm{n}=3$.

Abb. 34 (Seite 122) zeigt die Ergebnisse der qRT-PCR Analyse der Brn3.2-Genexpression in Sim1-überexprimierenden MN9D-Zellen ( $p c D N A 3:: S i m 1$, rot) im Vergleich zu in pcDNA3transfizierten MN9D-Zellen (blau). Während $24 \mathrm{~h}$ sowie $72 \mathrm{~h}$ nach der Transfektion keine Beeinflussung der Brn3.2-Expression durch Sim1 nachweisbar war (Ctr 1+0,05/-0,06; Sim1 1,1+0,06/-0,29; $P=0,154$ bzw. (Ctr $1+0,14 /-0,13$; Sim1 1,1+1,15/-0,7; $P=0,21$ ), konnte $48 \mathrm{~h}$ nach der Transfektion eine signiikante Heraufregulation der Brn3.2-Expression festgestellt werden (Ctr $1 \pm 0,1$; Sim1 1,94 $+0,31 /-0,27 ;{ }^{\star \star} P=0,0023$ ). Somit führt eine Überexpression von Sim1 in vitro zu einer signifikanten Heraufregulation der Brn3.2Expression in MN9D-Zellen innerhalb von $48 \mathrm{~h}$ nach Beginn der Transfektion. 


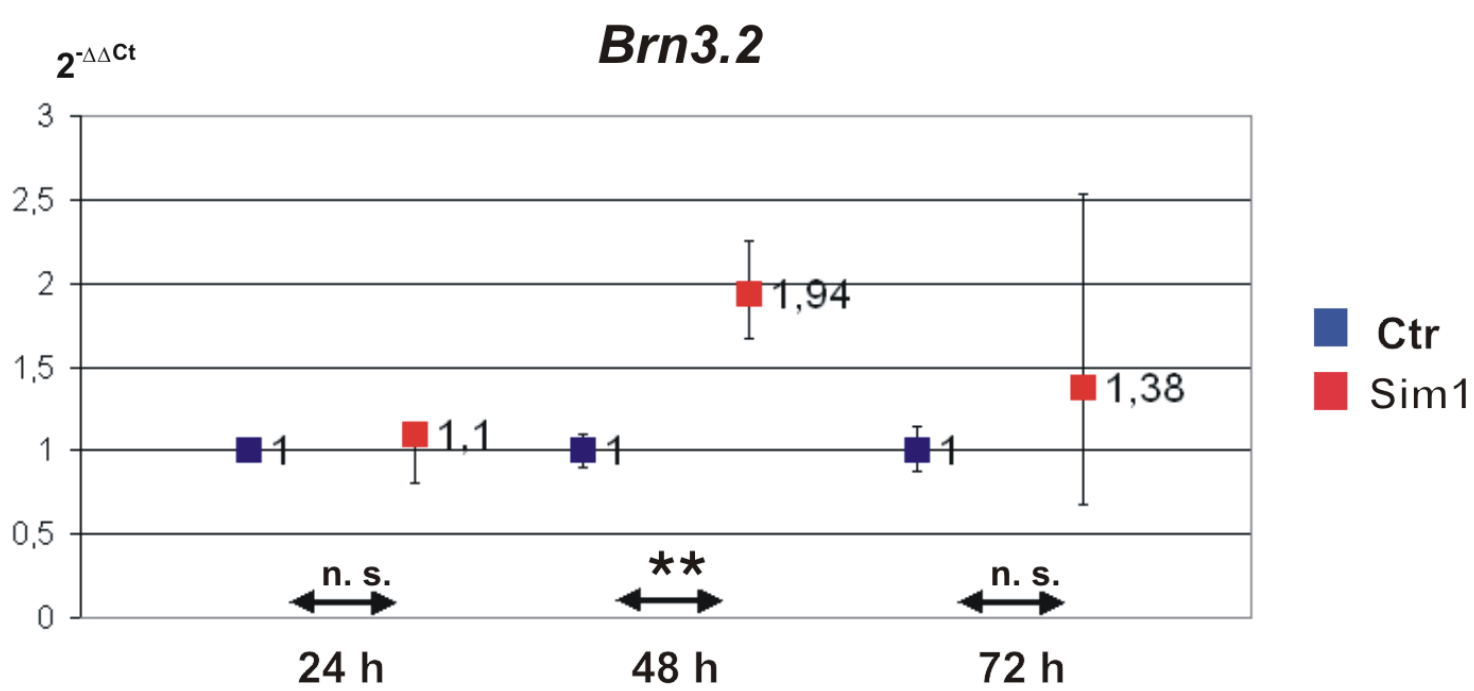

Abb. 34: Quantitative-„Real-Time“-PCR-Analyse der Genexpression von Brn3.2 in cDNA aus Sim1-überexprimierenden MN9D-Zellen (Sim1, rot) im Vergleich zu cDNA-Proben aus pcDNA3-transfizierten MN9D-Zellen (blau). Überexpression von Sim1 führt zu einer signifikant gesteigerten Expression von Brn3.2 in MN9D-Zellen innerhalb eines Zeitraumes von $48 \mathrm{~h}$ nach erfolgter pcDNA3::Sim1-Transfektion. Bestimmung der relativen RNA-Mengen mittels mathematischer Anwendung der vergleichenden $\Delta \Delta \mathrm{Ct}$ Methode, $\left(2^{-\Delta \Delta \mathrm{Ct}}\right)$, statistische Signifikanz: ${ }^{\star} P<0,05 ;{ }^{* \star} P<0,01 ;{ }^{\star \star \star} P<0,001$; statistisch nicht signifikant (n. s.) $P \geq 0,05, \mathrm{n}=3$. 


\section{Diskussion}

Während der Entwicklung des ZNS erfolgt die Induktion neuronaler Zellpopulationen bis hin zum Erreichen des jeweiligen terminalen Differenzierungszustandes über die Abfolge spezifischer, exakt regulierter Prozesse. Wie kompliziert hierbei die regulatorischen Netzwerke sind, welche die Induktion und Spezifikation neuraler Vorläuferzellen zu unterschiedlichen Zelltypen bestimmen, verdeutlicht die Tatsache, dass selbst Subpopulationen der gleichen neuronalen Zellpopulation sich in ihrer Abhängigkeit von extrinsischen Signalmolekülen und der Expression intrinsischer Faktoren erheblich unterscheiden können. Das umfassende Verständnis der molekularen Mechanismen der Entwicklung und Aufrechterhaltung der verschiedenen neuronalen Zellpopulationen ist Grundlage für die erfolgreiche Behandlung neurologischer und neurodegenerativer Erkrankungen. Die Relevanz der Erforschung der Entstehung und Steuerung der vielfältigen Funktionen des 5-HT-Systems des ZNS wird deutlich, wenn man die Auswirkungen einer Dysfunktion dieses Systems bedenkt. So sind Migräne, Formen der Depression, Zwangsneurosen sowie schwere Erkrankungen wie Borderline-Persönlichkeitsstörungen, Schizophrenie und Autismus, aber auch Drogenmissbrauch eng mit dem 5-HT-System verknüpft (Croonenberghs et al., 2007; Ressler und Nemeroff, 2000; Yoon et al., 2008). Darüber hinaus ist das 5-HT-System an Mechanismen der Gedächtnisbildung und des Lernens beteiligt (King et al., 2008).

Wie auch für andere Neuronenpopulationen ist das Netzwerk aus intrinsischen und extrinsischen Faktoren, welches für die Entstehung von 5-HT-Neuronen verantwortlich ist, bisher nur unzureichend aufgeklärt worden. Einen essentiellen Beitrag zur Entstehung zentraler 5-HT-Neurone steuern Signalmoleküle wichtiger Signalzentren bei. 5-HT-Neurone entstehen kaudal des IstO im Rhombencephalon aus neuroepithelialen Vorläuferzellen der ventrikulären Zone („Ventricular zone“, VZ). In unmittelbarer Nachbarschaft wird Fgf8 im Isthmus synthetisiert und freigesetzt (Crossley and Martin, 1995). Zu weiteren, bislang bekannten extrinsischen Faktoren gehören Shh (Briscoe et al., 1999; Echelard et al., 1993), sezerniert von der Grundplatte, sowie Fgf4 (Shamim und Mason, 1999). Dabei ist die Bedeutung des Einflusses von Fgf4 für die Entwicklung von 5-HT-Neuronen im Gegensatz zu den innen ontogenetisch verwandten dopaminergen (DA-) Neuronen hervorzuheben. Dennoch ist Fgf4 nicht allein für die Einschlagung des Entwicklungsweges von neuralen Vorläuferzellen zu 5-HT-Neurone verantwortlich. Weitere Untersuchungen auf diesem Weg sind notwendig, um weitere Faktoren ermitteln zu können. Die extrinsische Signalmoleküle Shh, Fgf8 und Fgf4 werden auf transkriptioneller Ebene durch intrinsische Faktoren zu einem regulatorischen Netzwerk ergänzt, welches jedoch nicht allgemeingültig, sondern im Hinblick auf die Entwicklung einzelner Subpopulationen 5-HT-Neurone, variabel ist. Zeitlich lässt sich 
die Entwicklung von neuralen Vorläuferzellen zu 5-HT-Neuronen in zwei Phasen gliedern, die durch die Expression von Transkriptionsfaktoren definiert werden. Nach Induktion der 5-HT-Vorläuferzellen treten diese in die zweite Entwicklungsphase, die postmitotische Entwicklung ein, welche beginnend mit der Differenzierung bis zur Ausbildung des terminalen 5-HT-Phänotyps andauert. Als mitotisch exprimierte, intrinsische Faktoren, welche zur Entwicklung 5-HT-Neurone beitragen, wurden bisher die Transkriptionsfaktoren Nkx2.2 und Mash1 identifiziert (Cheng et al, 2003; Pattyn et al., 2004; Guillemot et al., 1993). Der durch Shh induzierte Transkriptionsfaktor Nkx2.2 ist bedeutsam für die Spezifizierung ventraler Zelltypen und ist als einer der ersten Transkriptionsfaktoren der Induktionsphase in 5-HT-Vorläuferzellen exprimiert (Vokes et al., 2007; Hynes et al., 2000). Bereits in diesem frühen Stadium zeigt sich eine unterschiedliche Abhängigkeit von 5-HT-Subpopulationen von der Expression von Transkriptionsfaktoren. So sind 5-HT-Neuronen der kaudalen Gruppe von Nkx2.2 abhängig, rostrale 5-HT-Neuronen weisen diese Abhängigkeit jedoch nur mit Ausnahme des Abkömmlings des Rombomers (R) 1, dem Nucleus raphe dorsalis (NRD), auf (Ding et al., 2003; Pattyn et al., 2003). Wie Nkx2.2 wird auch Mash1 in ventralen Vorläuferzellen exprimiert, hierunter auch in 5-HT-Vorläufern. Eine ektopische Expression von Nkx2.2 und Mash1 ist jedoch, obwohl beide Transkriptionsfaktoren für die Entwicklung eines Großteils von 5-HT-Neuronen notwendig sind, nicht in der Lage 5-HT-Neurone zu induzieren (Pattyn et al. 2004). Die Identität von mindestens einem weiteren essentiellen Faktor, welcher die endgültige Festlegung von Vorläuferzellen auf den Entwicklungsweg von 5-HT-Neuronen bestimmt, konnte bisher nicht aufgedeckt werden. Mit Eintritt in die postmitotische Entwicklungsstufe von 5-HT-Neuronen werden die Transkriptionsfaktoren Gata2 (Craven et al., 2004), bzw. in Vorläuferzellen der kaudalen 5-HT-Neuronenpopulation im Rhombencephalon der Maus Gata3 exprimiert. Als einziger spezifischer Marker von 5-HT-Neuronen konnte bisher nur der Transkriptionsfaktor Pet1 bestimmt werden (Fyodorov et al., 1998). Pet1 reguliert u. a. die Expression der Gene Tph2, Vmat und Sert und hierdurch das Erreichen der terminalen Differenzierung zum 5-HT-Neuron (Hendricks et al., 1999).

Bis heute ist weder vollständig bekannt, wie die beschriebenen intrinsischen und extrinsischen Faktoren in Bezug zueinander stehen, noch ist bekannt welche weiteren Faktoren an der Entwicklung von 5-HT-Neuronen beteiligt sind. Weiter unten wird detailliert dargestellt, dass die bislang identifizierten Faktoren allein nicht zur terminalen Differenzierung der Vorläuferzellen und der Determinierung des serotonergen Phänotyps ausreichen. Die Aufklärung des komplexen Zusammenspiels extrinsischer Signalmoleküle und intrinsischer Faktoren während der Neurogenese erfordert ein geeignetes experimentelles System, welches es erlaubt, pluripotente Vorläuferzellen in ihrer Induktion und Differenzierung in unterschiedliche neurale Zelltypen zu beobachten und experimentell zu beeinflussen. Insbesondere die häufig frühe, embryonale Sterblichkeit von Mausmutanten 
und die zeitintensive Generierung von konditionellen Mutanten limitieren ihren Einsatz für die Erforschung von Induktions- und Differenzierungsmechanismen von neuralen Vorläuferzellen. Ein Ziel der vorliegenden Arbeit war es daher, ein geeignetes Kultursystem aus dem ventralen rostralen Rhombencephalon der Maus zu etablieren und dieses in Hinblick auf seine spezifischen Eigenschaften und zelluläre Zusammensetzung zu charakterisieren, als auch in gezielter Weise experimentell in seiner zellulären Entwicklung zu kontrollieren.

Ein häufig in der Literatur beschriebenes System ist das Kulturmodell primärer Neurospheres. Als Neurospheres werden frei-schwimmende Zellaggregate bezeichnet, deren Bildung auf die Proliferation von in ihnen enthaltenen Stamm- und Vorläuferzellen unter dem Einfluss von Mitogenen, z.B. Fgf2 oder Egf, zurückzuführen ist. Somit bietet das System die Möglichkeit, in vitro die Vorläuferzellpopulation eines Gewebes zu expandieren und hierdurch den Anteil von Vorläuferzellen zu vergrößern (Ciccolini, 2001; Gritti et al., 1995; Kelly C.M. et al., 2003; Reynolds und Weiss, 1992; Zhu et al., 1999). Nach Dissoziation der Neurospheres, Ausplattieren derselbigen unter Bedingungen, welche die Differenzierung begünstigen, und Behandlung durch unterschiedliche Faktoren ist es zudem möglich, diese Vorläuferzellen in eine spezifische Richtung hin zu einem bestimmten Neurotransmitterphänotyp zu dirigieren. Die Anwendung des Kultursystems primärer Neurospheres konnte bereits für viele verschiedene Bereiche sowohl des embryonalen als auch des adulten Gehirns von Säugern demonstriert werden, wie z. B. dem Mesencephalon, dem Striatum, dem Hippocampus und dem Telencephalon (Morshead et al. 1994; Palmer et al., 1997; Reynolds und Weiss, 1992; Roisen et al., 2001). Jedoch wurde bisher keine Anwendung dieses Kultursystems primärer Neurospheres aus dem embryonalen ventralen Rhombencephalon der Maus zur Analyse des Netzwerkes intrinsischer und extrinsischer Faktoren der Entwicklung von 5-HT-Neuronen beschrieben. Zu diesem Zweck wurde in der vorliegenden Arbeit Gewebe des ventralen rostralen Rhombencephalon der Maus des Embryonaltages E12 auf seine Fähigkeit zur Bildung von primären Neurospheres hin untersucht. Hierzu wurde das Gewebe zunächst mechanisch und enzymatisch dissoziiert. Die aus Einzelzellen bestehende Zellsuspension wurde unter dem Einfluss der Mitogene Egf und Fgf2 kultiviert. Die Kultivierung der Zellen erfolgte unter serumfreien Bedingungen, wodurch eine nicht kontrollierbare Einflussnahme unbekannter, im Serum enthaltener, Faktoren auf die Zellen verhindert wurde. Sowohl frei-schwimmende als auch teilweise adherente Zellaggregate, sogenannte primäre Neurospheres, konnten aus dem ventralen rostralen Rhombencephalon gewonnen werden, deren Bildung bereits nach vier Tagen sichtbar war (Abb. 5, Seite 80). Der Zeitpunkt der Präparation des ventralen rostralen Rhombencephalon der Maus wurde mit dem Embryonaltag 12 zeitlich nahe dem ersten Auftreten von rostralen 5-HT-Neuronen (E11) gewählt. Des Weiteren ist die Anzahl von in 
diesem Gewebe lokalisierten Vorläuferzellen zu diesem Zeitpunkt am höchsten. Ursprünglich war das Kultursystem primärer Neurospheres zur Anreicherung des Pools neuraler Stammzellen gedacht (Marshall et al., 2008; Rietze und Reynolds, 2006). Daraus folgt, dass die Neurospheres als solche zwei grundlegende Eigenschaften aufweisen müssen: Einerseits die Fähigkeit zur Selbsterneuerung und andererseits die Möglichkeit sich in alle in neuralem Gewebe vorliegenden Zelltypen zu differenzieren (Bazán et al., 2004; Uchida et al. 2000; Weissman, 2000), d. h. in Neurone, Astrozyten und Oligodendrozyten. Die von mir generierten primären Neurospheres besitzen durchaus beide Eigenschaften. Ein erster Hinweis auf die Fähigkeit zur Selbsterneuerung ist die Bildung sekundärer Neurospheres. Letztere wurden nach Dissoziation primärer Neurospheres und Kultivierung in minimaler Zelldichte unter gleichen Kulturbedingungen wie primäre Neurospheres, d. h. in Anwesenheit der Mitogene Fgf2 und Egf generiert (Abb. 6, Seite 81). Grundlegend sollten die Kulturbedingungen die Bildung eines sekundären Neurospheres aus einer einzelnen Stammoder Vorläuferzelle ermöglichen. Da in der vorliegenden Arbeit die dissoziierten primären Neurospheres in einer so geringen Zelldichte kultiviert wurden, ist anzunehmen, dass die gebildeten sekundären Neurospheres ebenfalls von einzelnen Vorläuferzellen abstammen. Gleichzeitig konnte durch die Bildung sekundärer Neurospheres nachgewiesen werden, dass die Bildung primären Neurospheres in der Tat auf die Proliferation von neuralen Vorläuferzellen zurückzuführen war und nicht auf eine Aggregatbildung der Zellen aufgrund einer zu hohen Zelldichte. Ein weiterer Hinweis auf die Fähigkeit zur Proliferation von in primären Neurospheres des ventralen rostralen Rhombencephalon der Maus (E12) enthaltenen neuralen Vorläuferzellen lieferten BrdU-Inkorporationsexperimente. Mitotisch aktive Zellen innerhalb der primären Neurospheres konnten durch Nachweis des inkorporierten BrdU nachgewiesen werden (Abb. 7, Seite 83). Schließlich waren auch mehrere Zellen innerhalb der primären Neurospheres immunreaktiv für das Intermediärfilament Nestin (Lendahl et al. 1990), ein etablierter Marker für Vorläuferzellen (Abb. 7D, Seite 83). Insgesamt belegen die Ergebnisse, dass die in dieser Arbeit generierten primären Neurospheres aus dem ventralen rostralen Rhombencephalon der Maus (E12) über die Eigenschaft der Selbsterneuerung verfügen. Darüber hinaus konnte die zweite grundlegende Eigenschaft primärer Neurospheres, d. h. die Fähigkeit zu Differenzierung in mehrere neurale Zelltypen (,Multilineage differentiation“), ebenfalls bestätigt werden. Für diesen Nachweis wurde folgenden experimentelles Protokoll angewandt. Primäre Neurospheres wurden während ihrer Proliferation über eine Zweitspanne von 2 h-8 h mit BrdU behandelt. Anschließend wurden die primären Neurospheres ausplattiert, und auf PORN-/Lam-beschichtete Deckgläschen plattiert, wodurch die Differenzierung der Zellen ermöglicht wurde. Drei Tage nach dem Ausplattieren wurden die Neurospheres fixiert und immunzytochemisch analysiert. Hierzu wurden $\beta$-III-Tubulin (Caccamo et al., 1989), Gfap 
(Bignami und Dahl, 1977) und O4 (Sommer und Schachner, 1981), als spezifische Marker für differenzierte Neurone, Astrozyten bzw. Oligodendrozyten eingesetzt. Es konnten Zellen nachgewiesen werden, die sowohl BrdU-positiv als auch $\beta$-III-Tubulin-immunreaktiv waren (Abb. 9E, Seite 88). Dies bedeutet, dass diese Neurone tatsächlich von proliferierenden Vorläuferzellen abstammten. Ebenso konnten O4-immunpositive Zellen nachgewiesen werden, die gleichzeitig BrdU-positiv waren (Abb. 9F, Seite 88). Somit stammte zumindest ein Teil der Zellen, welche auf den neuronalen bzw. den glialen Entwicklungsweg festgelegt waren, von proliferierenden neuralen Vorläuferzellen innerhalb der primären Neurospheres aus dem ventralen rostralen Rhombencephalon ab. Im Gegensatz zu O4-immunpositiven Zellen konnten in den primären Neurospheres keine Gfap-immunreaktiven Zellen detektiert werden. Dieser Befund beruht möglicherweise auf dem frühen Zeitpunkt der Kultivierung und/oder auf der spontanen und nicht experimentell gesteuerten Differenzierung der primären Neurospheres zu Astrozyten. An dieser Stelle sei daraufhingewiesen, dass sich innerhalb der primären Neurospheres auch O4- bzw. $\beta$-III-Tubulin-positive Zellen aufzeigen ließen, in denen keine gleichzeitige Immunreaktivität für BrdU vorlag (Abb. 9, Seite 88). Dies belegt, dass die $\beta$-III-Tubulin-positiven bzw. O4-immunpositiven jedoch BrdU-negativen Zellen bereits vor der BrdU-Behandlung ausdifferenziert waren und daher nicht von proliferierenden Vorläuferzellen in den primären Neurospheres abstammten. Für das hier etablierte Kultursystem primärer Neurospheres aus dem ventralen rostralen Rhombencephalon bedeutet dies, dass dieses Kultursystem eine heterogene, zelluläre Zusammensetzung aufweist, bestehend aus proliferierenden Vorläuferzellen aber auch aus bereits in die Differenzierung eingetretenen Zellen, Neuronen und Oligodendrozyten. Vereinzelt konnten sogar 5-HT-immunpositive Zellen nachgewiesen werden (Abb. 9D, Seite 88).

Die komplexe zelluläre Zusammensetzung der primären Neurospheres konnte zudem durch RT-PCR untermauert werden. Das Vorliegen von sich zu Neuronen und Oligodendrozyten differenzierenden Zellen konnte durch RT-PCR bestätigt werden (Abb. 8A und B, Seite 86). So ließen sich die Amplifikationsprodukt der Gene Nestin und $\beta$-II-Tubulin, nicht jedoch das Gen Gfap, nachweisen. Eine gesteigerte Expression der Gene Nkx2.2 und $L m \times 1 b$ in primären Neurospheres des ventralen rostralen Rhombencephalon der Maus (E12) im Vergleich zu primärem Gewebe gleichen Ursprungs (Abb. $8 \mathrm{C}$ ), weist auf eine Anreicherung der Zellpopulation primärer Neurospheres mit neuralen Vorläuferzellen hin. Interessanterweise konnte auch eine Expression des Gens Tph2 in primären Neurospheres des ventralen rostralen Rhombencephalon der Maus (E12) aufgezeigt werden (Abb. 8D). Die Expression des Tph2-Gens war in primären Neurospheres höher als im Gewebe, was auf den erstem Blick irritierend ist. Dieses Ergebnis kann jedoch dadurch erklärt werden, dass in primären Neurospheres der relative Anteil differenzierter 5-HT-Neurone gegenüber dem im Gewebe 
vorliegenden Anteil bezogen auf die Gesamtzellzahl höher ist. Dies mag auch der Grund für die gleich hohe Expression des Gens $\beta$-III-Tubulin im Vergleich zwischen primären Neurospheres einerseits und Gewebe gleichen Ursprungs anderseits sein. Die Charakterisierung des hier generierten Kultursystems primärer Neurospheres zeigte darüber hinaus, dass die generierten primären Neurospheres aus dem ventralen rostralen Rhombencephalon der Maus (E12) eine gewisse regionale Spezifizierung beibehalten haben. Dies konnte gezeigt werden, nachdem die korrekte, $d$. h. von Kontaminationen durch mesencephale Gewebeanteile freie, Präparation des ventralen rostralen Rhombencephalon durch RT-PCR überprüft worden war. Im präparierten Gewebe des ventralen rostralen Rhombencephalon der Maus (E12) war keine Expression des mesencephalen Markergens Otx2 feststellbar (Abb. 8A). Ebenso konnte gezeigt werden, dass Zellen der primären Neurospheres nach wie vor ihre Festlegung auf ihren rhombencephalen Ursprung besitzen, wie eine deutliche Expression des rhombencephalen Markergens Gbx2 (Brodski et al., 2003; Millet et al., 1999) dokumentierte. Ebenfalls exprimiert wurden in primären Neurospheres des ventralen rostralen Rhombencephalon der Maus (E12) die extrinsischen Signalmoleküle Shh und Fgf4 (Abb. 7C), deren Einfluss essentiell für die Entwicklung von 5-HT-Neuronen sind (Hynes und Rosenthal, 1999; Goridis und Rohrer, 2002). Hingegen wurde Fgf8 in primären Neurospheres im Gegensatz zu primärem Gewebe des ventralen rostralen Rhombencephalon der Maus (E12) nicht exprimiert. Dies beruht wahrscheinlich auf dem Fehlen des IstO und hieraus resultierend dem Fehlen des von inm ausgehenden Fgf8 Gradienten, wodurch wiederum Fgf8 normalerweise in seiner Expression aufrechterhalten wird. Hierbei sei darauf hingewiesen, dass die zur Generierung der primären Neurospheres isolierten Zellen bereits dem Einfluss von Fgf8 innerhalb des Gewebeverbandes zum Zeitpunkt E12 ausgesetzt waren. Eine Expression der Gene Gata2 und Pet1, als frühe und späte Markergene serotonerger Neurone, sowie des Gens Tph2, als Marker der terminalen Differenzierung zu 5-HT-Neuronen, konnten innerhalb der primären Neurospheres wie im primären Gewebe detektiert werden (Abb. 8D, Seite 86). So fand sich eine nahezu gleich starke Expression von Gata2 in primärem Gewebe des ventralen rostalen Rhombencephalon und in primären Neurospheres. Die Expression von Pet1 und Tph2 war in primären Neurospheres im Vergleich zu primärem Gewebe erhöht. In der Zellpopulation primäre Neurospheres des ventralen rostralen Rhombencephalon der Maus (E12) befanden sich somit auch einzelne Neurone, die bereits den terminalen Differenzierungszustand von $5-\mathrm{HT}$ Neuronen erreicht hatten. Dieser Befund wurde ebenfalls durch immunzytochemischen Nachweis der 5-HT-Expression bestätigt (Abb. 9D, Seite 88). Der Besitz einer regionalen Identität primärer Neurospheres aus dem ventralen rostralen Rhombencephalon der Maus steht im Einklang mit Ergebnissen für primäre Neurospheres anderer Gehirnareale, wie dem 
Mesencephalon, dem Cortex oder dem Striatum (Hitoshi et al., 2002; Ostenfeld et al., 2002; Parmar et al., 2002; Roussa et al., 2006; Armando et al., 2007).

Insgesamt konnte durch mehrere experimentelle Ansätze gezeigt werden, dass die im Rahmen dieser Arbeit generierten primären Neurospheres des ventralen rostralen Rhombencephalon der Maus (E12) über eine heterogene Zellzusammensetzung aus proliferierenden neuralen Vorläuferzellen und sich differenzierenden, neuronalen und glialen Zellen verfügen. Es konnte darüber hinaus festgestellt werden, dass dies, was auf den ersten Blick vielleicht als Nachteil angesehen werden könnte, sich aufgrund der Beibehaltung der regionalen Spezifizierung als Vorteil in der Untersuchung der Entwicklung 5-HT-Neurone erweist. Die Tatsache, dass nach Dissoziation der primärer Neurospheres die Differenzierung der Vorläuferzellen unter serumfreien Bedingungen erfolgte, stellt das hier etablierte Kulturmodell als besonders wertvoll für die Untersuchung des Einflusses extrinsischer Wachstumsfaktoren auf die Entwicklung von 5-HT-Neuronen dar.

Wir haben daher dieses System eingesetzt, um den Einfluss von Tgf- $\beta$ auf die Differenzierung von Vorläuferzellen des rostralen Rhombencephalon in Richtung des 5-HTPhänotyps zu untersuchen.

Hierzu wurden primäre Neurospheres einen Tag (DIV1) nach Dissoziation und Ausplattieren auf PORN-/Lam-beschichtete Kulturschälchen entweder mit $1 \mathrm{ng} / \mathrm{ml}$ exogenem Tgf- $\beta 1$ oder mit einem funktionell blockierenden Antikörper gegen alle TGF- $\beta$-Isoformen ( $\alpha$-Tgf- $\beta 1 / 2 / 3$ ), in einer Konzentration von $10 \mu \mathrm{g} / \mathrm{ml}$ behandelt. Als Kontrollen dienten unbehandelte, dissoziierte primäre Neurospheres der gleichen Präparation. An DIV3 wurde aus den behandelten Zellproben und den zugehörigen Kontrollen die Gesamt-RNA isoliert und das Genexpressionsmuster von Gata2, Pet1 und $L m \times 1 b$ in en experimentellen Gruppen durch qRT-PCR untersucht.

Mehrere Gründe haben zu der Entscheidung geführt, den Einfluss von Tgf- $\beta$ auf die Induktion und Differenzierung 5-HT-Vorläuferzellen in Richtung des 5-HT-Phänotyps zu untersuchen. Isoformen des Zytokins Tgf- $\beta$ sind an wichtigen zellulären Prozessen wie Proliferation, Differenzierung, Apoptose oder Überleben in mehreren Systemen beteiligt (Krieglstein et al., 2000 und 2002, Schober et al., 1999). Drei Tgf- $\beta$-Isoformen sind bisher bekannt, Tgf- $\beta 1,2$ und 3 , wobei nur die Isoformen 2 und 3 unter physiologischen Bedingungen im Gehirn exprimiert werden (Flanders et al., 1991). In Bezug auf die Entwicklung monoaminerger Neurone konzentrierte sich die Forschung bisher fast ausschließlich auf dopaminerge Neurone. So ist bekannt, dass Tgf- $\beta$ notwendig für die Induktion und Differenzierung mesencephaler dopaminerger Neurone aus Vorläuferzellen ist (Farkas et al., 2003; Roussa und Krieglstein 2004; Roussa et al. 2006). Für die Untersuchung einer Tgf- $\beta$-Funktion in der Regulation der Entwicklung mesencephaler DANeurone wurde die gleiche experimentelle Strategie wie für die Untersuchung der 
Entwicklung 5-HT-Neurone verwendet. Jedoch wurden hierbei primäre Neurospheres aus dem ventralen Mesencephalon generiert. Behandlung primärer Neurospheres des ventralen Mesencephalon durch eine exogene Tgf- $\beta$-Gabe führte zu einer signifikanten Steigerung der Anzahl immunpositiver Zellen für Nurr1, ein frühes Markerprotein DA-Neurone (Kim I.O. et al., 2003; Saucedo-Cardenas et al., 1998). Darüber hinaus war die Anzahl von Zellen die einen ausgeprägten neuronalen Phänotyp, sowie einer Immunreaktivität für $\mathrm{TH}$, besaßen ebenfalls signifikant gesteigert. Diese Ergebnisse wurden durch in vivo-Daten untermauert. So erbrachten immunhistochemische Untersuchungen an homozygoten Tgf- $\beta 2$-defizienten Mausembryonen des Embryonaltages 12 eine signifikante Reduktion der Anzahl DANeurone im Vergleich zu wt-Embryonen des gleichen Muttertieres. In Tgf- $\beta 2-/-$ Tgf- $\beta 3-/-$ Mutanten ist die Anzahl DA-Neuronen dramatisch reduziert jedoch nicht vollständig abwesend. Interessanterweise zeigte sich im Vergleich der dreialleligen Mutanten Tgf- $\beta 2-/-$ Tgf- $\beta 3+/-$ mit Mutanten des Genotyps Tgf- $\beta 2+/-$ Tgf- $\beta 3-/-$, dass der Isoform Tgf- $\beta 2$ eine größere Bedeutung für DA-Neurone zukommt als der Isoform Tgf- $\beta 3$. Dies manifestiert sich in einem deutlicheren Verlust DA-Neurone in Tgf- $\beta 2-/-;$ Tgf- $\beta 3+/-$ Mutanten (Roussa et al., 2004). Untersuchungen an in unserem Labor generierten Tgf- $\beta 2$-defizienten Mäusen haben gezeigt, dass am Embryonaltag 12 die Anzahl der rostralen 5-HT-Neurone ebenfalls signifikant reduziert ist (unveröffentlichte Daten unseres Labors). Dies ist durchaus kein überraschenden Ergebnis, wenn man die ontogenetische Verwandtschaft der Vorläuferzellen von DA- und 5-HT-Neurone bedenkt.

Die diesem Befund zugrunde liegenden molekularen Mechanismen aufzuklären war das Ziel unserer in vitro-Untersuchungen der Genexpression von behandelten primären Neurospheres und Primärzellen aus dem Gewebe des ventralen Rhombencephalon der Maus (E12). Gewählt wurden etablierte Markergene der mitotischen und postmitotischen Entwicklung von 5-HT-Neuronen. Erstens, Gata2 als mitotisch in 5-HT-Vorläuferzellen exprimiertes Markergen, welches insbesondere in rostralen 5-HT-Neuronen die Expression von Lmx1b und Pet1 initiiert (Craven et al., 2004) und an der Regulation des Eintritts in die postmitotische Entwicklungsphase von neuralen Vorläuferzellen beteiligt zu sein scheint (El Wakil et al., 2006). Fehlt Gata2, wie in Gata2-defizienten Mäusen gezeigt wurde, so führt dies zum frühen embryonalen Tod der Mutanten um den Embryonaltag E9.5-12.5 (Nardelli et al., 1999). Die vorliegenden Ergebnisse zeigen, dass eine Behandlung primärer Neurospheres des ventralen rostralen Rhombencephalon (E12) durch Tgf- $\beta$ zu keiner signifikanten Veränderung der Expression von Gata2 führt (Abb. 11, Seite 91). Eine in vitroStudie an direkt ausplattierten Primärzellen des rostralen Rhombencephalon der Ratte (E12) nach Tgf- $\beta$-Behandlung eine signifikante Steigerung der rostralen 5 -HT-Neurone (Galter et al., 1999). Insbesondere in letzterem Fall handelte es sich jedoch um ein grundlegend anderes Kultursystem. Erstens wurden die Vorläuferzellen nicht zuvor über die Generierung 
primärer Neurospheres expandiert. Damit kann in diesem Modell nicht wie in primären Neurospheres die Induktion der Entwicklung von Vorläuferzellen zu 5-HT-Neuronen sondern eher die Differenzierung von 5-HT-Neuronen durch externe Faktorengabe beeinflusst werden. Zweitens handelte es bei der Ratte um einen, sich hinsichtlich ihrer Entwicklung im Vergleich zur Maus, unterscheidenden Modellorganismus. Wurden, ähnlich zu genannten Arbeiten von Galter et al. (1999), nicht primäre Neurospheres des ventralen rostralen Rhombencephalon der Maus (E12), sondern Primärzellen dieses Gehirnbereichs ohne vorherige Expansion des Anteils von Vorläuferzellen an der Gesamtzellzahl ausplattiert, so zeigte sich, dass die Behandlung dieser Zellen durch Tgf- $\beta 1$ ebenfalls zu keinem deutlichen Anstieg der Expression von Gata2 führte (Abb. 13, Seite 94). Um des Weiteren die Notwendigkeit von Tgf- $\beta$ für die Induktion von 5-HT-Neuronen in primären Neurospheres des ventralen rostralen Rhombencephalon (E12) zu untersuchen, wurde ein funktionsblockierender Antikörper $(\alpha-\operatorname{Tgf}-\beta 1 / 2 / 3)$ in der Behandlung eingesetzt. Dieser Antikörper ist, wie vielfach in der Literatur beschrieben (Roussa et al., 2008), als blockierender Antikörper aller endogen exprimierten TGF- $\beta$-Isoformen etabliert. Behandlung primärer Neurospheres mit $\alpha$-Tgf- $\beta 1 / 2 / 3$ führte zu einer signifikanten Reduktion der Expression von Gata2 (Abb. 11, Seite 91). Daher ist zu vermuten, dass Tgf- $\beta$ für die Aufrechterhaltung der Gata2-Expression notwendig ist. In direkt ausplattierten Zellen des ventralen rostralen Rhombencephalon wurde die biologische Bedeutung von Tgf- $\beta$ für die Entwicklung 5-HT-Neurone durch Verwendung des synthetischen Inhibitors SB431542 untersucht. Dieser inhibiert die Rezeptoren Alk4/5 und 7 und blockiert hierdurch die Tgf- $\beta$ induzierte Signaltransduktionskaskasde (Alk5, Tgf- $\beta$-Rezeptor Typ I; Ho et al., 2006; Matsuyama et al., 2003). Wie aus der Rezeptorspezifität des Inhibitors SB431542 hervorgeht, blockiert dieser nicht nur die Tgf- $\beta$-abhängige Signaltransduktionskaskade, sondern auch z. B. die durch Activin, einem Mitglied der Tgf- $\beta$-Superfamilie, aktivierte Signalweiterleitung. Jedoch ist bisher für andere Mitglieder der Tgf- $\beta$-Superfamilie, wie dem genannten Activin, ein Einfluss weder auf die Entwicklung DA-, noch 5-HT-Neuronen beschrieben worden. Aus diesem Grund ist davon auszugehen, dass zur Untersuchung der Relevanz von Tgf- $\beta$ für die Induktion und Differenzierung 5 -HT-Neurone des ventralen rostralen Rhombencephalon der Maus der Inhibitor 431542 eingesetzt werden kann. Wurden primäre Neurospheres des ventralen Mesencephalon (E12) mit diesem Alk4/5/7-spezifischen Inhibitor behandelt, so führte dies zu einer signifikanten Reduktion der Anzahl DA-Neurone (Roussa et al., 2006). Behandlung von direkt ausplattierten Primärzellen des ventralen rostralen Rhombencephalon der Maus (E12) zeigen nach einer Behandlung mit dem Inhibitor SB431245 (Abb. 13, Seite 94) eine signifikanten Herabregulation der Gata2-Expression, was auf eine Aufrechterhaltung der Gata2-Expression durch Tgf- $\beta$ schließen lässt. Insgesamt zeigen $\alpha$-Tgf- $\beta-1 / 2 / 3$ und der Inhibitor SB431542 vergleichbare Effekte (Abb. 11 und 13). 
Insgesamt können die Ergebnisse von primären Neurospheres und direkt plattierten Primärzellen des ventralen rostralen Rhombencephalon nach Behandlung mit Tgf- $\beta$ so interpretiert werden, dass es sich bei der Regulation der Induktion und der Differenzierung um zwei verschiedene Regulationswege handelt. Die Induktion des 5-HT-Phänotyps wird durch Tgf- $\beta$ nicht über Gata2 reguliert, wohingegen Tgf- $\beta$ möglicherweise über die Regulation der Expression von Gata2 Einfluss auf die Differenzierung von Vorläuferzellen zu 5-HT-Neuronen nimmt. In beiden Kultursystemen ist jedoch Tgf- $\beta$ für eine Aufrechterhaltung der Expression von Gata2 notwendig.

Als nächstes Gen wurde Pet1 als postmitotisch exprimierter Transkriptionsfaktor und einziger bisher bekannter 5-HT-spezifischer Marker nach Behandlung durch Tgf- $\beta$ analysiert. Die Deletion dieses Markergens führt in Mausmutanten zu einer deutlichen Reduktion der Anzahl 5-HT-Neurone um etwa $70 \%$, sowie eine teilweise nicht vollständige Ausreifung der verbleibenden 5-HT-Neurone zum terminalen 5-HT-Phänotyp (Hendricks et al., 2003). Das jedoch nicht alle 5-HT-Neurone in Pet1-defizienten Mäusen verloren gehen, weist bereits daraufhin, dass es zumindest einen von Pet1-unabhängigen Entwicklungsweg für 5-HTNeurone geben muss. Die Analyse der Expression des postmitotischen Markergens Pet1 nach Behandlung der primären Neurospheres des ventralen rostralen Rhombencephalon der Maus durch exogenes Tgf- $\beta$ zeigte im Vergleich $\mathrm{zu}$ unbehandelten Kontrollen keine signifikante Einflussnahme von Tgf- $\beta$ auf die Pet1-Expression (Abb. 12, Seite 92). Wurden jedoch die Zellen primärer Neurospheres mit dem funktionsblockierenden $\alpha$ - Tgf- $\beta 1 / 2 / 3$ Antikörper behandelt, so resultierte hieraus eine signifikante Reduktion der Expression von Pet1 (Abb. 12, Seite 92). Dies weist darauf hin, dass Tgf- $\beta$ nicht die Pet1-Expression induziert, jedoch möglicherweise an der Aufrechterhaltung der Expression von Pet1 beteiligt ist. Des Weiteren lässt sich auf Basis dieser Ergebnisse spekulieren, dass die in vivo festgestellte, signifikante Reduktion der Anzahl rostraler 5-HT-Neurone in Tgf- $\beta 2$-/Mausmutanten des E12.5, eine von Tgf- $\beta$-abhängige Induktion der Entwicklung 5-HTNeurone über eine Tgf- $\beta$-regulierte Aufrechterhaltung der Pet1-Expression erfolgt. Wenn das Kulturmodell der direkt, d. h. ohne vorherige Expansion der Vorläuferzellen, ausplattierten Primärzellen des ventralen Rhombencephalon der Maus (E12) als experimentelles System angewendet wurde, so zeigte sich nach Tgf- $\beta$-Gabe keine signifikante Änderung der Pet1Expression im Vergleich zur unbehandelten Kontrolle (Abb. 14, Seite 95). Wurden die direkt ausplattierten Zellen mit SB431542 behandelt, so führte dies ebenfalls zu keiner Änderung der Pet1-Expression im Vergleich zum Expressionsniveau in unbehandelten Kontrolle (Abb. 14). Ähnlich den Ergebnissen zu Gata2 weisen die Expressionsdaten des Markergens Pet1 daraufhin, dass Induktion und Differenzierung von 5-HT-Neurone durch zwei unterschiedliche Wege reguliert werden könnten. Dies spiegelt deutlich die Komplexität der Regulation der Entwicklung 5-HT-Neurone wieder, ebenso zeigen die Ergebnisse deutlich, 
wie vielfältig die Interaktion intrinsischer und extrinsischer Faktoren ist. Ob eine parallele und konvergierende oder eine nacheinanderfolgende Regulation der Gene Gata2 und Pet1 vorliegt, ist bisher noch nicht analysiert. Davon abgesehen unterstreichen die Ergebnisse in Zusammenhang mit den dargelegten in vivo-Daten, auch wenn der genaue Mechanismus noch nicht aufgedeckt wurde, die Bedeutung von Tgf- $\beta$ für die Induktion 5-HT-Neurone.

Schließlich wurde die Expression von $L m \times 1 b$ nach Tgf- $\beta$-Behandlung in primären Neurospheres untersucht. Lmx1b ist ein Transkriptionsfaktor, der als postmitotisch exprimiertes Markergen in 5-HT-Neuronen die Expression von weiteren Genen der postmitotischen Entwicklung 5-HT-Neurone reguliert. Mäuse defizient für $L m \times 1 b$ besitzen keine zentralen 5-HT-Neurone und sterben perinatal (Ding et al., 2003). Der diesem Phänotyp zugrunde liegende Mechanismus ist jedoch nicht bekannt. Dies hebt die Relevanz dieses Transkriptionsfaktors für die Induktion von 5-HT-Neurone deutlich hervor. An dieser Stelle sei betont, dass $L m \times 1 b$ nicht ausschließlich in 5 -HT-Vorläuferzellen exprimiert wird, sondern auch in den ihnen ontogenetisch verwandten und sich rostral des IstO befindenden Progenitoren der mesencephalen DA-Neurone exprimiert wird. Dies könnte auf der Beteiligung von Lmx1b an der Ausbildung des IstO und damit der Expression von Fgf8 basieren (Guo et al., 2007), welches für die Entwicklung beider Neuronenpopulationen notwendig ist. Unerwarteterweise führt die Behandlung der primären Neurospheres des ventralen rostralen Rhombencephalon der Maus (E12) durch Tgf- $\beta$ (Abb. 10, Seite 90) zu keiner Beeinflussung der Expression von $L m \times 1 b$ in Bezug auf die unbehandelte Kontrolle. Die Behandlung primärer Neurospheres des ventralen Rhombencephalon (E12) durch Applikation des funktionsblockierenden Antikörper $\alpha$ - Tgf- $\beta 1 / 2 / 3$ (Abb. 10) hingegen zeigte eine nahezu vollständige Ausschaltung der Expression von $L m \times 1 b$ auf transkriptioneller Ebene im Vergleich zur unbehandelten Kontrolle. Dies könnte eine duale Funktion von Tgf- $\beta$ s in der Regulation des Gleichgewichtes von Proliferation und Differenzierung neuraler Vorläuferzellen wiederspiegeln. So könnte Tgf- $\beta$ zum einen durch negative Regulation der Lmx1b-Expression einen Eintritt der Vorläuferzellen in das Differenzierungsstadium begünstigen. Zum anderen könnte eine durch Tgf- $\beta$-vermittelte Aufrechterhaltung der Lmx1b-Expression in Vorläuferzellen Lmx1b-abhängige Mechanismen der Signaltransduktion positiv regulieren.

Nachdem mit Tgf- $\beta$ der Einfluss eines extrinsischen Faktor auf die Entwicklung von 5-HTNeuronen untersucht worden war, war es ein weiteres Ziel der Arbeit, die potentielle Rolle des intrinsischen Faktors Sim1 („Single-minded homolog 1“) für Differenzierung und Aufrechterhaltung 5-HT-Neurone des ZNS zu untersuchen. Der Transkriptionsfaktor Sim1 wurde aus mehreren Gründen als Komponente des regulatorischen Netzwerkes der Entwicklung 5-HT-Neurone in Betracht gezogen. Sim spielt eine Hauptrolle in der Bildung der Mittellinie in $D$. melanogaster. So haben Untersuchungen an transgenen $D$. melanogaster 
gezeigt, dass sim notwendig und ausreichend für die Differenzierung der Mittellinie des ZNS innerhalb der ventralen neurogenen Zone von D. melanogaster ist (Nambu et al., 1991). Das sim-Protein wirkt vermutlich über seine bHLH-(,Basic helix-loop-helix")-Domäne als Transkriptionsaktivator (Nambu et al., 1991). Im Allgemeinen sind bHLHTranskriptionsfaktoren u. a. für ihre Bedeutung in der Determinierung des Zellschicksals und ihre Rolle in Proliferations- und Differenzierungsprozessen während der embryonalen Entwicklung bekannt. Die Mittellinie ist das wichtigste Organisationszentrum für die Ausbildung der D-V-Achse in D. melanogaster und steuert die Entwicklung unterschiedlicher Neuronenpopulationen (Nambu et al., 1993; Lee et al., 1999; Tear, 1999). Konsequenterweise sterben sim-defiziente $D$. melanogaster und bilden keine Mittellinie aus. In der Maus wurden bisher zwei Homologe des sim-Gens aus D. melanogaster identifiziert, Sim1 und Sim2. Diese weisen nur zum Teil ein überlappendes Expressionsmuster auf. Sim1 wird im Gegensatz zu Sim2 direkt lateral zur Mittellinie des Diencephalon und des Rückenmarks sowie in weiteren Bereichen des ZNS, wie auch dem Rhombencephalon und in der sich entwickelnden Niere exprimiert (Goshu et al., 2002). Sowohl Sim1-als auch Sim2-defiziente Mäuse sterben perinatal. Sim2-defiziente Mausmutanten sterben aufgrund von Lungenatelektase und folglich einem Aussetzung der Atmung. Hier von grundlegend verschieden äußert sich der Phänotyp von Sim1-Mausmutanten. Auch diese Mutanten sterben perinatal, jedoch aufgrund von Entwicklungsdefekten des hypothalamischen Nucleus pariventricularis anterior (aPV), des Nucleus paraventricularis (PVN) sowie des Nucleus supraopticus (SO) (Michaud et al., 1998). Der Hypothalamus stellt eine Gehirnregion dar, welche eine Vielfalt von neurosekretorischen Populationen beinhaltet, die einen unterschiedlichen Entwicklungshintergrund besitzen. Ein weiterer Grund die Rolle von Sim1 näher zu untersuchen war, dass die in der Arbeit von Liu et al. (2003) dargelegten potentiellen Zielgene von Sim1 auch für Faktoren kodieren, welche in der Regulation der Entwicklung von 5-HT-Neuronen wichtige regulatorische Funktionen innehaben. Diese Zielgene wurden durch cDNA-Mikroarray-Analysen der Genexpression von Sim1überexprimierenden Neuro2a-Zellen, als artifizielles System im Vergleich zu nichttransfizierten Zellen ermittelt (Liu et al., 2003). Zu diesen möglichen Zielgenen gehört auch Gdnf. Gdnf, ein Mitglied der Tgf- $\beta$-Superfamilie ist ein etablierter Faktor des Überlebens mesencephaler dopaminerger Neurone in vitro und in vivo (Krieglstein 2004; Yang et al., 2008). Des Weiteren wurde in dieser Studie Gata2, ein an der Entwicklung 5-HT-Neuronen beteiligter bHLH-Transkriptionsfaktor, ebenfalls als Zielgen von Sim1 identifiziert.

Für die in dieser Arbeit durchgeführten Untersuchungen einer möglichen biologischen Bedeutung von Sim1 für die Entwicklung serotonerger Neurone als Vertreter ventraler Neuronenpopulationen, wurden Sim1-defiziente Mäuse im Vergleich zu wt-Mäusen des gleichen Wurfs in Bezug auf die Anzahl 5-HT-immunpositver Neurone untersucht. Zwei 
Stadien wurden hierzu herangezogen. Zum einen Embryonen des Stadiums E14.5, um die frühe Differenzierung von 5-HT-Neuronen zu analysieren. Zum anderen wurden neugeborene Mausmutanten (P0) untersucht. Die Ergebnisse zeigen, dass die Anzahl der 5-HT-Neurone zum Zeitpunkt E14.5 im Vergleich zum wt nicht signifikant verändert ist (Abb. 17, Seite 99). Dies deutet darauf hin, dass Sim1 nicht in die frühe Differenzierung von 5-HT-Neuronen involviert ist. Hierbei ist jedoch zu berücksichtigen, dass zu diesem frühen Zeitpunkt eine Unterscheidung der einzelnen 5-HT-Kerngebiete nicht möglich ist. Ähnliche Ergebnisse bezogen auf die Gesamtzahl 5-HT-Neurone wurden zum Zeitpunkt P0 ermittelt (Abb. 18, Seite 100). Vergleicht man jedoch die Anzahl 5-HT-Neurone in den einzelnen Nuclei raphes (B1-B9) von Sim1-defizienten Mäusen im Vergleich zu wt-Mäusen, so stellte sich heraus, dass die Anzahl der 5-HT-Neurone im NRD (B6/B7) um circa 30\% und damit signifikant reduziert war. Dies deutet darauf hin, dass Sim1 einen selektiven Einfluss auf die Entwicklung einer Subpopulation von 5-HT-Neuronen ausübt. Gleichzeitig weist dieses Ergebnis darauf hin, dass die unterschiedlichen 5-HT-Neuronenpopulationen möglicherweise unterschiedlichen regulatorischen Prozessen in ihrer Entwicklung unterliegen und unterschiedliche Abhängigkeit von einem intrinsischen Faktor, Sim1, aufweisen. In der Tat spiegelt sich die Heterogenität des 5-HT-Systems u.a. in der Existenz von neun unterscheidbaren Nuclei raphes (B1-B9) wieder, welche sich gemäß ihrer Lokalisation entlang de A-P-Achse in eine kaudale und eine rostrale Gruppe zusammenfassen lassen (Hornung, 2003). Neben ihrer Lokalisation unterscheiden sich die Kerne auch in den Projektionsgebieten, welche sie innervieren (Rubenstein, 1998, Westlund et al., 1991). Auch hinsichtlich einer Einflussnahme von extrinsischen Faktoren wie Tgf- $\beta$ zeigen sich Unterschiede zwischen den einzelnen 5-HT-Neuronengruppen. So führt eine externe Tgf- $\beta 1$, 2 oder 3 Gabe zu einer gesteigerten Anzahl rostraler 5-HT-Neurone um den E12 und E13 der Ratte, während die kaudale 5-HT-Neuronenpopulation zunächst nicht beeinflusst wird (Galter et al., 1999). Die Heterogenität beschränkt sich nicht allein auf die Lokalisation oder divergierende Abhängigkeit der Entwicklung und Aufrechterhaltung der einzelnen Kerngebiete von intrinsischen und extrinsischen Faktoren, sondern umfasst auch die zelluläre Morphologie und Funktionsfähigkeit der Neurone. So konnte gezeigt werden, dass 5-HT-Neurone des NRD und des Nucleus raphe magnus (NRM) deutlich bezüglich ihrer synaptischen Morphologie und ihren elektrophysiologischen Eigenschaften von einander abweichen (Kosofsky und Molliver, 1987; Trulson und Frederickson, 1987). Selbst innerhalb eines Kerns sind unterschiedliche Subpopulationen zu bestimmen, wie z.B. im NRD. Dem NRD kommt als Abkömmling des R1 eine gesonderte Stellung innerhalb der rostralen 5-HTNeuronenpopulation zu. U. a. gehen von diesem Kern aszendierende Projektionen zur Amygdala und dem Hypothalamus als Komponenten des limbischen System aus. 
Um die möglichen molekularen Mechanismen, auf welche sich die Reduktion von 5-HTNeuronen des NRD von Sim1-defizienten Mausmutanten um P0 zurückführen lassen könnten, aufzuklären, wurde ein in vitro-Zellsystem eingesetzt. Dies war notwendig, da Primärzellen des ventralen rostralen Rhombencephalon E12 sich nicht zur Durchführung von "Gain-of-function"-Experimenten aufgrund einer nur minimalen Transfektionseffizienz eignen. Es kamen daher MN9D-Zellen aus fusionierten Neuroblastoma und embryonalen mesencephalen Zellen zum Einsatz (Choi et al., 1991 und 1992), die unterschiedliche Differenzierungszustände der Zellen innerhalb der gleichen Kultur aufweisen. MN9D-Zellen gelten als Modellsystem zur Untersuchung der Entwicklung mesencephaler DA-Neurone und exprimieren die etablierten DA-Markergene ohne jedoch die elektrophysiologischen Eigenschaften vollkommen differenzierter DA-Neurone aufzuweisen (Rick et al., 2006). MN9D-Zellen eignen sich, wie in dieser Arbeit gezeigt werden konnte, bedingt durch die Expression von 5-HT-Markergenen (Gata2, Pet1, Tph2) auch als Modellsystem für 5-HTNeuronen (Abb. 19, Seite 101). Darüber hinaus macht eine gute Transfizierbarkeit diese Zelllinie zu einem idealen Modellsystem für "Gain“- und „Loss-of-function“-Experimente. So kann eine Überexpression von Nurr1 in MN9D-Zellen eine Differenzierung hin zum Phänotyp DA-Neurone induzieren und hierdurch die Zahl TH-immunreaktiver Zellen signifikant gesteigert werden (Castro et al., 2001). Die Differenzierung von MN9D-Zellen lässt sich des Weiteren durch Gdnf einleiten, was bedeutet, dass diese Zellen theoretisch auch für eine Behandlung durch extrinsische Faktoren nutzbar sind (Heller et al., 1996).

Um potentielle Zielgen von Sim1 unter den Genen, die bekannter Weise in die Entwicklung von 5-HT-Neuronen involviert sind, im Rahmen dieser Arbeit zu identifizieren, wurden klassische „Gain-of-function“-Experimente durchgeführt. Hierzu wurden MN9D-Zellen mit dem Überexpressionsplasmid pcDNA3::Sim1 transfiziert und die Änderung der Genexpression im Vergleich zu mit pcDNA3-transfizierten Zellen mittels qRT-PCR in einem Zeitraum von $72 \mathrm{~h}$ nach erfolgter Transfektion ermittelt. Die Effizienz der Überexpression wurde zuvor durch PCR und Western-Blot (Abb. 20 und 21, Seite 102 und 103) überprüft. Im Fokus der Untersuchungen stand zunächst der Einfluss von Sim1 auf die Expression bekannter Gene, die bereits als Mitglieder des transkriptionellen Netzwerkes der Entwicklung von 5-HT-Neuronen identifiziert worden waren. Hierdurch sollte eine Positionierung von Sim1 innerhalb dieses Netzwerkes ermöglicht werden. Eine Überexpression von Sim1 in MN9DZellen hatte in einem Zeitraum von $24 \mathrm{~h}$ bis $72 \mathrm{~h}$ nach der Transfektion keinen Einfluss auf die Expression des proneuralen Gens Mash1 (Abb. 22, Seite 104). Mash1 ist wie Sim1 ein bHLH-Transkriptionsfaktor, der in 5-HT-Vorläuferzellen des ventralen Rhombencephalon als auch in anderen Neuronenvorläuferzellen, teilweise kolokalisiert mit Nkx2.2, exprimiert wird (Pattyn et al., 2004). Dennoch konnte gezeigt werden, dass Mash1 eine spezielle und essentielle Funktion für die Entwicklung von 5-HT-Neuronen zukommt. Als Gene, die einer 
Mash1-Expression nachgeschaltet sind, konnten Gata2, Lmx1b und Pet1 bestimmt werden, somit gilt Mash1 als determinierender Faktor der zellulären Festlegung auf den Entwicklungsweg zu 5-HT-Neuronen. Mash1-defizienten Mausmutanten weisen einen nahezu vollständigen Verlust zentraler 5-HT-Neurone auf. Nur wenige 5-HT-Neurone lassen sich in der MHB (,Midbrain-hindbrain-boundary") nachweisen (Pattyn et al., 2004). Das Sim1 in vitro keinen Einfluss auf die Expression von Mash1 besitzt, lässt die Vermutung zu, dass Sim1 neurale Progenitoren während der frühesten Entwicklungsphase nicht beeinflusst. Eine maßgebliche Funktion in der Regulation des Überganges von mitotischer zur postmitotischen Entwicklungsphase serotonerger Vorläuferzellen des rostralen Rhombencephalon kommt dem Zink-Finger-Transkriptionsfaktor Gata2 zu. Gata2 wird durch Nkx2.2 und Nkx6.1 in Shh-abhängiger Weise induziert. Gata2-defiziente Mäuse sterben in frühen Embryonalstadien (E9.5-10.5) und weisen interessanterweise keine Abkömmlinge des R1 auf (Carven et al., 2004). Abkömmlinge des R1 sind die 5-HT-Neurone des NRD, welche die ersten sich entwickelnden 5-HT-Neurone darstellen. Somit zeigen Sim1defiziente Mäuse und Gata2-Mausmutanten einen ähnlichen Phänotyp hinsichtlich der Anzahl 5-HT-Neurone einer Subpopulation, dem NRD. Während in anderen Bereichen der Bildung zentraler 5-HT-Neurone die Expression von Gata2 notwendig ist, um die Expression der Transkriptionsfaktoren Lmx1b und Pet1 anzuschalten, ist Gata2 im ventralen R1 sogar ausreichend, um dort 5-HT-Neurone zu induzieren (Craven et al., 2004). Auch hier zeigt sich die zuvor angesprochene Variabilität der Entwicklungswege einzelner Subpopulationen, welche zum 5-HT-Neurotransmitterphänotyp führen. Ein weiterer Hinweis auf eine Regulation von Gata2 durch Sim1 kam durch Genexpressionsanalysen mittels cDNAMikroarray durch Liu et al. (2003) auf. Neuro2a-Zellen zeigten nach Überexpression von Sim1 und Arnt eine signifikante Steigerung der Gata2-Expression. Eine solche Steigerung der Expression konnte durch eine in dieser Arbeit durchgeführte Überexpression von Sim1 in MN9D-Zellen zu keinem Zeitpunkt innerhalb einer Dauer von $72 \mathrm{~h}$ nach Beginn der Transfektion gezeigt werden (Abb. 23, Seite 105). Zieht man in Betracht, dass sowohl Sim1 als auch Gata2 ihre Bedeutung für die Entwicklung 5-HT-Neurone in einer Subpopulation manifestieren, so kann spekuliert werden, dass sich eine Sim1-gesteuerte Regulation von Gata2 nur in bestimmten Zellen, d. h. zelltyp-abhängig, verläuft. Das verwendete Kultursystem der MN9D-Zellen spiegelt jedoch ein heterogenes Kulturmodell aller 5-HTSubpopulation und ihrer Vorläuferzellen wider und ermöglicht nur allen Subpopulationen gemeinsame Mechanismen zu untersuchen. Weiterhin legen die dargelegten Daten nahe, dass Sim1 in Bezug auf Vorläufer aller Subpopulationen 5-HT-Neurone keinen Einfluss auf die frühe Entwicklung dieser Neurone über eine Regulation von Gata2 besitzt. Wäre dies der Fall, so müsste sich ein Verlust von $\operatorname{Sim} 1$ und in seiner Folge ein Verlust der Gata2Expression bereits im Embryonalstadium E14.5 in Sim1-defizienten Mäusen als eine 
Reduktion der Anzahl 5-HT-Neurone bemerkbar machen. Ein Verlust von 5-HT-Neuronen lässt sich jedoch erst spät, um P0 im NRD feststellen.

Ganz anders ist jedoch die Situation im Hinblick auf eine Sim1-abhängige Regulation von Genen, die eine terminale Differenzierung von 5-HT-Vorläuferzellen steuern. Hierzu zählt Pet1 als einziger 5-HT-spezifischer Transkriptionsfaktor der ETS-Familie. Pet1-defiziente Mausmutanten weisen eine Reduktion der Gesamtzahl der 5-HT-Neurone um bis zu 70\% auf (Hendrickson et al., 1999 und 2003). Es entwickeln sich zwar 5-HT-Neurone, welche jedoch nicht den vollständigen, terminalen Differenzierungszustand erreichen. Somit könnte es sein, dass diese 5-HT-Neurone zunächst einem von Pet1-unabhängigen Entwicklungsweg folgen und eine Pet1-Expression nur während der terminalen Differenzierung erforderlich ist, um die nachgeschalteten, den 5-HT-Phänotyp determinierenden Gene Aadc, Sert, Vmat und Tph2 zu induzieren. Wurde in dieser Arbeit Sim1 in MN9D-Zellen überexprimiert, so führte dies $48 \mathrm{~h}$ und $72 \mathrm{~h}$ nach erfolgter Transfektion der Zellen zu einer signifikanten Steigerung der Pet1-Expression im Vergleich zu nicht transfizierten Zellen (Abb. 24, Seite 106). Der Vermutung, dass eine Pet1-Expression durch Sim1 induziert wird, wurde anschließend durch „Loss-of-function“-Experimente nachgegangen. Hierzu wurden MN9D-Zellen durch Sim1spezifische siRNA transfiziert und ihre Genexpression mit Zellen, welche zur Kontrolle mit einer nicht zu Genen der Säuger komplementären Ctr-siRNA transfiziert worden waren, verglichen. Dabei zeigte sich, dass $24 \mathrm{~h}$ nach der Transfektion eine Herabregulation der Expression von Sim1 in MN9D-Zellen in einer signifikanten Minderung der Pet1-Expression resultierte (Abb. 28, 111). Die Tatsache dass durch „Loss-of-function“-Experimente eine Sim1-induzierte Heraufregulation von Pet1 umgekehrt werden konnte, weist Pet1 als Zielgen von Sim1 aus. Damit lässt sich Sim1 eine erste Position innerhalb des transkriptionellen Netzwerkes der Regulation der Entwicklung 5-HT-Neurone zuweisen.

Einen weiteren Hinweis, dass Sim1 für die postmitotische Entwicklungsstufe 5-HT-Neurone und insbesondere der terminalen Differenzierung ist, erhielten wir im Rahmen dieser Arbeit durch Analyse der Auswirkung einer gesteigerten Sim1-Expression in MN9D-Zellen auf die Regulation der Expression des Tph2-Gens. Tph2 ist eine spezifisch im ZNS exprimierte Isoform der Tryptophanhydroxylase (Nakamura, K. und Hasegawa, 2007). Es stellt das limitierende Enzym der 5-HT-Synthese dar und definiert somit den terminalen Differenzierungszustand des 5-HT-Phänotyps (Zhang et al., 2006). $24 \mathrm{~h}$ und $48 \mathrm{~h}$ nach Transfektion der MN9D-Zellen durch das Überexpressionsplasmid pcDNA3::Sim1, zeigten diese im Vergleich zur durch pcDNA3-transfizierten Kontrollgruppe eine signifikante Steigerung der Tph2-Expression (Abb. 25, Seite 107). Aus diesen Daten geht hervor, dass Sim1 zum einen direkt auf das Gen Tph2 wirken und hierdurch positiv regulieren könnte. Denkbar wäre zum anderen aber auch, dass Sim1 das Gen Tph2 indirekt über die zuvor beschriebene Induktion von Pet1 reguliert. Neben den Nuclei raphes findet sich eine 
Expression des Tph2-Gens im Cortex, dem Thalamus, dem Hypothalamus, der Amygdala und dem Cerebellum (Zill et al., 2007). Wie bereits erwähnt, nimmt das zentrale 5-HTSystem über seine Projektionen Einfluss auf die Entwicklung seiner Zielregionen. Man könnte spekulieren, dass der NRD über seine Projektionen über die Amygdala in den Hypothalamus an der Entwicklung des Hypothalamus beteiligt ist. Fehlt Sim1 in Mausmutanten, so führt dies zur Verminderung der Anzahl 5-HT-Neurone des NRD, ggf. aufgrund einer nicht erfolgten Pet1- oder Tph2-Induktion in diesen Zelltypen. Eine Sim1Deletion führt schließlich in Mäusen zu einem Verlust neurosekretorischer Zellen des SON sowie PVN, was den perinatal eintretenden Tod der Mutanten zur Folge hat. Ob dies auf einen fehlenden regulatorischen Einfluss einer Sim1-abhängigen Subpopulation des NRD zurückzuführen ist, muss jedoch erst durch weiterführende Experimente geklärt werden. Zusammengefasst führen die aus diesem Teil der vorliegenden Arbeit resultierenden Ergebnisse zu einer Positionierung von Sim1 in der späten Determinierung des 5-HTPhänotyps unter besonderer Berücksichtigung der Bedeutung des Transkriptionsfaktors Sim1 für eine Subpopulation 5-HT-Neurone des NRD. Dennoch bleiben viele Fragen zum vollständigen Verständnis der Induktion und Spezifikation 5-HT-Neurone weiterhin unbeantwortet.

Ein weiteres Ziel der Arbeit war es somit bisher unbekannte Gene zu identifizieren, die an der Induktion und Spezifikation von rostralen 5-HT-Neuronen des Rhombencephalon beteiligt sein könnten. Hierdurch sollte eine Ergänzung fehlender Elemente innerhalb des transkriptionellen, regulatorischen Netzwerkes, welches die Entwicklung rostraler 5-HTNeurone steuert, erreicht werden. Obwohl Vorläuferzellen 5-HT- und DA-Neurone in naher ontogenetischer Verwandtschaft zueinander stehen und zum Teil die gleiche Abhängigkeit von signalgebenden Molekülen des umgebenden Gewebes während ihrer Entwicklung besitzen, ist dieses Netzwerk aus intrinsischen und extrinsischen Faktoren bis heute nur unzureichend entschlüsselt. Entscheidende signalgebende Zentren der näheren Umgebung sind zum einen der IstO, die Grenze zwischen Mesencephalon und Rhombencephalon, welcher für die Freisetzung des Signalmoleküls Fgf8 verantwortlich ist (Nakamura und Watanabe, 2005). Ein weiteres Signalzentrum stellt zum anderen die Grundplatte dar, von der aus sich ein nach dorsal schwächer werdender Gradient des Signalmoleküls Shh ausbildet. Shh wirkt als generell ventralisierender Faktor (Echelard et al., 1993). Sowohl 5-HT- als auch DA-Neurone sind als ventrale Populationen daher von Shh in ihrer Entwicklung abhängig. Eine vergleichbare Abhängigkeit der Zellen von einem Faktor gilt auch für Fgf8, welches im IstO synthetisiert und von diesem abgegeben wird (Ye et al., 1998). Fgf8 ist maßgeblich an der Ausbildung und Aufrechterhaltung dieses Signalzentrums, dem IstO, beteiligt (Martinez et al., 1999). Direkt rostral des Isthmus liegen die Vorläuferzellen mesencephaler DA-Neurone. Hingegen sind Vorläufer der serotonergen 
Neurone des Rhombencephalon wiederum direkt kaudal des Isthmus lokalisiert und zeigen eine mit größerer Entfernung zum IstO abnehmende Abhängigkeit von Fgf8. So zeigen serotonerge Abkömmlinge des R1 eine die am stärksten ausgeprägte Abhängigkeit von diesem Signalmolekül unter den verschiedenen 5-HT-Neuronenpopulationen (Teraoka et al., 2004; Walshe et al., 2002).

Wie bereits zuvor diskutiert ist Tgf- $\beta$ sowohl für die Entwicklung und Differenzierung DANeurone als auch der ihnen verwandten 5-HT-Neurone notwendig (Roussa und Krieglstein, 2004; Roussa et al., 2006). Die ontogenetische Verwandtschaft spiegelt sich auch in der Expression verschiedener Transkriptionsfaktoren wieder, die sowohl in Vorläuferzellen als auch in postmitotischen Entwicklungsstufen dieser beiden 5-HT- und DANeuronenpopulationen exprimiert werden. Zu nennen sind hierbei die Transkriptionsfaktoren Mash1 und Lmx1b (Pattyn et al., 2004). Lmx1b wird in beiden Vorläuferpopulationen exprimiert. So ist in 5-HT-Vorläufer eine Expression von Lmx1b nach Eintritt in die postmitotische Entwicklungsphase detektierbar. In DA-Vorläuferzellen wird die Expression dieses Transkriptionsfaktors beginnend mit der mitotischen Entwicklungsphase bis zum Erreichen des terminalen Neurotransmitterphenotyps beibehalten. Gemeinsamkeiten von 5-HT- und DA-Neuronen in der Expression von intrinsischen Faktoren und Abhängigkeit extrinsischen Signalmolekülen führen zu der Frage, in welchen Signalen sich beide Neuronenpopulationen in ihrer Entwicklung unterscheiden. Zu einem entscheidenden Faktor gehört Fgf4, der - sezerniert von der Grundplatte - als ein Signal der vorausgehenden zellulären Prägung wirkt. Fgf4 ist notwendig für die Induktion 5-HT-Neurone jedoch nicht der mesencephaler DA-Neurone (Kim et al., 2002). Obwohl notwendig, reicht Fgf4 jedoch nicht aus, um 5-HT-Neurone ektopisch zu induzieren (Ye et al., 1998). Dies verdeutlicht, wie unzureichend bisher der molekulare Mechanismus der Entwicklung von 5-HT-Neurone aufgeklärt wurde. Wesentliche Mitspieler in diesem Prozess sind zweifellos Otx2 und Gbx2, welche als wichtigste Faktoren überhaupt die Festlegung des IstO durch gegenseitige Hemmung bestimmen und hierdurch die territoriale Zugehörigkeit der Vorläuferzellen maßgeblich bedingen (Garda et al., 2001). Eine Verschiebung des Expressionsgebietes von Otx2 nach kaudal in transgenen Mäusen, führt zu einer Reduktion der Anzahl 5-HT-Neurone, wohingegen die Anzahl DA-Neurone steigt. Dem entsprechend führt eine Ausdehnung der Gbx2-Expression nach rostral zu einem Anstieg der Zahl 5-HT-Neurone auf Kosten der Anzahl DA-Neurone (Brodsky et al., 2003)

Ein experimenteller Ansatz, um Unterschiede in den Genexpressionsmustern von Vorläufern DA- und 5-HT-Neurone zu ermitteln und hierdurch fehlende Elemente zu identifizieren, war die Durchführung eines cDNA-Mikroarrays. Diese Methode ermöglicht den Vergleich der Expression von vielen Genen in einem Schritt. Hierzu wird RNA aus den zu vergleichenden Geweben oder Zellen extrahiert und in der nachfolgenden cDNA-Synthese diese durch 
unterschiedliche Fluoreszenzfarbstoffe markiert. Im Anschluss erfolgt die Hybridisierung jeder Probe auf einen Mikrochip. An diesen Träger sind an seiner Oberfläche in definierter Position synthetisch hergestellte spezifische Oligonukleotide gebunden. Nach der Hybridisierung und Entfernung der ungebundenen cDNA-Moleküle wird das Fluoreszenzsignal jeder Position auf dem Träger durch einen Laser ausgelesen. Der Vergleich der Signalstärke auf zwei zu vergleichenden Trägern wird schließlich bioinformatisch durchgeführt und hierbei die Signale normalisiert, um Artefakte, welche zu einer Fehlinterpretation der Daten führen würden, zu vermindern. Im Rahmen dieser Arbeit wurde ein cDNA-Mikroarray durchgeführt, um das Genexpressionsmuster des ventralen Mesencephalon mit dem des rostralen ventralen Rhombencephalon der Maus (E11) zu vergleichen. Hierfür wurde der GeneChip® Mouse Genome 430A 2.0 Array von Affimetrix verwendet, der einen Vergleich von 22000 gut charakterisierten Genen der Maus erlaubt. Als Ausgangsproben wurden am Embryonaltag (E) 11 aus dem entsprechenden Gehirnbereich isolierte Gesamt-RNA-Proben eingesetzt, da zu diesem Zeitpunkt die Entwicklung serotonerger und DA-Neurone beginnt und nur vereinzelt, erste postmitotische $5-\mathrm{HT}$ Neurone feststellbar sind. Somit sollten zu diesem Zeitpunkt Gene identifizierbar sein, welche wesentlich zur Entwicklung von 5-HT-Neuronen im Gegensatz zu DA-Neuronen beitragen. Zur Normalisierung der Daten wurden die Signalwerte der „Housekeeping“-Gene Gapdh, $\beta$-Aktin, Transferrin-Rezeptor und Pyrovatcarboxylase verwendet.

Bevor eine Analyse der durch den cDNA-Mikroarray gewonnen Daten des ventralen Mesencephalon und des ventralen rostralen Rhombencephalon vorgenommen werden konnte, war es erforderlich, eine Kontamination der beiden benachbarten Gehirnbereiche miteinander ausschließen zu können. Eine Kontamination konnte aufgrund in der Abb. 30 (Seite 114) dargelegten Ergebnisse ausgeschlossen werden. So ist Otx2, als spezifischer Determinant des Mesencephalon nicht in der Probe des Rhombencephalon exprimiert. Ebenso konnte im Mesencephalon keine Expression des Gbx2-Gens als Determinant des Rhombencephalon nachgewiesen werden. Das diese Daten verlässlich waren, zeigte der geringe $P$-Wert $(P<0,05)$. Um die kaudale Grenze des präparierten Gewebebereiches genauer bestimmen zu können, wurden die Expressionswerte der rhombomer-spezifisch exprimierten Hox-Gene genauer analysiert. (Hunt et al., 1991a; b; Marshall H., 1996). Die Daten zeigten, dass das eingesetzte Gewebe einen Bereich von direkt kaudal des Isthmus bis zum R6 umfasste. Des Weiteren wurden die gewonnenen Daten stichprobenartig auf ihre Richtigkeit durch qRT-PCR, als deutlich sensitivere Methode, validiert (Tab. 3, Seite 115). Die Ergebnisse zeigten, dass keine größeren Abweichung der Daten der qRT-PCR von denen des Mikroarray vorlagen. Somit waren die Expressionsdaten des cDNA-Mikroarray als zuverlässig einzustufen. Sofern Gene in die engere Auswahl als Kandidatengene, welche möglicherweise an der Regulation der Entwicklung von 5-HT-Neuronen beteiligt sind, 
aufgenommen wurden, wurden die zugehörigen Expressionsdaten des Mikroarrays ebenfalls mittels qRT-PCR überprüft (siehe hierzu Abb. 32, Seite 119).

Aufgrund der hohen Datenmenge die durch den Genexpressionsvergleich gewonnen wurden, war es notwendig die Auswahl der zu analysierenden Gene zu limitieren. So wurden zunächst nur Gene berücksichtigt, die im ventralen Rhombencephalon eine um das 2,5fach höhere Expression im Vergleich zum ventralen Mesencephalon aufwiesen. Gene die durch eine Herabregulation im Rhombencephalon eine ebenso wichtige Funktion in der Entwicklung 5-HT-Neurone besitzen könnten, wurden aufgrund der Datenmenge an dieser Stelle vom weiteren Auswahlverfahren ausgeschlossen. Die Gruppe der 300 am stärksten exprimierten Gene im ventralen Rhombencephalon im Vergleich zum ventralen Mesencephalon der Maus (E11) umfasste sowohl für Transkriptionsfaktoren als auch für Strukturproteine der EZM, Signalmoleküle, Enzyme, Regulatorproteine bis hin zu für Ionenkanäle kodierende Gene, so z. B. Ceacam11, Cyp26b1, Barx1, Rab25 oder Kcnq5. Eine zusätzliche Eingrenzung der Gruppe interessanter Gene wurde gemäß einer nachgewiesenen Beteiligung der Gene an entwicklungsbiologischen Prozessen, einer Involvierung an der Steuerung der Zellmigration, oder eine bereits nachgewiesene Beteiligung an der Differenzierung von neuralen Vorläuferzellen vorgenommen (Abb. 31, Seite 117). Im Rahmen dieser Arbeit, die sich insbesondere mit der Bedeutung von Tgf- $\beta$ und des Transkriptionsfaktors Sim1 für die Induktion und Spezifikation 5-HT-Neurone beschäftigte, wurde ein möglicher Bezug der Gene zu Tgf- $\beta$ und/oder mit Sim1 als weitere Parameter der Selektion gewählt. In die engere Auswahl kamen schließlich drei Gene, Brn3.2, Lhx8 und Rgs4, auf die im folgenden näher eingegangen werden soll.

Lhx8 wurde ausgewählt, weil dieser Transkriptionsfaktor nachweislich an der Spezifikation und Differenzierung unterschiedlicher Zelltypen während der embryonalen Entwicklung beteiligt ist. So konnte z.B. in Lhx8-defizienten Mäusen eine signifikante Reduktion der Anzahl cholinerger Neurone des Telencephalon festgestellt werden (Zhao et al., 2003). Die Möglichkeit einer ektopischen Induzierung der Lhx8-Expression durch Tgf- $\beta 3$ zusammen mit Fgf8 deutet auf eine denkbare Involvierung von Lhx8 über eine Tgf- $\beta$-induzierte Regulationskaskade in die Entwicklung 5-HT-Neurone hin (Inoue et al., 2006). Darüber hinaus wurde $L h x 8$ in Sim1- sowie Arnt-überexprimierenden Neuro2a-Zellen durch cDNAMikroarray-Analyse der Genexpession als potentielles Zielgen von Sim1 identifiziert (Liu et al., 2003).

Ebenfalls zur Gruppe der ausgewählten Transkritionsfaktoren, gehört das für Brn3.2, auch Pou4f2 genannt, kodierende Gen. Bisher konnte dem Transkriptionsfaktor Brn3.2 eine Bedeutung in der Regulation der Differenzierung der retinalen Ganglionzellen und der Haarzellen des auditiven Systems zugeordnet werden (DeCarvalho et al., 2004). Aufgrund seiner selektiven Expression in postmitotischen Neuronen scheint sich hierbei seine Funktion 
auf die Spezifikation des terminalen neuronalen Phänotyps zu beschränken. Ein weiterer Vertreter der Brn-Familie ist Brn2, welches mehrere für die vorliegende Arbeit interessante Eigenschaften aufweist. Wie Mash1 interagiert Brn2 mit der Promotorregion des NotchLiganden Delta1, wodurch das Delta1-Gen positiv reguliert wird. Somit ist Brn2 ein wichtiger Regulator der Neurogenese (Castro et al., 2006). In vivo-Untersuchungen durch Michaud et al. (1998) haben gezeigt, dass Brn2 einer Expression von Sim1 nachgeschaltet und wie dieses während der Entwicklung im anterioren Hypothalamus lokalisiert ist. Man geht davon aus, dass Sim1 für die Aufrechterhaltung der Brn2-Expression notwendig ist, die wiederum die terminale Differenzierung neurosekretorischer Zellen des SON und PVN steuert (Acampora et al., 1999). Sim1-defiziente Mäuse zeigen insbesondere in neuroendokrinen Zellen einen Verlust der Brn2-Expression. Brn2-defiziente Mausmutanten wiederum besitzen wie Sim1-Mutanten einen Defekt in hypothalamischen sekretorischen Neuronen. Ein Verknüpfungspunkt von Transkriptionsfaktoren der Brn-Familie und der Entwicklung der zentralen 5-HT-Neurone ergibt sich aus der Tatsache, dass Brn2 in der dorsalen Raphe des adulten Gehirns der Ratte exprimiert wird und dort mit Tph2 kolokalisiert. Die Tatsache, dass Brn2 in der Lage ist, die Expression von Tph2 über die Bindung des Promotors des Tph2Gens zu beeinflussen, macht die Brn-Proteinfamilie zu geeigneten Kandidaten als Regulatoren der Entwicklung 5-HT-Neurone (Scheuch et al., 2007). Aufgrund der Vermutung, dass Brn3.2 ein weiteres Zielgen von Sim1 sein könnte, wurden „Gain-offunction"-Experimente durchgeführt, um dies zu überprüfen. Hierzu wurde $\operatorname{Sim} 1$ in MN9DZellen überexprimiert und über einen Zeitraum von $72 \mathrm{~h}$ der Einfluss von Sim1 auf die Expression von Brn3.2 im Vergleich zu nicht Sim1-überexprimierenden Zellen mittels qRTPCR bestimmt. Eine Überexpression von Sim1 führt zu einer deutlichen, signifikanten Steigerung der Brn3.2-Expression $48 \mathrm{~h}$ nach erfolgter Transfektion (Abb.34, Seite 122). Somit wurde Brn3.2 im Rahmen dieser Arbeit erstmals als ein mögliches Element des regulatorischen Netzwerkes, welches die Entwicklung serotonerger Neurone beschrieben. Zudem war es möglich Brn3.2 innerhalb dieses Netzwerkes, als mögliches Zielgen von Sim1 zu positionieren. Da Sim1 nach Überexpression auch die Expression von Tph2 positiv reguliert (Abb. 25, Seite 107) und Tph2 wiederum durch Brn2 nachweislich reguliert wird, kann vermutet werden, dass Sim1 über Brn3.2 als auch Brn2 auf die Entwicklung von 5-HTNeuronen Einfluss nehmen könnte. Diese Vermutung soll daher durch weitere Experimente, wie „Loss-of-function“-Experimente und Untersuchungen von Brn3.2.-defizienten Mäusen untermauert werden. In zukünftigen Forschungsprojekten soll durch Brn3.2-Überexpression und durch Blockierung der Translation der Brn3.2-mRNA durch spezifische siRNA Experimente die Bedeutung dieses Transkriptionsfaktors für die Entstehung von 5-HTNeuronen aufgeklärt werden. Insgesamt ergeben sich drei mögliche Funktionswege, über die Sim1 das Tph2-Gen, und damit die terminale Differenzierung von 5-HT-Neuronen regulieren 
könnte. Zum einen eine direkte Regulation des Tph2-Gens (Abb. 25, Seite 107), zweitens eine indirekte Regulation von Tph2, welche durch eine Sim1-abhängige Regulation der Transkription von Pet1 vermittelt wird (Abb. 24, Seite 106) und schließlich eine Regulation über das Gen Brn2. Diese Wege könnten parallel zueinander oder nacheinandergeschaltet verlaufen sowie eine Abhängigkeit vom jeweiligen Zelltyp aufweisen. Bedenkt man, dass 5-HT-Neurone die Entwicklung von Zielregionen des Gehirns regulieren, so könnte hierdurch der Verlust des SON und PVN in Sim1-defizienten Mausmutanten (P0), welcher zur perinatalen Letalität der Mutanten führt, erklärt werden. So ist es vorstellbar, dass durch Verlust des Sim1-Gens einer der drei zuvor beschriebenen Regulationsmechanismen unerbrochen wird, woraus eine Reduktion der Anzahl 5-HT-Neurone des NRD resultiert. Der NRD wiederum projiziert über die Amygdala in den Hypothalamus. Ist eine 5-HTSubpopulation des NRD reduziert, wie dies in Sim1-defizienten Mutanten der Fall ist, so könnte dies wiederum über fehlende Projektionen dieser Neurone in den Hypothalamus dessen Entwicklung, insbesondere der neurosekretorischen Kerne, gravierend beeinträchtigen.

Rgs4 wurde als weiteres, dem ersten Anschein nach ungewöhnliches Kandidatengen ausgewählt. Für dieser Entscheidung waren mehrere Gründe ausschlaggebend. Das Rgs4Protein lässt sich ausschließlich im ZNS nachweisen und ist in seiner Expression zeitlich und räumlich genau festgelegt (Gold et al., 1997). Neben einer deutlich erhöhten Expression in der medianen und paramedianen Raphe der Maus (P0) ist auch eine Überlappung der Expression von Rgs4 mit dem Expressionsmuster von Sim1 nachweisbar. Für eine mögliche Regulation der Expression von Rgs4 durch Sim1 spricht auch die Beobachtung, dass in Sim1-defizienten Mausmutanten die Expression von Rgs4 im Hypothalamus reduziert ist (Caqueret et al., 2006). Eine Reduktion der Expression von Rgs4 konnte des Weiteren post mortem bei Schizophrenie-Patienten im Gyrus temporalis superior nachgewiesen werden (Bowden et al., 2007). Ein Befund, der ebenfalls eine Bedeutung von Rgs4 für das zentrale 5-HT-System unterstreicht. Als Regulator der Funktion G-Protein-gekoppelter Rezeptoren verschiedener Neurotransmitter besteht eine mögliche, direkte Beziehung zur Funktion des 5-HT-Systems, welches ebenfalls über G-Protein-gekoppelte Rezeptoren, wie z. B. dem somatodendritischen Rezeptor 5-HTR1a, der über einen negativen Rückkopplungsmechanismus die Freisetzung von Serotonin kontrolliert, im ZNS gesteuert wird. Eine Regulation des 5-HTR1a-Autorezeptors des NRD durch Rgs4 konnte in der Tat bereits gezeigt werden (Beyer et al., 2004). Ergebnisse und Literaturhinweise können so interpretiert werden, dass Sim1 über eine funktionelle Verknüpfung via die Expressionsregulation von Rgs4 in die Steuerung der Freisetzung von Serotonin in die Entwicklung und Aufrechterhaltung der dorsalen Raphe eingreift. Damit hat Sim1 über Rgs4 indirekt einen regulatorischen Einfluss auf 5-HT-Neurone sowie auf die Entwicklung von 
Zielregionen der 5-HT-Neurone, wie dem Hypothalamus. Aufgrund der beschriebenen Befunde wurde die Hypothese einer Regulierung der Expression von Rgs4 durch Sim1 in dem in dieser Arbeit angewendeten „Gain-of-function“-Modell überprüft. Wie die Ergebnisse zeigen, führt eine Sim1-Überexpression zu einer signifikanten Heraufregulation von Rgs4 nach 24 h (Abb. 33, Seite 121). Somit konnte mit Rgs4 eine weitere Komponente des Sim1nachgeschalteten Netzwerkes identifiziert werden. Eine direkte Beteiligung von Rgs4 an dem regulatorischen Netzwerk der Entwicklung serotonerger Neurone konnte nicht durch die bisher durchgeführten Experimente aufgedeckt werden. Ein Beitrag von Rgs4 zur Steuerung der Entwicklung serotonerger Neurone ist jedoch aufgrund seiner oben beschriebenen regulatorischen Funktionen und seines Expressionsmusters denkbar.

Fasst man die Möglichkeiten der Interaktion von Sim1 mit den hier genannten Genen zusammen, so ergibt sich eine denkbare duale Rolle des Transkriptionsfaktors Sim1 in der Entwicklung und Aufrechterhaltung von 5-HT-Neuronen. Zum einen eine Regulation der späten Differenzierung von 5-HT-Neuronen auf transkriptioneller Ebene über Brn3.2 oder Brn2, sowie Regulation von Pet1 und Tph2. Darüber hinaus ist eine Regulation der Entwicklung insbesondere einer Subpopulation des NRD und der Entwicklung von Zielregionen des zentralen 5-HT-Systems über eine Rgs4 vermittelte, funktionelle Steuerung des Autorezeptors 5-HTR1a denkbar.

Die im Rahmen der vorliegenden Arbeit gewonnenen Daten führen zu einer Erweiterung des bisher gültigen, jedoch unvollständigen regulatorischen Netzwerkes aus intrinsischen und extrinsischen Faktoren, welche die Entwicklung von 5-HT-Progenitoren hin zu terminal differenzierten 5-HT-Neuronen steuern. Der Beitrag dieser Arbeit ist zum Abschluss in der nachfolgenden Abbildung 35 dargestellt. 


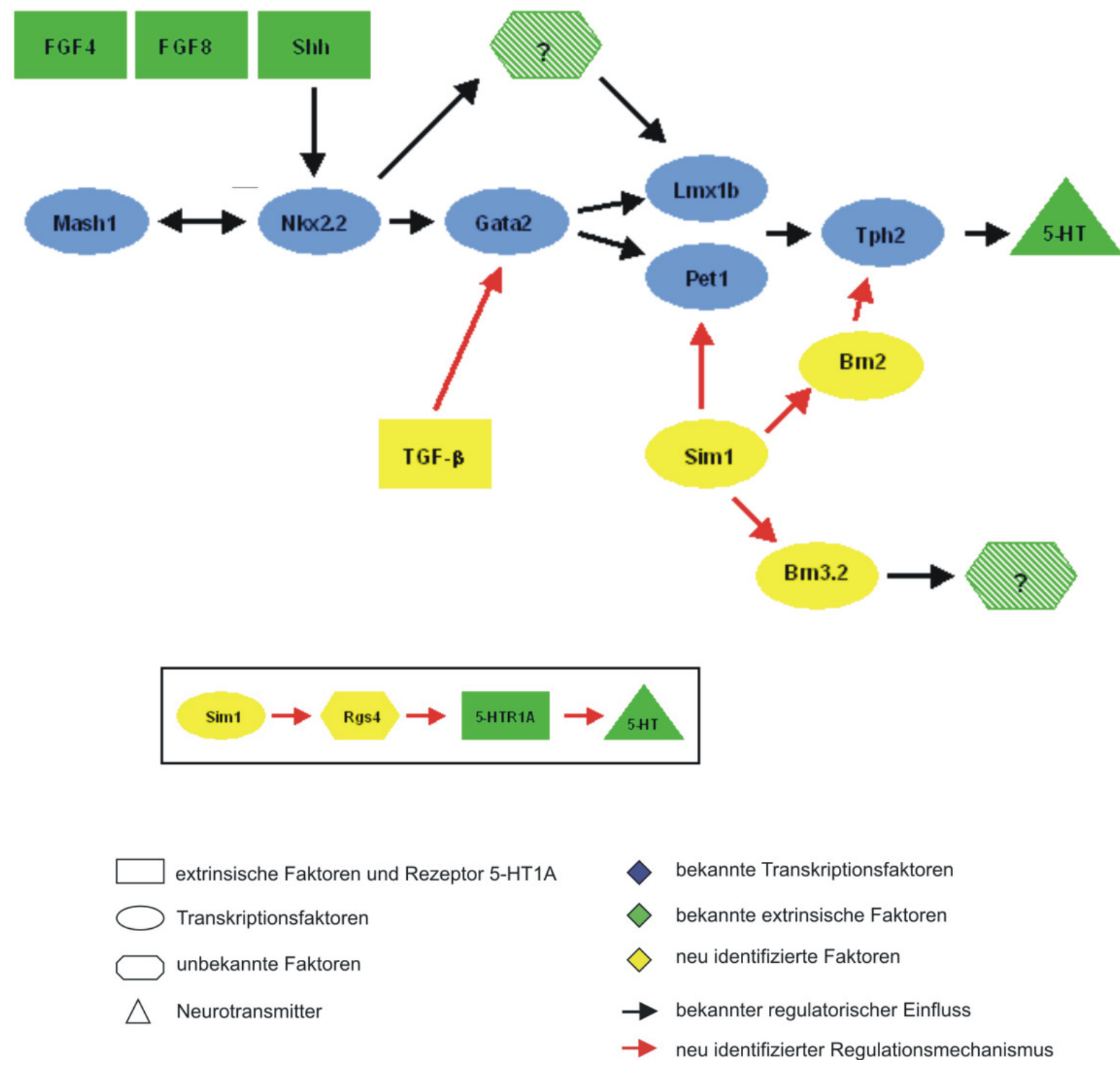

Abb. 35: Erweitertes Modell des regulatorischen Netzwerkes aus intrinsischen und extrinsischen Faktoren der Entwicklung serotonerger (5-HT-) Neurone des ventralen Rhombencephalon der Maus unter Berücksichtigung der Einflussnahme von Tgf- $\beta$ auf die Expression der Transkriptionsfaktoren Gata2 und Pet1, sowie multiple Sim1-abhängige Regulationswege der terminalen Differenzierung von 5-HT-Neuronen. Sim1 nimmt zudem Einfluss auf die Entwicklung von Zielgebieten des 5-HT-Systems über Regulation der Expression von Rgs4 und damit Regulation der Funktion des somatodendritischen 5-HTAutorezeptors 5-HTR1A (Kasten). 


\section{Anhang}

\subsection{Abbildungsverzeichnis}

Abb. 1: Kaudale und rostrale B-Gruppen serotonerger (5-HT-) Neurone des zentralen Nervensystems (ZNS) der Säugetiere und ihre Projektionen am Beispiel der Ratte.

Abb. 2: Schematische Darstellung der Lokalisation kaudaler und rostraler serotonerger (5-HT-) Neurone des ventralen Rhombencephalon unter Berücksichtigung der beiden essentiellen Organisationszentren, Isthmus-Organizer (IstO) und Grundplatte im zentralen Nervensystem (ZNS) der Maus des Embryonaltages (E) 12.

Seite 9

Abb. 3: Schematische Darstellung der Ausbildung des Isthmus-Organizer (IstO) der Maus des Embryonaltages (E) 8-9.5.

Seite 10

Abb. 4: Präparation des ventralen rostralen Rhombencephalon der Maus des Embryonaltages 12 (E12).

Seite 46

Abb. 5: Zellen des ventralen rostralen Rhombencephalon der Maus des Embryonaltages (E) 12 besitzen die Fähigkeit zur Bildung primärer Neurospheres.

Seite 80

Abb.: 6 Darstellung der zeitlichen Entwicklung (DIV12-22) eines sekundären Neurospheres aus dissoziierten, primären Neurospheres des ventralen rostralen Rhombencephalon der Maus (E12) unter Einfluss der Mitogene Fgf2 und Egf sowie serumfreier Kulturbedingungen.

Seite 81

Abb. 7: Zellen primärer Neurospheres des ventralen rostralen Rhombencephalon der Maus (E12) besitzen die Fähigkeit zur Proliferation.

Seite 83

Abb. 8: $\quad$ Vergleich der Genexpression zwischen primären Neurospheres (NS) und primärem Gewebe $(T)$ des ventralen rostralen Rhombencephalon der Maus (E12) mittels Polymerasekettenreaktion und genspezifischer Primer nach vorangegangener reverser Transkription (RT-PCR).

Seite 86

Abb. 9: Primäre Neurospheres des ventralen rostralen Rhombencephalon der Maus (E12) zeigen eine heterogene zelluläre Zusammensetzung. 
Abb. 10: Quantitative-„Real-Time“-PCR-(qRT-PCR)-Analyse der Expression des mitotisch in Progenitoren zentraler serotonerger (5-HT-) Neuronen exprimierten Gens $L m \times 1 b$ in einem repräsentativen Versuch.

Seite 90

Abb. 11: Quantitative-,Real-Time“-PCR-(qRT-PCR)-Analyse eines repräsentativen Versuchs der Expression des Gen Gata2 als frühes Markergen der Entwicklung serotonerger (5-HT-) Neuronen in cDNA aus dissoziierten und ausplattierten primären Neurospheres des ventralen rostralen Rhombencephalon der Maus des Embryonaltages (E) 12 nach externer Faktorengabe.

Seite 91

Abb. 12: Quantitative-,,Real-Time“-PCR-(qRT-PCR)-Analyse der Expression eines repräsentativen Versuchs des Gen Pet1 als frühstes spezifisches Markergen serotonerger (5-HT-) Neurone an cDNA aus dissoziierten und ausplattierten primären Neurospheres des ventralen rostralen Rhombencephalon der Maus des Embryonaltages (E) 12 nach externer Faktorengabe.

Seite 92

Abb. 13: Quantitative-„Real-Time“-PCR-(qRT-PCR)-Analyse eines repräsentativen Versuchs der Expression des Gen Gata2 als frühes Markergen der Entwicklung serotonerger (5-HT-) Neuronen in cDNA aus Primärzellen des ventralen rostralen Rhombencephalon der Maus des Embryonaltages (E) 12 nach externer Faktorengabe.

Seite 94

Abb. 14: Quantitative-,,Real-Time“-PCR-(qRT-PCR)-Analyse der Expression des Gen Pet1 als frühestes Markergen der Entwicklung serotonerger (5-HT-) Neuronen in cDNA aus Primärzellen des ventralen rostralen Rhombencephalon der Maus des Embryonaltages (E) 12 nach externer Faktorengabe.

Seite 95

Abb. 15: Immunhistochemischer Nachweis der Expression von Sim1 („Singleminded homologon 1") und Serotonin (5-HT-) in Zellen des Rhombencephalon der Maus des Postnataltages $(P) 0$.

Seite 96

Abb. 16: Nachweis der Sim1-Expression durch nicht-radioaktive RNA-in situHybridisierung (ISH) an sagittalen Paraffinschnitten (Schnittdicke $10 \mu \mathrm{m}$ ) der Maus des Embryonaltages (E) 12.

Seite 98

Abb. 17: Quantitativer Vergleich der Gesamtzahl serotonerger (5-HT-) Neurone des rostralen Rhombencephalon der Maus in Wildtyp (wt) und homozygoten Sim1-Mutanten des Embryonaltages (E) 14.5.

Seite 99 
Abb. 18: Vergleich der Gesamtzahl serotonerger (5-HT-) Neurone des rostralen Rhombencephalon der Maus zum postnatalen Zeitpunkt (P) 0 in Wildtyp (wt) und homozygoten Sim1-Mutanten.

Seite 100

Abb. 19: Analyse der Expression von Gata2, Pet1 und Tph2 als Vertreter von Markergenen der Entwicklung serotonerger (5-HT-) Neurone und des ventral exprimierten Transkriptionsfaktors Sim1 in MN9D-Zellen mittels Reverser Transkriptions (RT)-PCR.

Seite 101

Abb. 20: Reverse-Transkriptions-(RT)-PCR-Analyse der Überexpression von Sim1 in MN9D-Zellen nach $24 \mathrm{~h}, 48 \mathrm{~h}$ und $72 \mathrm{~h}$ nach Transfektion mit pcDNA3::Sim1 im Vergleich zu pcDNA3-transfizierten Kontrollen (Ctr) unter Berücksichtigung der jeweils für die PCR eingesetzten cDNA-Menge.

Seite 102

Abb. 21: Western-Blot-Analyse repräsentativer "Gain-of-function“-Versuche zum Zeitpunkt der jeweils höchsten Sim1-Proteinexpression.

Seite 103

Abb. 22: Quantitative-„Real-Time“-PCR-(qRT-PCR)-Analyse der Mash1Expression in cDNA aus MN9D-Zellen nach Überexpression des Transkriptionsfaktors Sim1 im Vergleich zu cDNA aus MN9DKontrollansätzen zu verschiedenen Zeitpunkten.

Seite 104

Abb. 23: Repräsentative Quantitative-,Real-Time“-PCR-(qRT-PCR)-Analyse der Expression von Gata2 in cDNA aus MN9D-Zellen nach Überexpression des Transkriptionsfaktors Sim1 im Vergleich zu cDNA aus MN9D-Kontrollansätzen zu verschiedenen Zeitpunkten.

Seite 105

Abb. 24: Quantitative-,,Real-Time“-PCR-(qRT-PCR)-Analyse der Pet1Expression in cDNA aus MN9D-Zellen nach Überexpression des Transkriptionsfaktors Sim1 im Vergleich zu cDNA aus MN9DKontrollansätzen zu verschiedenen Zeitpunkten.

Seite 106

Abb. 25: Quantitative-,Real-Time“-PCR-Analyse der Genexpression von Tph2 in cDNA aus Sim1-überexprimierenden MN9D-Zellen im Vergleich zu cDNA-Proben aus pcDNA3 transfizierten MN9D-Zellen zu unterschiedlichen Zeitpunkten.

Seite 107

Abb. 26: Transfektion von MN9D-Zellen mit Sim1-mRNA spezifischer siRNA bzw. einer nicht zur komplementären Sequenzbindung fähigen Kontroll-siRNA.

Seite 109

Abb. 27: Analyse der Herabregulation der Sim1-Expression mittels spezifischer siRNA (Sim1-Cy3) in MN9D-Zellen durch Reverse Transkriptions(RT)-PCR.

Repräsentative Analyse der Genexpression von Pet1 mittels 
Abb. 28: Quantitativer-,,Real-Time“-PCR in MN9D-Zellen nach Herabregulation der Expression von Sim1 mittels spezifischer siRNA (Sim1-Cy5) nach $24 \mathrm{~h}$ im Vergleich zu Ctr-siRNA-Alexa 488 transfizierten MN9D-Zellen.

Seite 111

Abb. 29: Quantitative-,Real-Time“-PCR-Analyse der Genexpression von Tgf- $\beta 2$ in cDNA-Proben aus Sim1-überexprimierenden MN9D-Zellen im Vergleich zu cDNA-Proben nicht Sim1-überexprimierender Zellen zu unterschiedlichen Zeitpunkten.

Seite 112

Abb. 30: Graphische Darstellung der relativen Werte der Genexpression im ventralen Rhombencephalon im Vergleich zum ventralen Mesencephalon der Maus des Embryonaltages (E) 11, ermittelt durch Vergleich der entsprechenden Genexpressionsmuster mittels cDNA-Mikroarray.

Seite 114

Abb. 31: Graphische Darstellung der relative Genexpression (2- $\left.{ }^{\Delta \Delta c t}\right)$ von ausgesuchten Genen, basierend auf einem Genexpressionsvergleich des ventralem Rhombencephalon mit dem ventralem Mesencephalon der Maus des Embryonaltages (E) 11.

Seite 117

Abb. 32: Gegenüberstellung der durch Quantitative-,,Real-Time“-PCR (qRT-PCR) bzw. cDNA-Mikroarray-Analyse erhaltenen, relativen Genexpressionsdaten der Kandidatengene Brn3.2, Lhx8 und Rgs4 im ventralen Rhombencephalon im Vergleich zum ventralen Mesencephalon der Maus des Embryonaltages (E) 11.

Seite 119

Abb. 33: Quantitative-,,Real-Time“-PCR (qRT-PCR) Analyse der Expression von Rgs4 in cDNA aus MN9D-Zellen nach Überexpression des Transkriptionsfaktors Sim1 im Vergleich zu cDNA aus MN9DKontrollansätzen zu verschiedenen Zeitpunkten.

Seite 121

Abb. 34: Quantitative-,,Real-Time“-PCR-Analyse der Genexpression von Brn3.2 in cDNA aus Sim1-überexprimierenden MN9D-Zellen im Vergleich zu cDNA-Proben aus pcDNA3-transfizierten MN9D-Zellen.

Seite 122

Abb. 35: Erweitertes Modell des regulatorischen Netzwerkes aus intrinsischen und extrinsischen Faktoren der Entwicklung serotonerger (5-HT-) Neurone des ventralen Rhombencephalon der Maus unter Berücksichtigung der Einflussnahme von Tgf- $\beta$ auf die Expression der Transkriptionsfaktoren Gata2 und Pet1, sowie multiple Sim1-abhängige Regulationswege der terminalen Differenzierung von 5-HT-Neuronen. 


\subsection{Tabellenverzeichnis}

Tab. 1: B-Gruppenklassifikation und Lokalisation der Nuclei raphes des Rhombencephalon der Säugetiere.

Seite 5

Tab. 2: Zur immunzytochemischen Charakterisierung von Primärzellen und primären Neurospheres des ventralen rostralen Rhombencephalon der Maus (E12) eingesetzte Primärantikörper.

Seite 54

Tab. 3: Gegenüberstellung der durch Quantitative-,,Real-Time“-PCR (qRTPCR) bzw. cDNA-Mikroarray Analyse erhaltenen, relativen Genexpressionsdaten des ventralen Rhombencephalon im Vergleich zum ventralen Mesencephalon der Maus des Embryonaltages (E) 11. Seite 115 


\subsection{Literaturverzeichnis}

Acampora, D, Mazan, S, Lallemand, Y, Avantaggiato, V, Maury, M, Simeone, A, Brûlet, P, (1995) Forebrain and midbrain regions are deleted in Otx2-/- mutants due to a defective anterior neuroectoderm specification during gastrulation. Development 121(10): 3279-90.

Acampora, D, Mazan, S, Lallemand, Y, Avantaggiato, V, Maury, M, Simeone, A, Brûlet, P, (1999) Forebrain and midbrain regions are deleted in Otx2-/- mutants due to a defective anterior neuroectoderm specification during gastrulation. Development 121(10):3279-90.

Adams, W, Kusljic, S, van den Buuse, M, (2008) Serotonin depletion in the dorsal and ventral hippocampus: Effects on locomotor hyperactivity, prepulse inhibition and learning and memory. Neuropharmacology. 2008 Jun 27. Epub ahead of print.

Armando, S, Lebrun, A, Hugnot, JP, Ripoll, C, Saunier, M, Simonneau, L, (2007) Neurosphere-derived neural cells show region-specific behaviour in vitro. Neuroreport 18(15):1539-42.

Azmitia, EC, Segal, M, (1978) An autoradiographic analysis of the differential ascending projections of the dorsal and median raphe nuclei in the rat. J Comp Neurol 179(3):641-67.

Barth, KA, Kishimoto, Y, Rohr, KB, Seydler, C, Schulte-Merker, S, Wilson, SW, (1999) Bmp activity establishes a gradient of positional information throughout the entire neural plate. Development 126(22):4977-87.

Bauer, H, Lele, Z, Rauch, GJ, Geisler, R, Hammerschmidt, M, (2001) The type I serine/threonine kinase receptor Alk8/Lost-a-fin is required for Bmp2b/7 signal transduction during dorsoventral patterning of the zebrafish embryo. Development 128(6):849-58.

Baumgarten, HG, Grozdanovic, Z, (1995) Psychopharmacology of central serotonergic systems. Pharmacopsychiatry Suppl 2:73-9.

Bazán, E, Alonso, FJ, Redondo, C, López-Toledano, MA, Alfaro, JM, Reimers, D, Herranz, AS, Paíno, CL, Serrano, AB, Cobacho, N, Caso, E, Lobo, MV, (2004) In vitro and in vivo characterization of neural stem cells. Histol Histopathol 19(4):1261-75.

Beck, SG, Pan, YZ, Akanwa, AC, Kirby, LG, (2004) Median and dorsal raphe neurons are not electrophysiologically identical. J Neurophysiol 91(2):994-1005.

Bertrand, N, Castro, DS, Guillemot, F, (2002) Proneural genes and the specification of neural cell types. Nat Rev Neurosci 3(7):517-30.

Beyer, CE, Ghavami A, Lin, Q, Sung, A, Rhodes, KJ, Dawson, LA, Schechter, LE, Young, $\mathrm{KH}$, (2004) Regulators of G-protein signaling 4: modulation of 5-HT1A-mediated neurotransmitter release in vivo. Brain Res 1022(1-2):214-20.

Bignami, A, Dahl, D, (1977) Specificity of the glial fibrillary acidic protein for astroglia. Histochem Cytochem 25(6):466-9. 
Böttner, M, Unsicker, K, Suter-Crazzolara, C, (1996) Expression of TGF-beta type II receptor mRNA in the CNS. Neuroreport 7(18):2903-7.

Bowden, NA, Scott, RJ, Tooney, PA, (2007) Altered expression of regulator of G-protein signalling 4 (RGS4) mRNA in the superior temporal gyrus in schizophrenia. Schizophr Res 89(1-3):165-8.

Briscoe, J, Ericson, J, (1999a) The specification of neuronal identity by graded Sonic Hedgehog signalling. Semin Cell Dev Biol 10(3):353-62.

Briscoe, J, Sussel, L, Serup, P, Hartigan-O'Connor, D, Jessell, TM, Rubenstein, JL, Ericson, J, (1999b) Homeobox gene Nkx2.2 and specification of neuronal identity by graded Sonic hedgehog signalling. Nature 398(6728):622-7.

Brodski, C, Weisenhorn, DM, Signore, M, Sillaber, I, Oesterheld, M, Broccoli, V, Acampora, D, Simeone, A, Wurst, W, (2003) Location and size of dopaminergic and serotonergic cell populations are controlled by the position of the midbrain-hindbrain organizer. J Neurosci 23(10):4199-207.

Caccamo, DV, Herman, MM, Frankfurter, A, Katsetos, CD, Collins, VP, Rubinstein, LJ, (1989) An immunohistochemical study of neuropeptides and neuronal cytoskeletal proteins in the neuroepithelial component of a spontaneous murine ovarian teratoma.. Am J Pathol 135(5):801-13.

Caqueret, A, Boucher, F, Michaud, JL, (2006) Laminar organization of the early developing anterior hypothalamus. Dev Biol 298(1):95-106.

Carpenter, WT, Jr, Buchanan, RW, Kirkpatrick, B, Tamminga, C, Wood, F, (1993) Strong inference, theory testing, and the neuroanatomy of schizophrenia. Arch Gen Psychiatry 50(10):825-31.

Castro, DS, Hermanson, E, Joseph, B, Wallén, A, Aarnisalo, P, Heller, A, Perlmann, T, (2001) Induction of cell cycle arrest and morphological differentiation by Nurr1 and retinoids in dopamine MN9D cells. J Biol Chem 276(46):43277-84.

Castro, DS, Skowronska-Krawczyk, D, Armant, O, Donaldson, IJ, Parras, C, Hunt, C, Critchley, JA, Nguyen, L, Gossler, A, Göttgens, B, Matter, JM, Guillemot, F, (2006) Proneural bHLH and Brn proteins coregulate a neurogenic program through cooperative binding to a conserved DNA motif. Dev Cell 11(6):831-44.

Chen, H, Chrast, R, Rossier, C, Gos, A, Antonarakis, SE, Kudoh, J, Yamaki, A, Shindoh, N, Maeda, H, Minoshima, S, (1995) Single-minded and Down syndrome? Nat Genet 10(1): 9-10.

Cheng, L, Chen, CL, Luo, P, Tan, M, Qiu, M, Johnson, R, Ma, Q, (2003) Lmx1b, Pet-1, and Nkx2.2 coordinately specify serotonergic neurotransmitter phenotype. J Neurosci 23(31):9961-7.

Choi, HK, Won LA, Kontur, PJ, Hammond, DN, Fox, AP, Wainer, BH, Hoffmann, PC, 
Heller, A, (1991) Immortalization of embryonic mesencephalic dopaminergic neurons by somatic cell fusion. Brain Res 552(1):67-76.

Choi, HK, Won, L, Roback, JD, Wainer, BH, Heller, A, (1992) Specific modulation of dopamine expression in neuronal hybrid cells by primary cells from different brain regions. Proc Natl Acad Sci U S A 89(19):8943-7.

Choi-Lundberg, DL, Lin Q, Chang YN, Chiang YL, Hay CM, Mohajeri H, Davidson BL, Bohn MC, (1997) Dopaminergic neurons protected from degeneration by GDNF gene therapy. Science 275(5301):838-41.

Ciccolini, F, (2001) Identification of two distinct types of multipotent neural precursors that appear sequentially during CNS development. Mol Cell Neurosci 17(5):895-907

Clarkson, ED, Zawada, WM, Freed, CR, (1997) GDNF improves survival and reduces apoptosis in human embryonic dopaminergic neurons in vitro. Cell Tissue Res 289: 207-210.

Consolazione, A, Cuello, A, (1982) The biology of serotonergic transmission,New York: John Willey \& Sons, Seite 29-61.

Cox, DA, Cohen, ML, (1996) 5-HT2B receptor signaling in the rat stomach fundus: dependence on calcium influx, calcium release and protein kinase C. Behav Brain Res 73(1-2):289-92.

Craven, SE, Lim, KC, Ye, W, Engel, JD, de Sauvage, F, Rosenthal, A, (2004) Gata2 specifies serotonergic neurons downstream of sonic hedgehog. Development 131(5): 1165-73.

Crews, ST, Thomas, JB, Goodman, CS, (1988) The Drosophila single-minded gene encodes a nuclear protein with sequence similarity to the per gene product. Cell 52(1): $143-51$.

Croonenberghs, J, Wauters, A, Deboutte, D, Verkerk, R, Scharpe, S, Maes, M, (2007) Central serotonergic hypofunction in autism: results of the 5-hydroxy-tryptophan challenge test. Neuro Endocrinol Lett 28(4):449-55.

Crossley, PH, Martin, GR, (1995) The mouse Fgf8 gene encodes a family of polypeptides and is expressed in regions that direct outgrowth and patterning in the developing embryo. Development 121(2):439-51.

Dahlström, A, Fuxe, K, (1964) Localization of monoamines in the lower brain stem. Experientia 20(7):398-9.

Dahmane, N, Charron, G, Lopes, C, Yaspo, ML, Maunoury, C, Decorte, L, Sinet, PM, Bloch, B, Delabar, JM, (1995) Down syndrome-critical region contains a gene homologous to Drosophila sim expressed during rat and human central nervous system development. Proc Natl Acad Sci U S A 92(20):9191-5.

Daval, G, Vergé, D, Becerril, A, Gozlan, H, Spampinato, U, Hamon, M, (1987) Transient 
expression of $5-\mathrm{HT} 1 \mathrm{~A}$ receptor binding sites in some areas of the rat CNS during postnatal development. Int J Dev Neurosci 5(3):171-80.

Dean B, Hayes W, (1996) Decreased frontal cortical serotonin2A receptors in schizophrenia. Schizophr Res 21(3):133-9.

DeCarvalho, AC, Cappendijk, SL, Fadool, JM, (2004) Developmental expression of the POU domain transcription factor Brn-3b (Pou4f2) in the lateral line and visual system of zebrafish. Dev Dyn 229(4):869-76.

Diefenbach, TJ, Sloley, BD, Goldberg, JI, (1995) Neurite branch development of an identified serotonergic neuron from embryonic Helisoma: evidence for autoregulation by serotonin. Dev Biol 167(1):282-93.

Ding, L, Mychaleckyj, JC, Hegde, AN, (2007) Full length cloning and expression analysis of splice variants of regulator of G-protein signaling RGS4 in human and murine brain. Gene 401(1-2):46-60.

Ding, YQ, Marklund, U, Yuan, W, Yin, J, Wegman, L, Ericson, J, Deneris, E, Johnson, RL, Chen, ZF, (2003) Lmx1b is essential for the development of serotonergic neurons. Nat Neurosci 6(9):933-8.

Dünker, N, Krieglstein, K, (2002) Tgfbeta2 -/- Tgfbeta3 -/- double knockout mice display severe midline fusion defects and early embryonic lethality. Anat Embryol (Berl) 206(12):73-83.

Durston, AJ, Timmermans, JP, Hage, WJ, Hendriks, HF, de Vries, NJ, Heideveld, M, Nieuwkoop, PD, (1989) Retinoic acid causes an anteroposterior transformation in the developing central nervous system. Nature 13;340(6229):140-4.

Echelard, Y, Epstein, DJ, St-Jacques, B, Shen, L, Mohler, J, McMahon, JA, McMahon, AP, (1993) Sonic hedgehog, a member of a family of putative signaling molecules, is implicated in the regulation of CNS polarity. Cell. 1993 Dec 31;75(7):1417-30.

Echevarría, D, Vieira, C, Gimeno, L, Martínez, S, (2003) Neuroepithelial secondary organizers and cell fate specification in the developing brain. Brain Res Brain Res Rev 43(2):179-91.

El Wakil, A, Francius, C, Wolff, A, Pleau-Varet, J, Nardelli, J, (2006) The GATA2 transcription factor negatively regulates the proliferation of neuronal progenitors. Development 133(11):2155-65.

Ema, M, Morita, M, Ikawa, S, Tanaka, M, Matsuda, Y, Gotoh, O, Saijoh, Y, Fujii, H, Hamada, H, Kikuchi, Y, Fujii-Kuriyama, Y, (1996) Two new members of the murine Sim gene family are transcriptional repressors and show different expression patterns during mouse embryogenesis. Mol Cell Biol 16(10):5865-75.

Ericson, J, Briscoe, J, Rashbass, P, van Heyningen, V, Jessell, TM, (1997) Graded sonic hedgehog signaling and the specification of cell fate in the ventral neural tube. Cold Spring 
Harb Symp Quant Biol 62:451-66.

Fan, CM, Kuwana E, Bulfone, A, Fletcher, CF, Copeland, NG, Jenkins, NA, Crews, S, Martinez, S, Puelles, L, Rubenstein, JL, Tessier-Lavigne, M, (1996) Expression patterns of two murine homologs of Drosophila single-minded suggest possible roles in embryonic patterning and in the pathogenesis of Down syndrome. Mol Cell Neurosci 7(1):1-16.

Farkas, LM, Dünker, N, Roussa, E, Unsicker, K, Krieglstein, K, (2003) Transforming growth factor-beta(s) are essential for the development of midbrain dopaminergic neurons in vitro and in vivo. J Neurosci 23(12):5178-86.

Flanders, KC, Lüdecke, G, Engels, S, Cissel, DS, Roberts, AB, Kondaiah, P, Lafyatis, R, Sporn, MB, Unsicker, K, (1991) Localization and actions of transforming growth factor-beta $s$ in the embryonic nervous system. Development 113(1):183-91.

Fuxe, K, (1965) Evidence for the existence of monoamine neurons in the central nervous system. 3. The monoamine nerve terminals. Z Zellforsch Mikrosk Anat 9;65:573-96.

Fyodorov, D, Nelson, T, Deneris, E, (1998) Pet-1, a novel ETS domain factor that can activate neuronal nAchR gene transcription. J Neurobiol 34(2):151-63.

Gage, FH, (2000) Mammalian neural stem cells. Science 287(5457):1433-8.

Galter, D, Böttner, M, Unsicker, K, (1999) Developmental regulation of the serotonergic transmitter phenotype in rostral and caudal raphe neurons by transforming growth factorbetas. J Neurosci Res 56(5):531-8.

Gard, AL, Pfeiffer, SE, (1989) Oligodendrocyte progenitors isolated directly from developing telencephalon at a specific phenotypic stage: myelinogenic potential in a defined environment. Development 106(1):119-32.

Garda, AL, Echevarría, D, Martínez, S, (2001) Neuroepithelial co-expression of Gbx2 and Otx2 precedes Fgf8 expression in the isthmic organizer. Mech Dev 101(1-2):111-8.

Gaspar, P, Cases, O, Maroteaux, L, (2003) The developmental role of serotonin: news from mouse molecular genetics. Nat Rev Neurosci 4(12):1002-12.

Gavalas, A, Davenne, M, Lumsden, A, Chambon, P, Rijli, FM, (1997) Role of Hoxa-2 in axon pathfinding and rostral hindbrain patterning. Development 124(19):3693-702.

Gingrich, JA, Ansorge, MS, Merker, R, Weisstaub, N, Zhou, M, (2003) New lessons from knockout mice: The role of serotonin during development and its possible contribution to the origins of neuropsychiatric disorders. CNS Spectr 8(8):572-7.

Glavic, A, Gómez-Skarmeta, JL, Mayor, R, (2002) The homeoprotein Xiro1 is required for midbrain-hindbrain boundary formation. Development 129(7):1609-21.

Gold, SJ, Ni, YG, Dohlman, HG, Nestler, EJ, (1997) Regulators of G-protein signaling (RGS) proteins: region-specific expression of nine subtypes in rat brain. $J$ Neurosci 17(20):8024-37.

Goodman, M, New, A, (2000) Impulsive aggression in borderline personality disorder. Curr 
Psychiatry Rep 2(1):56-61

Goridis, C, Rohrer, H, (2002) Specification of Catecholaminergic and Serotonergic Neurons. Nat Rev Neurosci 3(7):531-41.

Goshu, E, Jin, H, Fasnacht, R, Sepenski, M, Michaud, JL, Fan, CM, (2002) Sim2 mutants have developmental defects not overlapping with those of Sim1 mutants. Mol Cell Biol 22(12):4147-57.

Gritti, A, Cova, L, Parati, EA, Galli, R, Vescovi, AL, (1995) Basic fibroblast growth factor supports the proliferation of epidermal growth factor-generated neuronal precursor cells of the adult mouse CNS. Neurosci Lett 185(3):151-4.

Guillemot, F, Joyner, AL, (1993) Dynamic expression of the murine Achaete-Scute homologue Mash-1 in the developing nervous system. Mech Dev 42 (3):171-85.

Guo, C, Qiu, HY, Huang, Y, Chen, H, Yang, RQ, Chen, SD, Johnson, RL, Chen, ZF, Ding, $Y Q,(2007) L m \times 1 b$ is essential for Fgf8 and Wnt1 expression in the isthmic organizer during tectum and cerebellum development in mice. Development 134(2):317-25.

Guthrie, S, Lumsden, A, (1991) Formation and regeneration of rhombomere boundaries in the developing chick hindbrain. Development 112(1):221-9.

Heller, A, Price, S, Won, L, (1996) Glial-derived neurotrophic factor (GDNF) induced morphological differentiation of an immortalized monoclonal hybrid dopaminergic cell line of mesencephalic neuronal origin. Brain Res 725(1):132-6.

Hendricks, TJ, Francis, N, Fyodorov, D, Deneris, ES, (1999) The ETS domain factor Pet-1 is an early and precise marker of central serotonin neurons and interacts with a conserved element in serotonergic genes. J Neurosci 19(23):10348-56.

Hendricks, TJ, Fyodorov, DV, Wegman, LJ, Lelutiu, NB, Pehek, EA, Yamamoto, B, Silver, J, Weeber, EJ, Sweatt, JD, Deneris, ES, (2003) Pet-1 ETS gene plays a critical role in 5-HT neuron development and is required for normal anxiety-like and aggressive behavior. Neuron 37(2):233-47.

Hernandez, RE, Putzke, AP, Myers, JP, Margaretha, L, Moens, CB, (2007) Cyp26 enzymes generate the retinoic acid response pattern necessary for hindbrain development. Development 134(1):177-87.

Hitoshi, S, Tropepe, V, Ekker, M, van der Kooy, D, (2002) Neural stem cell lineages are regionally specified, but not committed, within distinct compartments of the developing brain. Development 129(1):233-44.

Joyner,Al, (1996) Engrailed, Wnt and Pax genes regulate midbrain--hindbrain development. Trends Genet 12(1):15-20.

Joyner, AL, Liu, A, Millet, S, (2000) Otx2, Gbx2 and Fgf8 interact to position and maintain a mid-hindbrain organizer. Curr Opin Cell Biol 12(6):736-41.

Kelly, CM, Zietlow, R, Dunnett, SB, Rosser, AE, (2003) The effects of various 
concentrations of FGF-2 on the proliferation and neuronal yield of murine embryonic neural precursor cells in vitro. Cell Transplant 12(3):215-23.

Kim, IO, Kim, IC, Kim, S, Kwon, YK, Han, PL, Jeon, SH, Kim, SH, (2005) CNS midline cells contribute to maintenance of the initial dorsoventral patterning of the Drosophila ventral neuroectoderm. J Neurobiol 62(4):397-405.

Kim, JY, Koh, HC, Lee, JY, Chang, MY, Kim, YC, Chung, HY, Son, H, Lee, YS, Studer, L, McKay, R, Lee, SH, (2003) Dopaminergic neuronal differentiation from rat embryonic neural precursors by Nurr1 overexpression. J Neurochem 85(6):1443-54.

King, MV, Marsden, CA, Fone, KC, (2008) A role for the 5-HT(1A), 5-HT(4) and 5-HT(6) receptors in learning and memory. Trends Pharmacol 2008 Aug 7.Epub ahead of print.

Kosman, D, Ip, YT, Levin,e M, Arora, K, (1991) Establishment of the mesodermneuroectoderm boundary in the Drosophila embryo. Science 254(5028):118-22.

Kosofsky, BE, Molliver, ME, (1987) The serotoninergic innervation of cerebral cortex: different classes of axon terminals arise from dorsal and median raphe nuclei. Synapse 1(2):153-68.

Krieglstein, K, Richter, S, Farkas, L, Schuster, N, Dünker, N, Oppenheim, RW, Unsicker, $\mathrm{K},(\mathbf{2 0 0 0})$ Reduction of endogenous transforming growth factors beta prevents ontogenetic neuron death. Nat Neurosci 3(11):1085-90.

Krieglstein, K, Strelau, J, Schober, A, Sullivan, A, Unsicker, K, (2002) TGF-beta and the regulation of neuron survival and death. J Physiol Paris 96(1-2):25-30.

Krieglstein, K, (2004) Factors promoting survival of mesencephalic dopaminergic neurons. Cell Tissue Res 318(1):73-80.

Krumlauf, R, Marshall, H, Studer, M, Nonchev, S, Sham, MH, Lumsden, A, (1993) Hox homeobox genes and regionalisation of the nervous system. J Neurobiol 24(10):1328-40.

Lauder JM, Wallace JA, Krebs H, Petrusz P, McCarthy K. (1982) In vivo and in vitro development of serotonergic neurons. Brain Res Bull 9(1-6):605-25.

Lauder, JM, Wilkie, MB, Wu, C, Singh, S, (2000) Expression of 5-HT(2A), 5-HT(2B) and 5HT(2C) receptors in the mouse embryo. Int J Dev Neurosci 18(7):653-62.

Lee, CM, Yu, DS, Crews, ST, Kim, SH, (1999) The CNS midline cells and spitz class genes are required for proper patterning of Drosophila ventral neuroectoderm. Int $\mathrm{J}$ Dev Biol 43(4):305-15.

Lendahl, U, Zimmerman, LB, McKay, RD, (1990) CNS stem cells express a new class of intermediate filament protein. Cell 60(4):585-95.

Liu, C, Goshu, E, Wells, A, Fan, CM, (2003) Identification of the downstream targets of SIM1 and ARNT2, a pair of transcription factors essential for neuroendocrine cell differentiation. J Biol Chem 278(45):44857-67.

Lo, LC, Johnson, JE, Wuenschell, CW, Saito, T, Anderson, DJ, (1991) Mammalian 
achaete-scute homolog 1 is transiently expressed by spatially restricted subsets of early neuroepithelial and neural crest cells. Genes Dev 5(9):1524-37.

Lumsden, A, Krumlauf, R, (1996) Patterning the vertebrate neuraxis. Science 15;274(5290):1109-15.

Maeda, R, Hozumi, S, Taniguchi, K, Sasamura, T, Murakami, R, Matsuno, K, (2007) Roles of single-minded in the left-right asymmetric development of the Drosophila embryonic gut. Mech Dev 124(3):204-17.

Marshall, H, Morrison, A, Studer, M, Pöpperl, H, Krumlauf, R, (1996) Retinoids and Hox genes. FASEB J 10(9):969-78.

Manabe, T, Tatsumi, K, Inoue, M, Matsuyoshi, H, Makinodan, M, Yokoyama, S, Wanaka, A, (2005) L3/Lhx8 is involved in the determination of cholinergic or GABAergic cell fate. $J$ Neurochem 94(3):723-30.

Manabe, T, Tatsumi, K, Inoue, M, Makinodan, M, Yamauchi, T, Makinodan, E, Yokoyama, S, Sakumura, R, Wanaka, A, (2007) L3/Lhx8 is a pivotal factor for cholinergic differentiation of murine embryonic stem cells. Cell Death Differ 14(6):1080-5. Epub 2007 Feb 23.

Marshall, GP, 2nd, Ross, HH, Suslov, O, Zheng, T, Steindler, DA, Laywell, ED, (2008) Production of neurospheres from CNS tissue. Methods Mol Biol 438:135-50.

Martí, E, Bumcrot, DA, Takada, R, McMahon, AP, (1995) Requirement of $19 \mathrm{~K}$ form of Sonic hedgehog for induction of distinct ventral cell types in CNS explants. Nature 375(6529):322-5.

Martin, GR, Eglen, RM, Hamblin, MW, Hoyer, D, Yocca, F, (1998) The structure and signalling properties of $5-\mathrm{HT}$ receptors: an endless diversity? Trends Pharmacol Sci 19(1):2-4.

Martinez, S, Crossley, PH, Cobos, I, Rubenstein, JL, Martin, GR, (1999) FGF8 induces formation of an ectopic isthmic organizer and isthmocerebellar development via a repressive effect on Otx2 expression. Development 126(6):1189-200.

Matsuo, I, Kuratani, S, Kimura, C, Takeda, N, Aizawa, S, (1995) Mouse Otx2 functions in the formation and patterning of rostral head. Genes Dev 9(21):2646-58.

Matsuyama, S, Iwadate, M, Kondo, M, Saitoh, M, Hanyu, A, Shimizu, K, Aburatani, H, Mishima, HK, Imamura, T, Miyazono, K, Miyazawa, K, (2003) SB-431542 and Gleevec inhibit transforming growth factor-beta-induced proliferation of human osteosarcoma cells. Cancer Res 63(22):7791-8.

Michaud, JL, Rosenquist, T, May, NR, Fan, CM, (1998) Development of neuroendocrine lineages requires the bHLH-PAS transcription factor SIM1. Genes Dev 12(20):3264-75.

Millet, S, Campbell, K, Epstein, DJ, Losos, K, Harris, E, Joyner, AL, (1999) A role for Gbx2 in repression of Otx2 and positioning the mid/hindbrain organizer. Nature 401(6749):161-4.

Moffett, P, Dayo, M, Reece, M, McCormick, MK, Pelletier, J, (1996) Characterization of 
msim, a murine homologue of the Drosophila sim transcription factor. Genomics 35(1):144-55.

Mohler, J, Vani, K, (1992) Molecular organization and embryonic expression of the hedgehog gene involved in cell-cell communication in segmental patterning of Drosophila. Development 115(4):957-71.

Morshead, CM, Reynolds, BA, Craig, CG, McBurney, MW, Staines, WA, Morassutti, D, Weiss, S, van der Kooy, D, (1994) Neural stem cells in the adult mammalian forebrain: a relatively quiescent subpopulation of subependymal cells. Neuron 13(5):1071-82.

Moustakas, A, Heldin, CH, (2005) Non-Smad TGF-beta signals. J Cell Sci 118(Pt 16): 3573-84.

Mu, X, Fu, X, Beremand, PD, Thomas, TL, Klein, WH, (2008) Gene regulation logic in retinal ganglion cell development: Isl1 defines a critical branch distinct from but overlapping with Pou4f2. Proc Natl Acad Sci U S A 105(19):6942-7. Epub 2008 May 6.

Murphy, DL, Zohar, J, Benkelfat, C, Pato, MT, Pigott, TA, Insel, TR, (1989) Obsessivecompulsive disorder as a 5-HT subsystem-related behavioural disorder. $\mathrm{Br} \mathrm{J}$ Psychiatry Suppl (8):15-24.

Nakamura, K, Hasegawa, H, (2007) Developmental role of tryptophan hydroxylase in the nervous system. Mol Neurobiol 35(1):45-54

Nakamura, H, Watanabe, Y, (2005) Isthmus organizer and regionalization of the mesencephalon and metencephalon. Int J Dev Biol 49(2-3):231-5.

Nambu, JR, Lewis, JO, Wharton, KA Jr, Crews, ST, (1991) The Drosophila single-minded gene encodes a helix-loop-helix protein that acts as a master regulator of CNS midline development. Cell 67(6):1157-67.

Nambu, JR, Lewis, JO, Crews, ST, (1993) The development and function of the Drosophila CNS midline cells. Comp Biochem Physiol Comp Physiol 104(3):399-409.

Nardelli, J, Thiesson, D, Fujiwara, Y, Tsai, FY, Orkin, SH, (1999) Expression and genetic interaction of transcription factors GATA-2 and GATA-3 during development of the mouse central nervous system. Dev Biol 210(2):305-21.

Nelson, RJ, Chiavegatto, S, (2001) Molecular basis of aggression. Trends Neurosci 24(12):713-9.

Nomoto, S, Adachi, K, Yang, LX, Hirata, Y, Muraguchi, S, Kiuchi,K, (1997) Distribution of RGS4 mRNA in mouse brain shown by in situ hybridization. Biochem Biophys Res Commun 241(2):281-7.

Nüsslein-Volhard C, Wieschaus E, (1980) Mutations affecting segment number and polarity in Drosophila. Nature 287(5785):795-801.

Olander, S, Nordström, U, Patthey, C, Edlund, T, (2006) Convergent Wnt and FGF signaling at the gastrula stage induce the formation of the isthmic organizer. Mech Dev 
123(2):166-76.

Ostenfeld, T, Tai, YT, Martin, P, Déglon, N, Aebischer, P, Svendsen, CN, (2002) Neurospheres modified to produce glial cell line-derived neurotrophic factor increase the survival of transplanted dopamine neurons. J Neurosci Res 69(6):955-65.

Palmer, TD, Takahashi, J, Gage, FH, (1997) The adult rat hippocampus contains primordial neural stem cells. Mol Cell Neurosci 8(6):389-404.

Pan, L, Deng, M, Xie, X, Gan, L, (2008) ISL1 and BRN3B co-regulate the differentiation of murine retinal ganglion cells. Development. 135(11):1981-90. Epub 2008 Apr 23.

Pandolfi, PP, Roth, ME, Karis, A, Leonard, MW, Dzierzak, E, Grosveld, FG, Engel, JD, Lindenbaum, MH, (1995) Targeted disruption of the GATA3 gene causes severe abnormalities in the nervous system and in fetal liver haematopoiesis. Nat Genet 11(1): 40-4.

Papalopulu, N, Clarke, JD, Bradley, L, Wilkinson, D, Krumlauf, R, Holder, N, (1991) Retinoic acid causes abnormal development and segmental patterning of the anterior hindbrain in Xenopus embryos. Development 113(4):1145-58.

Parmar, M, Skogh, C, Björklund, A, Campbell, K, (2002) Regional specification of neurosphere cultures derived from subregions of the embryonic telencephalon. Mol Cell Neurosci 21(4):645-56.

Pattyn, A, Hirsch, M, Goridis, C, Brunet, JF, (2000) Control of hindbrain motor neuron differentiation by the homeobox gene Phox2b. Development 127(7):1349-58.

Pattyn, A, Simplicio, N, van Doorninck, JH, Goridis, C, Guillemot, F, Brunet, JF, (2004) Ascl1/Mash1 is required for the development of central serotonergic neurons. Nat Neurosci 7(6):589-95.

Pattyn, A, Vallstedt, A, Dias, JM, Samad, OA, Krumlauf, R, Rijli, FM, Brunet, JF, Ericson, J, (2003) Coordinated temporal and spatial control of motor neuron and serotonergic neuron generation from a common pool of CNS progenitors. Genes Dev 17(6):729-37.

Pauwels, PJ, (2000) Diverse signalling by 5-hydroxytryptamine (5-HT) receptors. Biochem Pharmacol 60(12):1743-50.

Prakash, N, Wurst, W, (2004) Specification of midbrain territory. Cell Tissue Res 318(1): 5-14.

Proetzel, G, Pawlowski, SA, Wiles, MV, Yin, M, Boivin, GP, Howles, PN, Ding, J, Ferguson, MW, Doetschman, T, (1995) Transforming growth factor-beta 3 is required for secondary palate fusion. Nat Genet 11(4):409-14

Qiu, F, Jiang, H, Xiang, M, (2008) A comprehensive negative regulatory program controlled by Brn3b to ensure ganglion cell specification from multipotential retinal precursors. $J$ Neurosci 28(13):3392-403.

Rahimi, RA, Leof, EB, (2007) TGF-beta signaling: a tale of two responses. J Cell Biochem 
102(3):593-608.

Ressler, KJ, Nemeroff, CB, (2000) Role of serotonergic and noradrenergic systems in the pathophysiology of depression and anxiety disorders. Depress Anxiety. 12 Suppl 1:2-19 Reynolds, BA, Weiss, S, (1992) Generation of neurons and astrocytes from isolated cells of the adult mammalian central nervous system. Science 255(5052):1707-10.

Rhinn, M, Lun K, Luz, M, Werner, M, Brand, M, (2005) Positioning of the midbrainhindbrain boundary organizer through global posteriorization of the neuroectoderm mediated by Wnt8 signaling. Development 132(6):1261-72.

Rick, CE, Ebert, A, Virag, T, Bohn, MC, Surmeier, DJ, (2006) Differentiated dopaminergic MN9D cells only partially recapitulate the electrophysiological properties of midbrain dopaminergic neurons. Dev Neurosci 28(6):528-37.

Rietze, RL, Reynolds, BA, (2006) Neural stem cell isolation and characterization. Methods Enzymol 419:3-23.

Roelink H, Augsburger A, Heemskerk J, Korzh V, Norlin S, Ruiz i Altaba A, Tanabe Y, Placzek M, Edlund T, Jessell TM, (1994) Floor plate and motor neuron induction by vhh-1, a vertebrate homolog of hedgehog expressed by the notochord. Cell 76(4):761-75.

Roisen, FJ, Klueber, KM, Lu, CL, Hatcher, LM, Dozier, A, Shields, CB, Maguire, S, (2001) Adult human olfactory stem cells. Brain Res 890(1):11-22.

Roussa, E, Farkas, LM, Krieglstein K, (2004) TGF-beta promotes survival on mesencephalic dopaminergic neurons in cooperation with Shh and FGF-8. Neurobiol Dis 16(2):300-10.

Roussa, E, Krieglstein, K, (2004) Induction and specification of midbrain dopaminergic cells: focus on SHH, FGF8, and TGF-beta. Cell Tissue Res 318(1):23-33.

Roussa, E, Oehlke, O, Rahhal, B, Heermann, S, Heidrich, S, Wiehle, M, Krieglstein, K, (2008) Transforming growth factor beta cooperates with persephin for dopaminergic phenotype induction. Stem Cells 26(7):1683-94.

Roussa, E, Wiehle, M, Dünker, N, Becker-Katins, S, Oehlke, O, Krieglstein, K, (2006) Transforming growth factor beta is required for differentiation of mouse mesencephalic progenitors into dopaminergic neurons in vitro and in vivo: ectopic induction in dorsal mesencephalon. Stem Cells 24(9):2120-9.

Rubenstein, JL, (1998) Development of serotonergic neurons and their projections. Biol Psychiatry 44(3):145-50.

Saucedo-Cardenas, O, Quintana-Hau, JD, Le, WD, Smidt, MP, Cox, JJ, De Mayo, F, Burbach, JP, Conneely, OM, (1998) Nurr1 is essential for the induction of the dopaminergic phenotype and the survival of ventral mesencephalic late dopaminergic precursor neurons. Proc Natl Acad Sci U S A 95(7):4013-8.

Scheuch, K, Lautenschlager, M, Grohmann, M, Stahlberg, S, Kirchheiner, J, Zill, P, Heinz, 
A, Walther, DJ, Priller, J, (2007) Characterization of a functional promoter polymorphism of the human tryptophan hydroxylase 2 gene in serotonergic raphe neurons. Biol Psychiatry 62(11):1288-94.

Schober, A, Hertel, R, Arumäe, U, Farkas, L, Jaszai, J, Krieglstein, K, Saarma, M, Unsicker, K, (1999) Glial cell line-derived neurotrophic factor rescues target-deprived sympathetic spinal cord neurons but requires transforming growth factor-beta as cofactor in vivo. J Neurosci 19(6):2008-15.

Schonemann, MD, Ryan, AK, Erkman, L, McEvilly, RJ, Bermingham, J, Rosenfeld, MG, (1998) POU domain factors in neural development. Adv Exp Med Biol 449:39-53.

Shamim, H, Mason, I, (1999) Expression of Fgf4 during early development of the chick embryo. Mech Dev 85(1-2):189-92.

Shibaguchi, T, Kato, J, Abe, M, Tamamura, Y, Tabata, MJ, Liu, JG, Iwamoto, M, Wakisaka, S, Wanaka, A, Kurisu, K, (2003) Expression and role of Lhx8 in murine tooth development. Arch Histol Cytol 66(1):95-108.

Skagerberg, G, Björklund, A, (1985) Topographic principles in the spinal projections of serotonergic and non-serotonergic brainstem neurons in the rat. Neuroscience 15(2): 445-80.

Sommer, I, Schachner, M, (1981) Monoclonal antibodies (O1 to O4) to oligodendrocyte cell surfaces: an immunocytological study in the central nervous system. Dev Biol 83(2):311-27. Tear, G, (1999) Axon guidance at the central nervous system midline. Cell Mol Life Sci 55(11):1365-76.

Teraoka, H, Russell, C, Regan, J, Chandrasekhar, A, Concha, ML, Yokoyama, R, Higashi, K, Take-Uchi, M, Dong, W, Hiraga, T, Holder, N, Wilson SW, (2004), Hedgehog and Fgf signaling pathways regulate the development of tphR-expressing serotonergic raphe neurons in zebrafish embryos. J Neurobiol 60(3):275-88.

Thomas, JB, Crews, ST, Goodman, CS, (1988) Molecular genetics of the single-minded locus: a gene involved in the development of the Drosophila nervous system. Cell 52(1): $133-41$.

Timmer, JR, Wang, C, Niswander, L, (2002) BMP signaling patterns the dorsal and intermediate neural tube via regulation of homeobox and helix-loop-helix transcription factors. Development 129(10):2459-72.

Törk, I, (1990) Anatomy of the serotonergic system. Ann N Y Acad Sci 600:9-34.

Trulson, ME, Frederickson, CJ, (1987) A comparison of the electrophysiological and pharmacological properties of serotonin-containing neurons in the nucleus raphe dorsalis, raphe medianus and raphe pallidus recorded from mouse brain slices in vitro: role of autoreceptors. Brain Res Bull 18(2):179-90.

Tsai, FY, Keller, G, Kuo, FC, Weiss, M, Chen, J, Rosenblatt, M, Alt, FW, Orkin, SH, (1994) 
An early haematopoietic defect in mice lacking the transcription factor GATA-2. Nature. 371(6494):221-6.

Turner, EE, Jenne, KJ, Rosenfeld, MG, (1994) Brn-3.2: a Brn-3-related transcription factor with distinctive central nervous system expression and regulation by retinoic acid. Neuron 12(1):205-18.

Uchida, N, Buck, DW, He, D, Reitsma, MJ, Masek, M, Phan, TV, Tsukamoto, AS, Gage, $\mathrm{FH}$, Weissman, IL, (2000) Direct isolation of human central nervous system stem cells. Proc Natl Acad Sci U S A 97(26):14720-5.

Umetsu, D, Murakami, S, Sato, M, Tabata, T, (2006) The highly ordered assembly of retinal axons and their synaptic partners is regulated by Hedgehog/Single-minded in the Drosophila visual system. Development 133(5):791-800.

Unsicker, K, Meier, C, Krieglstein, K, Sartor, BM, Flanders, KC, (1996) Expression, localization, and function of transforming growth factor-beta $s$ in embryonic chick spinal cord, hindbrain, and dorsal root ganglia. J Neurobiol 29(2):262-76.

Unsicker, K, Strelau, J, (2000) Functions of transforming growth factor-beta isoforms in the nervous system. Cues based on localization and experimental in vitro and in vivo evidence. Eur J Biochem 267(24):6972-5.

Vokes, SA, Ji H, McCuine, S, Tenzen, T, Giles, S, Zhong, S, Longabaugh, WJ, Davidson, $\mathrm{EH}$, Wong, WH, McMahon, AP, (2007) Genomic characterization of Gli-activator targets in sonic hedgehog-mediated neural patterning. Development 134(10):1977-89.

Walshe, J, Maroon, H, McGonnell, IM, Dickson, C, Mason, I, (2002) Establishment of hindbrain segmental identity requires signaling by FGF3 and FGF8. Curr Biol 12(13):1117-23.

Wassarman, KM, Lewandoski, M, Campbell, K, Joyner, AL, Rubenstein, JL, Martinez, S, Martin, GR, (1997) Specification of the anterior hindbrain and establishment of a normal $\mathrm{mid} / \mathrm{hindbrain}$ organizer is dependent on Gbx2 gene function. Development 124(15):2923-34.

Wassef, M, Joyner, AL, (1997) Early mesencephalon/metencephalon patterning and development of the cerebellum. Perspect Dev Neurobiol 5(1):3-16.

Waterhouse, BD, Mihailoff, GA, Baack, JC, Woodward, DJ, (1986) Topographical distribution of dorsal and median raphe neurons projecting to motor, sensorimotor, and visual cortical areas in the rat. J Comp Neurol 249(4):460-76, 478-81.

Waters, ST, Lewandoski, M, (2006) A threshold requirement for Gbx2 levels in hindbrain development. Development 133(10):1991-2000.

Weissman, IL, (2000) Stem cells: units of development, units of regeneration, and units in evolution. Cell 100(1):157-68.

Westlund, KN, Sorkin, LS, Ferrington, DG, Carlton, SM, Willcockson, HH, Willis, WD, 
(1991) Serotoninergic and noradrenergic projections to the ventral posterolateral nucleus of the monkey thalamus. J Comp Neurol 295(2):197-207.

Woods, S, Farrall, A, Procko, C, Whitelaw, ML, (2008) The bHLH/Per-Arnt-Sim transcription factor SIM2 regulates muscle transcript myomesin2 via a novel, non-canonical E-box sequence. Nucleic Acids Res 36(11):3716-27

Yamada, T, Placzek, M, Tanaka, H, Dodd, J, Jessell, TM, (1991) Control of cell pattern in the developing nervous system: polarizing activity of the floor plate and notochord. Cell 64(3):635-47.

Yamaki, A, Noda, S, Kudoh, J, Shindoh, N, Maeda, H, Minoshima, S, Kawasaki, K, Shimizu, Y, Shimizu, N, (1996) The mammalian single-minded (SIM) gene: mouse cDNA structure and diencephalic expression indicate a candidate gene for Down syndrome. Genomics 35(1):136-43.

Yang, D, Peng, C, Li, X, Fan, X, Li, L, Ming, M, Chen, S, Le, W, (2008) Pitx3-transfected astrocytes secrete brain-derived neurotrophic factor and glial cell line-derived neurotrophic factor and protect dopamine neurons in mesencephalon cultures. J Neurosci Res. 2008 Jul 21. Published Online: 21 Jul 2008.

Ye, W, Shimamura, K, Rubenstein, JL, Hynes, MA, Rosenthal, A, (1998) FGF and Shh signals control dopaminergic and serotonergic cell fate in the anterior neural plate. Cell 93(5):755-66.

Yoon, HK, Yang, JC, Lee, HJ, Kim, YK, (2008) The association between serotonin-related gene polymorphisms and panic disorder. J Anxiety Disord. 2008 Mar 13. available online 13 March 2008.

Zhang, X, Beaulieu, JM, Gainetdinov, RR, Caron, MG, (2006) Functional polymorphisms of the brain serotonin synthesizing enzyme tryptophan hydroxylase-2. Cell Mol Life Sci. 63(1): 6-11.

Zhao, Y, Guo YJ, Tomac, AC, Taylor, NR, Grinberg, A, Lee, EJ, Huang, S, Westphal, H, (1999) Isolated cleft palate in mice with a targeted mutation of the LIM homeobox gene Ihx8. Proc Natl Acad Sci U S A 96(26):15002-6.

Zhao, Y, Marín, O, Hermesz, E, Powell, A, Flames, N, Palkovits, M, Rubenstein, JL, Westphal, H, (2003) The LIM-homeobox gene Lhx8 is required for the development of many cholinergic neurons in the mouse forebrain. Proc Natl Acad Sci U S A 100(15): 9005-10.

Zhao, ZQ, Scott, M, Chiechio, S, Wang, JS, Renner, KJ, Gereau, RW 4th, Johnson, RL, Deneris, ES, Chen, ZF, (2006) Lmx1b is required for maintenance of central serotonergic neurons and mice lacking central serotonergic system exhibit normal locomotor activity. $\mathrm{J}$ Neurosci 26(49):12781-8.

Zhu, G, Mehler, MF, Mabie, PC, Kessler, JA, (1999) Developmental changes in progenitor 
cell responsiveness to cytokines. J Neurosci Res 56(2):131-45.

Zhu, HJ, Burgess, AW, (2001) Regulation of transforming growth factor-beta signaling. Mol Cell Biol Res Commun 4(6):321-30.

Zill, P, Büttner, A, Eisenmenger, W, Möller, HJ, Ackenheil, M, Bondy, B, (2007) Analysis of tryptophan hydroxylase I and II mRNA expression in the human brain: a post-mortem study. J Psychiatr Res 41(1-2):168-73. 


\subsection{Plasmide und Sequenzen}

A: Ausgangsvektor pcDNA3 (Invitrogen, Leek, Niederlande) des Sim1-Überexpressionskonstruktes pcDNA3::Sim1

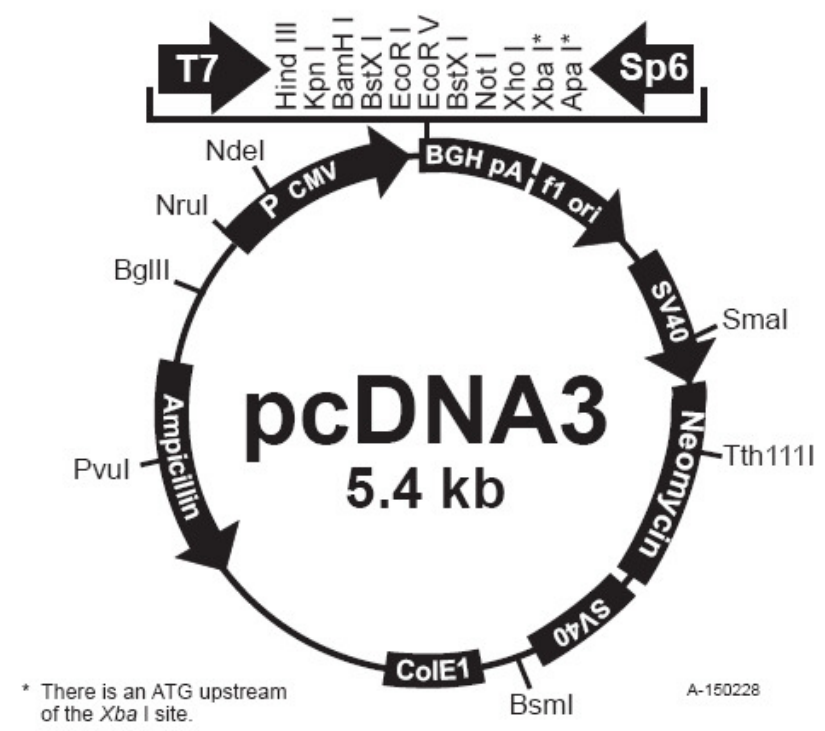

B: pGEM-T Easy Vektor System I, Ausgangsvektor des in situ-RNA-Sondenkonstruktes pGEM-T::Sim1 (305 bp)

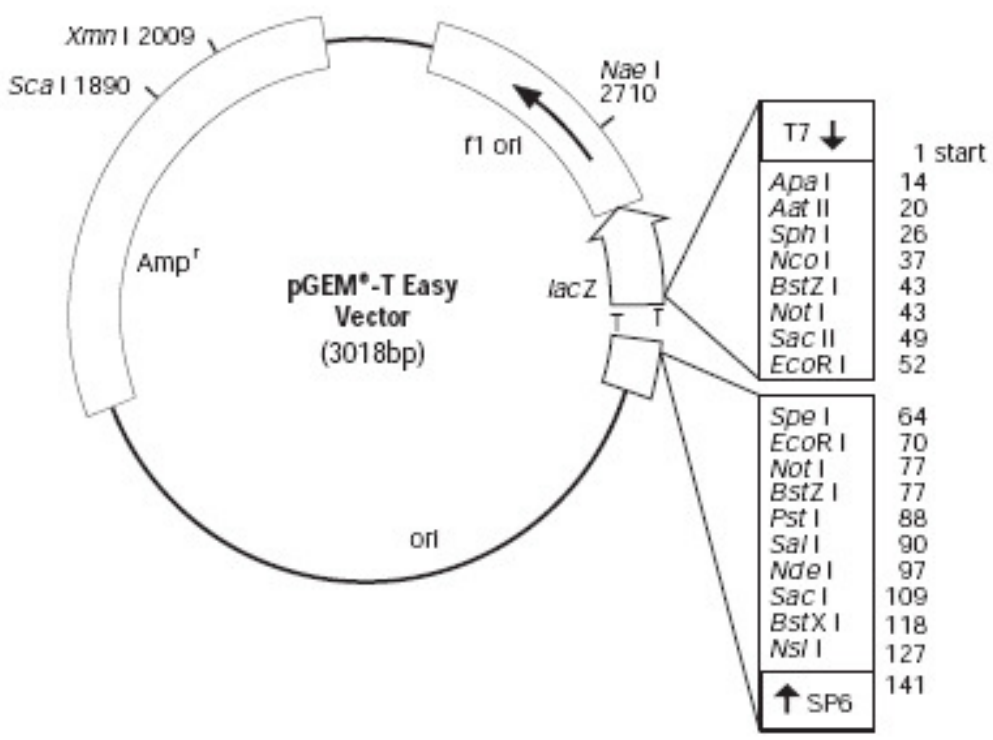


C: cDNA-Sequenz: Sim1 („Single-minded homolog 1“, D. melanogaster) der Maus (NM_011376); mit einer cDNA Gesamtlänge (,full-length“) von 2041 bp, unter Berücksichtigung des durch die Primer (grün) der Sondenklonierung flankieren Genabschnittes von 213 bp:

1 atgaaagaaa agtctaaaaa tgctgcccga acgaggaggg agaaagaaaa cagtgaattt

61 tatgaactgg ctaaattact gcctttaccc tcagccatca cctcccaact ggacaaagca

121 tccatcatca gactcacgac cagctatctc aaaatgagag tggtctttcc agaagggett

181 ggcgaggcgt ggggccacac cagtcgaacc agccccttgg acaacgttgg tcgcgaactc

241 ggctctcatc tactccagac tctggatggc ttcatcttcg tggtggeccc agatgggaag

301 atcatgtaca tttcagagac agcttcagtt cacctgggcc tttctcaggt agagctgact

361 gggaacagca tctatgaata tatccacccg gctgaccacg atgagatgac agccgtgctc

421 acagcccatc agccctacca ctctcacttt gtacaggagt acgagatcga acgctccttc

481 ttctaagga tgaagtgtgt tttggccaag cggaatgctg gcctcacctg cggtggctac

541 aaggtcattc actgtagtgg ctacctgaag atccgccagt acagcctgga tatgtctccc

$601 \mathrm{tttgatggat} \mathrm{gctaccaaaa}$ tgtgggettg gtggctgtgg gtcactccct gectccgagt

661 gctgtgacag agatcaaact acacagcaac atgttcatgt tccgagccag tctggatatg

721 aagcttattt tcctggactc cagggtggca gagctgactg gatatgaacc tcaggacttg

781 attgagaaga ccctgtacca tcacgtgcat ggctgtgaca ccttccacct acgctgtgca

841 caccacttac tgttggtgaa gggacaagtg accaccaagt actacaggtt cttggcgaag

901 cagggcggct gggtctgggt gcagagttac gccaccatcg tacacaacag ccgctcctcc

961 aggccgcact gcatcgtcag cgtcaactac gtcctcacag acacagaata caaagggcta

1021 cagctctccc tggaccagat atcagcctct aagcccact tctcctatac cagcagttcc

1081 actcccacta tctcggacaa caggaagggg gccaagtcaa ggctctccag tagcaagtca

1141 aaatctagga cctccccata tccccagtat tcgggattcc atactgagag atcggaatct

1201 gaccatgaca gccagtgggg tggaagtccc ctgactgata ctgcctcccc acagctcctg

1261 gacccagaga ggcctggctc tcagcacgaa ttgtcctgtg cgtataggca gttcccagat

1321 cgcagttctc tctgctatgg ttttgctctg gaccattcca ggctggtgga ggacaggcac

1381 ttccacaccc aagcctgcga gggaggacgg tgcgaggcag gcaggtactt cctgggagca

1441 ccacctactg ggagagatcc ctggtggggc tctcgagcag ctttgcctct taccaaggcc

1501 tccccggaga gcagagaagc ctatgagaac agcatgcctc atatcacctc catccacaga

1561 atccacggtc gaggtcactg ggatgaagat agtgtggtca gctctccaga ccctgggtca 
1621 gccagtgaat ctggtgaccg ataccgcacc gaacagtatc aaaatagccc acatgaacct 1681 agcaaaattg aaactctcat aagagccacc cagcagatga ttaaagagga agagaacaga 1741 ttacagctaa ggaaagcccc tccagaccaa ctggcttcca ttaatggagc tgggaaaaaa 1801 cactccctct gtttgcaaa ctatcaacag cccccaccca caggtgaggt ctgccacagc 1861 tctgctcttg ccagcacttc accatgtgac catatccagc agagagaggg aaagatgctc 1921 agccctcatg aaaatgacta tgacaacagc cccactgcac tgtctcggat aagtagtcct 1981 agttctgatc gcattacaaa gtctagttta atcctggcta aagactatct acattcagat 2041 atgtctcccc atcagacagc aggagaccat cctgccatct ctccaaactg tttggetcc 2101 caccggcagt atttgataa gcatgcctat acattgactg gttatgccct ggaacactta 2161 tatgacagtg agactattag aaactattcc ttgggctgca atggctcaca ctttgatgtg 2221 acttcccatc taaggatgca accagaccca gcacaaggac acaagggaac atctgttata 2281 ataaccaatg gaagttga

D: siRNA-Moleküle für die „Loss-of-function“-Experimente wurden von Qiagen GmbH (Hilden, Deutschland) bezogen:

1: AllStars Negative Control siRNA Alexa 488, keine Sequenzangabe verfügbar

2: siRNA-Sim1-Cy5, keine Sequenzangabe möglich, erstellt anhand der Sim1-Sequenz NM_011376, welche zu 99\% homolog zu NM_005068 ist.

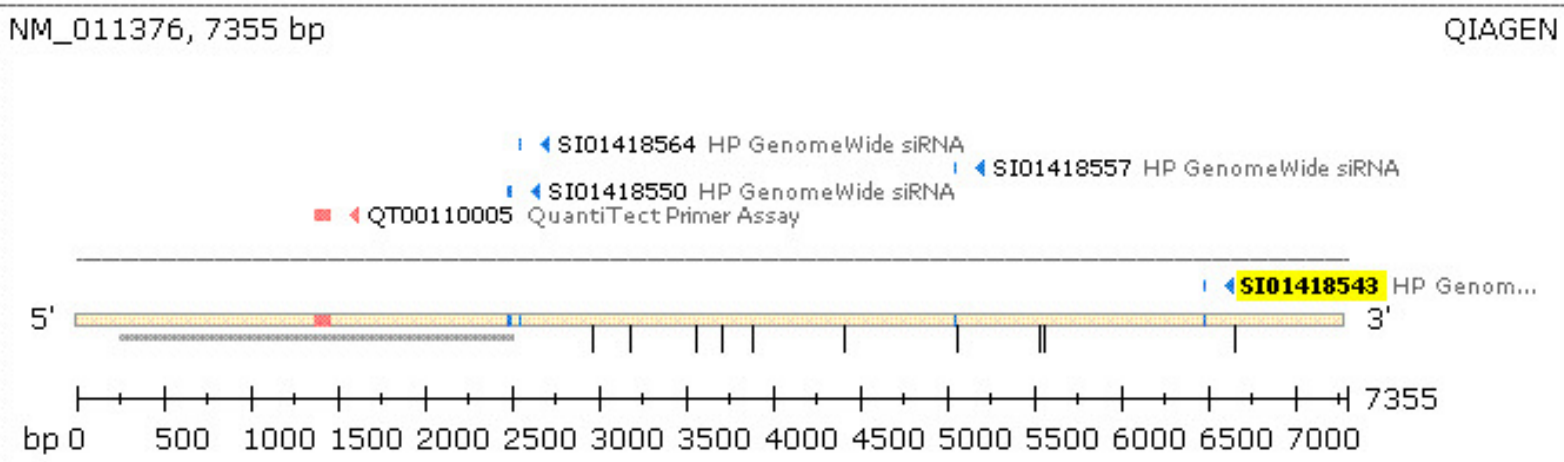

TNP
SNanscript Selected product




\subsection{Verzeichnis der verwendeten Abkürzungen}

$\alpha$

A

A. bidest

Aadc

Abb.

$\mathrm{AC}$

ad

Alk5

Amp

AP

A-P

APS

aPV

Arnt

Ascl1

Atoh1

$\beta$

B1-B9

BCIP

bHLH

Bmp

bp

BrdU

Brn3.2

BSA

bzw.

${ }^{\circ} \mathrm{C}$

ca.

cDNA

CHR

CME

CMF

CNS

Ct

Cy3/5

d. $h$.

$\Delta$ alpha, Antikörper gerichtet gegen, anti-

Absorption

Aqua bidestillata, bidestilliertes Wasser

Aromatic L-amino-acid-decarboxylase, Aromatische-L-Aminosäure-

Decarboxylase

Abbildung

Adenylatcyclase, Adenylatzyklase

ergänzen auf

Activin receptor-like kinase 5

Ampicillin

Alkalische Phosphatase

anterior-posterior

Ammoniumpersulfat

Nucleus pariventricularis anterior

Aryl hydrocarbon receptor nuclear translocator

Achaete-scute complex homolog 1, Synonym: Mash1

Atonal homolog 1

beta

Nuclei raphes, Raphe-Kerne

5-Brom-4-chlor-3-indoxylphosphat

basic helix-loop-helix-Motiv

Bone morphogenetic proteins, Knochen-morphogenetische Proteine base-pairs, Basenpaare

5'Bromo-2'Desoxy-Uridin

Brain-specific homeobox 3.2, Synonym: Pou4f2

Bovines Serum Albumin

beziehungsweise

Grad Celcius

circa

complementary DNA

Corticotropin releasing hormone

CNS midline element

Calcium-Magnesium-freies Medium

Central nervous system

Treshold cycle

Cyanin 3/5

das heisst

delta 


\section{D. melanogaster}

DA

$\mathrm{Da}$

$D A B$

DAPI

dATP

dCTP

dGTP

DEPC

DIG

DIV

DMEM

DMSO

DNA

DNase

dNTP

dTTP

DPP

D-V

E

E

E. coli

ECL

EDTA

Egf

egfr

en

ERK

et al.

EthBr

ETS

EZM

FACS

FCS

Fgf

FITC

Foxa2

FR

$g$

GABA

Gapdh
Drosophila melanogaster, Fruchtfliege

Dopamin; Dopminerg

Dalton

3,3-Diaminobenzidin-Tetrachlorid

4',6-Diamidino-2-phenylindol-Dihydrochlorid

Desoxyadenosintriphosphat

Desoxycytosintriphosphat

Desoxyguanosintriphosphat

Diethylpyrocarbonat

Digoxigenin

Day in vitro

Dulbecco's modified Eagle's Medium

Dimethylsulfoxid

Desoxyribonukleinsäure

Desoxyribonuklease

Desoxyribonukleosidtriphosphat

Desoxythymidintriphosphat

Decapentaplegic

dorso-venral

Effizienz

Embryonaltag

Escherichia coli

Enhanced chemiluminescense

Ethylendiamintetraacetat

Epidermal growth factor, Epidermaler Wachstumsfaktor

Epidermal growth factor receptor

Engrailed

Extracellular signal-regulated kinases

et alteres

Ethidiumbromid

DNA-Bindungsdomäne mit GGAA/T-Kernmotiv

Extrazelluläre Matrix

Fluorescence activated cell sorting

Fetal calf serum, fötales Kälberserum

Fibroblast growth factor, Fibroblasten-Wachstumsfaktor

Fluorescein

Forkhead box A2

Formatio reticularis

Gramm

Gamma-Aminobuttersäure

Glycerinaldehyd-3-phosphat-Dehydrogenase 


\section{Gata2/3}

Gbx2

GCR

Gdnf

Gfap

ggf.

G-Protein

$\mathrm{h}$

HBBS

HEPES

$\mathrm{Hh}$

Hox

HRP

$\lg G$

ISH

Islet1

IstO

$\mathrm{Km}$

$\mathrm{Km}$

$\lambda$

।

Lam

LB

Lhx8

Lmx1b

$m$

$\mathrm{m}$

$\mathrm{M}$

Mash1

Meis1

MEM

Mes

Met

MHB

$\min$

MMLV RT

MNGD

MNs

$\mathrm{MNV}$

MOPS

MP
GATA binding protein 2/3

Gastrulation brain homeobox 2

G-protein coupled receptor

Glia cell line derived neurotrophic factor

Glial fibrillary acidic protein

gegebenenfalls

Guaninnukleotid bindendes Protein

Stunde

Magnesium-freie Hank's balanced salt solution

$\mathrm{N}$-(2-Hydroxyethyl)-Piperazin-N'-2-Ethansulfonsäure

Hedghog

Homeobox, Homöobox

Horseradish peroxidase, Meerrettichperoxidase

Immunoglobulin Klasse G

in situ-Hybridisierung

Insulin related protein 1

Isthmus-Organizer

Kanamycin

Kanamycin

lambda, Wellenlänge

Liter

Laminin

Luria-Bertani

LIM homeobox 8,

LIM homeobox transcription factor 1 beta

Steigung

Milli

Mol, molar

Mouse achaete-scute homolog 1, Synonym: Ascl1

Myeloid ecotropic viral integration site 1 homolog

Modified Eagle's Medium

Mesencphalon

Metencephalon

Midbrain-hindbrain boundary, Mittlhirn-Nachhirn-Grenze

Minute

reverse Transkriptase aus murinem Leukämie Virus

Mouse neuronal cell line clone $9 D$

kraniales branchiales Motoneuron

viscerales Motoneuron

3-[N-morpholino]propansulfonsäure

Magermilchpulver 


\begin{tabular}{|c|c|}
\hline mRNA & messanger-RNA, Boten-RNA \\
\hline MW & Mittelwert \\
\hline $\mathrm{n}$ & Nano \\
\hline $\mathrm{n}$ & Probenanzahl \\
\hline n. s. & nicht signifikant \\
\hline NBT & Nitroblautetrazolium \\
\hline NFкB & Nuclear factor- $к B$ \\
\hline NGS & Normal goat serum \\
\hline Nkx & NKx transcription factor related \\
\hline$N M R I$ & Naval Medical Research Institute \\
\hline NRD & Nucleus raphe dorsalis \\
\hline NRM & Nucleus raphe magnus \\
\hline NS & primäre Neurospheres \\
\hline OD & Optische Dichte \\
\hline Opti-MEM & Reduced serum medium, modification of MEM Eagle's \\
\hline Otx2 & Orthodenticle homeobox homolog 2 \\
\hline $\mathrm{p}$ & piko \\
\hline P0 & Postnatalstadium \\
\hline PAGE & Polyacrylamid-Gelelektrophorese \\
\hline PAS & Period-Arnt-Sim-Domäne \\
\hline Pax2 & Paired box gene 2 \\
\hline PBS & Phosphat-buffered saline \\
\hline PCR & Polymerase-chain-reaction, Polymerasekettenreaktion \\
\hline Pet1 & Plasmacytoma expressed transcript 1 \\
\hline PFA & Paraformaldehyd \\
\hline $\mathrm{pH}$ & negativer Logarithmus der $\mathrm{H}^{+}$-lonenkonzentration \\
\hline Phox2b & Paired-like homeobox-domain protein 2 beta \\
\hline PI3K & Phoshoinosid 3-kinases \\
\hline PKA & Proteinkinase $\mathrm{A}$ \\
\hline PNS & Peripheres Nervensystem \\
\hline POA & Proligodendrocyte antigene \\
\hline PORN & Poly-Ornithine \\
\hline Pou4f2 & POU domain class 4 transcription factor 2, entspricht Brn3.2 \\
\hline PSN & Penicillin/Streptomycin/Neomycin \\
\hline PVDF & Polyvinylidendifluorid \\
\hline PVN & Nucleus paraventricularis \\
\hline P-Wert & Überschreitungswahrscheinlichkeit \\
\hline qRT-PCR & Quantitative-„Real-Time“-PCR \\
\hline $\mathrm{R}$ & Rhombomer \\
\hline RA & Retinoid acid, Retinolsäure \\
\hline RGC & Retinal ganglion cells, retinale Ganglienzellen \\
\hline
\end{tabular}




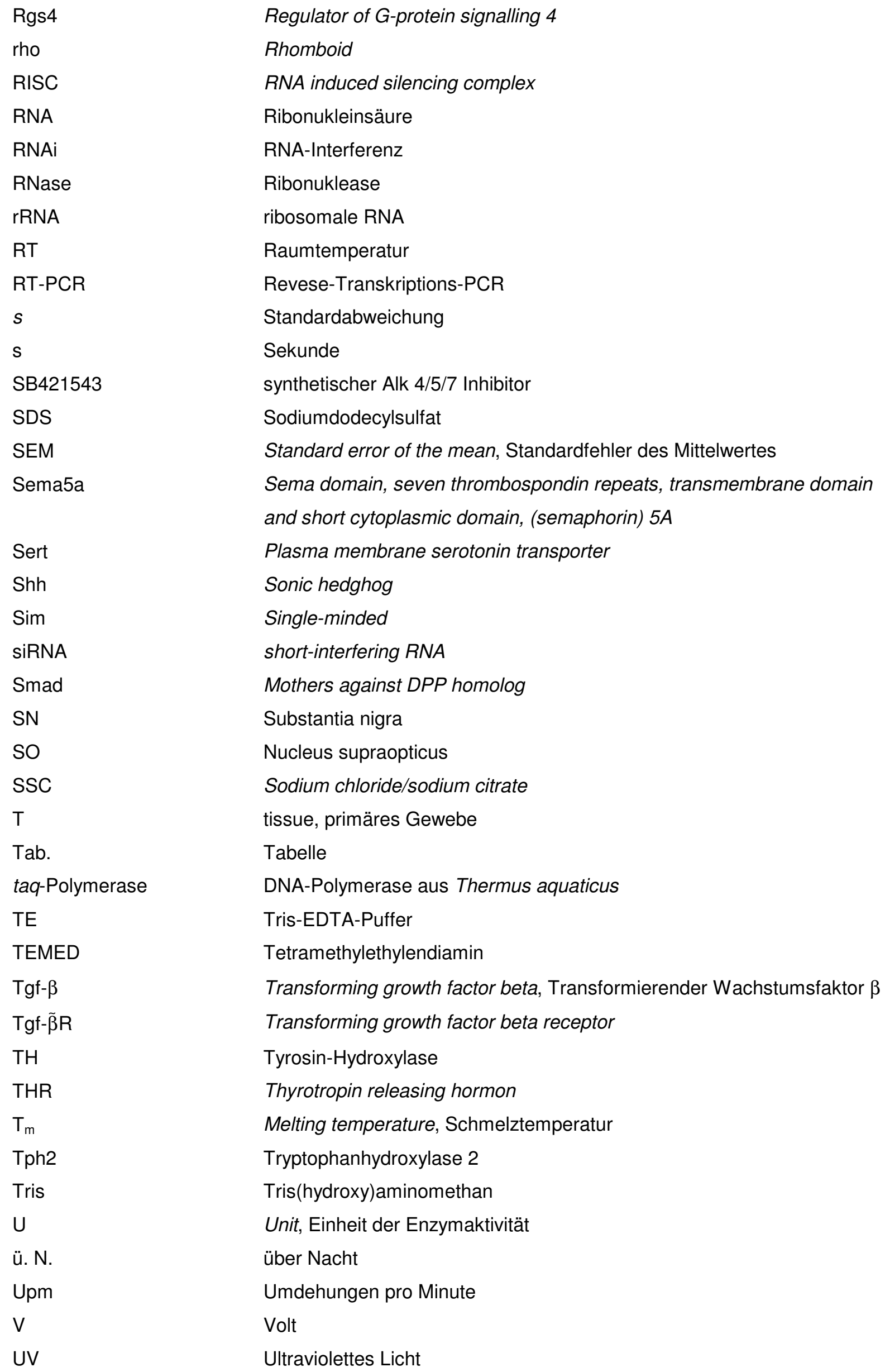




\begin{tabular}{|c|c|}
\hline Vmat & Vesicular monoamine transporter 2 \\
\hline VT & Volumenanteil \\
\hline VZ & ventrikuläre Zone, Neuroepithelium \\
\hline $\mathrm{w} / \mathrm{v}$ & weight/volume \\
\hline Wnt & Wingless-related MMTV integration site \\
\hline$w t$ & Wildtyp \\
\hline$\times$ & fach \\
\hline$\mu$ & Mikro \\
\hline z. B. & zum Beispiel \\
\hline ZNS & Zentrales Nervensystem \\
\hline $5-\mathrm{HT}$ & 5-Hydroxytryptamin, Serotonin/serotonerg \\
\hline 5-HTR & Serotonin-Rezeptor \\
\hline
\end{tabular}




\subsection{Curriculum vitae}

$\begin{array}{ll}\text { Name: } & \text { Osterberg } \\ \text { Vorname: } & \text { Nadja } \\ \text { geboren: } & 22.04 .1976 \\ \text { Geburtsort: } & \text { Kassel } \\ \text { Familienstand: } & \text { ledig } \\ \text { Wohnort: } & \text { Runzmattenweg 2, 79110 Freiburg }\end{array}$

\section{Schulausbildung}

$\begin{array}{lll}\text { Grundschule } & 1982-1986 & \text { Grundschule am Eichwäldchen, Kassel } \\ \text { Förderstufe } & 1986-1988 & \text { Josef von Eichendorf-Schule, Kassel } \\ \text { Gymnasium } & 1988-1995 & \text { Albert-Schweizer-Schule in Kassel } \\ \text { Abschluss } & 1995 & \text { Abitur }\end{array}$

\section{Hochschulausbildung und Berufstätigkeit}

\begin{tabular}{|c|c|c|}
\hline Studium der Biologie & 17.10.95.-.11.09.2002 & Gesamthochschule-Universität, Kassel \\
\hline Vordiplom & 15.10 .1998 & Gesamthochschule-Universität, Kassel \\
\hline Diplomstelle & 01.01.2002.-.30.09.2002 & $\begin{array}{l}\text { MPI für Experimentelle Medizin, } \\
\text { Göttingen } \\
\text { Abt:: Molekulare Biologie Neuronaler } \\
\text { Signale }\end{array}$ \\
\hline Diplom & 11.09 .2002 & Gesamthochschule-Universität, Kassel \\
\hline Doktorandenstelle & 01.10.2002.-.31.03.2004 & $\begin{array}{l}\text { MPI für Experimentelle Medizin, } \\
\text { Göttingen } \\
\text { Abt.: Molekulare Biologie Neuronaler } \\
\text { Signale }\end{array}$ \\
\hline Doktorandenstelle & $01.10 .2005-31.10 .2008$ & $\begin{array}{l}\text { Georg-August-Universität, Göttingen } \\
\text { Zentrum Anatomie } \\
\text { Abt.: Neuroanatomie }\end{array}$ \\
\hline $\begin{array}{l}\text { weiterführende } \\
\text { Beschäftigung }\end{array}$ & seit 01.11.2008 & $\begin{array}{l}\text { Albert-Ludwigs.Universität, Freiburg } \\
\text { Anatomie und Zellbiologie II } \\
\text { Abt.: Molekulare Embryologie }\end{array}$ \\
\hline
\end{tabular}

Freiburg, den 26.11.2008 
